\title{
El idioma de los dioses: \\ El discurso musical y los procesos de singularización
}

Juan Camilo Ruiz Salazar.

Agosto 2019.

Universidad Nacional de La Plata.

Facultad de periodismo y comunicación social.

Doctorado en comunicación. 


\section{Dedicatoria}

"Una vida sin música, es una vida sin sentido"

Coltrane

En 1997, en el batallón de Tolemaida, mientras prestaba servicio militar obligatorio, en una de las visitas dominicales, mis papás me llevaron el mejor presente: mi walkman con varios casetes, llenos de la música que disfrutaba para el momento; pude -por varios minutos- sentir algo diferente al proceso de resocialización al cual estaba expuesto en ese momento.

Esta tesis, sin lugar a duda no podría ser posible sin mis papás, quienes me colocarían, siendo un niño muy pequeño los audífonos del equipo de sonido de la casa; y desde entonces, la música siempre ha estado presente, como ellos, siempre apoyando y permitiendo re-sentir cada momento de la vida. Gracias a Luis Alberto y María Alicia, esta tesis tiene mucho de ustedes y solo puedo dedicarles cada línea de trabajo como forma de agradecer cada palabra, acompañamiento y apoyo en mis 40 años de vida.

A Marcos Antonio Suviabre Guevara, mi gran hermano chileno, la compañía de aprendizajes y charlas musicales durante dos años en Temuco, hace ya muchos años no nos vemos, pero aun así, publicaciones en redes sociales siguen teniendo efectos en mi vida, el título El idioma de los dioses, ¡es gracias a vos! que me presentaste tan grande canción, que terminaría por inspirar esta investigación doctoral. 


\section{Agradecimientos}

Agradecer es un acto extraño, pues siempre alguien queda por fuera o queda sin ser registrado, corro por lo tanto el riesgo, por primera vez, de escribir unos agradecimientos. El apoyo en la escucha constante y, en este caso, el escuchar las mismas canciones cientos de veces, parando y adelantando, en silencio, es un acto ¡sin límites! Marcela, agradezco toda la compañía y apoyo que durante estos años me brindaste; de igual forma a los amigos, Sandra Osses, Jorge Jaramillo, Teresa Suárez, sin los famosos “tiene cinco minutos para hablar de mi tesis" muchas de las ideas y de los problemas que surgieron en el desarrollo de esta investigación no estarían aquí presentes dando vida a esta obra, sin su cariño y apoyo, estoy seguro no habría llegado al lugar en el que me encuentro ahora.

A Johanna Quintero, Luisa Sánchez, Diana Guzmán, amigas y compañeras que no solo escucharon sobre la tesis, sino que además llegaron con ideas, libros ampliamente significativos sobre sirenas, ruidos y apuestas de vida, mucho de ustedes también está también en estas páginas, tardes de café, té y pizza, agradezco profundamente el momento en que los caminos se nos cruzaron.

A Daniel Aguilar, mi tutor, que con paciencia me acompañó en este camino. Cierro así estos agradecimientos, con quien sería un gran apoyo académico y el símbolo de la presión para poder terminar un proyecto que en ocasiones pareciera desbordar la vida misma. 


\begin{abstract}
El idioma de los dioses presenta al lector una aproximación al discurso musical desde la categoría del hechizo discursivo, una forma de ideología, en la cual se incorporan elementos propios de los estudios del discurso, en relación con procesos cognitivos, donde se busca ampliar los procesos o formas en que generalmente se aborda el análisis de la música, donde la lírica es central y se deja el sonido por fuera del análisis.
\end{abstract}

Así entonces, comprendiendo el hechizo discursivo en relación con el discurso, se incorporan elementos propios del sonido, en el marco de la cultura capitalística, para analizar desde éstos elementos los posibles procesos de singularización que el discurso musical puede producir.

Para este fin, se abordan cuatro álbumes de géneros musicales diferentes, de los artistas Taylor Swift, Maluma, Lowkey y Epica, reconociendo desde sus sonidos, en relación con las metáforas incorporadas en las líricas, los hechizos discusivos presentes en esos discursos musicales, esto con el fin, de construir desde las experiencias del mundo vivido por parte del autor de la investigación, en clave reflexiva, el reconocimiento de los posibles procesos de singularización vividos a lo largo del proceso investigativo. 
Tabla de Contenidos

Capítulo 1 The house of the rising sun: Introducción. 10

Capítulo 2 El pueblo unido jamás será vencido: sobre la ideología, la subjetividad y

los procesos de singularización.

1. Introducción

1 verso: La ideología como un problema de conciencia de clase y la construcción de la

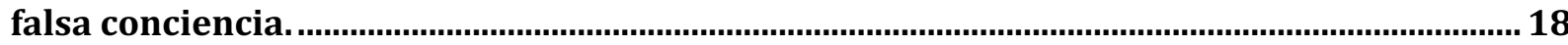

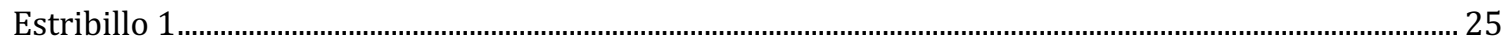

2 verso: la ideología como una cuestión de estructuras sociales ........................................... 26

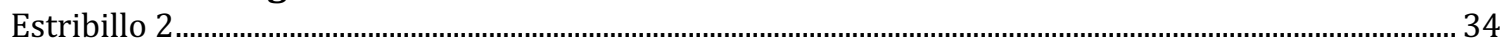

3 verso: la ideología es un texto, el discurso como ideología ................................................ 35

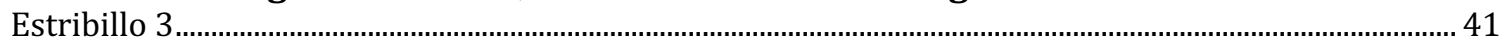

4 verso: La ideología como un modelo de pensamiento que guía la conciencia, la

estructura y el discurso. El proceso de la subjetividad ..............................................................42

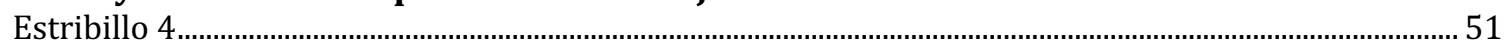

5. verso: La singularización en función de la crítica a la ideología, la subjetividad en una

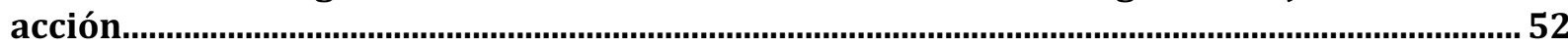

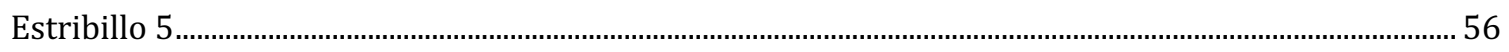

Cierre: El rol de la ideología en el marco investigativo del idioma de los dioses. ............ 57

Capítulo 3 Hurt: Significado del hechizo discursivo musical.......................................60

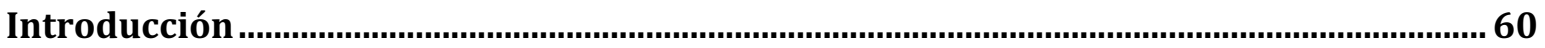

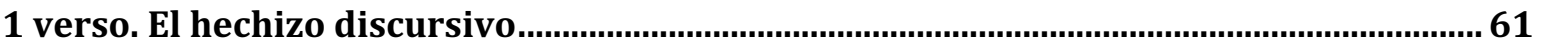

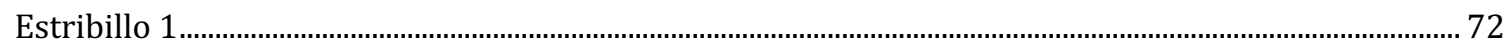

2 verso. La cognición en el hechizo discursivo ...................................................................... 73

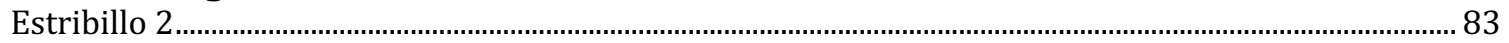

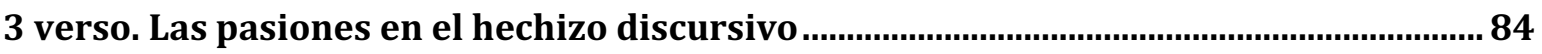

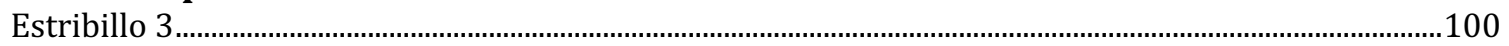

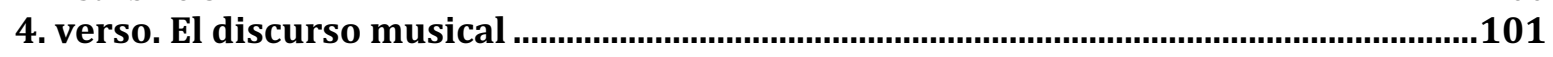

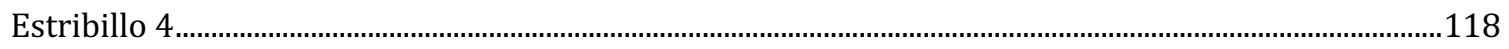

Cierre: el hechizo discursivo musical en el idioma de los dioses ....................................119

Capítulo 4 Muevan las industrias: el hogar de la industria cultural musical. .......... 121

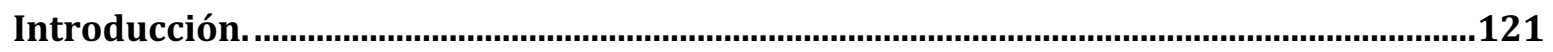

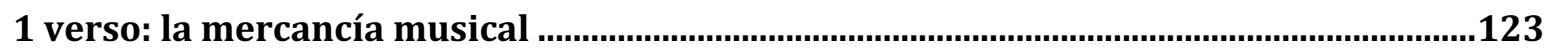

Taylor Swift, Una mirada al POP ...................................................................................................................129

Lowkey, Expresiones del Hip-Hop ………………..........................................................................130

Epica, apuestas sinfónicas para el Rock …………….....................................................................................131 
Maluma, las apuestas del reguetón ............................................................................................................132

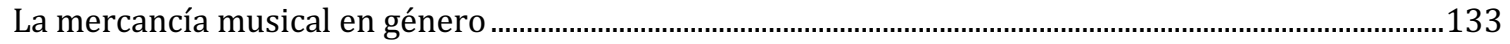

2 verso: la industria cultural musical - Producción. ...........................................................135

3 verso: la industria cultural musical - Distribución. .........................................................145

Los artistas del mainstream, una mirada hegemónica de la ICM...............................................................148

Los artistas del underground, una mirada contra hegemónica de la ICM.................................................155

4 verso: Miradas hegemónicas y contra hegemónicas de la ICM ......................................158

\section{Capítulo 5 Brain Damage: Particularidades de los discursos musicales analizados.}

Introducción:

162

"Los chicos solo quieren amor si es una tortura" Taylor Swift, el discurso musical del

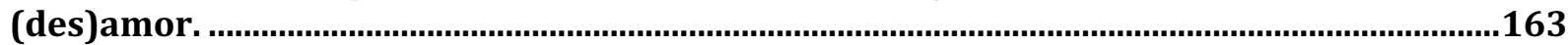

1 verso armonía baja. Los planos de la intimidad: el amor duele..................................................................165

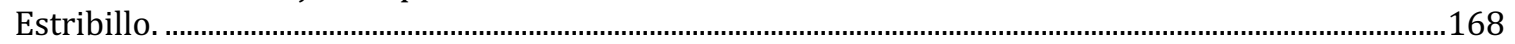

2 verso armonía media. Los planos del territorio: donde amamos. .............................................................169

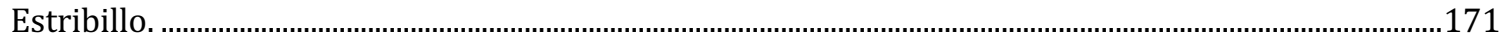

3 Verso armonía alta. Los planos de la seguridad: el lugar confiable para el amor.................................172

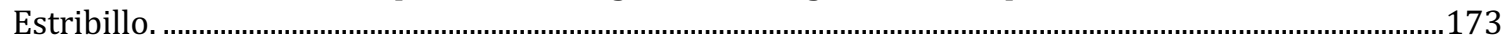

4. Verso. Generalidades del discurso musical de 1989..........................................................................175

"Haciéndome el amor hasta la madrugada" Maluma, el discurso musical de la

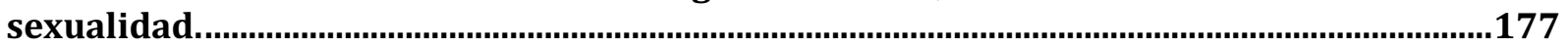

1. Verso armonía baja. Planos de la sexualidad: ¿qué es el sexo? .............................................................179

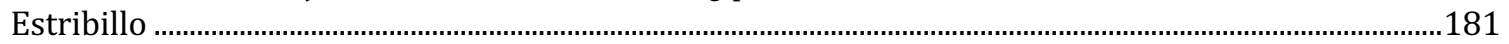

2 Verso. Armonía alta. Planos sobre la posesión del cuerpo: la mujer ........................................................182

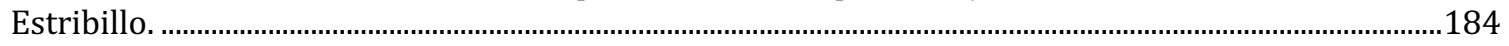

3. Verso armonía media. Los planos de la reafirmación: mujer para tirar. .............................................185

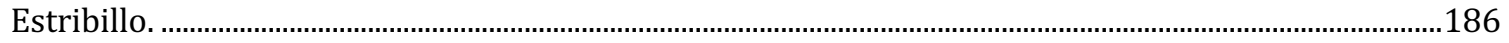

4. Verso. Generalidades del discurso musical de PB/DB.......................................................................187

"Soy el producto del sistema que nací para destruir" Lowkey, el discurso musical en la

guerra preventiva de Irak. .............................................................................................189

1. Verso armonías bajas. Planos del dolor: Una mirada a la guerra preventiva......................................191

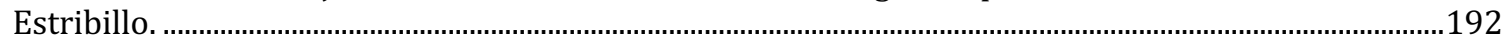

2. Verso armonías medias. Planos del despertar: Entender la violencia terrorista...............................194

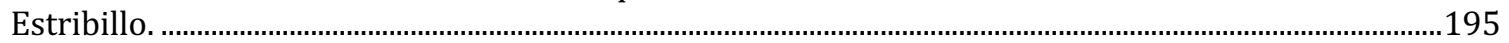

3 Verso. Planos ocultos: Lo que no quieren que veas del terror. …………………......................................196

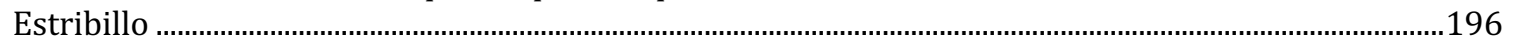

4. Verso. Generalidades del discurso musical soudntrack to the struggle.................................................197

“La agonía fantasmal” Epica, El discurso musical de la realidad. ..........................................199

1. verso armonías bajas. Planos de sensación de verdad: El engaño de la verdad ...................................201

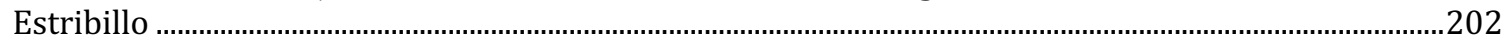

2 Verso. Planos de seguridad en la mentira: Sumergidos en la ausencia de verdad................................203

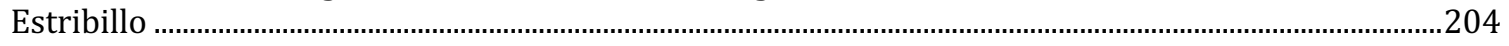

3 Verso. Planos de la sádica verdad: Abrazando la muerte..........................................................................205

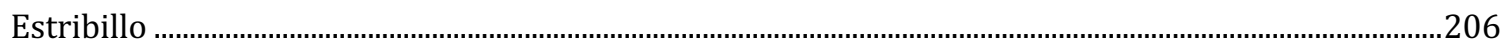

4 Verso. Generalidades del discurso musical The phantom agony.............................................................206 
Capítulo 6 El idioma de los dioses: El discurso musical y los procesos de

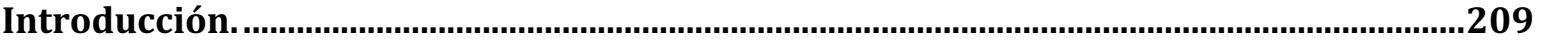

1 Verso. Hechizos discursivos en el idioma de los dioses. ..................................................211

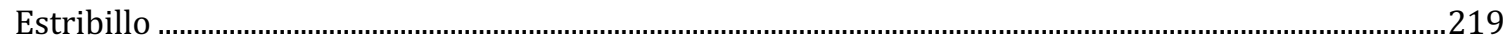

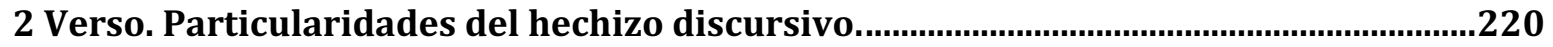

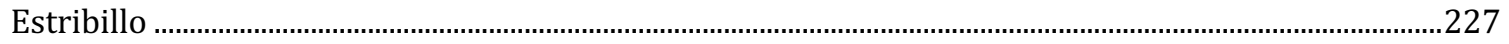

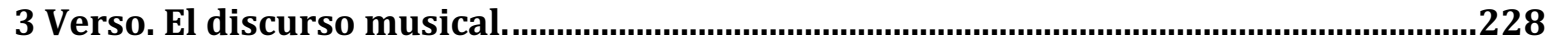

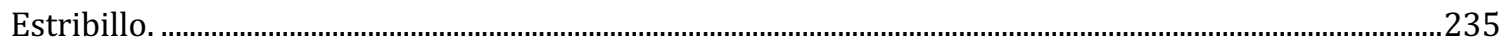

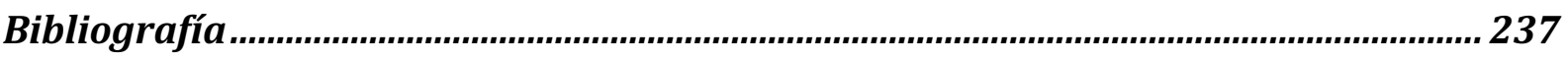

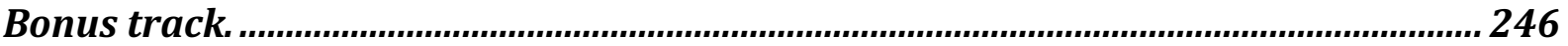

Sobre la producción del idioma de los dioses. Ampliación metodológica.......................246

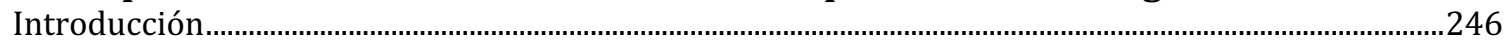

Reflexión epistemológica.......................................................................................................................246

Una breve biografía musical del investigador.......................................................................................251

Sobre partituras: Estrategia metodológica..............................................................................................25

Sobre instrumentos interpretados: Nivel técnico ……........................................................................260

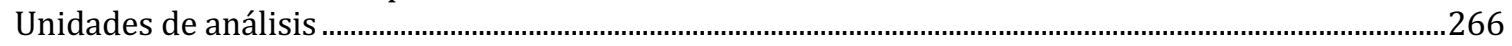




\section{Lista de tablas}

1. Aspectos relacionados en la producción de un álbum............................................141

2. Presencia de los álbumes mainstream (hegemónicos) en los procesos de distribución...............151

3. Presencia en redes sociales de los artistas mainstream (hegemónicos) .........................154

4. Presencia de los álbumes underground (contra-hegemónicos) en los procesos de distribución......157

5. Presencia en redes sociales de los artistas undergorund (contra-hegemónicos)....................158 


\section{Lista de figuras}

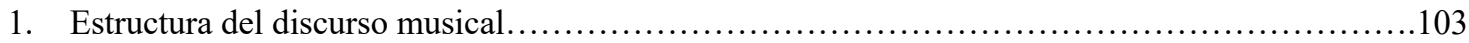

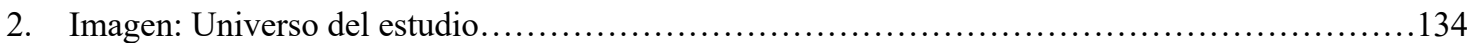

3. Relaciones reconocidas en la creación de un álbum............................................

4. Sujetos involucrados en la producción de los álbumes...................................... 142

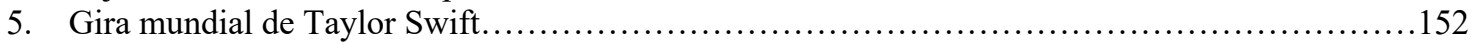

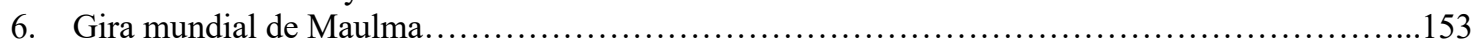

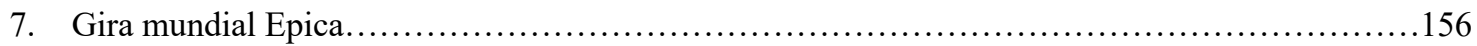

8. Imagen de las relaciones entre la armonía en relación con el ritmo en los segmentos de melodía del álbum

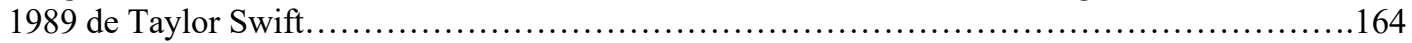

9. Imagen textura y relaciones de los planos de 1989 de Taylor Swift...........................177

10. Imagen de las relaciones entre la armonía en relación con el ritmo en los segmentos de melodía del álbum

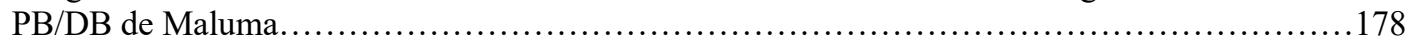

11. Imagen textura y relaciones de los planos de PB/DB de Maluma...............................188

12. Imagen de las relaciones entre la armonía en relación con el ritmo en los segmentos de melodía del Soundtrack

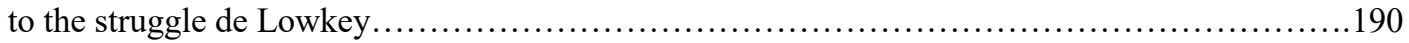

13. Imagen textura y relaciones de los planos de Soudntrack to the struggle de Lowkey................198

14. Imagen de las relaciones entre la armonía en relación con el ritmo en los segmentos de melodía del The

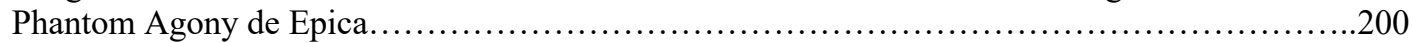

15. Imagen textura y relaciones de los planos de The phantom agony de Epica.......................207 


\section{Capítulo 1}

\section{The house of the rising sun: Introducción}

En la historia del rock existen canciones que marcan momentos claves del desarrollo de este género musical, una de ellas es The house of the rising sun, versada por la banda The Animals, permitiendo en medio de la invación británica terminar de dar un giro importante a la música de los años 60 del siglo pasado, reafirmando el rock como un género que acompañaría el resto del siglo, manteniendo su relevancia hasta los días en que se escribe esta tesis doctoral.

La introducción de El idioma de los dioses: el discurso musical y los procesos de singularización, busca evidenciar los momentos, movimientos y sentidos más importantes del documento, de igual forma, como se reconocen canciones importantes de géneros musicales, aquí se quiere establecer la ruta de lectura, sus relaciones, estructuras y el proceso de producción.

Los elementos más importantes o aportes, como si fuesen las canciones claves del desarrollo de una historia musical, son la construcción de dos categorías de orden teórico a partir de las cuales se produce una forma de comprender y aproximarse al objeto de estudio, se trata de: I) el hechizo discursivo, y II) el discurso musical. No solo se construyen estos elementos de orden teórico a forma de posibles canciones, también se elabora un aporte en la forma de interpretar los instrumentos, es decir, la apuesta metodológica de aproximación y análisis de los discursos musicales desde una perspectiva comunicacional.

Como una obra musical, este documento cuenta con una estructura respetuosa del discurso musical, así el lector, encontrará que cada capítulo recibe el nombre de una canción, que sirve 
como espacio reflexivo, y en su desarrollo interno, cuenta con versos y estribillos; en los versos se busca desarrollar los principales reconocimientos y aportes de orden teórico, mientras en los estribillos se reflexiona desde la canción los elementos teóricos. A lo largo del documento, se encuentrán una serie de íconos, que corresponden a archivos de audio grabados en el CD que acompaña el texto; la escucha atenta de las canciones y de los fragmentos de ejemplos del discurso musical es importante en la lectura del texto en general.

A su vez, la estructura busca dar cuenta del proceso investigativo por ende, en este primer capítulo introductorio, se presenta el orden general del texto, además de la metodología investigativa utilizada y aplicada a lo largo de todo el proceso, esto con el fin de brindar unas coordenadas que permitirán construir sentido a los capítulos siguientes.

En tanto proceso organizativo, en los dos siguientes capítulos: El pueblo unido jamás será vencido y Hurt, se presentan el proceso de objetivación ${ }^{1}$, por medio del cual no se pretende la construcción de un objeto de investigación objetivo, sino que se busca construir el marco interpretativo sobre el cual se produce dicho proceso, siendo además estos dos capítulos estados del arte sobre las dimensiones teóricas que se abordan y desarrollan. Acorde con lo anterior, en El pueblo unido jamás será vencido, se aborda la categoría de ideología, la cual se encarga de dar apertura del proceso de objetivación, aproximándonos a una de las categorías más complejas al interior de las ciencias sociales, como punto de inicio permite el desarrollo y comprensión de

\footnotetext{
${ }^{1}$ Al hablar de objetivación, se da razón de la propuesta de Absalón Jiménez, quien plantea la necesidad de construir el objeto de investigación en cuanto sus características de abordaje, permitiendo así reconocer lo que se investiga de forma coherente con el campo de estudio o disciplina (Torres \& Jiménez, 2006).
} 
la singularización ${ }^{2}$ y su relación con la ideología, donde se construye la categoría de hechizo discursivo ${ }^{3}$. En el capítulo Hurt, se amplía el concepto en términos de objetivación mediante la incorporación de la categoría del discurso y la apuesta por su comprensión en el marco de la música y, por lo tanto, se configura la forma en que se comprende el discurso musical.

Bajo esta estructura, por medio de los dos capítulos siguientes se consolidan las principales categorías de trabajo investigativo: el hechizo discursivo y, el discurso musical en relación con los procesos de singularización. Lo anterior para establecer las coordenadas para lograr el rastreo y construcción del corpus de análisis, proceso que se construye desde la idea de la industria cultural musical, donde no sólo se expone cómo funciona en términos de producción y distribución de los discursos musicales, sino que permite además la consolidación del corpus de estudio $^{4}$ donde se encuentran cuatro álbumes musicales de géneros diferentes, pertenecientes a los artistas: Tayor Swift, Maluma, Lowkey y Epica, este proceso descriptivo y analítico se desarrolla en el capítulo titulado: Muevan las industrias.

${ }^{2}$ Esta categoría es abordada desde Guattari, da razón de un momento o segundo en el cual es posible pensar el pensamiento no pensado y se genera una ruptura de orden ideológico, modificando el hechizo discursivo.

${ }^{3}$ En el hechizo discursivo en cuanto categoría de trabajo y propuesta de esta investigación, se relaciona con la forma en que se comprende y desarrolla la idea de ideología de la mano con el discurso, sin dejar de lado elementos como la conciencia de clase y la materialidad de la producción ideológica, se trata, por lo tanto, de la construcción que se realiza principalmente a lo largo del primer capítulo.

${ }^{4}$ El corpus de investigación se amplia en el capítulo de muevan las industrias, inicialmente es preciso señalar que los artistas que se evidencian en este apartado se relacionan con la industria musical del mainstream, o del discurso musical hegemónico (Taylor Swift y Maluma) en contraste con artistas del underground o del discurso musical contra hegemónico (Lowkey y Epica). 
Con este corpus de trabajo, se inicia el análisis de los discursos musicales y para ello, se optó por una estrategia metodológica de teoría fundamentada, la cual, en este caso, parte del reconocimiento de particularidades del discurso musical, en cada una cada una de las piezas musicales (60 en total); es necesario señalar que se tomó como unidad de análisis el álbum del artista en su integridad. Así las cosas, en cada una de las piezas, se establecieron momentos musicales a partir de las variaciones en el ritmo; en cada uno de estos momentos, se reconoció el tiempo y la intensidad del plano musical y de forma paralela, en la lírica organizada con los mismos momentos establecidos en el plano musical, se identificaron las metáforas que emplea el discurso para desarrollar sus posturas.

Ahora, por medio de los momentos, es posible relacionar el plano musical con el plano lingüístico, estableciendo de esta forma mapas en ATLAS.ti que relacionan como eje principal los tiempos e intensidades (sus relaciones posibles) con las metáforas. De esta forma, se construyen nuevos mapas donde se configuran las lógicas anidadas metafóricas de construcción de sentido en las expresiones musicales, siendo este proceso metodológico uno de los aportes de esta investigación al campo de la comunicación.

La organización y construcción mediante la vinculación de las categorías anteriores, lleva desde una postura hermenéutica interpretativa y crítica ${ }^{5}$. al desarrollo del capítulo Brain damage,

${ }^{5}$ Es preciso en este punto aclarar que se trata de una postura hermenéutica, donde la perspectiva de Hans-Georg Gadamer cobra sentido, toda vez que en el proceso de construcción del ejercicio investigativo se busca reconocer elementos propios de los contextos de producción de los discursos para su análisis, pero es el lugar del intérprete y su contexto histórico el que marca también elementos claves de la producción de sentido final frente al texto que se interpreta. 
donde se presentan cada unos de los álbumes. Así, a lo largo de éste, se encuentran las principales características del discurso musical en cada uno de los álbumes y a partir de las particularidades sonoras, se establecen sus relaciones con los procesos metafóricos, reconociendo de esta forma los procesos de anidación ${ }^{6}$ y en ellos, los sentidos en torno a temáticas específicas de cada una de las unidades del corpus.

De esta forma, el texto se aproxima a su último capítulo, El idioma de los dioses, donde se pone en discusión los elementos encontrados en el análisis, Brain damage, que permiten sistemáticamente responder a las preguntas y cumplir con los objetivos de la investigación.

La pregunta planteada para el trabajo se encaminó a reconocer ¿Qué tipo de procesos de singularización ${ }^{7}$ pueden surgir de los discursos musicales de Taylor Swift, Maluma, Lowkey y Epica? Para ello, se planteó como objetivo general de la investigación:

- Describir el tipo de singularizaciones que se pueden producir a partir de los discursos musicales que componen el corpus de investigación.

En su compañía, se han planteado una serie de objetivos específicos:

${ }^{6}$ En los estudios sobre las metáforas de la vida cotidiana (Lakoff \& Johnson, 2004), se establece como las metáforas funcionan o generan sentido en las relaciones que se producen entre ellas, este elemento es abordado y desarrollado de forma más amplia en el capítulo Hurt, donde se construye el discurso musical.

${ }^{7}$ Es preciso recordar que la singularización es reconocida como la posibilidad de pensar el pensamiento no pensado, a partir del trabajo realizado por Guattari (2005), este ejercicio se aborda y desarrolla de forma más completa en el capítulo El pueblo unido jamás será vencido y Hurt. 
- Reconocer los procesos de producción y distribución que son empleados por los artistas que componen el corpus de investigación.

- Establecer las particularidades de los discursos musicales de las y los artistas que componen el corpus de la investigación en los diversos planos que componen el discurso musical.

- Consolidar las particularidades del discurso musical como objeto de investigación con sus singularidades específicas como proceso de objetivación.

- Reconocer las particularidades presentes en los discursos musicales que puedan producir procesos de singularización.

El texto de esta investigación contiene el proceso de objetivación en sus primeros dos capítulos (El pueblo unido jamás será vencido y Hurt), de donde se construye el contexto sobre el cual se produce y reconoce el corpus de investigación en el capítulo Muevan las industrias, para dar paso al análisis y la exposición de las particularidades del discurso musical de los artistas del corpus en el capítulo Brain Damage, de donde se generan una serie de debates y discusiones que componen el último capítulo de la investigación con las conclusiones en el capítulo titulado El idioma de los dioses.

Antes de iniciar con el proceso de objetivación, el lector podrá ampliar elementos como la metodología con una exposición mucho más detallada en los Bonus Track, donde se desarrolla la estrategia en todos sus componentes y particularidades, además de encontrar los mapas construidos en ATLAS.ti (ejemplos) y muchos otros detalles del proceso de producción de esta obra, además en el CD también se encuentran elementos como el primer estado del arte en relación a lo que se estudia en comunicación al estudiarse la música, que permitió enfocar la 
investigación, además de los mapas completos desarrollados en el software empleado para este proceso investigativo. 


\section{Capítulo 2}

\section{El pueblo unido jamás será vencido: sobre la ideología, la subjetividad y los procesos de singularización.}

\section{Introducción}

La banda de canción protesta Quilapayún de Chile, fue la responsable de hacer famosa una de las canciones más reconocidas de este género musical a nivel mundial, se trata de El pueblo unido jamás será vencido, canción que será la excusa de este primer capítulo por su carga ideológica. La canción es por lo tanto una forma de aproximarnos al concepto de ideología.

La construcción de ideologías, en este caso, se relacionará con dimensiones específicas de su producción como mecanismo de consolidación en especial de subjetividad y singularización, éstas como partes integrales de la ideología.

Slavoj Zizek reconoce al menos tres acepciones de la ideología, que, en este caso, guían la producción de los tres primeros versos (momento) del capítulo; al respecto el autor nos plantea:

"la ideología como complejo de ideas (teorías, convicciones, creencias, procedimientos argumentativos); la ideología en su apariencia externa, es decir, la materialidad de la ideología, los Aparatos Ideológicos del Estado (AIE); y, finalmente el terreno más elusivo, la ideología "espontánea" que opera en el centro de la "realidad” social en sí" (Zizek, 2008, p. 16)

Posteriormente en un cuarto momento - "verso" se realizará un ejercicio de construcción de la noción de ideología propia del idioma de los dioses (hechizo discursivo), en la cual se relacionan 
elementos de los tres momentos previos, lo que permitirá cerrar este capítulo con las relaciones que la ideología establece con la subjetividad y la singularización.

Entre cada uno de los verso-apartados, se contará con un escenario denominado como estribillo, en el cual se relacionará la canción que da titulo al capítulo con los elementos que se desarrollan en el verso previo. Así entonces sin más preámbulos iniciemos el recorrido por la ideología, no sin antes poder escuchar la canción que da título al capítulo.

\section{1 verso: La ideología como un problema de conciencia de clase y la construcción de la falsa conciencia.}

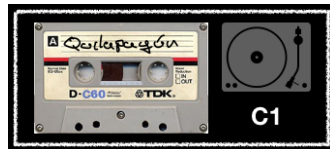

Una de las primeras formas en que se abordó la categoría de ideología en las ciencias sociales, es a través del entramado conceptual consolidado en el trabajo de Karl Marx, donde es preciso al menos señalar el valor de textos como Grundrisse (1986) y el Capital (2014), donde la categoría de ideología será clave en términos de la comprensión del modelo social capitalista.

De estos trabajos no sólo surgieron elementos analíticos en términos de categorías que permiten la consolidación de un modelo explicativo del funcionamiento del capitalismo, también se formaron corrientes de orden político y se levantaron banderas revolucionarias en diversos territorios. De hecho estos modelos serán clave para poder comprender la historia del siglo XX (Hosbawn, 1998), en especial desde las perspectivas y formas en que se asumió y comprendió la noción de ideología en el proceso revolucionario.

Ahora bien, al interior de las ciencias sociales en general el trabajo de Marx también será clave en la producción de conocimiento, de hecho al interior de prácticamente toda disciplina o ciencia del campo de las humanas o sociales, se reconocerá la denominada escuela de Frankfurt, 
donde los aportes de este autor serán el centro o foco de trabajo por parte de un gran número de académicos.

Reconociendo entonces el valor que se ha producido en torno a los conocimientos producidos por este tipo de pensamiento, se hace evidente el motivo por el cual esta investigación parte de una categoría como ideología, la cual en este punto cuenta con un sentido o forma específica.

El mundo o sistema capitalista parte o se nutre de una idea clave, la cual gira en torno a los procesos de dominación, la idea de la explotación del hombre por el hombre, a partir de la construcción o consolidación del hombre como mercancía (Marx, 2014), para lo cual el proceso de dominación mediante la ideología es la clave.

Será entonces la ideología una forma o construcción de ideas por medio de las cuales se garantiza el orden de dominación y explotación en los dominados, de forma específica podríamos en este escenario definir la ideología como "ideas que permiten legitimar un poder político dominante" (Eagleton, 1997, p. 19), esta forma de abordaje de la ideología permitirá la consolidación de una primera vertiente de sentido.

Para comprender esta idea es preciso también reconocer elementos, categorías que describen el funcionamiento del proceso del pensamiento marxista, al menos es preciso abordar la idea de lucha de clases. En este sentido el motor de las sociedades es activado por un proceso, denominado al interior del pensamiento marxista como el materialismo histórico, en el cual es el proceso del desarrollo de los antagonismos sociales los que promueven los grandes cambios de las sociedades, permitiendo por ejemplo el paso de un modelo feudal al capitalista por medio de la revolución burguesa. 
Es decir, para que pueda existir el cambio social, es preciso que se generen antagonismos entre clases sociales, la materialización de esos antagonismos se producirá entonces mediante la lucha de clases, pero para que ésta se pueda presentar es preciso la presencia de conciencia de clase.

Así entonces, si la lucha de clases es posible mediante la conciencia de clase, es preciso retomar aquella noción de ideología que garantiza o mejor, legitima el orden de explotación del orden político ${ }^{8}$, pues será en estas relaciones que se comprenderá la ideología como una categoría positiva ${ }^{9}$, en la medida que no permite la conciencia de clase y por lo tanto impide el orden revolucionario.

Un muy buen ejemplo de este tipo de relaciones, se encarna al comprender que mediante la ideología se pierde la capacidad de racionalidad y de crítica, al ser éste un proceso mediante el cual se podría decir, se adiestra a las clases obreras para el cumplimiento de un rol específico en las sociedades, de forma que se borra no sólo la posibilidad de pensar por fuera del mensaje en una botella, donde se contiene el todo, sino que con ella también se desdibuja la capacidad revolucionaria de la clase (Adorno, 2008), así la ideología integra las formas cotidianas de comprensión del mundo mediante una suerte de mentira, que oculta los procesos de dominación

\footnotetext{
${ }^{8}$ Es preciso señalar que este entramado funcionará no sólo en el marco de un orden político, económico y cultural capitalista, sino también será funcional en términos de otros ordenes como socialistas, comunistas o anarquistas entre otros.

${ }^{9}$ Se alude aquí a la propuesta de Byung-Chul Han quien en su texto Psicopolítica en 2017, propone la positividad como ausencia de posibilidad de pensamiento crítico, así las cosas, se genera un orden de ideas totales que no pueden ser puestas en duda o ser pensadas.
} 
y los legitima, de allí que sea la ideología considerada en este escenario como una falsa conciencia y se construya entonces en torno a ella una categoría de orden positiva (Han, 2017).

La dinámica anterior llevó al interior de este proceso de abordaje del mundo social a producir una suerte de mistificación en torno al materialismo histórico, es decir, el núcleo del pensamiento se encuentra en la historia sin poner en tensión ¿cuál historia o cómo se genera el proceso histórico? De allí surgirá una de las principales críticas al marxismo, pues se reconocerá en él una suerte de dogmatismo histórico, de allí algunos de sus representantes de orden político, construirán la idea de la ideología como mentira, la verdad en el sentido de oposición será el conocimiento otorgado por el materialismo histórico y la posibilidad revolucionaria de la lucha de clases (Benhabib, 2008).

En el análisis que realiza Benhabib se utilizará la noción de crítica a la razón instrumental, en la medida que será el mismo marxismo el que caerá bajo la anterior mirada en una razón instrumental, que no permitirá la crítica o abordaje diferenciado, se trata de eso que denominamos hace unas líneas como dogmatismo histórico. Este punto será clave en la producción de la categoría de ideología, en la medida que será esa falsa conciencia la que no permite el proceso revolucionario.

Acorde con lo presentado hasta este momento, es preciso comprender que la ideología será una categoría positiva en la medida que no permite la revolución o mejor, el desarrollo del materialismo histórico, es su impedimento y en términos políticos, su gran enemigo, pues se tratará desde este espacio de un grupo de ideas que consolidan las dinámicas de dominación legitimándolas, impidiendo por lo tanto observar o reconocer el estado de explotación del hombre por el hombre. 
Se trata por lo tanto del núcleo de la dominación en las sociedades, dominación que no requiere necesariamente de la fuerza física, sino que logra mediante el convencimiento garantizar el sometimiento de amplias mayorías sociales a un pequeño grupo de poder. La ideología así garantiza el orden social mediante la producción de una cultura ${ }^{10}$ que asegura la producción de subjetividades que entienden y aceptan tanto la forma de explotación como el sometimiento incluso con agrado.

Se puede en este punto relacionar esta aproximación a la ideología con una forma de violencia: la subjetiva, la más visible de las violencias, que afecta o mejor, que opera sobre los sujetos (Zizek, 2009), así la ideología como forma de violencia subjetiva es la producción de un grupo de ideas que legitiman el orden social de dominación mediante la latencia o posibilidad de aplicación de la violencia subjetiva, se trata entonces de la cultura de la falsa conciencia.

Es así un tema más complejo que tan solo comprender la ideología como una falsa conciencia, pues ésta, se relaciona y consolida con todo un entramado cultural, que permite en términos de mercancía la producción del grupo de ideas que garantiza el orden de dominación, no sólo en el sujeto y su subjetividad, sino que en el grupo cultural, siempre bajo la noción de amenaza de

${ }^{10}$ Entendiendo por cultura la consolidación de una mercancía, como lo señala Félix Guattari y Suely Rolnik, donde la cultura no da razón del binomio tener o no tener, escapando también de la noción de cultura nacional, donde un grupo de sujetos comparten unos principios de identidad específicos, consolidando entonces la cultura como una mercancía que es producida en el marco de las sociedades capitalistas, por lo tanto se tratará de algo similar a una coca-cola, en cuanto mercancía, con un fetiche y un ejercicio de dominación intrínseco en su valor de mercancía en cuanto tal. 
instalación y operación de violencias sobre el sujeto, así entonces se puede garantizar la producción y mantenimiento del orden de dominación.

La ideología entonces como falsa conciencia se puede concebir como una suerte de hechizo, que recae sobre los sujetos, construyendo y consolidando las formas en que se comprende el orden de explotación de forma legítima, así el sujeto pese a ser explotado y dominado, gracias a este hechizo que comprende este orden como natural al hombre y por lo tanto legítimo (Dews, 2008). Aceptando por tanto el orden social y comprende o asume como legítimas las formas de violencia subjetivas que pueden operar sobre él si intenta romper el orden social establecido, pues además no sólo lo acepta, sino que gracias al hechizo considera estas rupturas como elementos negativos de su ser en el marco social.

Las luchas sociales de orden revolucionario, por lo tanto, construirán su núcleo en las formas de producción de conciencia de clase, en cuanto está negara la ideología, es decir buscará hacer evidentes los mecanismos de dominación y explotación, como formas no legitimas del orden social, promoviendo por lo tanto otras formas de organización. Ahora bien, este orden de pensamiento nos lleva a consolidar rupturas no sólo con la falsa conciencia, sino que además requiere la producción de otras subjetividades, que reconozcan lo ilegitimo, es decir, la producción de otro orden cultural, sobre el cual operan otras formas de conciencia que permitirán la ruptura del orden dominante y explotador.

El anterior proceso permite comprender en gran medida las lógicas de la revolución cultural de Mao Zedong en China, donde una de las principales banderas revolucionarias fue la prohibición de la música occidental, contemplando en ella la instalación del orden cultural dominante del sistema capitalista. Es por lo tanto la resistencia a la inclusión y producción de esa 
falsa conciencia o ideología propia del modelo de producción capitalista, pero entonces se podría igual afirmar que se produce otra falsa conciencia, que permite el orden de explotación y dominación de otro orden económico: el comunista.

En términos generales, en este punto la ideología se instala como una forma de producción de subjetividades, mediante la instalación de un hechizo que puede ser configurado como la falsa conciencia, que garantiza la consolidación de un orden social legitimo, con procesos de dominación de unos grupos sociales a otros, fundamentados en la producción de una cultura que como mercancía se establece y contiene no sólo valores de cambio y de producción, sino un componente muy importante: el fetiche.

Marx al asumir la mercancía y su secreto (el fetichismo) nos señala que: "a primera vista, una mercancía parece un objeto natural, evidente y por sí mismo trivial. Pero, al analizarla, vemos algo muy intricado, lleno de sutilezas metafísicas y de enredos teológicos” (Marx, 2014, p. 72), son esos enredos y sutilizas las que en este caso encierran o mejor, contienen el sentido de la cultura como mercancía que permite la producción de un orden de subjetividades que conllevan el proceso de legitimación del orden social de dominación y explotación en una sociedad.

Es preciso en este punto destacar que el sujeto se encuentra prácticamente sometido por el hechizo, por la falsa conciencia, dejando así sólo un camino para romper el sentido positivo de la ideología, la revolución como posibilidad de cambio. ¿Se tratará entonces de la producción de un nuevo fetiche en la mercancía cultura para garantizar un nuevo orden de dominación y explotación? 
La anterior pregunta funciona en términos de comprender que si los ordenes sociales que se conforman en trono a la idea de un Estado-Nación, bajo la idea moderna, requerirán de algún tipo de garantía para la legitimidad del orden mismo, donde la cultura que contiene las formas de producción de subjetividades, se relacione con una conciencia específica, vale decir en este caso, con un hechizo, con una ideología, donde se pueda verter la posibilidad de violencia subjetiva de forma diferenciada, en un caso sobre el valor individualista del capitalismo o en el valor colectivo del modelo comunista, de igual forma podría rastrearse las formas de violencias subjetivas en el marco de otros modelos, como el socialista o el anarquista entre otros.

En este campo, es la ideología una categoría que se aplica sobre el orden de ideas como señala Zizek, a un grupo de individuos que comparten una falsa conciencia sobre las formas de organización social.

\section{Estribillo 1}

De pie, luchar / El pueblo va a triunfar / Será mejor / La vida que vendrá / A conquistar / Nuestra felicidad / Y en un clamor / Mil voces de combate se alzarán / Dirán / Canción de libertad / Con decisión / La patria vencerá (Ortega, 1973).

En la canción de Quilapayún se puede observar en el fragmento que se ha traído como excusa, la búsqueda o mejor, el reconocimiento de una conciencia de clase (el pueblo va a triunfar), que se contrapone al orden dominante; es preciso reconocer que esta canción surgirá en el año 1973 en Chile, año en el que Allende es presidente y será derrocado del poder por medio de un golpe militar a manos de Augusto Pinochet. 
La conciencia de clase que se establece en este fragmento guía a la revolución (mil voces de combate se alzarán), negando así la falsa conciencia que permitió el golpe militar, retornando así a una cultura que basada en el Estado-Nación (la patria vencerá), que se establece mediante la idea de la libertad y felicidad (nuestra felicidad / canción de libertad).

Aparece en este fragmento de nuestra canción un elemento muy interesante (la vida que vendrá), donde el futuro es la clave en la posibilidad de producción de fractura con la falsa conciencia, ¿es posible romper un hechizo sobre el ahora? O ¿sólo será posible sobre la posibilidad futura?, un elemento que sobre la ideología contemplada como falsa conciencia y hechizo es relevante, en la medida que las rupturas y la producción de conciencia de clase será posible en la construcción de un orden social diferente, siempre en el futuro, en la promesa, en el devenir.

Bajo esta mirada el devenir de la conciencia de clase, será sin lugar a dudas: la verdad, es decir la revolución de las clases dominadas y explotadas.

\section{2 verso: la ideología como una cuestión de estructuras sociales}

Una vez reconocida la ideología en cuanto falsa conciencia, en las ciencias sociales surge otra perspectiva, en la cual se indaga ya no por el efecto de la presencia de ideología, sino sobre los procesos de construcción de ésta, vale decir en cierto sentido la materialidad de la ideología.

Así entonces se reconoce la construcción del edificio ideológico, en él la presencia del Estado-Nación moderno será de nuevo un elemento clave para la comprensión del proceso. Lo anterior en la medida que una lógica de fondo sigue siendo fundamental en el proceso de 
explicación y descripción del fenómeno, la dominación de unos grupos sociales por parte de otros.

Acorde con lo anterior, en este caso se centrará la mirada sobre, las formas de reproducción social del modelo de dominación (Althusser, 2008), vale decir en este sentido los mecanismos que socialmente son reconocidos para la reproducción de las clases sociales, especialmente de las clases dominadas. En relación con la mirada anterior "falsa conciencia", se trataría ya no de cómo funciona ésta o que efectos tiene en términos de dominación, sino como se materializa el proceso en los grupos dominados.

Althusser, en este sentido retomara una idea de Marx presente en la "Grundrisse” (1986), la infra estructura y la súper estructura, por medio de las cuales se garantiza la reproducción de la clase obrera para el caso del capitalismo moderno.

La infraestructura funcionará como si fuese la base y el primer piso de un edificio, donde se encuentra la esencia de los procesos de producción, es decir, el sistema económico de un orden social específico, éste deberá para su existencia y mantenimiento en el tiempo garantizar por lo menos la reproducción de la clase obrera, es decir, del hombre mercancía que permitirá la producción de nuevas mercancías (Althusser, 2008). Para lograr este proceso, se ha servido de los dos siguientes pisos del edificio ideológico, espacios donde se constituye la súper estructura.

El segundo nivel entonces será aquel donde se reconocen los Aparatos del Estado (AE), reconociendo en ellos principalmente el uso de la coerción (no exclusiva o única) como mecanismo para garantizar la reproducción del sistema, se tratará por lo tanto de aparatos como el ejército, la policía y las leyes, que de forma coercitiva implican una garantía para el 
cumplimiento del orden social y en él la posibilidad de reproducción de los mecanismos de dominación (Althusser, 2008), así entonces, cualquier sujeto o mejor, subjetividad que intente fracturar el orden social establecido dejando en tensión la posibilidad de reproducción del mismo será regulado por medio de los AE. Teniendo en cuenta la noción del hechizo y de la "falsa conciencia”, se puede ingresar al tercer espacio, en el cual se produce ese procesos de hechizo que garantizará el sometimiento ya no por medio de coerción sino por convencimiento.

El tercer nivel entonces, estará compuesto por los Aparatos Ideológicos del Estado (AIE), donde el proceso de convencimiento deberá ser incrustado en los procesos subjetivos, consolidando esa primera idea de "falsa conciencia" que permite y garantiza los procesos de dominación y la reproducción del sistema. Se trata de espacios como la familia, la iglesia, los sindicatos, los centros de formación escolar (colegios y universidades), la cultura y la información como noticias (Althusser, 2008).

Así entonces, por medio de estas instituciones se logra la consolidación de un proceso de convencimiento del funcionamiento del orden social, logrando de esta forma que sea por este medio que el sujeto mismo se regule y no requiera casi de la intromisión de los AE para regularlo, pues es su misma subjetividad la que permite no sólo el reconocimiento de los elementos deseables al interior del sistema, sino que también reconocerá la maldad de sus actos al atentar contra el orden social.

Así entonces el hechizo ya no sólo es promulgado de una forma extraña, sino que además gracias al trabajo de Althusser, ahora cuenta con todo un espacio social, de orden estructural que garantiza el proceso de dominación y en él la obediencia de un grupo o clase social frente a la 
clase dominante. Surge por lo tanto en este ejercicio una forma de dominación donde toda una maquina de organización de la vida social ésta presente.

De esta perspectiva quedarán en evidencia dos elementos de análisis, si en el ejercicio de la falsa conciencia, la historia será un punto de flexión y crítica a la propuesta como un elemento de orden dogmático, en este caso se reconocerá por un lado el determinismo económico y por el otro lado el determinismo Estatal.

En esta propuesta de comprensión de la ideología, al ser el primer piso (infra estructura) el modelo económico, toda la producción de ideología se orienta a la reproducción del sistema económico, dejando de lado cualquier otro tipo de opción o elemento determinante del proceso ideológico, a este ejercicio se le ha denominado determinismo económico, pues los sujetos quedan determinados de forma casi que absoluta por los mecanismos productivos y sus requerimientos de reproducción.

Por el otro lado, si observamos con atención, encontramos que toda la súper estructura se fundamente en el orden del Estado, ya sea en los AE o en los AIE, dejando de esta forma todo un escenario en el que es sólo el Estado el encargado de garantizar la reproducción del sistema de producción por medio de la coerción o el convencimiento, el Estado aparece por lo tanto por un lado supeditado al proceso económico y la ideología tanto a ese escenario productivo como al generado por el Estado-Nación.

Gramsci en uno de sus textos más reconocidos y discutidos "los cuadernos de la cárcel” (1975), de hecho, llama la atención sobre las diferencias sociales de la organización estatal entre occidente y oriente, como un elemento clave para poder pensar y asumir los mecanismos de 
construcción de conciencia de clase. Se trata por lo tanto de un determinismo de la producción ideológica en el marco de un solo escenario de producción el Estado.

Ahora bien, más allá de las formas de determinismo que pueden encontrarse en este escenario de discusión, llama la atención de forma poderosa la consolidación o reconocimiento de todo un mecanismo de grandes dimensiones que permitirán la reproducción del sistema, tanto económico como de organización del poder. Todos estos mecanismos garantizan por lo tanto una forma de poder vertical de dominación, las relaciones entre todos estos mecanismos y aparatos son lo que podría ser reconocido como la hegemonía, pues es la encargada de garantizar cierto orden de las formas de organización (Thwaites, 1994).

Así entonces la hegemonía será la disposición de una serie de mecanismos y aparatos en diversos lugares y momentos de la organización social, de forma acorde con su contexto, que permiten y garantizan la reproducción ya no solamente del aparato productivo económico, sino de todo el esquema cultural que permite los ciclos de dominación en un orden social específico. Retornamos de esta forma a una noción de cultura que es producida, muy de la mano con la idea de la cultura como mercancía propia de un sistema social, como puede ser el capitalismo en cada uno de los territorios donde esta presente, valdría decir algo así como la cultura mercancía de los procesos capitalísticos (Guattary \& Rolnik, 2005).

Ahora bien, comprendiendo las formas en que se materializa la producción de la ideología, ya sea desde la mirada de la relación entre las estructuras (Althusser), o desde la producción de una cultura de orden hegemónica (Gramsci) y la cultura como mercancía capitalística (Guattari \& Rolnik), es preciso contemplar que en este escenario la ideología es más relevante por su función que por lo que ella significa en sí misma, es decir no deja del todo de lado la noción de la "falsa 
conciencia" que abordamos en el verso anterior. Se tratará por lo tanto de una ampliación en la observación y descripción del fenómeno ideológico.

Pese a lo anterior, este nuevo espacio material de la ideología permite abordar elementos que en el primer momento era casi imposible. La violencia subjetiva es evidente en la falsa conciencia, pero pensar o abordar la violencia objetiva es una tarea que nos permite de forma contundente el reconocimiento de los aspectos materiales de la ideología.

Comprenderemos por la violencia objetiva, aquella que es producida por el sistema económico (Zizek, 2009), donde por ejemplo como señaló Marx, el hombre es transformado en mercancía. Aquí el determinismo económico de nuevo es una clave fundamental, pues la violencia objetiva implica el reconocimiento de todas las formas violentas que operan en el orden social, sometiendo cuerpos y subjetividades con el fin de garantizar la reproducción del sistema mismo; sin embargo, estas formas de violencia parecieran imperceptibles para la mayoría de sujetos que componen el sistema social.

Así entonces, aparece la ideología una vez más como sospecha o como concepto positivo, pues en la medida que impulsa un grupo de ideas específicas que giran en torno a la violencia subjetiva permiten ocultar los procesos de violencia objetiva que mantiene el sistema operando y sobre todo reproduciéndose. La violencia objetiva puede entenderse por ejemplo: cuando al pensar los salarios en un momento del desarrollo del capitalismo se estableció que debería contemplar un rubro para consumos culturales, como parte integral de salario, permitiendo de esta forma el consumo de un sector de la economía que requería de un impulso (Bolaño, 2013), el obrero encontró nuevas formas de consumo a través del incremento de su salario, pero no 
puedo ser consiente del proceso económico de explotación y de su configuración como mercancía que consume y reproduce el sector económico cultural.

Se trata por lo tanto de la relación que se comienza a establecer ya no sólo de la ideología como una falsa conciencia sino además como todo un conglomerado de mecanismos que materialmente se utilizan para regular y garantizar el proceso hegemónico de distribución del poder, donde las formas violentas de orden objetivo de este proceso material de producción quedan escondidas gracias a las violencias subjetivas que operan sobre los sujetos en el marco del orden social.

Así entonces el edifício ideológico como materialidad de la construcción de las ideologías nos abre el debate en torno a las relaciones entre dos violencias hasta este momento, la violencia subjetiva que opera sobre el sujeto y la violencia objetiva que produce el orden de reproducción del sistema. Acorde con este proceso la cultura capitalística se encargará de garantizar hasta cierto punto la consolidación de un proceso de comprensión del mundo por parte de las subjetividades desde lo que comprendemos como violencia subjetiva, allí el gran valor de esta mercancía-cultura en términos de la producción de un fetiche específico. La violencia subjetiva.

Por otro lado, es preciso además reconocer como la violencia objetiva del sistema se encuentra además sustentada y legitimada principalmente por los $\mathrm{AE}$, quienes guían y establecen las formas en que trabajan de forma legal. Así entonces se garantiza que este tipo de violencia (objetiva) sea no sólo escondida, sino además se encuentre de forma legítima, o al menos legalizada en el marco de las normas de reproducción del sistema social y económico, la ideología en este caso como falsa conciencia producida en este esquema material de su producción estará encargada de no confrontar o incluso de estar incapacitada de reconocer la 
violencia objetiva, adoptándola como un proceso natural del orden social, de allí que la hegemonía como la sumatoria operacional de todos los mecanismos y dispositivos que permiten la reproducción del sistema sea comprendida y aceptada por grandes grupos de sujetos dominados por el sistema mismo.

Acorde con lo anterior la ideología servirá como producción de sentido en el marco de una lógica dominante que asegura la reproducción del campo hegemónico (Barrett, 2008), en este campo hegemónico se esconde la violencia objetiva y se opera la dominación por medio de la violencia subjetiva principalmente, es decir, de forma muy coherente podemos resaltar la idea de Althusser donde los AE operan por medio de la coerción principalmente, mientras los AIE los realizarán por medio del convencimiento, éste último garantizará la presencia constante de la violencia subjetiva que convence las formas de comprensión del orden social en las subjetividades, que como ya observamos se producen como mercancías en la cultura capitalística, de no ser útil este proceso de convencimiento, entonces la coerción aparecerá en escena, y en estas relaciones la violencia objetiva permanece por fuera del alcance de los procesos de crítica incluso a la ideología misma.

En líneas generales se puede observar ahora no sólo como se produce la noción de ideología sino como ésta materialmente cobra un sentido en términos de su producción para garantizar la reproducción del sistema en diversas esferas (económica, social y política), a través de una cultura específica, donde aparecen formas de violencia resultantes de las formas de dominación, de nuevo aquí la noción de clase es de gran relevancia, pues las formas materiales de la ideología continúan con la perspectiva original planteada por Marx, donde la acción del sujeto será 
reducida a un lugar de inacción sino se relaciona con una conciencia de clase en el marco productivo de la sociedad.

No obstante, como podremos observar en nuestro siguiente verso, la ideología puede ser un elemento de gran relevancia por fuera de las lógicas de estructuración de la sociedad en clases, y con ellas las conciencias amarradas a éstas.

\section{Estribillo 2}

"La patria está / Forjando la unidad / De norte a sur / Se movilizará / Desde el salar / Ardiente y mineral / Al bosque austral / Unidos en la lucha y el trabajo / Irán / La patria cubrirán / Su paso ya / Anuncia el porvenir" (Ortega, 1973).

En este fragmento aparecen una serie de nociones que permiten comprender elementos claves que han sido discutidos a lo largo del último verso, se trata de abordar nociones que son empleadas como elementos de lucha pero no de debate, pese a que estos mismos garanticen formas de dominación.

Iniciemos el elemento anterior a partir de la línea "unidos en la lucha y el trabajo", donde se puede de forma preliminar abordar sin conocer el sentido otorgado por su autor, la composición de la idea de lucha y trabajo, como dos factores de unión, dejando de lado la posibilidad de comprender por ejemplo la violencia objetiva presente en el trabajo, sin embargo es éste el elemento de unión, así los AIE han realizado un excelente trabajo, pues por más revolución que se proponga, algunos elementos aparecen intactos, el orden hegemónico de producción a través del trabajo y los trabajadores permanece sin reflexión en este fragmento de la canción protesta. 
El segundo elemento relacionado con el primer estribillo es la idea de porvenir. Una idea que desde la materialidad de la ideología es clave para garantizar un orden social específico, de nuevo la idea de futuro, pero ahora un futuro mejor, labrado por el trabajo, elementos que curiosamente pueden ser encontrados en el núcleo del capitalismo mismo.

En líneas generales se puede observar en este fragmento de la canción como a pesar de ser protesta garantiza de igual forma elementos aprendidos y construidos en una cultura específica, que en medio de todo no rompe con los elementos claves del orden social dominante, puede que permita a largo plazo el cambio de sujetos en los lugares de dominación, pero el orden del poder sigue siendo un elemento que no se piensa o expone, de hecho se puede observar como el fragmento se basa en elementos que atañen a la violencia subjetiva (a lo largo de toda la canción), donde los trabajadores, los anhelos y el porvenir son el centro del discurso, dejando de lado las violencias objetivas del sistema, que produjeron en un primer lugar las formas de dominación y de las violencias.

\section{3 verso: la ideología es un texto, el discurso como ideología}

Tal vez las mayor ruptura en la producción de sentido en torno a la ideología se configura en la aproximación como discurso, así entonces “el término ideología no es más que una forma cómoda de categorizar bajo una denominación toda una serie de cosas diferentes que hacemos con los signos" (Eagleton, 1997, p. 243), entrando de esta forma en el campo de la producción de sentido, podría decirse en el campo de la semiótica.

Es así que entramos en el campo de la ideología más elusivo en las palabras de Zizek, pues la ideología como formas de ideas son más potentes pues no sólo son ideas, sino que de forma más 
profunda permiten la producción de sentido, es decir, la ideología sería la forma o coordenadas sobre las cuales construimos relaciones que permiten comprender las acciones, hechos y formas en que se tramitan las experiencias del sujeto en el marco del sistema social.

En este sentido se deslinda de la ideología las categorías de clase social, conciencia, y especialmente de lucha de clase, tomando así una forma un poco más autónoma, pues puede ser relacionada con grupos sociales que no necesariamente pertenecen a un proceso de enclasamiento. Pensemos entonces, que es posible en este sentido hablar de forma diversa de la ideología ya no sólo en términos del proceso de producción económica, se libera por lo tanto del determinismo económico y Estatal.

En el campo de la ideología como discurso, es posible abordar y pensar en ideologías minoritarias, hecho que iría en contra de la noción de lucha de clases, por ejemplo, pero permitiría comprender ideologías de orden más subjetivo, aunque igual compartiendo el sentido (coordenadas de comprensión) con grupos de sujetos, como lo es en grupos de gustos musicales, Punk, Rock, o por ejemplo en grupos de animalistas o feministas (Rorty, 2008).

En juego por lo tanto en la ideología como discurso se pone en evidencia las representaciones, es decir, la ideología comienza a conectarse con otros campos del conocimiento, dejando las distancias o divisiones entre el conocimiento y sus ordenes cada vez menos presentes, aquí no sólo se encontrarán relaciones con las representaciones sociales, sino también con los imaginarios, y con categorías como la de Doxa en la teoría de Pierre Bourdieu, quien explica como la categoría de ideología ha sido explorada por diversas dimensiones del conocimiento haciendo de ella una categoría oscura y en exceso compleja, motivo por el cual él opto por 
trabajar desde su producción la idea del Doxa en vez de ideología (Bourdieu \& Eagleton, 2008, p. 298).

Es tal vez por elementos como los señalados en las líneas anteriores que es este el campo más elusivo de la ideología, pues además escapará de la dimensión de verdad o falsedad en la conciencia, en la subjetividad, pasando por lo tanto a las formas de representación y construcción de sentido común en el mundo.

El discurso es por lo tanto mucho más que un texto escrito, es todo el mapa de coordenadas sobre las cuales logramos producir sentido, de hecho en este aproximación podríamos estar mucho más cercanos a esa idea del hechizo, pero es ahora uno que no sólo es instalado por un proceso material, sino que en el proceso de producción de subjetividades puede modificarse y variar.

Lo anterior implica una ruptura fundamental con las dos proposiciones anteriores, donde la ideología es construida como un campo estático, es decir, la verdad o la mentira, mientras que el discurso no contempla esas nociones, sino que se produce, reproduce, muta, cambia y modifica de la mano con la producción semiótica del sujeto. Así la ideología deja de ser estática, puede modificarse y transformarse de diversas formas, como la mercancía y su fetiche.

Pensemos por un momento en la ironía, ésta como forma de aproximación a la crítica de la ideología sólo es posible mediante el reconocimiento del sentido y la consolidación de un mecanismo semiótico en la subjetividad que lleva desde las coordenadas del sentido a consolidar el proceso ideológico mismo, en algunos casos será sólo a través de la ironía donde se podrá reconocer la ideología (Pêcheux, 2008). 
Para comprender la ideología en la clave de discurso es además necesario lograr incorporar importantes elementos ofrecidos por el psicoanálisis, elementos como el deseo, de donde se pueden desprender preguntas como: ¿es posible la existencia del fetiche sin el deseo?, ahora ¿cómo el sujeto produce el sentido por fuera de sí mismo?, en este campo el ejercicio del reconocimiento de un niño en el espejo por primera vez es clave, pues allí logra reconocerse por fuera de sí mismo y por primera vez consolida la producción de una representación, la de sí mismo (Lacan, 2008).

La producción de representaciones y la capacidad del sujeto de reconocerse por fuera de sí mismo, es clave en la consolidación del ejercicio de la ideología en cuanto discurso, pues permite además la inclusión del deseo y en él, desde la producción de subjetividades, la consolidación de pertenencias a procesos de representación del mundo, vale decir, de coordenadas que guían la forma de producción de sentido del mundo cotidiano, pero también de otros mundos.

Ahora bien, surgen algunas preguntas ¿Por qué una ruptura tan fuerte en el sentido de la ideología?, esta indagación es clave para comprender este abordaje, la ideología como falsa conciencia y con su materialidad en la forma de producción, es clave para comprender el proceso de conformación del Estado-Nación y sus mecanismos de dominación como orden social, pero como forma de aproximación a un mundo contemporáneo ya no será tan apropiada. Lo anterior es una gran preocupación en las ciencias sociales, comprender los nuevos mecanismos de organización del mundo, las nuevas subjetividades que son agrupadas por ejemplo bajo el nombre de nuevos movimientos sociales, pero ¿qué los hace nuevos? Para algunos académicos la 
diferencia puede encontrarse justamente en la noción de lucha de clases, en ella la noción de ideología y conciencia de clase.

Los nuevos movimientos sociales, juegan con formas de representación en las que el EstadoNación ya no es necesariamente el mayor actor en juego, comprendiendo de esta forma que las lógicas de poder se encuentran cursando otros escenarios que superan la lógica sobre la cual se pensó en un inicio la ideología. Es decir, el mundo y sus formas de organización y distribución del poder cambiaron, como ejemplo de este proceso puede tomarse la diferencia entre el arte de gobernar y la gubernamentalidad (Browne, 2009), donde podría reconocerse el paso del poder vertical al biopoder.

La ideología como discurso que produce y permite la consolidación del sentido mediante la semiotización ${ }^{11}$ colectiva, permite una aproximación más completa y compleja a las realidades de los nuevos movimientos sociales, a diferencia de aquellos movimientos sociales basados en la conciencia y lucha de clase, donde el caso más relevante será siempre el movimiento obrero.

Para comprender esta ruptura en las formas de organización social, bastaría con pensar o retomar las propuestas de Immanuel Wallerstein en el "análisis del sistema mundo" (2005) o en otra vía similar pero diferente presente en la propuesta de Michel Hardt y Toni Negri en "el imperio" (2000), donde se puede destacar un elemento en común, la forma en que el EstadoNación comienza a perder su gran rol como organizador de las formas de producción social,

${ }^{11}$ En este campo se inicia el uso de una categoría utilizada por Guattari, la semiotización como parte de la producción de sentido en la subjetividad capitalística, es decir procesos de producción de sentido colectiva, compartida que permite la producción de identidades diversas. 
pasando ya sea a grandes conglomerados económicos o a organizaciones supranacionales que determinan formas y mecanismos del orden de dominación y poder en los territorios.

Es en esta ruptura donde, comprender como otras formas de significación toman cada vez mayor valor, y así la posibilidad de aproximarnos a la ideología bajo la forma de discurso que permite la producción de coordenadas de la vida, por medio de las cuales se otorga sentido al orden social.

Ahora bien, en esta forma ideológica discursiva, también surgen formas de violencia, se tratará de la violencia simbólica (Zizek, 2009), por medio de la cual se producen relatos de sentido sobre las formas en que la sociedad se encuentra organizada, sobre las formas de producción de sentido principalmente. Este punto permite además la consolidación de una aproximación a la noción de Doxa de Bourdieu, donde es a través de la violencia simbólica que se producen en prácticas y mecanismos que guían las formas sociales de producción social (Bourdieu \& Eagleton, 2008).

Por último, es preciso comprender que la ideología en clave de discurso busca salir de la dinámica cartesiana de verdad y falsedad, por ejemplo en la conciencia de clase versus ideología como falsa conciencia. Se trata por lo tanto de una aproximación que busca comprender los mecanismos de producción de sentido y en ella de producción de violencias simbólicas a través de múltiples negaciones de subjetividades.

En resumen, la ideología como discurso permite comprender que la ideología no sólo se desarrolla como un mecanismo material que garantiza la reproducción del sistema de producción, sino que además otro tipo de consumos, informaciones y pensamientos pueden 
entrar en la producción de la ideología que ya no como conciencia, permite brindar sentido a las formas de interacción en el orden social, pero en este mismo sentido, permite o abre la posibilidad de la singularización, que será parte del debate más adelante. De allí que se ha querido utilizar la metáfora de la ideología como coordenadas de la vida, la forma en que el sujeto la piensa, reflexiona y actúa en ella.

\section{Estribillo 3}

"Y ahora el pueblo / Que se alza en la lucha / Con voz de gigante / Gritando: ¡adelante! / El pueblo unido, jamás será vencido / El pueblo unido jamás será vencido" (Ortega, 1973) Este fragmento de nuestra canción guía del análisis de este capítulo, ya no tendrá relevancia en términos de producción de conciencia de clase, del llamado al pueblo para alzarse en la lucha.

Se tratará por lo tanto de las formas en que logra enlazarse con los discursos presentes en los sujetos para brindar sentido a las líneas, de esta forma desde una propuesta de la deconstrucción se podría decir que lo importante será el sentido que receptor genera sobre el discurso, de esta forma al menos podría reconocerse tres opciones que se han trabajado desde el análisis del discurso.

Se podrá contar con sujetos de acuerdo con sus prácticas comunicativas (Verón, 1996) (prodestinatarios) que con un discurso ideológico se encuentran de acuerdo con la postura del pueblo, del nosotros, de la militancia por el bien de la nación; otro grupo de personas (paradestinatarios) pueden asumir una posibilidad de creer o no en el sentido que otorgan a las letras de la canción, sin estar plenamente convencidos o en negación al sentido que producen frente al contenido de la letra desde sus discursos ideológicos; un tercer grupo de (contradestinatarios) con un discurso ideológico contrario a lo que plantea la letra de la canción 
simplemente cerraran su capacidad de escucha o pelearán desde sus discursos ideológicos la propuesta de esta letra.

Es decir, desde la ideología como discurso como se mencionó en líneas anteriores, se pierde la noción de verdad o falsedad, la mirada dicotómica se desdibuja, para dar paso a las posibilidades de interpretación y construcción de sentido a partir de una serie de coordenadas presentes en los sujetos, se abrirá de esta forma las posibilidades no sólo de la ideología sino también de dominación, se abre el campo de las micro-políticas, el bio-poder y el micro-poder.

\section{4 verso: La ideología como un modelo de pensamiento que guía la conciencia, la} estructura y el discurso. El proceso de la subjetividad

Hasta este punto se ha logrado dejar en evidencia las tres formas más relevantes en las que se aborda la ideología, relacionando hasta este punto dos elementos, la noción o rol del Estado y segundo las formas de violencia, de este último se han reconocido al menos tres formas de violencia: objetiva, subjetiva y simbólica (Zizek, 2009).

Ahora bien, en el abordaje de la ideología como discurso se abrió una perspectiva que desde Wallerstein o Hardt \& Negri, encuentra argumentos para presentar la reducción del poder y el rol del Estado-Nación, frente al cual aparece el mercado como un nuevo actor de relevancia en los mecanismos de dominación y distribución del poder en las sociedades contemporáneas.

Acorde con lo anterior, en este cuarto verso, se busca la producción desde el reconocimiento de los elementos entregados hasta el momento, de una noción de ideología que permita la aproximación al modelo de producción y reproducción económica, social, política y cultural en la cual se desarrolla la presente investigación. 
En un primer momento, la ideología es reconocida como un hechizo, separándonos de la idea de falsa conciencia, es decir, principalmente de la dicotomía entre verdad-falsedad. Así el hechizo o grupo de ideas que componen la ideología sigue presente, ahora éste conectado con el discurso, en la medida que es el grupo de ideas, las que serán las que componen las coordenadas de nuestras realidades en diversas esferas y escenarios de la vida.

He aquí una primera conexión relevante, se trata del hechizo con el discurso. Pero aunque este ya no funcione de forma bipolar, sino que permita múltiples formas de hechizos y estos a su vez sean validos y legítimos, nacen dos preguntas, ¿Cómo se produce esta forma de ideología del hechizo discursivo? Y segundo, ¿Cómo pueden coexistir tantos hechizos discursivos en el mismo grupo social?

Para poder contestar la primera pregunta, será necesario retomar algunos elementos que son trabajados en el verso dos de este capítulo, donde se presenta la ideología como materialidad. Se trata del trabajo realizado por Althusser en trono a los AIE, donde además se construyó el edificio ideológico con los elementos referentes a la infra y súper estructura.

En este caso se mantienen estos elementos, un proceso de reproducción del sistema social que se relaciona con las formas de producción económica, ahora incluyendo un elemento que podría considerarse como nuevo, se trata de la no absoluta relevancia del Estado en este proceso, es decir, mediante el Imperio, desde la mirada y trabajo realizado por Hardt \& Ngeri (200), donde la existencia de organizaciones supranacionales, como las Naciones Unidas (ONU), Organizaciones No Gubernamentales (ONG), el rol de por ejemplo los partidos políticos en cuanto el proceso de relacionamiento con los pueblos se ve en parte reemplazado por las ONG, y la capacidad de regular por medio de la ley (AE), el orden social gracias a la intervención de 
normatividades por encima de las constituciones nacionales promovidas y construidas por la ONU y sus diversas agencias como la Organización Internacional del Trabajo (OIT) y la Organización Mundial del Comercio (OMC) Hardt \& Negri (2000), será preciso incluir otros actores o lugares de producción del hechizo discursivo en el edificio ideológico.

Acorde con lo anterior, se trata por lo tanto de complejizar un poco más el modelo, en la medida que por un lado la infra-estructura se mantiene de forma casi igual, en la medida que el sistema económico determina en gran medida el proceso de configuración del hechizo discursivo, pero ahora no sólo se encuentra en el marco de ese primer piso, sino que además como mecanismo de garantía de su reproducción ha logrado incluir otros elementos en los siguientes niveles del edificio ideológico.

Así entonces en el segundo nivel, donde se contemplaron los AE, es preciso incluir ahora un elemento que, denominaremos como: Aparatos del Mercado (AM), que por medio de estrategias principalmente de orden coercitivo garantizan la reproducción del sistema, aquí entonces, es preciso incluir el rol de ONG's y de organismos supranacionales (OIT, OMC, ONU, entre otros), quienes regulan además las acciones de los estados nacionales. Es entonces en la relación entre AE y AM donde por medio de la coerción se garantiza que el modelo económico y por tanto de producción y reproducción de las formas de dominación y distribución del poder continúen de forma adecuada para el sistema mismo.

Continuando con la producción del edificio ideológico, en el último de los pisos donde Althusser reconocerá los AIE, éstos estarán acompañados a su vez de lo que denominaremos Aparatos Ideológicos del Mercado (AIM), donde por medio del convencimiento se garantizará la reproducción del sistema. En este caso se tomará un elemento incluido en los AIE, se trata de la 
cultura y la información, pero ahora con un nuevo nivel de relevancia, pues éstos se encontrarán inmersos en lo que denominamos en esta investigación como industria cultural, elemento que será abordado y ampliado en el tercer capítulo de la investigación. La industria cultural por lo tanto será el principal actor de los AIM que acompañan a los AIE.

De esta forma podría considerarse que se refuerza en cierto sentido el determinismo económico, pues ahora ya no sólo el Estado es el encargado de garantizar la producción y reproducción de las formas del poder y la dominación, sino que además el mercado entra a compartir un escenario de poder prácticamente con la misma relevancia a la del Estado, así entonces, Estado y Mercado concentrarán las dinámicas de producción y reproducción social.

Ahora bien, como se ha evidenciado a lo largo de esta capitulo, la ideología cuenta con una importante relación con la cultura y la subjetividad. Este elemento es relevante en la medida que se esta asumiendo la ideología como un hechizo discursivo producido en un esquema específico de orden social, el cual se ha consolidado a partir de la idea de Althusser bajo la imagen del edificio ideológico.

Al tratarse de un proceso de hechizo discursivo, éste se encarna en un sujeto específico, el cual habita ese edificio ideológico, siendo sometido constantemente por las diversas formas de violencia, que como observamos en líneas anteriores tienen una dinámica muy interesante: dos violencias (subjetiva y simbólica) que se encargan constantemente de ocultar la violencia objetiva del sistema, permitiendo de esta forma la reproducción del sistema, así las formas de producción de subjetividad se encarnan principalmente mediante esas dos formas de violencia que se encargan de operar en el sujeto (subjetiva y simbólica), éstas curiosamente se relacionan con dos lugares específicos del edificio ideológicos (AE - AM y AIE - AIM). Por otro lado la 
violencia objetiva seguirá siendo parte de la infra estructura, es decir de las formas de producción económica y en ella la materialización de formas de dominación y explotación del hombre por el hombre ${ }^{12}$.

Ahora bien, la inclusión de las formas del mercado al interior del edificio ideológico, juegan un rol muy importante, en la medida que permitirá además desdibujar dos elementos: el primero de ellos es la lucha de clases, pues ahora ésta se transforma más en la inclusión en el mercado de grupos o sectores minoritarios, y por el otro lado, la necesidad de la conciencia de clase, pues en este sentido la ideología ya no será falsa conciencia, sino formas de comprensión y búsquedas de inclusión en el sistema social contemporáneo.

Lo anterior permitirá a su vez poder comprender procesos relacionados con los nuevos movimientos sociales, donde la finalidad ya no se encuentra en el cambio del sistema económico, político y social, sino donde principalmente se juega es en la ampliación e inclusión de grupos minoritarios (principalmente) en el orden social existente, sin que sea necesario el cambio de las estructuras profundas, vale decir, modificación de las violencias subjetivas y simbólicas, dejando de lado las violencia objetivas.

En este punto es preciso reconocer algunos elementos del trabajo realizado por Lacan, quien en líneas anteriores fue reconocido por desarrollar la propuesta de construcción del yo por fuera

${ }^{12}$ Incluyendo ahora la explotación del hombre por el mismo hombre, es decir, prácticas de la cultura capitalística donde se desdibujan las fronteras del dueño de los medios materiales de producción y quien vende su fuerza de trabajo, destruyendo así las clases determinadas por la explotación, pues ahora un solo sujeto puede cumplir con los dos roles, se trata en este caso, por ejemplo de las formas de auto-explotación en procesos digitales en red (Han, 2017). 
de si mismo, en este ejercicio de la producción de la representación del yo, también es posible encontrar un elemento que se ha ido construyendo a lo largo de este capitulo, la diferencia entre lo Real y la Realidad (Lacan, 2008).

Así entonces cuando estamos hablando de las violencias subjetivas y simbólicas estamos construyendo el escenario de la Realidad, donde los AE-AM y los AIE-AIM se encargan de regular ya sea por el convencimiento o por la coerción la reproducción del sistema. Este tipo de hechizo discursivo lleva a que los sujetos del orden social actúen de acuerdo con el discurso hegemónico que permite la dominación y la distribución del poder presente en el sistema social, llevando incluso a que muchos de los procesos de lucha social sean incorporados sobre el hechizo mismo, sin buscar así la ruptura de las estructuras profundas del sistema mismo.

Por el otro lado la violencia objetiva se relaciona con lo Real, es decir con las formas en que opera el sistema social, político, económico y cultural, pero que son ocultadas por medio de la construcción del hechizo Realidad como forma de garantía de no cambio de los procesos hegemónicos al interior de la sociedad.

Ahora bien, teniendo en cuenta que se ha establecido la relación entre lo Real y la Realidad, es posible establecer como éstas son parte fundante de lo que denominamos el hechizo discursivo, es decir la ideología. Ahora bien no se quiere plantear en este campo que lo Real equivale a la verdad mientras que la Realidad equivale a la mentira, retornando a la dicotomía fundante de la primera mirada de la ideología. Se quiere por lo tanto dejar en evidencia que la ideología en cuanto hechizo discursivo constituye diferentes verdades y por lo tanto diversas formas de comprensión del mundo, las cuales son legitimas y validas para los sujetos, quienes han construido sus realidades sociales conforme estos hechizos discursivos. 
En la aproximación de la construcción social de la realidad se aborda una categoría que podría relacionarse de forma intima con la ideología como hechizo discursivo, se trata del universo simbólico (Berger \& Luckmann, 2005), donde se consolida el proceso de significación del mundo social, y donde por lo tanto, es posible la construcción social de la realidad. En cierto sentido podría decirse que el universo simbólico socialmente producido, y por medio del cual se garantiza la reproducción del orden social de dominación y distribución del poder, se aproxima a la idea de hegemonía, en la cual nos alejaremos parcialmente del trabajo de Gramsci en la medida que ya no se encontrará el partido, la clase y el Estado como actores principales del proceso, sino que ahora la hegemonía será también integrada por los elementos propios del mercado, que escapan del control y el poder estatal, la hegemonía será por lo tanto en este proceso una categoría muy cercana al universo simbólico desarrollado en líneas anteriores.

Hasta este punto se ha querido establecer las formas en que se produce y consolidan los principales efectos de ese hechizo discursivo como definición de ideología. Es el momento de abordar un segundo componente, ¿pueden coexistir diversos hechizos ideológicos en un mismo grupo social?, esta es una clave importante, pues es justamente en este punto donde la noción de verdad y mentira, la mirada dicotómica se rompe, se desvanece.

El orden social que se desarrolla en este escenario es principalmente el que se basa en la idea de la libertad del sujeto, libertad que cada vez se encuentra más relacionada con la capacidad o mejor, con las formas del consumo, así entonces, el orden coercitivo y del convencimiento se desarrolla más desde la garantía de los procesos de consumo del mercado, el cual además requiere de multiplicidad de sujetos, de subjetividades, pues es en este tipo de aproximación donde se permite la construcción de más formas de mercados, no obstante, si los nuevos sujetos 
como se mencionó en líneas anteriores, buscan es la inclusión en el mercado y en el orden social, es decir, buscan modificar elementos propios de la Realidad pero no de lo Real, se generan cambios sustanciales que no modifican los elementos hegemónicos más relevantes.

Ahora bien, teniendo en cuenta los elementos desarrollados hasta este punto es preciso ahora modificar un poco más la idea del edificio ideológico de Althusser, al cual ya se le integraron elementos propios del mercado, pero ahora, ese edificio deberá ser además comprendido en gran medida como una "estructura, estructurante, estructurada" (Bourdieu, 2000), aproximándonos por lo tanto a la noción de campo de Bourdieu, pues como se puede observar el ahora hechizo ideológico es en realidad una estructura, que además funciona como factor estructurante de las formas de producción de subjetividades y a su vez se encuentra estructurada por los mismas formas de subjetividades, así se consolida una suerte de lugar que determina y es determinado. Es importante incluir esta forma de aproximación en la medida que permite la inclusión del sujeto en el hechizo discursivo, éste no existirá sin sujetos y subjetividades, que se expresan en formas de subjetividad, en las culturas.

Ahora bien, el hechizo discursivo no se puede relacionar con un campo cerrado, momento en el cual se genera una ruptura con el campo de Bourdieu, en cuanto discurso, este tipo de ideología, permite la producción de posibilidades no reflexionadas por el sistema mismo. Es decir, su capacidad estructurante no es plena, sino que puede ser volcada y parcialmente destruida por las formas de significación de los hechizos, como diferentes formas de verdades y de mentiras.

La noción de ideología como hechizo discursivo, permite no sólo navegar en el campo de las Realidades sino también el reconocimiento de lo Real, la deconstrucción de los dos en nuevas 
posibilidades de significación, producción de nuevas subjetividades, e incluso de culturas, que pueden llevar a rupturas de los procesos hegemónicos de dominación, es por este valor del discurso que se ha querido asumir la ideología en cuanto hechizo discursivo, pues incluye en su propia forma de abordaje la ruptura, la grieta.

Así entonces el campo de la ideología no se encontrará estático o auto-contenido, sino que en su misma construcción contará con grietas, éstas serán las que permitirán los procesos de singularización, otras formas de sentido, es decir las rupturas de los hechizos ideológicos para su modificación.

En últimas todo el espacio ideológico ${ }^{13}$, donde se contienen diversos hechizos discursivos que permiten la producción de diversos ordenes sociales que se correlacionan y coexisten, bajo un principio básico (el consumo), cuenta con sujetos, subjetividades, vale decir discursos, que se mueven por el espacio ideológico a grandes velocidades, mutando, modificándose y cambiando, se tratará por lo tanto a una idea similar a la del campo de inmanencia, donde los conceptos viajan a velocidades infinitas en un campo finito (Deleuze \& Guattari, 2001), con la diferencia que en este caso el espacio ideológico no tiene límites físicos, o de otro tipo, no será por lo tanto un campo finito, sino un espacio con espacios habitados y otros por reconocer y habitar.

${ }^{13}$ A partir de este momento ya no se reconoce un campo o edificio ideológico, pues éstos en su rol cerrado de contención y plena garantía de la reproducción del sistema social no permitirá la presencia de los discursos y sus irrupciones, así las cosas se establecerá la noción del espacio ideológico. 
Será la subjetividad la que nos permita abrir grietas y habitar nuevos lugares del espacio ideológico, modificando por lo tanto nuestros hechizos discursivos y así las posibilidades de ocupación del mundo mismo, es esta la función o expresión de la singularización.

\section{Estribillo 4}

“De pie, cantar / El pueblo va a triunfar / Millones ya, / Imponen la verdad / De acero son / Ardiente batallón / Sus manos van / Llevando la justicia y la razón / Mujer / Con fuego y con valor / Ya estás aquí / Junto al trabajador" (Ortega, 1973).

De nuevo nos encontramos con un fragmento de la canción que da razón a este capítulo, en este caso el sentido que se produce dependerá de los hechizos discursivos que guían el proceso de producción de sentido mismo de la letra.

Es decir, la letra puede ser motivo de lucha pero principalmente de identificación para colectivos o grupos que comparten hechizos discursivos, en este sentido, por ejemplo puede ser todo un baluarte para un grupo feminista que quiere "imponer la verdad" permitiendo "llevar la justicia y la razón" de frente a los elementos que componen sus hechizos discursivos, que a su vez estarán en la lógica de la equidad frente a los derechos al interior del sistema social, económico, político y cultural.

Se tratará por lo tanto recordando el escenario anterior (la ideología como discurso), donde el proceso de significación del contenido por parte del interprete donde se construirá el valor de aceptación, negación, rechazo, aceptación parcial del discurso. Todo dependiendo de los lugares en el espacio ideológico y de las coordenadas de reconocimiento del discurso mismo, es decir, del hechizo discursivo que permite la producción de sentido. 
No se tratará por lo tanto necesariamente de una canción revolucionaria, puede ser ahora un mensaje de apropiación del sistema, de ampliación y profundización de la democracia por ejemplo, pero no se pondrá en tensión la organización del sistema mismo.

Puede ser así, Quilapayún un mecanismo de construcción de Realidad, que ocultará lo Real, todo esto gracias a las coordenadas ofrecidas y producidas por el hechizo discursivo, que además podrá ofrecer grietas al interior del sistema para la producción de procesos de singularización.

\section{5. verso: La singularización en función de la crítica a la ideología, la subjetividad en una acción.}

En los apartados anteriores a esta sección, se ha querido dejar en evidencia las tres formas más utilizadas para el abordaje de la ideología, llegando así en un cuarto verso a la producción de la noción de ideología que guiará este proceso investigativo; en este proceso se han tomado varias categorías que son íntimamente relacionadas con la ideología, se trata de la subjetividad, la cultura y la singularización.

Ahora bien, en este campo se quiere establecer el sentido que se les otorga a estas categorías con el fin ya no sólo de producir un modelo de pensamiento que da razón a la ideología, sino que además se relaciona con otras categorías, retomando un poco la lógica de Deleuze y Guattari en su texto ¿Qué es la filosofía? Donde un "concepto"14 sólo cuenta con producción de sentido en la

${ }^{14}$ En el texto de Deleuze y Guattari, se utiliza la noción de concepto en términos filosóficos, dando además un contenido específico a si mismo, es decir, un concepto será un elemento que se explica y funciona en ausencia de nociones de tiempo y contexto, por el orden de producción de conocimiento de este documento investigativo, no es posible establecer la construcción de 
medida que se relaciona con otros que permiten así dar explicación y sentido a su funcionamiento en sí mismo (Deleuze \& Guattari, 2001).

Acorde con lo anterior, comprender la ideología implica también reconocer los nexos y relaciones con la cultura, la subjetividad y la singularización, iniciemos por lo tanto el reconocimiento de estas categorías que permiten la consolidación de la ideología en cuanto hechizo discursivo.

El hechizo discursivo es en términos prácticos, procesos de producción de subjetividades en un grupo de coordenadas orientadoras del sentido en el espacio social, coordenadas que como se ha podido observar a lo largo de este escrito permiten la legitimación o no de las formas y dinámicas de producción y reproducción de la dominación y las formas de distribución y ejercicio del poder.

La ideología como hechizo discursivo por lo tanto se expresan en los cuerpos de los sujetos, permitiendo actuar, interpretar y llenar de sentido los procesos de interacción en el campo social y del espacio ideológico, por medio de esas coordenadas orientadoras del sentido. Ahora bien, estos procesos de producción de sentido en cuanto discursos pueden ser modificados o mutados, se trata de la presencia de las grietas en los hechizos discursivos que permiten sus modificaciones y mutaciones.

conceptos, optando por lo tanto por categorías, que se relacionan con las nociones de tiempo y contexto. 
Los procesos de modificación y ruptura de los hechizos ideológicos son denominados en esta investigación como procesos de singularización. Sin embargo antes de poder adentrarnos en la forma de comprender la singularización es preciso adentrarnos en las formas que se asume la cultura, y en ella la producción de subjetividades.

Hablar de la producción cultural tiene todo un sentido en términos del contexto histórico, económico y político, es decir, la cultura se produce por los sujetos en contextos específicos que derivan en espacios o escenarios culturales específicos. Actualmente, en las sociedades contemporáneas, tendríamos que reconocer culturas producidas en el marco de los sistemas capitalistas, valdría decir culturas capitalísticas (Guattaru \& Rolnik, 2005).

Las culturas capitalísticas son entonces lugares de sentido y de discurso que garantizan en gran medida los procesos de reproducción del sistema social, valdría decir en este ejercicio, las relaciones entre los (AE-AM y AIE-AIM) en constante interacción, con un efecto específico en la promoción de subjetividades construidas mediante el marco del consumo (Sztainjnszrajber, 2011a).

Se trata por lo tanto de procesos de subjetividad, en los que los consumos culturales guían en gran medida la producción de sentido. La cultura capitalística entonces nos lleva a establecer que las producciones de subjetividades mediante identificaciones se relacionan profundamente con los mecanismos del mercado del orden social vigente.

Así entonces el hechizo discursivo se fundamenta actualmente en la cultura capitalística, estableciendo así unas coordenadas de sentido en el discurso que producimos y que materializamos, que de forma hegemónica permitirá la reproducción del sistema mismo, ya no 
sólo mediante el convencimiento y la coerción, sino en un lugar más profundo: en la producción de nuestras subjetividades.

Lo anterior implica reconocer que la subjetivación capitalística funciona y tiene lugar tanto en los escenarios de los dominados como de los dominadores, la cultura es por lo tanto en este punto el lugar de la hegemonía que garantiza las subjetividades reproductoras del sistema en todos los lugares y dimensiones. Ahora bien, en un escenario tan determinado por el orden social y su garantía de reproducción, es preciso recordar que como discurso, la subjetividad tiene grietas y puede romper las formas de estas producciones. Así entonces, la ruptura y la producción de una singularidad en las subjetividades, es lo que denominamos como singularización (Guattari \& Rolnik, 2005).

Se trata por lo tanto en este sentido de la producción de otras subjetividades de orden singular que pueden o no romper la cultura capitalística, pueden de hecho poner en tensión las coordenadas de la realidad o de lo real sin necesidad de modificar profundamente las formas de reproducción del sistema, pero como singularización, modificaran las coordenadas de la producción de sentido del hechizo discursivo, vale decir en este punto de la ideología.

El proceso de singularización por lo tanto, se genera y aprovecha profundamente las grietas del proceso de reproducción, dejando en evidencia o mejor, permitiendo observar las formas de violencias presentes en los hechizos discursivos, llevando por lo tanto a la modificación y transformación del mismo, se podría por lo tanto comprender que la singularización guarda una gran relación con la crítica a la ideología, pues deja en evidencia las relaciones que se componen en su interior y al exponer esos mecanismos de funcionamiento, conlleva posibilidades de modificación de ésta. 
Lo anterior implica por lo tanto reconocer que la singularización es la crítica a la ideología como hechizo discursivo puesto en acción, llevando a la modificación de coordenadas de producción de sentido, donde las subjetividades producidas en la cultura capitalística varían y mutan, así las garantías de la reproducción del sistema social cuentan con un sinnúmero de fisuras producidas en el campo de la subjetividad que buscan garantizar su reproducción.

De nuevo retorna en este punto, la imagen del espacio ideológico en el que los sentidos producidos en el hechizo discursivo viajan a velocidades infinitas, permitiendo la producción en un sentido de reproducción de subjetividades, pero a su vez en estas relaciones a infinitas velocidades también se producen las rupturas y los encuentros con las grietas que rompen con esas subjetividades capitalísticas preestablecidas, llevando a las singularizaciones que como críticas al hechizo ideológico producen otras subjetividades, variantes y mutantes.

\section{Estribillo 5}

"Y ahora el pueblo / Que se alza en la lucha / Con voz de gigante / Gritando: ¡adelante! / El pueblo unido, jamás será vencido / El pueblo unido jamás será vencido” (Ortega, 1973).

La producción de la cultura capitalistica en este caso nos permite abordar de nuevo un fragmento de la canción, donde por ejemplo los circuitos de producción y distribución de la banda Quilapayún (Warner Music Group), se enfoca en segmentos poblacionales específicos, en los cuales tal vez la noción y sentido revolucionario no es el enfoque central.

Retomando la idea anterior, el proceso de consumo y en él de la producción de una cultura capitalística, la canción que tenemos en nuestras manos, por medio de lo que denominaremos más adelante el discurso musical, por medio de sus diversos planos, puede producir ya sea la 
reproducción del sistema mediante el consumo de la mercancía pieza musical o disco, pero además puede producir procesos de singularización, donde sujetos en la composición de sus subjetividades, pueden por ejemplo romper la noción del nosotros como mecanismo de dominación y eliminación de la capacidad crítica de producción de sentido.

"Y ahora el pueblo / que se alza en la lucha" puede buscar la construcción del nosotros con conciencia de clase, pero a su vez puede evidenciar las grietas presentes en el nosotros de la militancia por la causa, abriendo otras posibilidades de significación y así consolidando singularizaciones que pueden modificar en esas singularidades de la subjetividad los ordenes sociales de dominación y distribución del poder.

\section{Cierre: El rol de la ideología en el marco investigativo del idioma de los dioses.}

El idioma de los dioses: el discurso musical y los procesos de singularización, es una investigación que busca desarrollar una serie de preguntas sobre el rol de la música en cuanto discurso en la construcción de subjetividades y en ellas las posibilidades de singularización.

Acorde con lo anterior, este primer capítulo ha buscado reconocer dos de las categorías centrales del proceso investigativo, se trata de la ideología, como núcleo de pensamiento y producción de sentido, mediante el cual es posible comprender la singularización.

Así entonces, en líneas generales se ha construido una noción de ideología que reconoce las tres vertientes históricas y principales del abordaje de esta categoría, se trata de la ideología en cuanto falsa conciencia, posteriormente en su materialidad y finalmente como discurso. Permitiendo de esta forma la consolidación de una noción ajustada a los intereses investigativos, 
el hechizo discursivo, en el cual se relacionan elementos de las tres perspectivas, pero que además incluye elementos propios del mercado en el marco de las sociedades contemporáneas.

La inclusión del mercado con un rol de poder en la producción de procesos de dominación y distribución del poder, más allá de un interés exclusivamente de la investigación, busca incorporar en la materialidad de la ideología elementos que permitan la producción de una cultura de orden capitalística, donde es posible mediante el consumo cultural reconocer los mecanismos de identificación y subjetividad conectores de la singularización.

En este sentido la singularización se ha querido dejar en evidencia en cuanto la capacidad singular de la subjetividad en la consolidación de sentidos diferentes, valdría decir algo similar a la diferencia en la diferencia ${ }^{15}$. Ejercicio en el cual se materializa la crítica a la ideología y en ella el reconocimiento y ampliación de las grietas que el hechizo ideológico contiene.

Así las cosas, la singularización logra romper con los hechizos discursivos materializados mediante las violencias de orden subjetivo y simbólico, permitiendo la apertura y reconocimiento de la violencia objetiva, vale decir en este sentido, el reconocimiento de las coordenadas de la realidad que en su producción ocultan el plano de lo real.

Ahora bien, contemplando que abordamos el proceso desde una perspectiva discursiva no podemos caer en la tentación de asumir la relación realidad-falso y real-verdad, pues será en la producción de subjetividades como materializaciones discursivas que se reconocerán o

${ }^{15}$ En este caso se hace relación al debate que propone Rodrigo Browne a partir de el diferendo de Lyotard (Browne, 2014). 
producirán las singularizaciones, por lo tanto las violencias mutarán también acorde con las subjetividades, el orden de lo real en este sentido puede ser el reconocimiento de la violencia objetiva que no tiene un valor único, también en términos del discurso muta y fluctúa.

Para finalizar, es necesario ampliar la noción de discurso en relación con la música, de donde surgen las siguientes preguntas: ¿Cómo comprender entonces el discurso? ¿Cuáles son sus categorías significantes? ¿Cuál es el rol de las coordenadas de la producción de sentido en el discurso? Son estas las preguntas que orientan nuestro siguiente capítulo, donde abordaremos el sentido del discurso y la construcción de una tercera categoría clave de la investigación, el discurso musical. 


\section{Capítulo 3}

\section{Hurt: Significado del hechizo discursivo musical}

\section{Introducción}

En el capítulo anterior revisamos la noción de ideología aproximándonos a la noción de hechizo discursivo, así las cosas, "Hurt” canción de la banda estadounidense Nine Inch Nails, sirve como ancla para pensar este segundo capitulo, el cual inicia con lo que comprenderemos por hechizo discursivo, dando paso a los procesos cognitivos que tienen lugar en este escenario, ingresando así en las pasiones que tienen lugar en el hechizo discursivo, permitiendo de esta forma dar lugar a las particularidades del discurso musical en cuanto un aspecto que clave del hechizo discursivo.

Cada uno de los elementos reseñados en el párrafo anterior da razón de uno de los versos que compone esta capitulo, mediante los cuales se busca responder a preguntas tales como: ¿qué es el hechizo discursivo?, ¿qué relacione se establece entre el hechizo discursivo y la cognición? ¿la cognición es un proceso exclusivo de nuestro cerebro? ¿cuáles son las relaciones entre la música

y la cognición? ¿por qué es relevante incorporar sentimientos y emociones en los procesos cognitivos al relacionarlos con la música? ¿cuáles son los elementos que contiene o que se desarrollan al interior de lo que denominamos como discurso musical?

A lo largo de este capitulo se buscará dar respuesta a este tipo de preguntas, de forma que las respuestas que se producen en cada uno de los casos permita continuar con el desarrollo del capítulo, donde se encuentra uno de los elementos más relevantes de esta investigación, la objetivación del objeto de investigación, es decir, la construcción de un objeto específico para la 
observación, en nuestro caso el discurso musical, que se encuentra cruzado y relacionado íntimamente con el hechizo discursivo, los procesos cognitivos, los sentimientos y emociones entre otros elementos que se podrán ver a lo largo del capítulo.

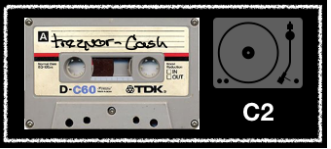

El titulo de este capítulo obedece a una canción de la banda norteamericana del género Rock llamada Nine Inch Nails, tal vez una de las más reconocidas y prestigiosas del escenario rock alternativo de los años 90, escrita por Trent Reznor vocalista de la banda, públicada en el año 1995, pero tal vez es la canción que cuenta con uno de los mejores cover de la historia de la música contemporánea, en el 2002 Johnny Cash, versaría la canción a su estilo, mejorando la versión original a la pieza musical que le brinda el título a este capítulo, se recomienda al lector escuchar las dos versiones de la pieza musical antes de iniciar la lectura de este apartado del documento.

\section{1 verso. El hechizo discursivo}

Tal vez al indagar y observar las teorías y aproximaciones en torno al discurso, se encuentre que las primeras miradas provienen de campos del conocimiento como la lingüística, donde además más adelante en la historia ingresaran importantes aportes de la sociología y de la psicología social. Ahora bien en ese primer momento del discurso como elemento de estudio, es preciso establecer su rol como elemento, vale decir como un objeto específico, dejando de esta forma una primera y fuerte mirada del discurso y su análisis como una metodología para el estudio.

Ahora bien, en este primer momento pareciera que el discurso se circunscribe básica y esencialmente con la idea del texto y sus particularidades, se trataría por lo tanto de un fenómeno 
exclusivamente digno de la lingüística y sus formas del conocimiento, dejando de lado las posibilidades de trabajos de orden interdisciplinar, como sucedería más adelante. Este escenario plantea por lo tanto un primer debate o apertura frente al discurso, donde se establece las diferencias entre las gramáticas de los textos y los estudios de discurso (Van Dijk, 2010).

De la anterior diferencia se puede reconocer como en el primero de los lineamientos se genera un importante interés en las formas en que se produce el lenguaje articulado, donde por ejemplo la construcción de pronombres y oraciones será el foco central, dejando de esta forma en evidencia el uso del lenguaje. Así entonces se reconocerán las estructuras de superficie del texto, su coherencia lineal, el cumplimiento de las macro-reglas, para poder pasar al análisis de las macro y micro estructuras del lenguaje (Van Dijk, 2010).

En el segundo lineamiento, donde se busca producir estudios de discurso, se establece una apertura de la mirada anterior, donde a través del trabajo interdisciplinar se le entregan otras cualidades al discurso, "así, un discurso es una unidad observacional, es decir, la unidad que interpretamos al ver o escuchar una emisión. Es decir, una gramática sólo da una aproximación de las verdaderas estructuras empíricas de discursos emitidos" (Van Dijk, 2010, p. 20). Así entonces es preciso reconocer la validación de los elementos gramaticales aportados por la lingüística, pero además se reconoce su insuficiencia para dar razón de procesos mucho más complejos, así nos alejamos de la idea del discurso en cuanto una metodología y comenzamos la consolidación o construcción de un campo del saber.

Lo anterior, busca dejar en evidencia que al hablar o abordar el discurso se está dando razón de mucho más que un texto y sus reglas de producción, incorporando otros elementos de gran relevancia, entre los cuales como se observará más adelante, se encuentra el proceso cognitivo 
del sujeto y las formas de producción de sentido (Laclau, 2014), donde por ejemplo es posible reconocer las formas en que se otorga sentido a Dios, o en otras palabras a elementos místicos, girando de esta forma de un problema gramatical a un proceso tal vez más complejo donde el texto juega un importante rol en la producción de sentido, pero por sí mismo no puede explicarlo.

Continuando con la idea anterior, por ejemplo es imposible abordar el discurso sin su componente performático, espacio en el cual por ejemplo se puede incorporar elementos relacionados con la pragmática del discurso, donde no sólo es relevante el proceso de producción del texto sino además toda su puesta en escena, el tono, la cadencia, la entonación (Van Dijk, 2010), de forma muy similar más no igual a la música, donde es preciso comprender en su discurso la melodía, la armonía y el ritmo para establecer su sentido.

Es preciso en este punto realizar una pequeña reflexión, en el marco de la modernidad y su proyecto se produjo una suerte de producción de elementos hegemónicos, validos y legítimos, entre ellos, la existencia y uso del lenguaje articulado por medio de grafemas, de hecho es tan fuerte esta forma de comprensión del mundo que incluso se llegó a considerar un pueblo o cultura en términos de civilizado o bárbaro, según la existencia de textos escritos y el registro de su memoria, vale decir de su historia (Wallerstein, 2003), elemento que hoy en día sigue en disputa de forma constante, de hecho la mejor forma de demostrar el conocimiento se genera mediante la producción de textos escritos, por ejemplo las tesis doctorales.

Por lo tanto en la hegemonía del texto escrito es donde podemos comprender esa primera mirada del discurso, donde es necesario incorporar otros elementos, otros puntos de reflexión, entre los cuales y no exclusivamente se encuentra la pragmática del lenguaje, donde por ejemplo 
se puede llegar a incorporar elementos como lo son el cuerpo de quien enuncia un discurso, donde sus ademanes además incorporan sentido en este proceso, no sólo su entonación y ritmo.

Es decir, en el discurso no sólo juegan los elementos textuales sino que además es preciso incorporar los elementos paratextuales, donde, por ejemplo, se puede trabajar la perspectiva de Habermas en el acto de habla (Habermas, 2001), donde el proceso comunicativo escapa de la textualidad e incorpora otros elementos para la producción de sentido (Van Dijk, 2010).

Ahora bien, la hegemonía del texto escrito será por lo tanto en sí mismo un discurso, no sólo se trata de las formas en que se producen o expresan textos escritos o hablados, en el discurso se incorporan además otros elementos claves de una cultura, así entonces, por ejemplo, el hecho que se cuente con un proceso de reconocimiento legítimo del lenguaje escrito es en sí mismo todo un acto performático de organización y producción de un orden específico, donde esta situación en sí misma se podría considerar como discurso.

Nos encontramos entonces ahora en un campo difuso, sin embargo la mejor forma de comprender el discurso y su análisis será enfocando la mirada en los procesos de producción de sentido. Espacio donde las formas textuales serán claves, pues por ejemplo en la repetición de elementos o reglas lingüísticas podremos establecer géneros literarios, es decir, brindar un mínimo orden a los actos de habla (Van Dijk, 2010). La idea central es por lo tanto que a partir del uso y aplicación del lenguaje dimensionamos la experiencia humana en el mundo, brindando elementos de orden que permiten la producción de sentido de la experiencia misma del sujeto en su mundo cotidiano. 
Pero además en estos escenarios aparece también la retórica, donde se pondrá en juego las formas de producción de sentido, así sujetos se enfrentan para validar y promover formas específicas de sentido del mundo (Laclau, 2014). Este ultimo elemento requiere de un mayor desarrollo, pues implica el reconocer los problemas de la producción de sentido, ahora desde el discurso, lugar donde se materializará el hechizo discursivo.

Una forma de comprender el anterior elemento es en el reconocimiento por ejemplo de los múltiples sentidos que se producen desde géneros literarios como la poesía, donde el lenguaje no busca ser una suerte de espejo de la realidad, sino el de abrir posibles procesos significativos. Aquí entramos en una de las discusiones más relevantes frente al discurso.

En las formas más funcionalistas del discurso se abordará por ejemplo desde la lingüística el valor de verdad del texto, es decir su plena relación entre lo que se produce en el texto y lo que existe en la realidad, como si se tratar de un espejo que nunca puede mentir. Ahora bien, al plantear este proceso podríamos preguntarnos ¿el discurso y por lo tanto el lenguaje y su texto deben ser fieles a lo real o a la realidad?, en el momento que evidencia una de las dos formas o de sus expresiones de violencia (simbólica, subjetiva y objetiva) entonces ¿es falsa?, no sería por lo tanto esta ¿una mirada muy cercana a la falsa conciencia?

En la mirada por lo tanto del valor de verdad del discurso como espejo, nos limitaríamos en la producción del hechizo discursivo, pues por un lado asumiríamos que se trata de un propuesto impuesto, por el otro, el discurso sólo sería valido en la medida que refleja una realidad, hecho que por ejemplo, en términos de poder nos podría estar postulando una nueva idea, relacionada con la materialidad de la ideología donde el discurso por lo tanto sería el resultado del edificio ideológico. Una vez más sería un proceso impuesto de significación sobre los sujetos. Sin 
embargo como observamos el discurso puede encontrarse en lugares que abren los procesos de significación y que además se alejan de la imposición, aquí el arte y en especial las vanguardias nos muestran otras formas posibles de significar el mundo, de allí en gran medida la posibilidad de la singularización.

Acorde con lo planteado hasta el momento, y en concordancia con la postura que busca consolidar esta investigación, el discurso se reconoce como un proceso mucho más complejo, donde la producción de sentido a partir del mismo es en sí mismo un proceso relacionado con el hechizo discursivo, es decir, los discurso sirven en términos de "hechizos" o formas de producción de sentido frente al mundo y la vida no sólo cotidiana sino incluso también profundamente racional, a partir del cual se dimensionan las coordenadas de nuestra realidad.

Al interior de las ciencias sociales se pueden reconocer tres corrientes claves del pensamiento, el funcionalismo, la escuela crítica y una última que podríamos reconocer como la racionalista, la primera de ellas impulsada por el pensamiento de Talcott Parsons, la segunda por Karl Marx y la tercera por Max Weber, cada una de ellas cuenta con un principio ordenador, sobre el cual no es posible dudar, así entonces en el primer caso se tratara del sistema y sus funciones como factor organizativo, en el segundo la historia como motor de los conflictos de clase y de allí los cambios sociales y en la tercera, la racionalidad como proceso organizativo de las sociedades. En cada uno de estos caso podríamos observar como cada uno de estos elementos se determina o configura como una suerte de hechizo que guía toda la producción de conocimiento y formas tanto de interacción como de intervención de las sociedades.

Por medio del ejemplo anterior, se quiere por lo tanto evidenciar como incluso desde los modelos epistemológicos es posible rastrear la presencia de hechizos discursivos que llevan a la 
producción de las dimensiones de la realidad sobre las cuales producimos sentido, permitiendo conocer, comprender y actuar en los contextos sociales, políticos y culturales. De hecho cada una de estas formas de producir la realidad, nos llevan a observar, a ver formas diferentes de la realidad y de lo real, siendo cada una de estas válida para cada actor según su hechizo discursivo, de allí la imposibilidad de asumir el discurso como un reflejo absoluto de la verdad.

Ahora bien, es el momento de retomar parcialmente algunos de los aportes que nos brindan los estudios de lingüística sobre el discurso, en la medida que aunque el texto (asumido exclusivamente como lenguaje articulado) no sea un reflejo pleno de la verdad, pero en su composición deja en evidencia importantes elementos de las formas en que reconocemos, dimensionamos y producimos sentido en el marco de nuestros procesos de conocimiento.

Se trata en este caso, de reconocer el rol que por ejemplo tienen las metáforas a partir de las cuales podemos evidenciar las principales formas de producción de sentido del mundo (Lakoff \& Johnson, 2004), es decir, las formas en que hablamos y utilizamos metáforas dejan en evidencia los marcos mentales a partir de los cuales vemos y producimos la realidad en la cual nos encontramos inmersos.

El rol de las metáforas y las metonimias como elementos que dejan en evidencia las formas como producimos el mundo, será uno de los elementos que Laclau, por ejemplo, rastreara y dejara en evidencia en términos de un proceso clave en la producción de la retórica de las sociedades, donde es posible encontrar formas del sentido en sujetos y actores específicos, pero además formas en las que las sociedades se producen y reproducen (Laclau, 2014). 
Ahora bien, el proceso de vinculación entre el discurso en términos de hechizo discursivo, busca vincular de forma mucho más profunda las nociones de discurso e ideología, de allí que se optara por esta construcción, que además ahora cuenta con unas materialidades o expresiones específicas, a través de las metáforas y las metonimias. Este vinculo no es nuevo, de hecho puede rastrearse en los trabajos de Laclau, Van Dijk y por ejemplo en los de Neila Pardo quien nos plantea que: “Así, el discurso es entendido como el lugar en el que se observan las relaciones que potencialmente ocurren entre el uso de la lengua y las manifestaciones ideológicas que allí se inscriben" (Pardo, 2013, p. 49).

Acorde con lo anterior, algunas formas de rastrear y comprender el hechizo discursivo será a través de sus materialidades, donde encontramos las metáforas y las metonimias, donde “la metáfora (...), impregna la vida cotidiana, no solamente el lenguaje, sino también el pensamiento y la acción. Nuestro sistema conceptual ordinario, en términos del cual pensamos y actuamos, es fundamentalmente de naturaleza metafórica" (Lakoff \& Johnson, 2004, p. 39), donde comprendemos o abordamos la metáfora en términos de cómo vivimos o comprendemos una cosa en términos de otra, permitiendo por lo tanto la producción de sentido a través del relacionamiento y vertido de contenido de una cosa en otra.

Es preciso además, aproximarnos a la metáfora no como un valor absoluto en sí mismo, sino que éste depende de la forma, espacio y relaciones que se establecen, es decir, por lo general una metáfora no se encuentra sola sino que trabaja de forma sistemática (anidada), lo que nos lleva a comprender el proceso de producción de las mismas por fuera de las reglas del lenguaje, llevándonos de nuevo hacia la pragmática del lenguaje, donde podemos comprender las 
relaciones que se establecen y en ellas el sentido que produce el hechizo discursivo (Lakoff, 2013).

Acorde con lo anterior, las metáforas funcionaran en varios niveles, donde por ejemplo sirven como proceso de orientación, es decir, por medio de las metáforas podemos dar coordenadas de espacio que ubican de forma coherente con nuestra experiencia del mundo, los sentidos de las cosas que pensamos o construimos, por otro lado, las metáforas puede ser también ontológicas, permitiendo establecer la forma de experiencia del mundo, pero además también pueden servir para ejercicios de recipiente, donde incorporamos un elemento en otro, abriendo así el surgimiento de las metonimias (Lakoff \& Johnson, 2004).

A partir del trabajo realizado por Lakoff \& Johnson (2004), es posible distinguir y encontrar parcialmente las siguientes expresiones de las metáforas, a partir de las cuales es posible rastrear las formas o coordenadas de producción de sentido mediante el uso de las mismas, como vestigios o evidencias de las formas en que producimos el sentido del mundo, vale decir de las coordenadas de nuestros hechizos discursivos.

- Metáforas orientacionales: donde se establecen relaciones del orden bipolar (arriba-abajo, dentro-fuera, delante-atrás, profundo-superficial, central-periférico)

- Metáforas ontológicas: evidencian las formas como pensamos y reconocemos el mundo que nos rodea, se pueden reconocer entonces procesos relacionados con puntos o coordenadas específicas de la experiencia humana en el mundo (extensiones de la tierra, el campo visual, acontecimientos, acciones, actividades y estados). Espacio en el cual podemos establecer de igual forma las metáforas de recipientes.

Ahora bien, en el estudio realizado sobre "las metáforas de la vida cotidiana" por Lakoff \& Johnson (2204), deja en evidencia la diferencia entre metáforas y metonimias a partir de la 
siguiente idea "las metáforas son principalmente una manera de concebir una cosa en términos de otra, y su función primaria es la comprensión. La metonimia, por otra parte, tiene primariamente una función referencial, es decir, nos permite utilizar una entidad por otra" (p.74), dejando de esta forma en evidencia la producción de formas específicas de metonimias como las podemos observar a continuación:

- La parte por el todo

- El producto por el producto

- El objeto usado por el usuario

- El controlador por lo controlado

- Una institución por la gente responsable

- El lugar por la institución

- El lugar por el acontecimiento

Se trata por lo tanto de reconocer las materialidades de los hechizos discursivos a partir de las singularidades evidentes a partir de las formas de su producción mediante el uso o apropiación de las metáforas y las metonimias, donde por lo tanto las principales coordenadas del proceso de significación del mundo se hacen presentes.

Ahora bien, es preciso retomar aquella idea donde se señala que las metáforas y las metonimias se anidan, es decir, funcionan en relación con otras en el marco de un proceso de producción de sentido, ninguna de ellas podría significar en el vacío, requiere de compañías para poder establecer relaciones y en ellas las coordenadas del sentido. Tomemos un ejemplo para este punto, en el primer capítulo de este documento, se señaló que se asumiría un cambio entre el campo ideológico y el espacio, dos elementos que metafóricamente sirven en términos de recipiente, donde la ideología es sumergida o integrada a un algo que la contiene, en la idea del 
campo, se retomaría otras formas metafóricas, donde se establece un recipiente con límites, es decir con líneas o fronteras que producen además una orientación, el adentro de, o el fuera del campo, por lo tanto podríamos en ese sentido buscar los espacios pre-ideológicos, mientras que en la otra figura, al hablar de espacio, este contenedor no cuenta con límites y por lo tanto abre toda la posibilidad de la singularización a partir de aquella idea de pensar el pensamiento no pensado.

En el caso anterior, es posible por lo tanto reconocer como las metáforas que construyen en este caso un aproximación al conocimiento, determinan la existencia o no de posibilidades o movimientos, no es lo mismo jugar un partido de futbol en un campo que en un espacio, este pequeño cambio de contenedor modifica en sí misma toda la experiencia posible del juego, pero además deja en evidencia la fuerza que contienen las metáforas a la hora de evidenciar las coordenadas y por tanto de posibilidades de los hechizos discursivos en la producción de sentido de nuestras vidas. Piense finalmente, en qué sucede cuando asumimos que la historia es la gasolina de los conflictos y de los cambios sociales, o cuando asumimos que es la racionalidad la base de la organización social, por último, cuando asumimos que es en las funciones del sistema donde encontramos las legitimaciones del orden social en el que vivimos. ¿Acaso en cada una de ellas no se modifica toda la experiencia humana de la vida?

En este primer componente sobre la significación del discurso, se buscó dejar en evidencia como la experiencia física de observar y comprender el mundo se relaciona íntimamente con los modelos o marcos mentales que guían la producción de sentido de la vida en sí misma, así las cosas, se retoma la idea de los hechizos discursivos, en la medida que son los discursos por 
medio de los cuales comprendemos el mundo y le brindamos sentido, operando por lo tanto como un hechizo que modifica nuestra experiencia física del mundo.

\section{Estribillo 1}

A la luz de los elementos establecidos hasta este punto, en una primera mirada de "Hurt", la clave se encontraría en estudiar la lírica de la pieza musical, es decir la letra y en ella el uso de metáforas que evidencian componentes del hechizo discursivo, así por ejemplo la idea de: “uso mi corona de mierda, en mi trono embustero" (Reznor, 1994) no requiere especificar que el autor se siente o se plantea como el rey de un espacio o lugar específico, el cual además es desdeñado como algo inútil o sin valor.

Ahora bien, como pudimos observar a lo largo de este primer verso, es preciso incorporar elementos propios de la pragmática del lenguaje, después de observar o escuchar las dos versiones de la canción "Hurt", es posible vivenciar cambios en los procesos de significación, mientras en la versión de Nine Inch Nails, se encuentra un escenario “industrial” donde por ejemplo la alusión a consumo de drogas pesadas mediante la línea "la guja perfora un orificio, el viejo pinchazo familiar" en el segundo caso interpretado por Johnny Cash, la construcción gira hacia lo realizado en su vida, sus excesos y pasos por la cárcel, pese a que la canción mantiene los elementos de la armonía, toda su experiencia cambia, el texto o lírica de la pieza musical no nos garantiza entonces la comprensión del discurso, requerimos ampliar la mirada e integrar todos los elementos posibles para producir entonces una comprensión más completa de lo que se construye en el hechizo discursivo.

Por último, en este verso se cierra con la idea de cómo el hechizo discursivo modifica la forma en que experimentamos y observamos el mundo, así las cosas, es preciso reconocer como 
de hecho la estética de las dos canciones, desde el rock alternativo industrial de Nine Inch Nails, establece una forma de comprender y abordar ese hechizo específico, mientras que toda la experiencia que se produce a partir de la propuesta country de Johnny Cash genera un efecto diferente en términos de significación, se podría decir entonces que nuestro hechizo discursivo determina en gran medida esa experiencia frente a una pieza musical con dos versiones, ahora es necesario adentrarnos en el funcionamiento o lógicas de la cognición en relación con el hechizo discursivo.

\section{2 verso. La cognición en el hechizo discursivo}

A partir de lo expuesto hasta este momento, se propone una nueva discusión en la medida que se está planteando que los hechizos discursivos tienen la potencia de modificar la forma en que físicamente vemos el mundo, es decir moldean la experiencia física del mundo en el que vivimos. Por lo tanto, surge aquí una pregunta clave ¿Cómo pueden los hechizos discursivos modificar nuestra experiencia física del mundo?

Una respuesta parcial, pero adecuada a este ejercicio se encuentra en el marco de los procesos cognitivos del hombre en las sociedades. Donde es preciso establecer por lo tanto una primera idea, el hechizo discursivo se materializa en el cuerpo del ser humano, de hecho desde esta perspectiva sería posible comprender fenómenos relacionados con la estética y algunos estudios 
que se fundamentan en las sub-culturas o las denominadas tribus urbanas ${ }^{16}$. Los hechizos discursivos por lo tanto cuentan con una potencia trascendental en la vida humana.

De hecho en este sentido puede comprenderse parcialmente la idea de Emile Durkheim al trabajar "El suicidio" (1928), donde nos propone dos condiciones claves para la generación de los medios materiales suficientes para dar fin a la vida, por exceso o defecto de pertenencia a un colectivo, dando así origen al suicidio altruista y al egoísta, es decir, en clave de lo que se plantea en esta propuesta a partir del compromiso o ausencia de compromiso; en términos de nuestros hechizos discursivos podemos de hecho provocar nuestra propia muerte, sea por cumplir con los principios de nuestro hechizo o por ausencia del mismo, no sería esta una clave donde podemos observar como los hechizos discursivos materializan nuestros cuerpos también.

Ahora bien, una forma de comprenderla o abordarla es la anteriormente desarrollada, otra es tratar de establecer las formas y mecanismos por medio de las cuales se produce y construye el hechizo discursivo en los cuerpos de los seres humanos, así las cosas, la psicología social nos ofrece un campo clave para comprender este ejercicio, a partir de los estudios que se orientan a la cognición social, donde la memoria es un factor clave del proceso de producción de sentido en el mundo, a partir de la noción de cognición social (Condor \& Antaki, 2000).

Una de las miradas en torno a este proceso se encuentra justamente en lo que podemos denominar como las "fallas de la memoria", donde la capacidad de recordar las acciones y

${ }^{16}$ En este punto, es relevante reconocer que no se trata de la comprensión del fenómeno desde perspectivas como las tribus urbanas o desde las sub-culturas, sino se trata de una apuesta por la puesta en marcha en escena de la ideología por medio de las prácticas de los sujetos. 
sucesos del pasado tal cual sucedieron se hacen relevantes, es decir, de nuevo encontramos una imagen que se a utilizado en varias ocasiones a lo largo de este texto, la idea del espejo que no miente, la memoria no puede alcanzar este tipo de expresión en la medida que siempre modifica pequeños elementos de nuestras experiencias del pasado (Sierra, 1991). En gran medida esto obedece a los procesos de codificación y recuperación de las experiencias.

En los estudios realizados en torno a la memoria, se han reconocido dos tipos de memorias, la de corto y la de largo plazo, ahora bien en la segunda se formulan procesos y procedimientos en los que el cerebro trabaja mediante las neuronas, así las cosas a diferencia de una computadora (metáfora usual para pensar en el cerebro), nuestro cerebro no almacena archivos sino que codifica las experiencias mediante entramados neuronales, a estos entramados que son de orden genérico se les ha denominado como marcos mentales o como esquemas mentales (Sierra, 1991).

Lo anterior, implica reconocer que no tenemos una experiencia particular almacenada en nuestros cerebros, sino que de forma genérica articulamos las experiencias y los conocimientos, a través de los marcos/esquemas, a partir de los cuales podemos establecer formas de actuación, de allí que a los marcos mentales también se les reconozca como frames o guiones, a partir de los cuales reconocemos las expresiones del mundo e interpretamos las formas de interactuar en un escenario específico de la vida.

Antes de continuar retomemos las formas en que la memoria operan en nuestra forma de comprender el mundo, al establecer que la memoria cuenta con procesos de codificación de las experiencias y de recuperación de las mismas, estamos de igual forma dejando en evidencia como se construye el conocimiento, en este sentido también toma lugar la materialización en 
nuestros mapas neuronales, los hechizos discursivos, como formas de aproximación a la comprensión y producción de sentido de la vida.

Hasta este punto contamos con dos materializaciones de los hechizos discursivos, el primero y más profundo de ellos se reconoce en los mapas neuronales de nuestro cerebro, quienes a su vez se materializan en las metáforas y metonimias que utilizamos para describir y llenar de sentido la vida cotidiana, pero además también las formas del conocimiento científico, por ejemplo, a partir de nuestras experiencias previas, construimos mecanismos de codificación en relación a las nuevas experiencias, pero además de igual forma consolidamos espacios o mecanismos de recuperación de las mismas. Así entonces se producen conocimientos genéricos sobre experiencias pasadas en torno a tres elementos esenciales: objetos, secuencias y conceptos, a partir de los cuales generamos comprensión y sentido en las acciones y en las situaciones con las cuales interactuamos (Sierra, 1991); lo anterior implica reconocer que el proceso de codificación mediante los marcos mentales, se realizan al menos procesos de selección, abstracción, interpretación e integración, generando de esta forma recuerdos en la memoria incompletos, pues en el proceso se incluyen distorsiones, confusiones e incluso errores de codificación (Sierra 1991). Se trata por lo tanto en este proceso de encontrar o ubicar el mecanismo por medio del cual se producen y materializan los marcos mentales.

De acuerdo con lo anterior, es posible encontrar en estos mecanismos (codificación y recuperación) el origen de los marcos mentales, sobre los cuales por ejemplo Lakoff ha planteado como el pensamiento conservador y el progresista se puede rastrear en la construcción de marcos específicos, donde por ejemplo la familia en cuanto metáfora del Estado puede ser fundamental para el reconocimiento de las formas en que producimos sentido, acorde con los 
marcos que "gobiernan" o codifican nuestra memoria y por lo tanto determinan formas específicas de la construcción de sentido en la vida.

En consonancia con lo que se ha planteado hasta este punto, los marcos mentales no sólo nos permiten como sujetos el reconocer o brindar sentido en las formas que reconocemos las acciones, pautas y formas de comportamiento, sino que además en ellas es posible reconocer las formas en que nos podemos poner en común, es decir interactuar con otros sujetos en contextos específicos de la vida. Retomaremos por lo tanto la idea que se mencionó pero no se desarrollo plenamente hace unas líneas, se trata de la cognición social.

En términos amplios se reconocen dos aproximaciones claves frente a la cognición social, se trata de la perspectiva de los mentalistas, quienes tienen un especial interés en establecer los mecanismos psicológicos que posibilitan a los individuos reconocerse a sí mismos y a los demás con diferencias y particularidades acordes con los contextos; de forma paralela la perspectiva de la propiedad compartida se interesa en los modos como las personas en tanto miembros de un contexto socio cultural específico reconocen y describen el mundo social en el cual se encuentran inmersos, centrando la mirada en la capacidad de pensarse en el marco de las interacciones sociales (Condor \& Antaki, 2000).

A partir de la idea de la propiedad compartida, la cognición social, la memoria y los marcos mentales contarán con un rol clave en nuestras sociedades, se trata de garantizar la posibilidad de interacción entre sujetos, pero además nos presenta interesantes retos al pensar temas como la multiculturalidad, o la interacción entre cogniciones sociales diversas. Es decir, pese a que se contemple la propiedad compartida, es imposible establecer que sea la misma o un principio universal para todos los sujetos humanos. 
De forma similar Berger y Luckmann, en su trabajo "la construcción social de la realidad" (2005), dejan en evidencia la relevancia del proceso de significación, vale la pena relacionar aquí la propiedad compartida, sería posible solo a través de los universos simbólicos a partir de los cuales se produce el sentido (Berguer \& Luckmann, 2005), es decir los hechizos discursivos tendrían sentido en la medida que se plantean como universos simbólicos que se transforman en propiedades compartidas de la cognición social y por lo tanto se materializan en los marcos mentales de los sujetos que pertenecen a un contexto específico.

Lo anterior, pudiera parecer una suerte de cárcel, donde los sujetos se encontrarían sujetos al contexto y la propiedad compartida, sin embargo es preciso establecer que la memoria pese a contar con un proceso social clave, es en la singularidad de la experiencia humana donde se configura la memoria, por lo tanto pese a ser compartida, es en esa singularidad posible la producción de sentidos otros, a partir de los cuales podremos encontrar las formas de pensar el pensamiento no pensado, vale decir la singularización.

Sin embargo, lo anterior implica abrir la pregunta de como es que podemos modificar o moldear no sólo la memoria sino además los sentidos compartidos por medio de la cognición social, debemos por lo tanto retornar a la idea de la memoria en la experiencia del sujeto, donde en su historia personal se establecerán elementos o rasgos de valoración que permiten establecer las formas en que se puede reconocer cual es la mejor forma de acción, forma que se encuentra en los marcos mentales, pero que además expresamos mediante nuestras metáfora y metonimias.

Lo anterior nos implica incorporar un elemento más, donde es a partir de esas formas de producción de sentido donde además se construyen mecanismos de valoración, es decir, a partir de las metáforas, las metonimias, los marcos que se dejan en evidencia, que permiten además su 
producción los universos simbólicos, contamos con procesos de valoración que permiten o no tomar acciones, decisiones o posibles rutas de acción.

Acorce con lo anterior contamos entonces con un escenario donde el hechizo discursivo además de estar íntimamente vinculado con la producción de sentido, además en esa producción de sentido se permitirá la valoración de nuestras acciones, donde además convergen elementos como la experiencia humana en el mundo, los universos simbólicos y en ellos las formas en que comprendemos y por lo tanto asignamos contenido ya sea a lo real o la realidad. Es decir, las formas en que valoramos nuestro mundo, que pueden rastrearse en las formas materiales del hechizo discursivo (metonimias, metáforas, marcos mentales) se establece también la posibilidad de reconocer formas de violencias, sus roles y sentidos, dando y otorgando por lo tanto sentido a la existencia de la realidad y de lo real.

Lo planteado hasta el momento implicaría en cierto sentido establecer que el hechizo discursivo produce toda forma de valoración, sin embargo es preciso incorporar otros elementos que también juegan un rol clave en este proceso, pues al incluir la experiencia del sujeto en el mundo, estamos incluyendo también elementos claves de la construcción y materialización de la cognición, se tratará por lo tanto de las emociones, las paciones y los sentimientos, elementos que serán retomados y ampliados en el siguiente verso de este capítulo.

En el proceso de valoración en el desarrollo de las sociedades occidentales, existen tres posturas que son interesantes retomar, a partir del trabajo de Victoria Camps (2011), donde se resalta el rol de la racionalidad de frente a las emociones, surgen para la autora tres autores históricos claves a ser retomados: Aristóteles, Spinoza y Hume, quienes en nuestro caso nos 
aportas tres perspectivas de la relación entre los sentimientos y los procesos evaluativos de los sujetos.

En el primero de los autores rastreados en el trabajo de Camps, Aristóteles, juega un rol donde se establece la virtud como un elemento clave tanto de los sujetos como del desarrollo de las sociedades occidentales, en este caso la virtud será comprendida como el dominio de las pasiones por parte de la racionalidad, como una suerte de cálculo del correcto actuar en forma coherente con los objetivos y principios (Camps, 2012), posición que podríamos relacionar con el hecho social racional mentado y orientado a fines de Weber (1996), en la medida que es la racionalidad el eje principal de la producción de sentido, así en este escenario los sentimientos quedan sometidos o dirigidos por la capacidad de la razón.

Ahora bien, frente a esta posición es importante reconocer que este tipo de interacción, no implica en la lectura de Camps, la conformación de una forma de conocimiento, sino de una forma de evaluación, por medio de la cual, se busca configurar una suerte de garantía en el marco de las acciones encaminadas a lo que podríamos reconocer como bien común, así las cosas nuestros sentimientos, en forma de pasión, pueden ser guías que sin el uso de la razón pueden conducir a procesos contrarios a los que se comparten o buscan como colectivo (Camps, 2012).

En una relación donde no contamos con un sometimiento de un sentimiento por la razón sino de una interacción entre estos encontramos la postura de Spinoza, quien para Camps, a través del reconocimiento de pasiones tristes y alegres, es posible la contraposición de éstos para la orientación correcta en el proceso de evaluación de las acciones, así la razón ya no se encuentra en un lugar de poder o dominio sobre las emociones, sino que se tratará de una capacidad del 
sujeto para encontrar la pasión adecuada que permita contraponer y modificar la emoción y así producir otros mecanismos o formas de evaluación y acción en el mundo (Camps, 2012).

Acorde con lo anterior, Camps establece la necesidad, por lo tanto, de la posibilidad de construir o encontrar afecto común, vale decir, muy parecido a la línea que trabaja la autora al pensar Aristóteles, es la posibilidad ahora de construir mecanismos por medio de los cuales sean las pasiones alegres aquellas que permitan la consolidación de un proceso de evaluación y en él de selección de una forma de acción que pueda ser afectivamente correcta para los colectivos, de nuevo retomaríamos por lo tanto aquella noción del bien común. Este hecho nos propondría por lo tanto bajo el trabajo de Camps, la posibilidad de reconocer sentimientos que surgen de la razón (Camps, 2012).

Antes de ingresar en la ultima de las propuestas que nos menciona Camps, es preciso dejar en evidencia como en estos dos casos contamos con una presencia relevante de la razón en el proceso de producción de valoraciones en el marco de las acciones de los sujetos, ahora bien, en el ultimo de los autores trabajados por Camps, se genera una ruptura con la idea de la razón que gobierna los sentimientos, dejando así en el escenario una postura donde las emociones gobiernan los procesos racionales, este último elemento se establece a partir del trabajo de Hume.

Ingresamos de esta forma en el tercer escenario donde podemos encontrar otra forma de relacionamiento entre la razón y las emociones, donde la razón será la esclava de las pasiones, lo anterior, lo establece Camps, a partir de su trabajo con la obra de Hume, donde logra establecer como las pasiones y los sentimientos se sienten, dominando de esta forma la experiencia humana, este elemento, lleva por lo tanto a plantear que la moralidad no es una experiencia de la 
razón sino que la moralidad se siente, y desde allí se establecen las formas de acción e interacción.

Ahora bien para Camps, en este escenario es clave comprender cómo, o mejor, por que se puede sentir una expresión de la moralidad, hecho que llevaría a la relación con los otros, es decir, la posibilidad de establecer empatía o identificación con algo o alguien, que permita el despertar de la moralidad en nuestros cuerpos (Camps, 2012). Este hecho supondrá en cierto sentido (como se ampliará más adelante) el surgimiento y necesidad de aparatos legales que regulen las acciones de los sujetos de comunidades de la forma más acorde con la moralidad construida por el colectivo.

Por último, es preciso en este ejercicio de la comprensión de la relación entre pasiones y racionalidad, dejar en evidencia como existe un foco relevante sobre el proceso por medio del cual los sujetos establecen prioridades de acciones, por medio de los cuales dirigimos y procesamos elementos cotidianos o más amplios para dirigir comprender y establecer el curso de acción más adecuado, como pudimos observar en el trabajo de Camps, se trataría de tres escenarios donde la relación entre razón y emoción siempre esta en tensión.

Ahora bien, es desde la perspectiva de Hume en relación con Nusbbaun, donde podemos establecer profundas relaciones entre los marcos mentales, resultado de los procesos cognitivos, que materializan los hechizos discursivos y las formas en que valoramos y producimos sentido. Así entonces es necesario pasar a nuestro siguiente verso, donde nos ocuparemos de las emociones, su forma de producción y sus relaciones con los hechizos discursivos. 


\section{Estribillo 2}

En este punto es clave recordar nuestras experiencias sonoras, en la medida que por ejemplo, quien escribe estas líneas vivió la juventud en los años 90 del siglo pasado, siendo seguidor del movimiento de rock alternativo, principalmente de la banda de Seattle Nirvana, además de otras que surgirían en la escena alternativa, unas más conocidas que otras, como Nine Inch Nails, la cual fue parte de la experiencia vital en la juventud con la pieza musical "Hurt" en especial por su video lanzado en la cadena de videos musicales Mtv con una versión en vivo donde se genera la imagen de un animal muerto en proceso de descomposición con una cámara a alta velocidad.

Pareciera que esos elementos anteriores no son relevantes al interior de la investigación, sin embargo, esa experiencia singular de la vida y la historia personal, permite establecer algunos elementos claves de la memoria, por lo tanto de los marcos mentales que guían la forma de comprender y vivir el mundo de un sujeto específico, en este caso de quien escribe estas líneas, ahora bien, algunos de esos elementos serán compartidos con otros seguidores del movimiento alternativo de los años 90 en varias partes del mundo.

Lo anterior, quiere dejar en evidencia que la experiencia frente a "hurt" la versión de Nine Inch Nails, se registra y opera desde un lugar específico de la memoria, permitiendo de esta forma la consolidación de una experiencia específica, diferente a la que se produce con la versión de Johnny Cash, autor que se relaciona en este caso con una experiencia del ser adulto, en la medida que el autor fue conocido por quien escribe estas líneas en el siglo actual, cuando se iniciaron rastreos sobre música blues y folk, encontrando este autor, llevando a que la forma de asumir y vivir la pieza musical sea diferente, pues opera con marcos mentales, redes neuronales, 
diferentes pero conectadas, pues tienen un elemento en común para su proceso de organización, la canción "Hurt".

Se trata por lo tanto en este segundo verso, de reconocer como la experiencia del sujeto en el mundo vivido cuenta con importantes aportes en la construcción de los hechizos discursivos, pero además con los procesos de evaluación de las acciones y de la experiencia misma del mundo, es posible repetir este ejercicio a partir de las experiencias con las que cuenta el lector, de forma previa ya sea a los interpretes de la canción "hurt" o de la canción, donde tal vez el referente pueda ser la película "logan” del año 2017 que utilizó la versión de Cash para el tráiler de promoción, cualquiera de estas opciones entre muchas otras más, tendrán en efectos no sólo en la forma que se escucha la pieza musical, sino que además permitirá toda una relación de aceptación o rechazo de la misma.

Ahora bien, el verso que se trabajó cerro con la idea de las pasiones, pues parte de nuestra interpretación del mundo y de la evaluación de nuestras acciones, como pudimos observar, no se basa en el uso exclusivo de la razón, sino que además se cuenta con un profundo rol de las pasiones y las emociones, como aquellas que se activan en nuestros marcos mentales cuando escuchamos una pieza musical y podemos volver a sentir calor u olores de un lugar y un momento específico de la vida. Es el momento por lo tanto de trabajar las pasiones y las emociones al interior del hechizo discursivo.

\section{3 verso. Las pasiones en el hechizo discursivo}

Acorde con lo presentado hasta este punto, es preciso dejar en evidencia como se ha querido mostrar el rol de la racionalidad en el marco de la producción de sentido, así entonces, los 
sentimientos y las pasiones son un componente importante en el proceso del sentido, donde si bien la racionalidad es una parte relevante no es la única, sino que se relaciona con otros elementos y procesos, es el momento por lo tanto de darle cuerpo a este proceso.

Se tratará por lo tanto del reconocimiento de las formas en que las emociones tienen lugar en el campo del proceso cognitivo, donde además se generan importantes pautas valorativas en los sujetos, permitiendo darle cuerpo completo a los hechizos discursivos, ya no sólo como un ejercicio de ideas del orden racional sino también con un importante vinculo con las emociones que determinan las formas en que producimos y generamos sentido en el marco de nuestras vidas cotidianas.

Existe en este ejercicio un elemento que es clave y por lo tanto deberá ser el inicio de este proceso, se trata de la construcción de los objetos, es decir, en términos del conocimiento los sujetos producimos o reconocemos como objetos todo aquello sobre lo cual producimos conocimiento (Sztajnszrajber, 2011b), lo anterior en ningún momento quiere decir o suponer que esos objetos sean objetivos, sino que por el contrario se cargan de subjetividad en el proceso mismo de interacción entre el sujeto y el objeto, se trata por lo tanto de la experiencia humana del conocer.

Ahora bien, en ese proceso de construcción del objeto, de reconocimiento, el mismo se relaciona históricamente con las formas en que en su historia personal el sujeto le otorga valores al objeto, permitiendo por lo tanto reconocer en él mismo una experiencia y en ella su orientación de beneficio o perjuicio (Nussbaum, 2017), lo anterior no en una experiencia bipolar, sino dinámica, pues esta producción se produce en un contexto específico que otorga y permite la incorporación de sentido. 
De lo anterior, es preciso además reconocer que no sólo se trata de la producción fría y calculada de la interacción entre el objeto y la razón, sino que además la experiencia se materializa mediante la experiencia histórica en un sentir, parecida por lo tanto a la idea de Hume donde la moralidad se siente, por lo tanto nuestra relación con los objetos se establece a partir de la experiencia previa, elemento que rastreamos con la memoria en el verso anterior, pero además en este caso vincula emociones que permiten sentir la propiedad de beneficio o perjuicio del objeto acorde con el contexto, la emoción que se produce y su interacción con la racionalidad, es decir, se trataría de una forma de comprender las formas en que los marcos toman funcionalidad o materializan su operación.

Recordemos que los marcos mentales permiten a los sujetos establecer formas de acción, ahora bien, según lo que estamos planteando en este punto, esas formas de acción se encontrarán mediadas no sólo por el marco existente, sino que además éste se encuentra en interacción con la historia previa y la emocionalidad que se despierta y llena de sentido la posibilidad de interacción, con el objeto que, interactuamos en cuestión. Así entonces la idea de los marcos profundos y los superficiales cobra una nueva dimensión, se trataría de marcos genéricos (profundos) que se llenan de sentido, posibilidad, y valoración a partir de los marcos específicos (superficiales) (Lakoff, 2013) espacio en el cual además toma sentido la emocionalidad y la razón, así entonces se materializa el hechizo discursivo.

Retomando la idea anterior, es preciso reconocer por lo tanto que es a partir de la emocionalidad que producimos los objetos y en ellos construimos una valoración que permite reconocer la valoración del mismo, dejando por lo tanto expuesta la forma en que significamos el mundo, donde además todo nuestro hechizo discursivo juega en rol de no sólo otorgar sentido 
sino además permitir la producción de racionalidades adecuadas y coherentes con aquello que sentimos por el objeto en interacción.

El punto anterior nos lleva por lo tanto al debate que se produce con los universos simbólicos, compartidos por un grupo social, lugar donde Berger y Luckmann, establecen un elemento para la construcción social de la realidad, pues la intromisión de las emociones y la experiencia histórica del sujeto puede entrar en debate y modificar esos universos simbólicos. Pareciera esta una discusión que negaría la posibilidad de la historia personal y la producción del hechizo discursivo con las formas del sentir, sin embargo si no fuese éste el proceso, contradictorio, las sociedades se encontrarían todas en una suerte de proceso de automatización, donde los sujetos comparten plenamente no sólo el universo simbólico sino que además sus experiencias llevarían a la producción igual de todos los objetos en interacción.

El ejercicio anterior es relevante, pues como plantea Laclau (2014), para la existencia de una hegemonía siempre se requiere de la negación de la misma, es decir ningún modelo puede ser total, en la medida que al ser total se desocupa el mismo de sentido, se naturaliza, así las cosas su posibilidad de ser pensada o racionalizada, e incluso sentida, se desaparecería por completo (Laclau, 2014). Así las cosas, la negación que se propone en líneas anteriores garantiza en sí misma la producción de sentidos colectivos, sentidos que a su vez se encuentran siempre en disputa por su sentido por los grupos que hacen parte del colectivo, de hecho también por los sujetos que están inmersos en este proceso y que buscan otorgar desde sus experiencias históricas el sentido frente a un objeto específico, vale recordar que en el objeto de hecho se puede contener otro sujeto. 
Retomando, es en la forma que nos relacionamos con los objetos del mundo en el que nos encontramos inmersos, donde establecemos valoraciones que se vinculan principalmente a partir de la emocionalidad vinculada, así las cosas, cognitivamente los marcos mentales se relacionan profundamente con nuestra experiencia vital del mundo, la cual además como plantea Hume en palabras de Camps, se establece principalmente a través de los sentidos, que permiten la producción de racionalidades, que explican y además aportan en la producción del sentido.

El ejercicio de incorporar el sentido y rol de la emocionalidad en la producción de procesos cognitivos, tiene un lugar en el marco de esta investigación, pues el corpus que se aborda se relaciona principalmente con una forma de emocionalidad, la música, que no puede ser comprendida como algo exterior a nuestros sentidos y formas de comprender el mundo desde la emocionalidad, como se ampliará en nuestro siguiente verso. Pero además de ser una suerte de accidente en el marco de esta problematización, es además la apertura de otras formas de comprensión del proceso cognitivo y la consolidación de marcos mentales, vale decir de los hechizos discursivos, permitiendo por lo tato no sólo comprender la relación que el sujeto establece con la música, el arte en general, sino también con sus miedos.

Vale la pena desarrollar un poco más la idea anterior, desde miedos considerados como patológicos, espacios donde la construcción del sentido de la vida cotidiana puede llegar a perder toda dimensión. Por ejemplo, en temas relacionados con la música, donde personas en casos variados se siente perseguidas por la música, así determinados géneros relacionados con sus infancias pueden ser detonantes de ataques similares a los epilépticos, motivo por el cual estos sujetos comienzan a variar sus formas de interactuar con los territorios, esto con el fin de garantizar no escuchar música de sus infancias (principalmente pero no exclusivamente) que les 
pueda detonar un ataque (Sacks, 2007). En los casos de gente perseguida por la música, es posible evidenciar como existe materialmente una serie de conexiones profundas entre el hechizo ideológico, el cuerpo y en especial la historia personal de los sujetos en el mundo.

Los ejemplos anteriores son parte del trabajo realizado por Oliver Sacks (2007), en su trabajo "Musicophilia: tales of music and the brain", donde resalta casos de estudio en los cuales es posible establecer el nexo que en esta investigación se viene detallando, así por ejemplo el autor dedicará un capitulo a casos de personas perseguidas por la música, también dedicara un campo muy interesante de su estudio a los casos relacionados con la sinestesia, donde los tonos musicales inspiran colores u olores específicos, en muchos casos, relacionados con la historia de vida de los sujetos (Sacks, 2007).

Ahora bien, el hecho de resaltar algunas patologías de orden siquiátrico trabajadas por Sacks en este espacio, es en clave de evidenciar como es posible establecer los nexos entre los hechizos discursivos, los sentimientos, las pasiones y en general el cuerpo, como medida que permite establecer que en últimas el hechizo discursivo nos lleva a ver físicamente el mundo en el cual interactuamos de una forma específica. Esas formas de ver por ejemplo se pueden relacionar con las formas en que sentimos la moral, como lo propone Camps en el trabajo sobre Hume, de nuevo, escapamos del imperio de la racionalidad, para poder dar razón de un espacio ideológico ocupado por nuestros hechizos discursivos.

Del trabajo de Sacks (2007) vale la pena resaltar otro elemento clave en los casos reconocidos como "perseguidos por la música", para lo cual es necesario ampliar uno de estos casos. Se trata de uno de sus pacientes, un médico deportivo que recibe un rayo después de una práctica del equipo de futbol americano con el que trabaja, como resultado de este accidente el paciente no 
sufre mayores traumatismos, sin embargo meses después del evento, se encuentra en su casa cuando comienza a escuchar música en su cabeza, no encuentra ningún tipo de artefacto que lo este generando, es su cabeza de forma "autómata" quien produce los sonidos, el paciente sólo podrá regular estos sonidos, que en un momento se convierten en algo insoportable por su continuidad, por medio de la interpretación de un piano, es decir, como una suerte de materialización de la música en su cabeza en una práctica, pese a que sólo en la infancia asistió a un par de clases de piano (Sacks, 2007).

¿Por qué el paciente de Sacks en el ejemplo anterior escuchó notas de piano?, ¿Por qué no se trató de notas de batería, saxo, guitarra o de violín?, en gran medida el autor explica este tipo de relaciones por las experiencias que se producen en el marco de la historia, pero principalmente en la consolidación física de la memoria, lugar donde los marcos mentales tienen un gran sentido como observamos en líneas anteriores.

La construcción por lo tanto de las formas en que observamos, comprendemos y actuamos en el mundo tienen una profunda conexión con las formas en que nuestro cerebro se consolida, es preciso establecer este punto, en la medida que en los estudios neuronales, ha sido posible establecer lugares específicos de funcionalidad del cerebro para determinadas acciones, sin embargo dos elementos se han reconocido, operan en toda la masa cerebral, algunos sentimientos y la música (Sacks, 2007).

Ahora bien, antes de ingresar profundamente en la música, retomemos un poco la noción de los sentimientos y su función en el proceso evaluativo de los sujetos en sus formas de interactuar en la vida cotidiana. La idea central por lo tanto se trata de reconocer en los sentimientos, las 
principales guías de producción de sentido acorde con las relevancias cognitivas construidas en las experiencias previas.

Teniendo en cuenta los elementos que se han reseñado hasta este punto, es preciso ahora incorporar cuatro elementos claves que destaca Nussbaum (2017) frente a los sentimientos, así entonces: I) éstos son parte constitutiva del pensamiento valorativo, II) el pensamiento valorativo se vincula profundamente con el proceso ético y el sentir moral de los sujetos, III) la música en conjunto con las artes en general, cuenta con un rol relevante en la producción y composición de las emociones y, IV) la relación entre cognición y emocionalidad es un elemento clave para comprender el pensamiento valorativo ético (Nussbaum, 2017). Elementos, que como se han observado a lo largo de este capítulo componen las formas en que se construyen y consolidan los hechizos discursivos, las formas en que comprendemos y actuamos en el mundo de forma en que incluso en cada una de las metáforas, metonimias, los marcos que las relacionan, se produce una relación clave con los sentimientos.

Ahora bien, es preciso reconocer en el campo de los sentimientos en cuanto valoración su triple dimensión, en la medida que las emociones se relacionan o construyen frente a un objeto (que puede ser un sujeto), es decir, éstas no se producen en el vacío sino que se producen siempre en una interacción; segundo son intencionales, es decir, cuentan con intencionalidad y por lo tanto guían las acciones de los sujetos, al entrar por lo tanto en relación con un objeto se producen intencionalidades desde los sentimientos como formas de producción de juicios de valor, este elemento nos lleva a su tercera característica, son creencias complejas, es decir, sus formas de acción, interacción y emergencia son diversos, no operan de igual forma con todos los objetos, y de hecho pueden variar frente al objeto de acuerdo al contexto (Nussbaum, 2017). 
Ahora bien, para comprender un poco la trilogía anterior, podemos tomar como ejemplo la relación con las mascotas, donde en la niñez se puede contar con una experiencia traumática (el robo de comida por un gato, el mordisco de un perro, entre muchas otras opciones), con el tiempo racionalmente puedo comprender que el animal doméstico no representa riesgo alguno, sin embargo mi emotividad seguirá presentando en muchos casos, un ejercicio de atención, de hecho de ansiedad frente a la interacción con el objeto animal doméstico, así las cosas se construye una emocionalidad frente a un objeto, que direcciona mis interacciones con el objeto, pero además la racionalidad no logra guiar o acomodar estas formas de emocionalidad, dejando en evidencia como creencia sumamente compleja, pues no es posible su sometimiento al proceso racional.

En este caso es posible retomar la idea de los filósofos estoicos, quienes proponen la superación del miedo por medio de la razón, así las cosas para este grupo de pensadores, el miedoso es una persona sin conocimiento, sin embargo, en el pensamiento de ellos, se reconoció como existe un miedo que supera toda forma racional, el miedo a la muerte (castro Gómez, 2017). Frente a la construcción y reconocimiento de las emociones nos adentramos en un mundo sumamente complejo de ideas, de allí que se optó en el primer capítulo de esta tesis, por denominar el hechizo discursivo, dando razón de un elemento místico, que pareciera escapar de su explicación racional, se trata por la incorporación de las emociones, que parecieran en ocasiones guiar nuestras acciones sin ningún tipo de registro u sustento racional.

Las creencias por lo tanto se relacionan profundamente con nuestras emociones, por ejemplo "la creencia que un animal de plumas puede hacerme daño", despertando toda una emocionalidad, ahora bien, de nuevo contamos con el problema de la verdad, ¿es la frase anterior 
(sobre los animales de plumas) una verdad?, sin lugar a dudas podríamos decir que no necesariamente, sin embargo un sujeto con fobia a los animales emplumados sentirá y actuará conforme a ese sentir y creer, de allí que:

He mencionado la verdad. Y es, por descontado, una consecuencia de la perspectiva que vengo desarrollando el que las emociones, como otras creencias, pueden ser verdaderas o falsas, y (lo que es un asunto independiente) justificadas e injustificadas, razonables o irrazonables. El hecho de experimentar una emoción depende de cuáles sean las creencias de una persona, no de si las mismas son verdaderas ofalsas (Nussbaum, 2017, p. 69).

El anterior fragmento de Nussbaum nos recuerda la experiencia y vida del sujeto, en la composición de la memoria, a través de los mecanismos de codificación y recuperación de los marcos mentales (Condro \& Antaki, 2000), abriendo de esta forma la relación entre los marcos mentales, los sentimientos y los sentidos de vida, consolidados como se ha querido evidenciar a lo largo de la investigación en el hechizo discursivo. Lo anterior implica que es en el ejercicio de otorgar importancia o relevancia a un objeto (o suceso) que se construye la intensidad de los sentimientos que se viven o despiertan en el mismo. Es decir, ante mayor relación reconocida entre el objeto/suceso y los fines o sentidos de vida reconocidos, mayores serán los sentimientos que se despiertan en el sujeto (Nussbaum, 2017), guiando de esta forma la producción de valoraciones que permitan las acciones del sujeto.

No todos los sentimientos ingresan en el campo de la racionalidad evaluativa de la acción del sujeto, también existen un grupo de sentimientos que escapan a su capacidad racional, abriendo de esta forma escenarios mucho más complejos, donde no podemos establecer relaciones o 
campos explicativos del proceso mismo de evaluación de la acción frente a un sujeto, objeto o suceso, simplemente los sentimientos pueden gobernar toda forma de producción de sentido en casos específicos (Nussbaum, 2017).

Ahora bien, los sentimientos tienen formas de expresión y de estar en el cuerpo variados, es decir, existen grupos de éstos que pueden estar presentes a lo largo de la vida sin contar con expresiones fuertes (el amor a los padres), haciendo presencia relevante por ejemplo frente a la posibilidad de ausencia del objeto, sujeto o suceso, en este caso la muerte de uno de los padres; otros se presentan de forma categórica en momentos mucho más específicos, es decir, los sentimientos tienen mecanismos y formas de interacción que llevan a la producción de sentido en el marco de momentos o contextos específicos, esto implica además la construcción de momentos en los que se puede contar con conflictos de emociones, en los que éstos pueden actuar de forma contradictoria, aun así algunos prevalecen en el proceso de producción del sentido en ese contexto, esto se debe a lo que Nussbaum relaciona como la frescura del sentimiento (Nusbbaum, 2017).

Acorde con lo presentado hasta este punto es necesario incluir una nueva forma de diferencia o de comprensión de los sentimientos, se trata del reconocimiento de elementos como el apetito, estados de animo y deseos de acción, en los cuales la emocionalidad es parte activa pero son a su vez elementos diferentes de la experiencia humana. Lo anterior en la medida que tanto los apetitos, los estados de animo y los deseos de acción, pueden llevar a modificar las acciones de los sujetos, sin embargo en estos casos el proceso evaluativo guiado por la emoción construida en la historia de vida de los sujetos (Nussbaum, 2017), no es el factor clave del proceso de producción de sentido, aquí entonces esta investigación se aleja parcialmente de esas tres 
nociones en la medida que el foco de interés se encuentra en las formas y mecanismo profundos de producción de sentido.

A lo largo de los últimos años se ha tratado de establecer las relaciones entre los procesos fisiológicos y los sentimientos, sin embargo, el ejercicio de estas investigaciones ha dejado en evidencia como los sentimientos son coherentes no con una plena naturaleza humana, sino con sus contextos, vale pensar, por ejemplo, las formas diversas en que se relacionan las emociones con la muerte, donde de acuerdo con contextos sociales, tanto los sentimientos como sus expresiones difieren, así por ejemplo en culturas africanas la muerte se relaciona con la alegría que garantiza que el sujeto que ha muerto no pase malos momentos en su camino eterno a causa de la tristeza de sus más allegados (Nussbaum, 2017), recordándonos además un elemento frente al escenario de los sentimientos en la modernidad, el hombre es el animal que sobre todo ha buscado la dominación de los sentimientos a partir de la racionalidad, como lo planteamos en el verso anterior, donde por ejemplo, en Aristóteles, Spinoza y Hume, se da la relación razón-sentir, en los dos primeros de ellos con una presencia más relevante de la razón, según el trabajo de Camps (2012), sin embargo también en el caso de Hume podremos encontrar como en ocasiones no es suficiente con el sentir la moralidad (Camps, 2012), pues ésta puede llevar al desconocimiento de otros e incluso a la realización de acciones consideradas poco morales.

Llegados a este punto, las emociones sirven en la producción o construcción de procesos evaluativos, donde su relación con los marcos, el lenguaje y en últimas con toda la producción de los hechizos discursivos, deja en evidencia como los sentimientos si bien son naturales al hombre, son sus contextos sociales quienes lo operacionalizan y brindan sentido, retornamos por lo tanto a la complejidad del espacio ideológico, donde también se presentan los elementos o 
pautas que brindan sentido a nuestros sentimientos, sin embargo tenemos la posibilidad de entrar en tensión con ellos a partir de la singularización.

Ahora bien, en este marco de la producción del sentido, es ahora relevante comprender al menos una serie de sentimientos que pueden resultar claves para la comprensión de las formas en que guiamos en occidente nuestros sentimientos, en el marco del proyecto moderno, permitiendo así reconocer una serie de contextos a partir de los cuales se ha producido materialmente la producción de sentido.

(I) La Vergüenza: Es preciso comprender la vergüenza en clave del reconocimiento de aquellos elementos que evaluamos como propios o impropios, es en esa relación que podrá ser comprendido y asumido el cambio no sólo en la valoración de los actos sino además sus relaciones con otros factores más amplios. Será por lo tanto en la vergüenza donde podrá reconocer una emoción que evalúa las acciones, donde además se puede perder el principio moral, así las cosas, el sentir vergüenza implicará el verse observado por no cumplir con los elementos claves del comportamiento reconocido como moral en la sociedad. "la vergüenza consiste en el sentimiento derivado de la caída de la imagen que uno tiene de si mismo, la pérdida de reputación, el descrédito ante algún otro o ente de la sociedad" (Camps, 2012, p. 111).

(II) La compasión: En relación con la vergüenza, la compasión también requiere de otros para poder ser sentida, sin embargo en este caso no se trata de la forma en que los otros nos observan, se trata en este caso de las formas en que nos identificamos con los otros, es decir, sólo en la medida que reconocemos al otro y producimos procesos de identificación es posible la construcción y el sentimiento de compasión, este será para Camps una expresión que determina 
la condición humana (Camps (2012). Ahora bien, en la compasión existe de igual forma una de las mayores perversiones humanas frente a las acciones consideradas morales.

Lo anterior se relaciona con la profunda individualidad del sentimiento en el sujeto, en la medida que la compasión es posible sentirla frente a personas o sujetos próximos, pues requiere del proceso de identificación, proceso que por motivos del hechizo discursivo puede incluso impedir que surja el sentimiento frente a sujetos que materialicen elementos contrarios al hechizo que guía la producción de sentido. Es por este motivo que para Camps se requiere de sistemas normativos, pues estos permitirán regular las formas en que se expresan y materializan en acciones prácticas la compasión que se pueda tener frente a otros sujetos, de hecho puede regular la ausencia de la misma.

(III) La indignación: En este tercer escenario se establece una profunda relación entre esta emoción y el odio, en la medida que la indignación entre las emociones establecidas hasta este punto, se basa en el reconocimiento que se genera sobre el sujeto que siente, es decir, en este escenario la indignación surge en la medida que no se es reconocido como sujeto, por lo tanto en ese surgir del sentimiento se puede producir el odio hacia el otro, al no reconocer-me como sujeto que siente por lo tanto la indignación (Camps, 2012).

(IV) El miedo: Se trata de una de las emociones que mayor racionalidad han recibido, es decir, los estoicos por ejemplo planteaban que los sujetos que tienen miedo es a causa de la ignorancia, así las cosas la forma de superar el miedo es a partir de la racionalidad, sin embargo este grupo de filósofos - los estoicos - reconocerán finalmente que existen miedos que jamás podrán ser superados por la razón, como por ejemplo el miedo a la muerte, como se mencionó en líneas anteriores. 
Ahora bien, el miedo tiene profundas raíces en la forma en que se ha organizado las formas políticas de nuestras sociedades, de allí por ejemplo la discusión entre Hobbes y Spinoza, el primero de ellos planteará el orden social a partir y como efecto del miedo individual en la comprensión del hombre como lobo para el hombre, de donde los hombres se unen bajo el gran leviatán, es decir el Estado. Por el otro lado el segundo de estos autores Spinoza, al reconocer en el miedo una pasión triste, reconocerá en ella su incapacidad de desarrollo y movimiento de las organizaciones políticas, abriendo de esta forma no la posibilidad del desarrollo de los sujetos sino la producción de servidumbres voluntarias y en ellas modelos profundamente autoritarios de poder (Camps, 2012).

(V) La confianza: Ahora bien, frente al miedo la forma de superarlo es a partir de la confianza, es decir, en este campo se rompe la noción de estar quieto por las posibilidades futuras, para "tener fe" que se pueden cambiar, allí la confianza. Vincular el "tener fe" en este campo es importante, pues la confianza es la base de los grandes discursos y creencia místicas, sin la confianza este tipo de instituciones no tienen poder o posibilidad de creencia en los sujetos, así las cosas, para comprender esta emoción es necesario ingresar a la misma desde lo místico, es preciso confiar.

Ahora bien, en el establecimiento de tecnologías de organización social como la burocracia, las leyes etc, la perdida de la confianza sobre la misma es una constante, motivo por el cual es preciso siempre establecer en estas mismas instituciones la esperanza de lo que pueden generar a futuro, es la forma por lo tanto de manejar el miedo que se produce en las sociedades contemporáneas, de allí que por ejemplo se plantee en el miedo el manejo de la ansiedad (Ruiz, 2015). 
Sin embargo, es en la confianza de los sujetos, no sobre las instituciones sino sobre las posibilidades de cambio en orientación a los principios éticos y morales que se han construido en sus hechizos discursivos que es posible el cambio, vale decir la producción y seguimiento de otras emociones como las mencionadas hasta este punto, permitiendo entonces en el reconocimiento de los otros y en el ejercicio de la autonomía, la posibilidad del cambio y lograr alcanzar los principios morales.

Acorde con lo presentado hasta este punto es clave reconocer como es a través de las emociones que se guía la producción de sentido y valoración de las acciones que se materializan en los hechizos discursivos, es decir, más que un proceso racional como forma del conocimiento, aquí se trata de reconocer las formas del sentir como forma de conocimiento, que nos lleva a construir y consolidad decisiones prácticas, pero además las emociones al estar profundamente vinculadas con los marcos mentales en los que se materializa el hechizo discursivo, queda en evidencia las formas en que producimos sentido. Ahora bien, a lo largo de los tiempos existe y a existido un reconocimiento a patrones o acciones del hombre donde se presenta de forma más potente las emociones.

Se tratará del arte, es en el arte donde se deja en evidencia esta forma del conocimiento, que como vimos puede ser tan o más potente que la racionalidad, en especial por su profundo relacionamiento con los marcos mentales en los que se produce y materializan nuestros hechizos discursivos. Es el momento por lo tanto de reconocer una forma de arte con todas sus singularidades, tal vez una de las formas de arte más viejas, que acompañan al hombre desde su nacimiento como especie, se trata de la música. 
Es tan potente esta forma de arte, que como se evidenció en apartados de este documento, ha sido la música un elemento de especial interés en el estudio de problemas cerebrales, constituyendo campos como el de la musicoterapia, no obstante, en este campo no se quiere observar patologías, se quiere dejar en evidencia los profundos efectos que tiene sobre el conocimiento las emociones que se producen y evocan desde la música, como lo evidencia el trabajo Musicophilia (Sacks, 2007), además no es gratuito que Heinrich Christoph Koch un importante compositor Alemán, definiera la música como "Música. Con este (...) término se designa hoy en día el arte de expresar los sentimientos mediante sonidos" Koch en (Dahlhaus \& Eggebrecht, 2012, p. 20), es el momento por lo tanto de adentrarnos en las particularidades del discurso musical.

\section{Estribillo 3}

En el estribillo anterior, reconocimos nuestra experiencia vivida sobre la canción "Hurt", ahora es el punto de lograr reconocer que es en esa experiencia singular donde se producen o evocan una serie de sentimientos y pasiones que se sienten en el cuerpo a partir de la experiencia sonora.

Sin lugar a dudas, la canción "hurt" evocara alegría que nos lleve a bailar eufóricamente a lo largo del espacio en el que nos encontramos escuchándola, no sólo su armonía, melodía, ritmo y timbre, nos evoca otro tipo de experiencia, sino que además aquellas formas en que la vivimos en el pasado la cargan de sentido, generando un proceso de avaluación de la experiencia y en ella de posibles acciones.

La música cuenta con una potencia increíble en la movilización de nuestros marcos mentales, como lo observamos a lo largo de este verso, sino que además deja en evidencia nuestros 
hechizos discursivos, preguntémonos por ejemplo, cuantas personas pueden rechazar esta canción en cualquiera de sus versiones por el hecho de ser parte del "mainstream" de la industria cultural musical norteamericana?, de hecho ahora es posible relacionar los sentimientos y pasiones que se despiertan al escuchar "el pueblo unido jamás será vencido" frente a "hurt” de dónde provienen las diferencias?, este verso debería aproximarnos a elementos que nos permitiesen solucionar esas dudas, la clave se encuentra en nuestros hechizos discursivos que cuentan con la potencia de movilizar nuestras pasiones y emociones a lugares que son difíciles de racionalizar, pues precisamente se trata de la ruptura con la idea que plantea que "la racionalidad nos salvará”.

\section{4. verso. El discurso musical}

Adentrarnos en el proceso de comprensión del discurso musical implica el reconocimiento de una serie de particularidades con las que cuenta este espacio, para este fin se han querido establecer al menos cinco esferas específicas, a partir de las cuales sea posible el reconocimiento de esta forma del discurso, permitiendo así consolidar el proceso de objetivación que se ha desarrollado hasta este punto.

Acorde con lo anterior, se trata de las siguientes esferas: I) estructura, II) gramática, III) contexto, IV) subjetividad y V) cognición, todos en relación con la música y su forma de producción, pero principalmente de comprensión, permitiendo así el ingreso a la industria cultural musical relacionada con la distribución, que será la discusión del tercer capítulo. Ahora bien, iniciemos por lo tanto nuestro reconocimiento del discurso musical por medio de una aproximación a la primera esfera: la estructura musical. 
Al establecer la idea de estructura vienen a la mente las discusiones sobre las meta estructuras lingüísticas, sería en este caso un castigo al arte musical, suponer o establecer una forma de construcción similar, o que busque emular el mismo proceso de conocimiento. Así las cosas, se ha querido establecer una forma o estructura que permita dar razón del discurso musical, para lo cual es fundamental iniciar planteando de forma preliminar una noción de música, la cual se relaciona con un conjunto de sonidos y/o ruidos que son organizados en una línea temporal con el fin de representar experiencias, sentimientos y/o emociones por parte de un autor.

Acorde con lo anterior, es posible construir una estructura preliminar de la música, la cual contará con cuatro dimensiones (Copland, 2014), una horizontal, una vertical una oblicua y una cuarta relacionada con el color que se produce en la relación oblicua, es decir que se relaciona con el horizontal y el vertical en todos sus puntos y momentos produciendo una sensación o textura. Se tratará de esta forma de un discurso que cuenta con cuatro dimensiones.

La dimensión horizontal la reconoceremos como la armonía de una pieza musical, en la cual se contempla la interacción de sonidos y/o ruidos unos tras otros en un espacio temporal, es decir, en este escenario se genera una temporalidad de la música, con un inicio y un final determinado por la armonía como una dimensión que establece el horizonte del discurso musical. En este caso la relevancia no se encuentra en el grupo de sonidos y/o ruidos que tienen lugar en un momento de la pieza musical, sino la forma en que se desarrollan en su totalidad en términos de tiempo de desarrollo.

Ahora bien, se requiere de la segunda dimensión, donde se trata de un corte vertical como dimensión, en este caso nos aproximamos a la polifonía, pues el interés ya no se encontrará en el desarrollo temporal de los sonidos y/o ruidos, sino de aquellos que se encuentran 
simultáneamente en un momento específico de la dimensión horizontal (armonía), así entonces, es en la interacción de estos sonidos y/o ruidos que es posible reconocer la melodía de la pieza musical.

La tercera dimensión de la estructura musical da razón del más complejo pues se trata de una dimensión de orden oblicua; lo que se quiere establecer con la metáfora de lo oblicuo es la relación constante que establece esta dimensión con las otras dos, es decir, en este campo nos interesa la forma en que se producen y reproducen los sonidos y/o ruidos en cada momento de la pieza musical en relación con los otros momentos de la misma, así entonces podemos reconocer la melodía.

Finalmente, la cuarta de las dimensiones se relaciona con lo que denominamos como timbre, es decir, se comprende la textura que se produce en las relaciones de las otras tres dimensiones, permitiendo así la consolidación de la experiencia del discurso, este tipo de experiencia suele ser relacionada con los colores que evoca la música, en sus relaciones entre armonía (horizontal), melodía (vertical) y ritmo (oblicua) ${ }^{17}$. Permitiendo así la construcción de la siguiente imagen:

1. Estructura del discurso musical.

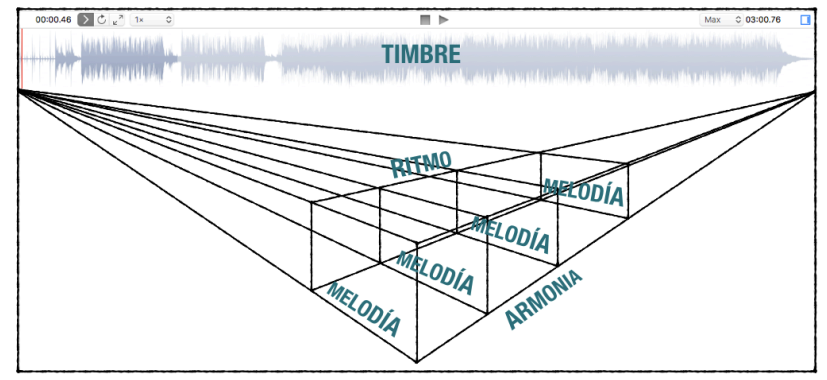

${ }^{17}$ Con el fin de establecer elementos rastreables a lo largo del corpus de investigación, esta estructura se encuentra relacionada con elementos de la armonía para los momentos de las piezas musicales que serán analizadas, teniendo en cuenta el tiempo y la intensidad, estos elementos pueden ser ampliados en los Bonus Track, donde se amplia la metodología de la investigación. 
Figura 1. Estructura del discurso musical, fuente el autor

Este tipo de estructura musical o de relaciones que permiten su estructuración se reconocen en varios tipos de estudios realizados a lo largo de la investigación que se produce sobre el discurso musical, así entonces, por ejemplo es importante reconocer los aportes que surgen desde esta dinámica de interacción de los sonidos y/o ruidos en la racionalidad que se puede establecer en los discursos musicales (Weber, 2015), en la medida que este tipo de interacciones, en clave del pensamiento de Weber, permite reconocer intencionalidades en la forma que se establecen las dimensiones anteriores, en relación con la construcción de un todo.

Ahora bien, si bien esta forma de aproximarnos a la racionalidad de la música en términos de su estructura discursiva es preciso reconocer que "la música (...) puede ser de afectos, pero no de conceptos" (Dalhaus \& Eggebrecht, 2012, p. 56), abriendo un debate trascendental frente al discurso musical, que se relaciona con la subjetividad y en ella lo inefable, que será una discusión que se realizará más delante de forma profunda, por ahora, es preciso dejar indicado que aunque exista una estructura del discurso musical, éste no garantizará la emergencia de elementos propios de un análisis en términos de producción de sentido o de intencionalidad por parte del autor(es) del discurso.

Teniendo en cuenta que existe una estructura musical este tipo de estructura lleva a la producción y consolidación de otro elemento, se tratará de la gramática musical, la cual se encarga de permitir la operación o puesta en escena de la estructura. Es en la gramática musical donde aparecen en escena las notas musicales, en un primer momento de la discusión sobre la gramática, para el caso de Weber, por ejemplo, sólo las notas serán parte de la música (Weber, 2015), excluyendo así la posibilidad de incorporar ruidos en el discurso musical, sin embargo al ingresar en este debate es preciso comprender que el discurso musical no contempla en el caso de 
esta investigación elementos extra-musicales, es decir, la incorporación de sonidos de latidos de un corazón (como en el álbum dark side of the moon de Pink Floyd), o sonidos de ambiente, no se reconocen como elementos extra musicales sino como partes integrales de la música

(Maconie, 2007), sin embargo estos ruidos que se incorporan en el discurso musical no cuentan con una traducción o valor específico en el marco de la gramática musical, en la medida, que en esta se reconoce principalmente las notas, las escalas y la afinación de un instrumento entre otros elementos, que permiten la producción de tabulación o notación musical.

De lo anterior es clave entonces reconocer que en la gramática musical, es posible por medio de una serie de criterios producir la escritura musical, de donde será posible la reproducción de piezas musicales por parte de un interprete que pueda dar lectura de la gramática, que se desarrolla en el campo de la estructura anteriormente descrita.

Ahora bien, el hecho que exista una gramática específica no garantiza la reproducción plena del discurso musical, pues en el ejercicio de la interpretación de la misma, el interprete de un instrumento puede incorporar variaciones que se escapan a la gramática misma (Maconie, 2007), es decir, la gramática musical, se encarga de dejar en evidencia los principales elementos que requiere el discurso musical para su reproducción, sin embargo, abre también posibilidades para la interpretación de la gramática variando los procesos de producción del mismo, pensemos en este caso por ejemplo en la forma en que se puede variar un sonido en la medida que se mueve el dedo en el diapasón de la guitarra al momento de interpretar la nota, modificando de esta forma la intención. De hecho este ejercicio de variaciones en ocasiones se reconocen como arreglos, algunos músicos en este ejercicio han explorado interesantes procesos de singularización en el discurso musical, variando la notación y tabulación del discurso, estableciendo nuevos códigos 
para que el interprete de un instrumento pueda incorporar sonidos, tiempos, a su gusto, se trata del trabajo, por ejemplo, de Jhon Cage, quien por ejemplo a través del silencio de los instrumentos permite la construcción de una obra basada en el silencio para escuchar los ruidos del ambiente, siendo esta una obra única e irrepetible, pues este discurso musical se basará en los sonidos y/o ruidos que se producen en el ambiente de los espectadores (Pardo, 2001).

Para muchos autores musicales y expertos en el tema, se trata por ejemplo de la no ruptura de los elementos estructurales y gramaticales la construcción de la buena música (Dahlhaus \& Eggebrecht, 2012), sin embargo esta buena música se encuentra además en clave de respetar las racionalidades construidas en torno a la estructura y la gramática en momento específicos de la historia, tanto Dalhauss como Eggebrecht, también reconocen que es el contexto el que determinará la calidad de la buena o mala música, dejando así de lado la mirada del cumplimiento de las normas gramaticales racionales del discurso musical.

El contexto en este punto cumple entonces con dos aspectos que vale la pena reconocer, el tecnológico y el cultural. En el primero de ellos por ejemplo es preciso reconocer como el desarrollo de tecnologías permite la modificación de las estructuras y las gramáticas musicales en su puesta en escena, por ejemplo, la construcción de auditorios más grandes para escuchar música en espacios sociales donde la amplificación electrónica no existía, llevó a la modificación de los instrumentos musicales, llevando a la necesidad de construir nuevas formas de notación acorde con la tecnología presente en el instrumento, el caso del piano y sus desarrollos es un caso para comprender este ejercicio, de hecho es una de las calves del trabajo realizado por Weber (2015) y por Maconie (2007). En los estudios realizados por estos dos autores, en especial en el desarrollado por Maconie, se llega a reconocer como la arquitectura juega un rol clave en 
términos de acústica como tecnología del desarrollo del discurso musical, llegando incluso a producirse y construirse edificios que cuentan con afinación en sus espacios para garantizar el sonido apropiado para la experiencia humana, bajo el nombre de "Palladio".

Cuando incorporamos la tecnología como elemento clave del discurso musical, es posible comprender otros fenómenos que para los más puristas de la música serían procesos extra musicales, por ejemplo el hip-hop, que se basa en el break (Wheeler, McFadyen, \& Dunn, 2016), el cual se reconoce como la parte de una canción donde la batería o el bajo es el factor central del fragmento musical, que será repetido de forma constante, sin dejar que otros momentos de la misma pieza musical suenen, de allí que se usen dos discos simultáneos, pasando del break de una canción al otro. Este tipo de ejercicio musical, podría ser reconocido como extra musical, vale decir, el hip-hop no es musical, sin embargo es la tecnología del LP o disco de vinilo el que permite esta forma de experimentación y así el dj o quien maneja los discos, se convierte así, en interprete de un nuevo instrumento, los dos tornamesa con un amplificador que permite pasar del sonido de un disco al otro, produciendo además toda una técnica de interpretación, la cual no cuenta con una notación. Este tipo de ejercicio musical generó un problema en la distribución musical, pues no se podía publicar o distribuir música de estos artistas sin infringir derechos de autor, hecho que llevo a que se generará lo que conocemos hoy como beat-box, es decir un microordenador que produce sonidos que permiten la construcción de los break que ahora escuchamos en los discos que se venden de hip-hop, sin problemas de derechos de autor, así un nuevo instrumento musical aparece en escena.

El contexto tecnológico además cuenta con una profunda influencia en la forma en que escuchamos hoy en día los discursos musicales, al abordar ya no la esfera de la aparición o 
modificación de los instrumentos, sino en términos de la grabación y distribución de los discursos musicales, elemento que se desarrollará mucho más en le tercer capítulo de esta tesis relacionado con la industria cultural musical, sin embargo vale la pena en este momento dejar en evidencia que por ejemplo, la apertura económica en Colombia, no es por casualidad, una de las grandes promotoras del rock colombiano en dos aspectos, el acceso a instrumentos, pero principalmente un sonido característico, efecto de las tecnologías presentes en los estudios de grabación que existían en el país para la década de los noventa del siglo pasado (Bellon, 2010).

Es el momento de reconocer el contexto cultural, el cual de igual forma como pudimos observar se relaciona con el tecnológico, sin embargo en este punto se trata del espacio social en el cual se desenvuelve el discurso musical, como se mencionó en líneas anteriores, la categoría de la buena o mala música, se relacionó con el cumplimiento de los cánones gramaticales, sin embargo, este ejercicio de lo bueno o lo malo de una pieza musical se relaciona más con el espacio en el cual tiene lugar la experiencia de escucha del discurso mismo, es decir, los actos de escucha en relación con el espacio social en que se desarrolla, permiten la consolidación de la bondad o maldad de una pieza musical, lo anterior se puede comprender de forma mucho más clara cuando nos imaginamos una pieza musical de Bach en una discoteca urbana latinoamericana, sin lugar a duda, en este caso pese a la grandeza de Bach musicalmente, esta será una mala música en su contexto, tal vez la mejor música en este escenario sea un reggaetón.

Así las cosas, al hablar del contexto cultural en el discurso musical, se trata de la apertura de la experiencia del sujeto oyente en un escenario social específico, hecho que como veremos más adelante, marcará de forma trascendental el rol del discurso musical en la producción de sentidos 
y procesos cognitivos, pues se trata de la apertura a un nuevo componente del discurso musical, la subjetividad.

Para comprender la subjetividad en el arte en general y en la música en particular, es preciso comprender que en estos espacios existe lo inefable (Jankélévitch, 2005). Es decir, en la música existen elementos que no son posibles de establecer como proceso significativo en clave de significación unívoca, vale decir, en la música existen muchos elementos como arte, que no se pueden comunicar, de allí su valor inefable, que se escapa de cualquier análisis o desarmado por medio de su estructura, gramática y contexto.

En gran medida el aspecto inefable o incomunicable de la música se encuentra en la subjetividad del oyente, es decir, en gran medida la experiencia del escuchar una pieza musical se relaciona con la experiencia vital del sujeto en su historia de vida, haciendo entonces que el discurso musical, cuente con importantes elementos inefables, es decir, abre una discusión de gran profundidad, se trata de la incapacidad de establecer elementos positivos en las relaciones que se establecen en grupos de sujetos mayoritarios con el discurso musical, pues es la experiencia y en ella la subjetividad la que permite construir el sentido y la significación sobre el discurso musical a través de las diferentes piezas musicales, como observamos en el desarrollo de la memoria, las pasiones y sentimientos en la consolidación del hechizo discursivo.

De lo anterior, se puede explicar que una pieza musical pueda contar con sentidos diferenciados para diversos sujetos, evocando la misma pieza sentimientos y emociones contrarias (Jankélévitch, 2005), en la medida que es la experiencia de los sujetos la que permite llenar de sentido la pieza que se escucha. De nuevo la relación entre la buena y la mala música entra en escena, pues ya no sólo el contexto determina la bondad o maldad de una pieza en 
especial, sino que además la subjetividad y las experiencias previas del sujeto en su mundo llenan también de sentido esa posibilidad. Lo anterior puede ser además observado en casos donde como se señaló en párrafos anteriores, existen personas que se encuentran perseguidas por la música, llevándolos incluso a desarrollar ataques de tipo epiléptico al escuchar determinados ritmos o géneros musicales (Sacks, 2007).

Como se puede observar al adentrarnos en el campo de la subjetividad, en el discurso musical, las pasiones y las emociones que se desarrollaron en otros apartados de este documento, vuelven a escena, en este caso como parte integral del proceso de significación, pues es en esos elementos cognitivos donde el discurso musical puede contar o no con una valoración relevante en la experiencia vital de los sujetos, llevando en ocasiones a poder producir procesos de singularización, donde se podría volver a mencionar el caso de Jhon Cage, como ejemplo que permite evidenciar los procesos que piensan el pensamiento no pensado, abriendo nuevas posibilidades de experiencia frente a este caso la música.

Es preciso en este punto, señalar una particularidad de los sentidos con los que cuenta el hombre, la visión, el tacto, el olfato, el gusto y la audición, la última de ellas es clave para el discurso musical, pues éste es principalmente escuchado, ahora bien, es clave en términos cognitivos señalar que el sentido que primero se activa en el hombre (incluso antes de nacer) es el oído (Maconie, 2007), así las cosas, el primer sentido que vinculamos en nuestra experiencia con el mundo es el oído, de allí su gran relevancia en la construcción de procesos cognitivos, de hecho es el principal sentido que nunca se apaga en la vida humana, mientras dormimos el oído se encarga de brindarnos información que puede de hecho interrumpir el sueño. La música y por 
lo tanto el discurso musical cuenta con una gran influencia en nuestros procesos cognitivos, en nuestros hechizos discursivos.

Existe una mirada que permite justificar las líneas anteriores, Platón fue reconocido por odiar la música por dos aspectos, por ser nomológico y segundo, por su capacidad de distraer entre las melodías a los ciudadanos de los aspectos relevantes de la república (Jankélévitch, 2005). Miremos estos dos elementos un poco más a fondo; en el primero de ellos es clave comprender que la música no evoca o produce dialogo, se trata de un esquema en el que se construye un oyente que escucha más no que interactúa con el discurso musical, tan sólo puede escucharlo, pero además, éste se encuentra compuesto de tal forma que puede incluso evocar colores o sabores, recordemos la discusión sobre la sinestesia que se generó en líneas anteriores a causa de los trabajos de Sacks (2007), permitiendo lo que para Jankélévith es una suerte de embrujo, vale decir en nuestro caso un hechizo.

Es el hechizo o embrujo que produce la música lo que llevaría a Platón a plantear su inconformismo con este tipo de arte, pues mientras las personas -ciudadanos- se encuentran bajo sus efectos, pierden la capacidad de pensar o de actuar en razón a aquellos elementos que son relevantes para la república (Jankélévitch, 2005), se trata por lo tanto de una mirada que nos recuerda la noción de falsa conciencia del capítulo anterior, o si se quiere, de formas de realidad, conformadas por la violencia simbólica y subjetiva, no obstante el mismo Jankélévith (2005) además de otros autores como Carmen Pardo (2001), dejaran en evidencia que esta forma de hechizo puede ser funcional también para la producción de procesos de singularización, como es el caso de la obra sobre el silencio de Jhon Cage, que se mencionara en líneas anteriores, o el 
caso del Punk que rompe con el escenario del rock ingles -principalmente- a través de la modificación de la forma de interpretación de los instrumentos.

En últimas, se trata aquí de resaltar el valor que tiene la música y por lo tanto el discurso musical en la intervención del hechizo discursivo, en especial, al comprender las relaciones que éste tiene con los procesos cognitivos, de lo cual es posible comprender que no sólo Platón pensó en la capacidad de hechizo de la música, sino que además también agencias de seguridad han pensado lo mismo, pero en línea con la posibilidad de ruptura del orden establecido, así por ejemplo, el FBI en Estados Unidos de América, declaro que ciertos tipos de música y cánticos de los sindicalistas operaban como mecanismos de "lavado de cabezas", llevando incluso a la pena de muerte a canta autores de música protesta a inicios del siglo pasado (Lynskey, 2011), o en el caso de Chile se prohibió la música con contenidos ideológicos en la política pública de cultura bajo la dictadura de Augusto Pinochet (Gobierno, 1992).

Lo inefable de la música implica al mismo tiempo poner en tensión de nuevo la capacidad del discurso musical, es decir, si la experiencia del sujeto en el mundo es clave en el proceso de significación de este tipo de discurso, es posible asegurar que no opera como lavado de cabezas, para que un discurso musical tenga la potencia de producir movimiento hegemónicos, o por el contrario pueda establecer elementos que permitan la singularización es preciso tener en cuenta al menos que no todo tipo de escucha lo producirá, que al menos es preciso resaltar o reconocer algunas formas diferenciadas de la experiencia del sujeto que escucha los discursos musicales.

En la obra de Theodor Adorno sobre la música, se puede encontrar un especial énfasis en diversos elementos que constituyen este escenario de análisis, estudio y reflexión, donde por ejemplo, las formas de interpretación de los instrumentos juegan un rol de gran relevancia en la 
producción de la música, así como las formas en que se pueden reconocer los oyentes (Adorno, 2006), dejando en evidencia la siguiente clasificación:

I) Oyente ideal. Se trata de aquel oyente que cuenta con una formación en el arte de la música, permitiéndole reconocer las estructuras que conforman las melodías, entre otros elementos característicos del discurso musical. En este caso se trata de oyentes que se enfocan en las estructuras y gramáticas musicales que conforman las piezas.

II) El buen oyente. Un buen oyente si bien no necesariamente cuenta con la formación que le permite comprender las estructuras y gramáticas musicales, cuenta con la capacidad de reconocer instrumentos en las piezas musicales, así mismo puede diferenciar de forma los momentos de las piezas.

III) Consumidor cultural. El oyente consumidor cultural no es un sujeto que pueda reconocer los instrumentos o momentos de una pieza musical, sino que llevado por los procesos de la industria cultural busca la consolidación de colecciones de autores por el placer del fetiche en la mercancía.

IV) El oyente emocional. Este tipo de oyente se relaciona con la música a partir de los sentimientos y sensibilidades que se despiertan en su corporeidad a través del ejercicio de la escucha, así entonces, no busca procesos de colección de las mercancías musicales, tampoco se encuentra en la capacidad de reconocer los instrumentos que son usados en una pieza musical o los momentos de la misma. 
V) El oyente resentido. Se trata del oyente que rechaza nuevos tipos de música, en especial bajo el ejercicio de conservar los valores tradicionales de la música que ha sido construida bajo la mirada de la kulture ${ }^{18}$.

VI) El oyente del entretenimiento. En este tipo se encuentra el oyente que utiliza la música como compañía en la realización de diversas actividades, donde más allá del valor de la música lo que interesa es el ejercicio de llenado de espacios en silencio.

Establecer o mejor, reconocer en el trabajo de Adorno (2006) esta forma de construir o diferenciar formas de oyentes, es importante en la medida que no sólo nos lleva a consolidar la tensión con la idea positiva (en cuanto norma o ley) que todo acto de escucha o toda pieza discursiva musical tiene el poder de modificar los hechizos discursivos, además de lo anterior, es preciso contemplar que un sujeto puede pasar por todos estos espacios o formas de escuchar la música en una misma pieza musical, de nuevo la subjetividad juega un rol relevante en todo este proceso.

Ahora bien, no sólo el tipo de sujeto que escucha tiene un rol de relevancia en este proceso, sino que además el tipo de destinatario pensado también entra en juego de forma relevante, así entonces tomando los legados del análisis de discurso, enfocado en los procesos políticos, se relacionan tres tipos de destinatarios, sobre los cuales se puede asumir la facilidad del discurso

${ }^{18}$ Algunos autores trabajan la diferencia entre la cultura hegemónica como kulture en oposición a la cultura popular. Así entonces en este caso se asume el oyente resentido como aquel que reconoce sólo la música como algo originado en la clase hegemónica. 
en su relación con los hechizos discursivo de los públicos posibles, Eliseo Verón (1996) evidencia: I) Prodestinatario, II) Paradestinatario ${ }^{19}$ y III) Contradestinatario.

I) Prodestinatario. Se trata del partidario político de aquel que realiza un discurso político, ahora bien para el caso del discurso musical un prodestinatario será aquella persona que se encuentra a gusto con un género musical o una banda o artista específico, por lo tanto el ejercicio de este artista podrá contar con una mayor posibilidad de interacción de sus discursos con el sujeto, pues al igual que en el discurso político no tendrá que realizar el ejercicio de convencimiento ideológico en términos de los hechizos discursivos.

II) Paradestinatario. Se trata de aquella persona que: no esta acorde, ni en rechazo, del político que enuncia el discurso. Para el caso de la música se tratará del oyente que no cuenta con una postura clara frente a un género o artista específico, permitiendo así la posibilidad de incorporar el discurso musical en su universo simbólico.

III) Contradestinatario. Se trata de aquella persona que está en oposición con el discurso político enunciado por el actor político. Para el caso de la música se trata de aquel oyente que no cuenta con ningún tipo de proximidad con un género musical o artista, llegando a rechazar el discurso musical proveniente de ese escenario, teniendo en cuenta que en el ejercicio de rechazo también se configura una interacción que tendrá por lo tanto efectos en la singularización del sujeto.

${ }^{19}$ Eliseo Verón reconoce este componente como el tercero, después del contradestinatario, sin embargo por la lógica que se busca establecer en este documento se ha cambiado el orden. 
Nos resta un tercer componente en términos de la subjetividad y en ella de la incidencia en los procesos cognitivos y por lo tanto en los hechizos discursivos, donde es preciso reconocer el rol político del discurso musical. Lo anterior implica establecer que no basta con tener un especificidad en la forma de escuchar el discurso o contar con una proximidad al género o artista, sino que además, el rol que se le otorga a la música como practica comunicativa también será de gran relevancia. Pues en esta práctica es donde la interacción cuenta con mayor fortaleza, en este punto el discurso musical tiene un valor político frente a la vida cotidiana.

La práctica comunicativa es definida por Jair Vega como: “Más que procesos simplemente técnicos se constituyen en un conjunto de elementos que configuran direccionalidades, relaciones de poder, etc., que de manera simbólica llevan implícitas posiciones ideológicas" (Vega, 2015, p. 225), estos procesos llevado al acto comunicativo reseñan la idea de la práctica comunicativa, que en este caso se juega en el proceso de interacción, Jair Vega reconoce tres tipos de prácticas comunicativas (Vega, 2015).

I) Prácticas comunicativas legitimadoras. Son las que se orientan a la continuidad o de hecho repiten los modelos hegemónicos de los procesos comunicativos. Para el caso del discurso musical se tratará de los géneros, artistas y oyentes que no buscan ningún tipo de pretensión o de oposición con el sistema social vigente y los limites sociales instalados por los sectores hegemónicos de la sociedad. Así entonces el uso del discurso musical se relaciona con una práctica especifica en el entramado del universo simbólico, por medio del cual se oculta la violencia del sistema, es decir se reproduce la realidad.

II) Prácticas comunicativas de resistencia. Son las que se orientan como su nombre lo dice a la producción de modelos de resistencia en los procesos comunicativos, frente a los modelos 
hegemónicos. En este caso existe un fuerte componente de denuncia; para el caso del discurso musical se trata por lo tanto de aquellos discursos que buscan evidenciar lo real, o aquel discurso que busca evidenciar la violencia del sistema. Acorde con lo anterior, se trata entonces de géneros, artistas y oyentes que no se encuentran satisfechos con el modelo social y los limites del sistema hegemónico, exponiendo de esta forma ejercicio de crítica a la ideología dominante.

III) Prácticas comunicativas de proyecto. En este caso se relacionan procesos comunicativos que cuentan con un proyecto claro que no se relaciona con los modelos hegemónicos, pero que tampoco busca la producción de un discurso de denuncia y resistencia, concentrado por lo tanto en la construcción y consolidación de su proyecto específico. En este caso, se trata de un discurso musical, donde el género, el artista y/o el oyente busca la producción de sentidos diferentes de mundo, vale decir la transformación de los universos simbólicos, el cambio en el hechizo discursivo.

Así las cosas, la subjetividad y en ella la cognición cuentan con tres campos mínimos reconocidos en términos de variaciones que rompen con las ideas positivas que se han señalado en páginas previas, la forma en que se escucha, el tipo de destinatario que se establece y la práctica comunicativa, ingresan como elementos que permiten reconocer la complejidad del discurso musical, a lo cual debemos además incorporar la característica inefable, que se escapa de estos tres elementos pero que de igual forma son parte en la construcción de sentidos.

Por último, además de los elementos reconocidos en este espacio: estructura, gramática, contexto, subjetividad y cognición, queda un elemento más por reconocer en este ejercicio, se trata de la industria cultural musical, por medio de la cual se realiza el proceso de distribución pero que además como veremos más adelante cuenta con importantes efectos en los procesos de 
construcción del discurso musical en especial en la línea del mainstream y la cultura capitalística, tema que nos ocupara el próximo capitulo.

\section{Estribillo 4}

Para cerrar parcialmente este capítulo es posible ahora, reconocer no sólo los efectos del discurso musical sobre los hechizos discursivos, sino que además podemos reconocer los procesos que se desarrollan al interior de esa relación, donde la experiencia vital, los sentimientos y las pasiones son claves en la consolidación del proceso de significación. Todos estos elementos los encontramos en las dos versiones de la pieza musical "Hurt", ahora gracias a este ultimo verso, podemos reconocer en cada una de las versiones los elementos que la integran en cuanto discurso musical.

Así las cosas "Hurt” para el caso de la versión de Johnny Cash cuenta con una duración de 3 minutos 49 segundos, en su campo armónico, donde interactúan básicamente tres instrumentos, piano guitarra y voz, en cada uno de los momentos se puede reconocer gracias a la melodía como las intensidades varían en la polifonía que se construye, en la interacción de la melodía a lo largo de la armonía podemos reconocer un ritmo, principalmente del orden conocido como country, lento y con momentos de tensión, de donde podremos reconocer el timbre, que podría relacionarse con un campo de color gris, reflexivo, ¿una textura que evoca la tristeza tal vez?, ¿la reflexión?

Este último verso, nos entrega las principales características que serán desarrolladas en clave metodológica para el análisis de los discursos musicales seleccionados para esta investigación, no sólo en clave de procedimiento, sino principalmente en términos de lo que implican en los procesos de significación del mundo y en él de la consolidación de hechizos discursivos. 


\section{Cierre: el hechizo discursivo musical en el idioma de los dioses}

El recorrido que propone "Hurt" como capítulo de este documento, deja en evidencia la forma en que se construye y materializa el hechizo discursivo que se construyó en el capítulo "el pueblo unido jamás será vencido", permitiendo así reconocer las características principales de la forma en que el hechizo discursivo tiene lugar en nuestros cuerpos.

Además de lo anterior, este capítulo permitió la consolidación del objeto de estudio de esta investigación, el discurso musical, el cual se encuentra ahora cargado de una serie de elementos y especificidades, entre las cuales se quiere resaltar la subjetividad, lo inefable, su gramática y estructura, que tienen roles y efectos sobre los procesos cognitivos de los sujetos en las sociedades contemporáneas.

De lo anterior se relacionan dos ejercicios claves a ser resaltados en este punto, se trata de la experiencia vital del sujeto en términos de la construcción y acceso a sentidos al experimentar un discurso musical, pero de igual forma, el poder que éste puede ejercer a su vez sobre el sujeto, llegando en ocasiones a consolidar o promover cambios en las formas que se produce el sentido, espacio en el cual se conectan los dos capítulos, pues es en este sentido, que se posibilita la producción de procesos de singularización.

El arte como se señaló en varios apartados de este capitulo cuenta con un profundo poder en la promoción y generación de procesos de singularización, un motivo por lo cual se puede explicar o comprender este proceso, es en la medida que la creación del arte demanda como su nombre lo dice creatividad, la cual en muchas ocasiones demanda el pensar y actuar por fuera de 
lo establecido, momento en el cual la posibilidad de una singularización es mucho más amplia y posible.

Ahora bien, en el arte y la música en especial, es preciso saber o al menos reconocer no solo la creatividad presente en la creación, sino también como ésta puede verse influida o incluso determinada por los marcos de la distribución, momento en el que el arte pasa de ser ese elemento a constituirse como mercancía, de allí por ejemplo que el hip-hop en sus orígenes no pudiera ser distribuido y comercializado. Así como la música es una de las formas del arte más viejas en acompañar al hombre en su desarrollo, también es tal vez una de las formas del arte que en el hoy en día se desvanece en cuanto arte para configurarse como mercancía, de allí que uno de los principales renglones de la economía en torno a la industria cultural se produzca en torno a la música y su distribución.

Es el momento por lo tanto de iniciar un nuevo recorrido, el de la industria cultural musical, permitiéndonos adentrarnos en las formas en que opera y se produce este tipo de mercancías, pues en gran medida el poder del discurso musical en los hechizos discursivos se encuentra relacionado con los amplios y bastos mecanismos de producción y distribución de las mercancías sonoras. No sólo en el capítulo que nos espera "muevan las industrias” se reconocerá el fenómeno de la industria cultural musical, sino que además nos permitirá comenzar a reconocer el espacio en el cual se desarrollará esta investigación, vale decir el corpus, los artistas y sus lugares al interior de este complejo escenario de lo que denominamos como: industria cultural musical. 


\section{Capítulo 4}

\section{Muevan las industrias: el hogar de la industria cultural musical.}

\section{Introducción.}

El discurso musical no puede ser ajeno a los contextos en los que se desarrolla, como observamos en el capítulo anterior, los contextos tecnológicos, sociales y culturales son una pieza clave para comprender su desenvolvimiento, ahora es el momento de incursionar un poco en procesos de orden económico, en la medida que implican mucho más que un modelo de producción, sino que se relacionan con la consolidación de lo que denominamos en el primer capítulo como la cultura capitalística.

"Muevan las industrias" canción insignia de la historia del rock latinoamericano, de la banda los prisioneros de Chile, es tal vez uno de los mejores ejemplos de las relaciones del discurso musical con la cultura capitalística. La banda nace durante la dictadura militar de Augusto Pinochet, contexto en el cual se ponen en el país del sur a prueba las lecciones económicas de los Chicago-Boys (Mallarino, 2010), es el primer territorio en probar y poner en juego las reglas del hoy conocido neoliberalismo, proceso que traería por su aplicación una crisis económica para el año 1982, donde el número de desempleados en el país crecería rápidamente por un par de años.

En ese contexto, el autor de esta pieza musical Jorge Gonzáles, vocalista de los prisioneros, recuerda un viaje en el metro de Santiago de la capital chilena, donde escribe en un viaje las letras y melodías básicas de la pieza musical, inspirado por el desempleo y por el hecho que uno de los parientes de la banda había sido retirado de su empleo, así surge "muevan las industrias" 
(Álvarez, 2014), pieza que sería parte integral del segundo álbum de la banda, con el cual se daría a conocer a lo largo del continente.

Incorporar elementos anecdóticos en la introducción de este capítulo no es un ejercicio de descripción del origen o la historia tras una pieza musical, se trata de incursionar en una perspectiva del discurso musical, al observar este fenómeno no podemos dejar de lado elementos propios del mismo, cómo es su construcción en cuanto mercancía, que se mencionaría parcialmente en el primer capítulo, es el momento de lograr reconocer su función en cuanto productora de plusvalía y principalmente, de su ejercicio en la construcción de fetiches, a partir de los cuales los procesos de identificación se ponen en escena, para lo cual los circuitos de distribución y consumo son un elemento de gran importancia, pero que no serían posibles sin los procesos de producción, espacios en los cuales se configuran deseos, intensidades del cuerpo y en estas relaciones, la cultura capitalística como expresión del contexto, en el cual se producen y tienen lugar los hechizos discursivos, retomando todos los procesos de producción y sin lugar a duda de distribución de las mercancías.

Acorde con lo anterior, muevan las industrias busca dejar en evidencia el rol del discurso musical en cuanto mercancía, además de establecer una serie de relaciones que permiten comprender las formas en que funciona la industria cultural musical, abriendo finalmente el paso a la presentación de cuatro artistas que serán el foco central del resto de esta investigación. Así las cosas, este capítulo cierra nuestro proceso de objetivación dando paso a un análisis del discurso musical para reconocer en él los posibles procesos de singularización. la pieza que da razón de este tercer capítulo. 


\section{1 verso: la mercancía musical}

Comprender la noción de mercancía implica iniciar con un elemento que será de gran valor en los estudios de la economía política, el origen del valor de una mercancía, es decir, el origen de donde surge la posibilidad de ser intercambiada por otras mercancías, en el caso del proyecto moderno capitalista, por dinero.

Ahora bien, David Ricardo y Adam Smith en sus textos "Principios de economía política y tributación" (1817) y la "Investigación sobre la naturaleza y causas de la riqueza de las naciones “(1776) respectivamente, proponen una interesante mirada en el origen del valor de la mercancía enfocando sus miradas principalmente en los proceso de distribución (el capital) posteriormente será Marx en su texto El capital (2014) quién abordara la doble dimensión del valor de la mercancía; el valor de uso y el valor de cambio, permitiendo reconocer los procesos de producción (el consumo). Es por lo tanto posible reconocer el tiempo socialmente necesario para la producción de las mercancías por parte de los obreros que venden su fuerza de trabajo a los dueños de los medios materiales de producción.

Ahora bien, más allá de iniciar una extensa discusión del orden económico, en este caso la pregunta clave gira en torno a ¿cuál es la mercancía que se comercializa, distribuye y consume en torno a la música? Principalmente cuando comprendemos que la música es una experiencia del orden inmaterial que compromete o vincula los sentidos, las pasiones y los demás elementos que fueron abordados en el capítulo dos al comprenderlos en el marco del discurso musical.

La pregunta nos retorna a la idea de la tecnología, así las cosas la mercancía sobre la cual se fija o construye la industria cultural musical es sobre soportes que permiten la reproducción de la 
experiencia musical, así las cosas, es en la experiencia musical donde se puede encontrar el fetiche de la mercancía, es decir, el agama señala Zizek (Fiennes, 2012) comprendida como la propiedad metafísica no material o positiva que se contiene en la expresión física de la mercancía.

La mejor forma de comprender el punto anterior es mediante un breve recorrido por las formas o mejor, los formatos sobre los cuales se ha basado la industria cultural musical, proceso que es reconocido por Simon Firth (2001) quien al menos reconoce cuatro momentos claves de la Industria Cultural Musical (ICM):

1. La industria de los derechos, especializada en regular el uso de cuerpos humanos para la interpretación principalmente por la memoria, de las piezas musicales. En este punto al no existir aún la notación de la música, su forma de distribución es a partir de los interpretes mismos, en este caso, se regularán los espacios y escenarios en los cuales es posible la producción y reproducción de las piezas musicales.

2. La industria impresa, con el surgimiento de la impresa y la notación musical, rompe la necesidad de regular los lugares de exposición del discurso musical, pues es posible por primera vez, separar la experiencia musical de la necesidad de un sujeto con la memoria suficiente para la reproducción del discurso musical, en la medida que ahora será posible en el hogar reproducir las notas a partir de la lectura de las notaciones musicales. De la mano con el nacimiento de las partituras y la ICM de la impresa, surgen de igual forma con mayor fuerza los negocios vinculados con la producción de instrumentos, en la medida que se amplía el mercado que demanda por estas tecnologías, que ahora serán parte integral de los hogares con los recursos económicos disponibles, tanto para estudiar las formas de la notación musical como la posibilidad de comprar instrumentos como pianos, chelos y violines entre otros.

3. La industria de la imprenta no escrita, donde el surgimiento de tecnologías como el cilindro de cera y posteriormente el vinilo, permitirá contar con una nueva forma de reproducción de la experiencia musical, por primera vez en este caso sin la necesidad de 
un intérprete de los instrumentos, bastará contar con el soporte tecnológico adecuado para la reproducción de estos formatos. En este punto la capacidad de innovación de los artistas y compositores, pasa a ser de gran relevancia en la creación de las mercancías, dando apertura al mercado organizado mediante el star-sistem ${ }^{20}$.

4. La industria electrónica, donde por medio de diversas tecnologías electrónicas como su nombre lo evidencia, se comienza a relacionar la música con escenarios públicos y privados sobre los cuales se construye toda una serie de experiencias musicales que trascienden el espectro específicamente musical, pasando a ser un elemento para otras industrias culturales como la televisión y el cine por mencionar algunas. Así entonces la tecnología requerida para alcanzar la experiencia musical pierde exclusividad, pues un dispositivo puede servir para múltiples usos, entre los cuales está escuchar música, como es una computadora o un celular inteligente, así entonces se inician procesos de distribución relacionados con otros espacios de la industria cultural como se señaló.

Como se puede observar en este breve recorrido por las formas en que se ha transformado la ICM, lo que ha cambiado a lo largo del tiempo son las tecnologías o soportes mediante los cuales se permite la consolidación de una industria que vende en últimas, el fetiche de la experiencia musical, más sin embargo no vende música en sí misma.

De la mano con la ICM y sus formatos es preciso de igual forma reconocer el crecimiento de otras industrias, como es el caso de las relacionadas con la manufactura de instrumentos tanto acústicos como eléctricos y electrónicos, de igual forma, toda la industria construida para la oferta de soportes para la generación de las experiencias musicales, donde podemos resaltar

${ }^{20}$ La industria del satr- sistem se refiere principalmente a la organización de la industria por autores e interpretes que garantizan las ventas de los soportes musicales, se podría pensar por ejemplo en los Beatles, o en Elvis Presley. 
algunas a manera de ejemplo: el disco de vinilo, el casette, el cd y el mp3 como las formas más populares de reproducción de la experiencia musical.

En este punto es clave destacar la doble dimensión que se comienza a desplegar en el marco de la ICM frente al discurso musical, por un lado la mercancía que permite el intercambio, vale decir en este caso los formatos/tecnologías que permiten la reproducción de la experiencia musical, es en estas tecnologías que será posible la composición o reconocimiento del valor de cambio, pues la construcción y producción de éstas requiere tanto de un dueño de medios materiales de producción como de una serie de sujetos que vendan su fuerza de trabajo para la consolidación de la mercancía, de donde se despliega un primer valor, ahora bien, este valor no determina plenamente el valor de una mercancía, sino que requerimos también del valor de uso, espacio en el cual se consolida lo que denominamos en líneas anteriores como: la experiencia musical; finalmente no se trata de adquirir un vinilo por sí mismo, sino lo que encierra ese vinilo en cuanto una experiencia deseada, por ejemplo el vinilo de un gran artista o que modificaría las formas del discurso musical, el álbum blanco de los Beatles, o el Dark side of the moon de Pink Floyd. Es en ese valor de uso, en la posible experiencia musical donde se configura el fetiche por el discurso musical.

Ahora bien, una vez reconocemos que la ICM no se encarga de producir como tal una mercancía sino que se fija principalmente en la producción y reproducción de fetiches en torno a la experiencia musical en sí misma, podemos reconocer los elementos claves de una perspectiva como la de la industria que se basa en el star-sistem, en la medida que no son los vinilos o los diversos soportes lo que permiten la venta de las mercancías, sino los fetiches que se producen 
en torno a los sujetos o bandas que interpretan sobre los soportes discursos musicales, los cuales son ampliamente deseados por grupos de sujetos consumidores.

En este punto al reconocer el fetiche de la mercancía musical como el eje principal de su producción y reproducción, que sólo será posible en la medida que grupos de sujetos consumidores, desea y consume los formatos o tecnologías para la reproducción de los discursos musicales, que la ICM debe organizar la forma no sólo de producir sino también de distribuir los formatos para el consumo, así entonces, nace para su organización la concepción del género musical (Straw, 2001), por medio del cual la ICM puede establecer formas de producción de discursos musicales para públicos especializados, por ejemplo los públicos que disfrutan del Pop, del Punk, Del Reguetón.

La organización de la ICM por medio de géneros no implica en ningún caso que sea, por lo tanto, la responsable absoluta de las formas en que los sujetos producen procesos de identificación o de consumo frente a los discursos musicales, de hecho el mismo Will Straw, en sus investigaciones señala como el mercado musical es de los más difíciles en términos de garantizar el éxito de una mercancía en términos de venta, señalando que cerca del $80 \%$ de los proyectos emprendidos tiende al fracaso en ventas de las tecnologías disponibles para la reproducción de la experiencia musical (Straw, 2001), donde quienes realmente cuentan con el poder para mover la industria sean los sujetos que disfrutan de las experiencias musicales, dejando a la ICM en un espacio de reacción en torno al mercado por encima de una posibilidad real de imponer las tendencias del consumo.

Es clave incorporar esta discusión en la medida que al hablar de los géneros no sólo nos referimos a formas de organización para la producción de las ICM, sino que también es posible 
incorporar diferentes formas de identificación por parte de sujetos que se encuentran presentes en las sociedades que consumen discursos musicales, que podría decirse se trata de todo el planeta tierra. Reconocer por lo tanto, diversos procesos de identificación implica de forma simultánea establecer relaciones posibles entre géneros y formas ideológicas, vale decir hechizos discursivos que establecen las formas de comprender y actuar en torno a la vida cotidiana, como se pudo observar a lo largo del primer y segundo capítulo de este documento.

En este punto, es clave comenzar entonces a reconocer los cuatro artistas que son parte integral de esta investigación, cada uno de ellos seleccionado por ser parte de un género diferente, por lo tanto, de hechizos discursivos diferentes y grupos identitatarios diversos. Se trata de cuatro géneros que además responden a niveles diferentes de existencia en el marco del mercado de la ICM, dos de ellos del orden global, es decir, géneros reconocidos, interpretados y consumidos en el mayor de los planos posibles, mientras los otros dos géneros se relacionan con campos locales, es decir, géneros que dan razón de procesos de interpretación y consumo principalmente de ordenes locales.

En el plano más amplio del consumo se seleccionaron dos géneros, el POP y el Hip-Hop, mientras que para el plano más estrecho se seleccionó el Rock Sinfónico y el Reguetón. Se consolida de esta forma con estos géneros una forma de reconocer diversos espacios o posibilidades de hechizos discursivos, que a su vez dejan en evidencia procesos de identificación por parte de sujetos consumidores de las experiencias musicales. 
Taylor Swift, Una mirada al POP

Es tal vez una de las artistas más conocidas en el marco de la ICM en el género POP de la última década, cantante y compositora nacida en Estados Unidos, quien inició su carrera como cantante del género Country, pero cambiaría su categorización musical al POP.

Taylor Swift, es reconocida por la Billboard como una de las artistas más relevantes de la ICM al contar con 5 canciones como número 1, 22 canciones en el top 10 y 75 canciones registradas en los diversos conteos realizados por esta revista, además la artista aparece en seis listados relevantes de la misma revista, ya no desde sus canciones sino como artista (Billboard, 2018). Hecho que como observaremos más adelante planteará a esta artista como la mayor representante del mainstream del ICM.

Ahora bien, el POP en cuanto género representado por Taylor Swift, es reconocido por dos acepciones, la primera de ella se relaciona el nombre POP con lo popular, comprendido desde la lógica del consumo, es decir, se trata tal vez de uno de los géneros más grandes y que más ganancias produce al ICM; la segunda acepción del término POP, se relaciona con la noción del Pop corn, que en esencia se encuentra íntimamente relacionado con la primera mirada, pues se habla del POP por su relación con el éxito de tres minutos (el tiempo que se demoran los popcorn en el cine para su producción) (Bellon, 2010).

El POP de Taylor Swift busca por lo tanto reconocer en este ejercicio, los grupos mayoritarios de consumo reconocidos como el mainstream, donde se abordan los procesos identitatarios más amplios en clave del consumo y la producción de mercancías musicales en la ICM. 


\section{Lowkey, Expresiones del Hip-Hop}

El hip-hop como género musical tendrá su aparición en New York como expresión de los negros del Bronx, y que después se convierte en un género global que en muchas ocasiones se encuentra como dispositivo de minorías en todo el mundo (Tijoux, 2014), siendo éste no sólo sujeto de la ICM sino que además se produce desde diversos lugares sin la ingerencia permanente de la gran ICM, en la medida que los requisitos técnicos para su producción son tal vez los menos exigentes de todo el panorama de géneros musicales.

Al interior de este género aparece Lowkey, rapero britanico-iraqui, su nombre: Kareem Dennis, quien es reconocido como un activista político de temas relacionados por ejemplo con la ocupación de los territorios palestinos, su activismo no sólo se presenta en el marco del espacio público-político sino que su principal herramienta es la música.

Acorde con lo anterior, en este escenario reconocemos no sólo un género del orden global, sino que además en su interior podemos establecer un artista que no se encuentra en el marco del mainstream, de hecho no aparece en uno sólo de los listados de la Billboard, sin embargo en los círculos del consumo del hip-hop más undergroud es reconocido como un gran artista.

Lo anterior implica no sólo reconocer el género hip-hop, sino además la posibilidad de procesos de identificación ya no sólo con una experiencia musical, sino que en ella se incluyen elementos relacionados con la política y el sistema de organización social, económica e industrial del orden mundial, es decir, se establece un nuevo hechizo discursivo presente en este discurso musical. 
Sobresale en el caso de este artista, el hecho de ser undergroud, elemento que será más adelante en términos de producción y distribución ampliado, dejando incluso en evidencia como algunos artistas dan prelación al rol político por encima del su rol musical, de allí que sea tal vez el artista de esta investigación con menor información disponible en términos de la ICM

\section{Epica, apuestas sinfónicas para el Rock}

Al igual que el Hip-Hop el Rock es de la mano con el POP uno de lo tres d géneros más grandes de la ICM, no obstante, en todos éstos se encuentran sub géneros o expresiones diferenciadas del discurso musical, en este caso el Rock es tal vez uno de los más complejos en términos de sus diferencias y esquemas de organización, pasando desde el rockabilly hasta el trash o death metal, entre otros. Una de las divisiones que se encuentran al interior del rock y que además es de orden minoritario es el rock sinfónico, el cual busca adaptar e incorporar las formas de notación de las armonías, melodías y ritmos propias de la música clásica, con la incorporación de instrumentos del Rock, como la batería, las guitarras, el bajo y las voces, que en este caso incluyen por ejemplo los rasgos guturales del Trash o Death metal.

En este escenario del rock sinfónico aparece la banda Epica, una de las primeras en experimentar y desarrollar este tipo de discursos musicales, oriundos de Países Bajos, incorporan en este género líricas del orden místico, en la medida que esta música al experimentar con los rasgos del discurso musical clásico, el cual en origen tiene importante influencias y nexos con los elementos sagrados de la iglesia católica, al ser objeto de la experimentación del rock, relacionado con lo profano, en sus líricas se consolida también las tensiones no sólo entre géneros sino también entre las apuestas de dos hechizos discursivos diferentes, relacionados con lo sagrado y lo profano. 
Ingresa de esta forma un tercer proceso indentitatario, en esta ocasión desde un género que se reconoce como hegemónico de la ICM o mainstream, pero que en su variación con lo sinfónico se ubica en los lugares no hegemónicos de la producción del rock como género, de allí que en los listados de la Billboard, cuente con tres apariciones en los listados, en ningún de los casos se encuentra en un top 100, son tres canciones que lograron ingresar en los conteos, en los puestos 105, 110 y 139, además no es reconocida como banda en ningún listado (Billboard, 2018), a diferencia por ejemplo de Taylor Swift quien como pudimos observar aparece en seis de los listados de artistas grandes de los procesos de medición.

Maluma, las apuestas del reguetón

En el Caribe Colombiano surgiría a finales de los años 80 y principios de los años 90 el género Champeta, el cual además daría algunos aportes al surgimiento del género reguetón a lo largo de centro américa y el caribe (Giraldo, 2011), de allí que sus mayores expositores sean de estos territorios, entre los cuales, un colombiano cuenta con un gran nivel de relevancia, se trata de Maluma, su nombre Juan Luis Londoño, quien ha ganado premios Grammy por sus producciones musicales.

El reguetón como género musical es tal vez uno de los últimos en aparecer en escena al momento de escribir estas líneas, no se trata como en el caso del Pop o el Rock de géneros que podría considerarse como clásicos dentro de la ICM, dejando así en evidencia la capacidad de adaptación y movilidad de la misma a la hora de reconocer las formas en que los públicos determinan el mercado mismo de la industria, llevando por ejemplo a que este género de un lugar local y de hecho periférico en la producción de discursos musicales, llegue a consolidar no sólo 
un género sino además uno que hoy en día se podría considerar casi del orden global, parecido al origen del Hip-hop.

Ahora bien, el ejercicio anterior se puede observar en la medida que el cantante Maluma, cuenta en la revista Billboard con tres reconocimientos en sus listas, a diferencia de Epica, los tres reconocimientos de Maluma se encuentran en el top 100, tres de sus canciones se han ubicado en los lugares 48, 51 y 87 (Billboard, 2018).

En este caso damos entonces la apertura a el cuarto género sobre el cual sujetos producen procesos de identificación, en este caso de uno que es de orden local, pero que cuenta con procesos de difusión amplio y reconocimiento del orden global.

La mercancía musical en género

Hasta este punto, se reconoció como la mercancía musical se basa en términos de industria en la consolidación de diversas tecnologías que sirven como soporte para su reproducción, sin embargo tal vez lo más relevante no es el soporte sino la experiencia que se genera frente al soporte, la experiencia musical en sí misma, espacio donde reconocemos el fetiche de la mercancía, es decir su propiedad inmaterial en la cual el valor de uso toma su mayor expresión pero además, es en esta característica donde se fija el deseo y en él su posibilidad de consumo.

La mercancía musical entonces, para garantizar sus procesos de distribución (que abordaremos más adelante) se ha organizado principalmente a través de géneros, por medio de los cuales se busca la vinculación con grupos de identificación, es decir, grupos de sujetos que producen identificaciones con estas experiencias en las cuales se pueden reconocer hechizos discursivos específicos. 
Ahora bien, este ejercicio permite además reconocer hasta este punto los principales ejes de la investigación que se desarrolla, en clave de cuatro géneros con unas condiciones específicas y unos artistas que los representan, permitiendo la consolidación de un esquema de producción de sentido específico al interior del universo musical. Podríamos por lo tanto establecer el universo que estudia el "Idioma de los dioses", a partir del siguiente esquema:

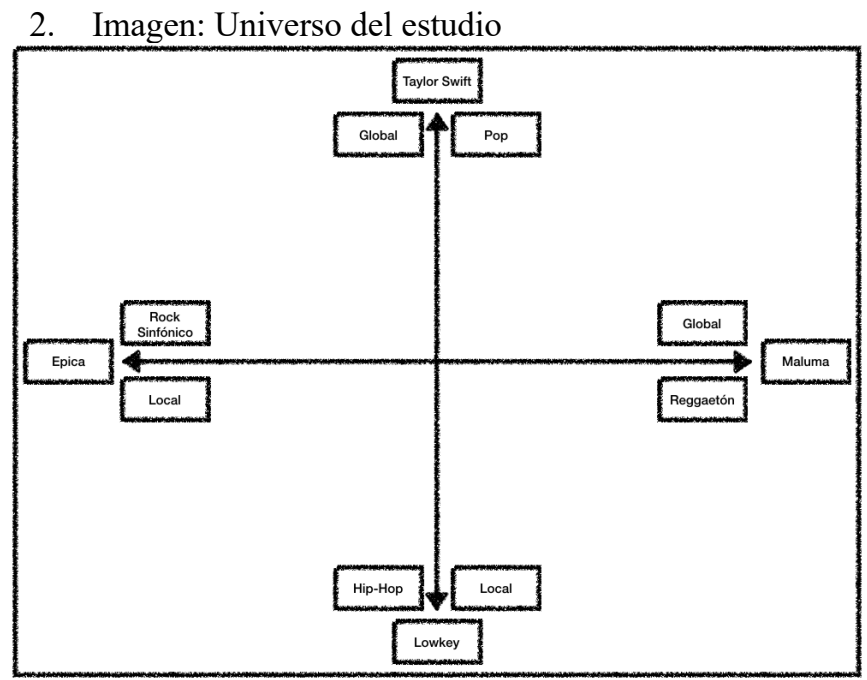

Fuente: Diseño del autor.

Es preciso recalcar en este universo musical se reconocen cuatro hechizos discursivos, cuatro formas de reconocer formas de producción de sentido diferentes en torno a la vida cotidiana, elementos relevantes a la hora de comprender las posibilidades de producción de singularizaciones en cada uno de estos espacios, los cuales además han buscado en su forma de producción reconocer de igual forma elementos relacionados con los planos de lo real y la realidad como se discutió en el primer capítulo, permitiendo de esta forma analizar más adelante los procesos de singularización al interior de campos propios de lo real o la posibilidad del mismo en la realidad. Los ejes representados por Lowkey y Epica, por el origen de sus discursos musicales en clave no sólo de sus líricas sino en sus demás dimensiones del discurso musical 
buscan representar el plano de lo real, mientras que Taylor Swift y Maluma por las mismas condiciones se relaciona con el campo de la realidad.

\section{2 verso: la industria cultural musical - Producción.}

Toda industria se basa en la producción de una mercancía ${ }^{21}$, en la medida que ésta cuente con mayor deseo más exitosa podrá ser la industria misma. Ahora bien, como observamos la mercancía que se produce y distribuye en la ICM se basa principalmente en la posibilidad de permitir la experiencia musical, para lo cual se sirve de varios dispositivos o tecnologías por medio de las cuales se genera el acceso a la experiencia musical sin la necesidad de contar con el conocimiento en torno a la interpretación de los instrumentos.

Ahora bien, esos mecanismos o tecnologías que permiten la reproducción de la experiencia musical requieren de igual forma dos procesos, ambos observados y estudiados por personas como Adam Smith, David Ricardo y Marx, se trata del proceso de producción y el de distribución, ambos conectados finalmente con el discurso musical, en especial al comprender que estos procesos desbordan los límites establecidos como proceso económico, en la medida que permiten o se adentran en lo que Guattari denomina como la producción de máquinas, hombres máquinas que, por ejemplo, pueden desear, es decir, el hombre maquina produce deseo, en él, toma lugar en este escenario la lógica del consumo pero ya no sólo como un mecanismo de

${ }^{21}$ Comprendiendo en este punto que los servicios también son contemplados o comprendidos como una mercancía en ese caso del orden inmaterial. 
satisfacción del deseo individualizado, sino que además en este proceso se configura lo que denominamos como cultura capitalística (Guattari, 2017).

Lo anterior implica reconocer que los procesos de producción y distribución de mercancías en el marco del funcionamiento del capitalismo no escapan de la producción y configuración de los deseos, permitiendo de esta forma reconocer que éstos no son efecto de un sujeto individualizado, sino que tienen y toman lugar en el sujeto en cuanto máquina, que produce constantemente sentidos e intensidades, en las cuales por ejemplo se pueden materializar experiencias musicales.

Ahora bien, en el marco de la cultura capitalística debemos abordar la configuración de un sujeto con un cuerpo específico, el cual Deleuze y Guattari denominan como el cuerpo sin órganos (Deleuze \& Guattari, 2004), donde por ejemplo, la experiencia musical no puede comprenderse como un proceso que se relaciona con un cuerpo que experimenta exclusivamente a través de sus oídos la experiencia en sí, sino que es en todo su conocimiento y pensamiento en el que se materializa la experiencia, así entonces no se trata de un cuerpo compuesto por órganos que definen la experiencia vital, sino que es en relación con el contexto y su consolidación en cuanto máquina que la experiencia puede tener sentido o lugar en la configuración del hechizo discursivo.

De todo lo anterior que sea además clave poder reconocer los procesos de producción y distribución como dos elementos claves que permiten la configuración de los deseos en el marco de la cultura capitalística, iniciemos por reconocer la producción. 
Al margen de la tecnología que se utilizada para distribuir la posibilidad de la experiencia musical (tecnologías o mercancías de la ICM), es clave comprender que hoy por hoy, al producir discursos musicales se requiere de una serie de tecnologías claves. Así por ejemplo sería imposible entender la ICM sin la aparición de la radio, en la medida que es gracias a uno de los artefactos o dispositivos claves de esta industria, basada en el uso del micrófono (Theberge, 2001), el cual será además una de las piezas claves para la producción de los discursos musicales relacionados con la ICM.

La existencia y apropiación del micrófono no sólo para registrar las líricas sino de hecho como parte constitutiva de muchos de los instrumentos que hoy en día alimentan la industria como lo es la guitarra eléctrica, permitieron dar el paso a la grabación de los sonidos y con la aparición de las mezcladoras, el uso de diversos micrófonos para la producción de grabaciones mucho más complejas donde se presentan experiencias musicales posibles para la reproducción mediante tecnologías (Theberge, 2001).

Lo anterior pareciera evidente, sin embargo, un punto relevante poder reconocer como la existencia y aparición de este tipo de tecnologías al interior de la ICM produce no sólo la posibilidad de reproducir la experiencia musical sino que además la puede modificar de forma tal, que pueda ser una experiencia totalmente diferente a la que un sujeto pueda tener al escuchar en un concierto a su banda o artista preferido.

Retomemos la idea anterior, los primeros experimentos con el micrófono para la grabación de piezas musicales, buscaron emular al máximo la experiencia del hombre de frente a la banda o músicos, así las cosas se instalaron dos micrófonos en un maniquí para lograr la experiencia más cercana a la humana (Maconie, 2007). Ahora bien, con la aparición de las mesas de mezcla, se 
comenzaron a incluir más micrófonos y con ellos la posibilidad de modificar la exposición o volumen de cada uno de los instrumentos al interior de la sala de grabación, como resultado, se edita la música y nos alejamos cada vez más de la experiencia humana de la música (Theberge, 2001), pasando al campo de las simulaciones musicales, en cuanto tenemos ahora un simulacro del sonido más allá de lo que se buscó en un inicio, el de repetir con la mayor fidelidad la experiencia de asistir a la interpretación de músicos.

Lo anterior, contará con profundos efectos en términos de la producción de los discursos musicales, pues no sólo la posibilidad de mezclar los sonidos, sino además de emularlos por medios digitales, modifica profundamente la ICM, antes de estas tecnologías era preciso contar con todos los músicos en una sala para realizar la grabación, la cual además se realizaba en tiempo real y se registraba sin la posibilidad de mezclar o cambiar lo registrado, hoy en día un mismo músico puede construir e interpretar todos los instrumentos para después mezclar o cambiar cualquier parte gracias a la digitalización de la música y con ella la posibilidad de mezclar los sonidos, de igual forma por medio de procesos digitales computacionales.

Los cambios no sólo se producen en el nivel técnico sino que éstos cuentan con profundos efectos en términos sociales, es decir, tengamos en cuenta que la mayoría de los proyectos que se inician al interior de la ICM no son un éxito asegurado, por lo tanto es preciso contemplar que entre menor sea el capital invertido en el proceso de producción y mayores sean sus ventas mediante la distribución, mayores serán las ganancias, así entonces al momento de grabar un álbum, entre menos músicos se encuentren relacionados con el proceso, pues se tendrán mayores ganancias posibles, relación contraria a los sujetos técnicos que se incluyen en la grabación de las piezas musicales (Illescas, 2015), es decir, la ICM cuenta con un grupo de personas que 
venden sus fuerzas de trabajo, relacionadas con un saber técnico y son parte de los gastos regulares de la industria, en otro lugar se establecen los músicos, quienes cada vez son menos al interior de la ICM, de hecho se pueden reconocer al menos dos espacios claves de organización de la fuerza de trabajo, la primera encargada de buscar talentos y la segunda de garantizar la calidad de las mercancías ofrecidas al mercado (Firth, 2001).

Al momento de producir discursos musicales en el escenario de la grabación de las piezas, es clave por lo tanto comprender, cuanta tecnología, cuantas personas se encuentran vinculadas con el proyecto, de hecho se ha encontrado que las industrias principales de la música (Sony, Universal y Warner) hoy en día generan sus mayores ganancias por medio de artistas solitarios, es decir, sujetos que son cantantes a los cuales se les contratan los mínimos músicos necesarios para la producción de las mercancías (Illescas, 2015).

Acorde con lo anterior al pensar en la producción de los discursos musicales no sólo contemplamos todos los elementos expuestos en el primer y segundo capítulo, que sin lugar a duda, son parte del proceso productivo creativo, sino que además se deben incluir los procesos propios del ingreso de capital, vale decir, de los recursos y tecnologías que permiten la consolidación del dispositivo o formato que permitirá la reproducción de las piezas musicales.

Teniendo en cuenta lo contemplado hasta este punto es posible establecer algunas comparaciones entre mercancías producidas por los artistas que se presentaron desde los géneros, ahora contemplando en cada uno de los casos un álbum específico, donde sea posible reconocer unos mínimos utilizados en la producción de estas piezas o mercancías que permiten las experiencias musicales de sujetos específicos con procesos de identificación. 
3. Relaciones reconocidas en la creación de un álbum.

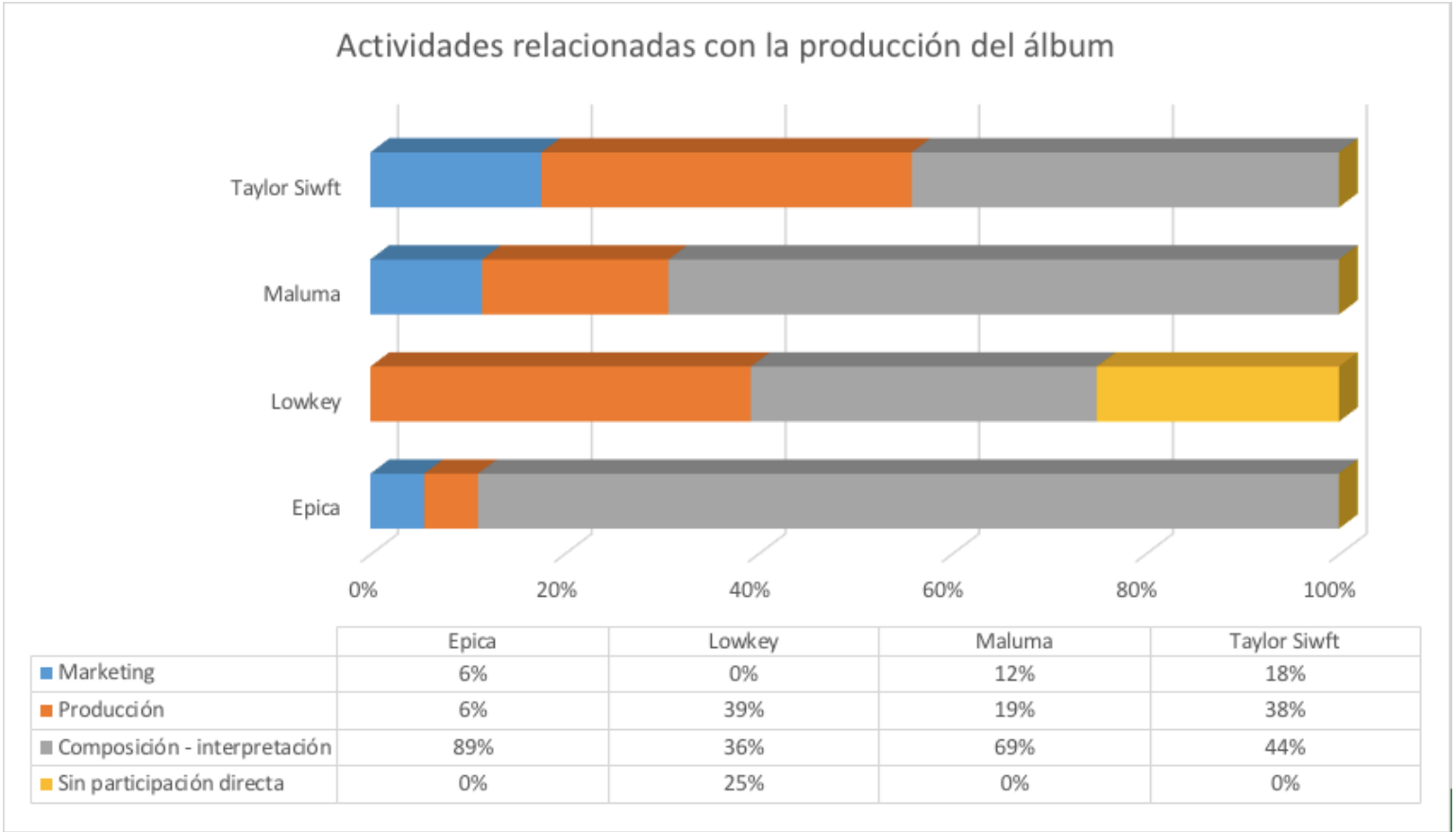

Fuente: Gráfica realizada por el autor con datos de www.allmusic.com

En este ejercicio agregado, es posible reconocer algunos elementos de la producción de la mercancía musical, tres ejercicios de la construcción de las piezas, la primera de ellas la composición e interpretación de las piezas musicales en sí mismas, espacio donde el arte en cuanto tal, tiene su mayor aparición, en el caso del gráfico representado por el color gris, seguido por un segundo campo relacionado con la producción, es decir, la asistencia técnica para garantizar el proceso de grabación, mezcla y fundido final de todas las piezas musicales, representado en el color naranja, en un tercer espacio contamos con un nuevo renglón de la producción de las mercancías, el cual no se relaciona directamente con el proceso de producción o interpretación, se trata del marketing, en color azul, donde se establecen los sujetos relacionados con la composición de los aspectos propios del mercadeo específico del álbum, desde sacar las fotos hasta la producción de las tapas de los discos. 
Resalta en color amarillo para el caso de Lowkey, un ítem denominado como "sin participación directa" se trata en este caso de audios que son utilizados como partes del álbum que son tomados de entrevistas, discursos y seminarios, a partir de los cuales se componen apartados específicos del álbum, así las cosas, se trata de elementos del orden extramusical, pero que efectivamente componen y se comprometen con el discurso musical en desarrollo.

Ahora bien, para poder analizar los ejercicios de producción de las mercancías es necesario poder ampliar la mirada, es decir, reconocer las particularidades de cada uno de los cuatro renglones anteriores para lo cual se han construido las siguientes categorías:

1. Aspectos relacionados en la producción de un álbum.

\begin{tabular}{|c|c|c|}
\hline Bloque & Categoría & Aspecto relacionado \\
\hline Marketing & - & $\begin{array}{l}\text { Todos los actores relacionados con la promoción y consolidación de } \\
\text { la mercancía musical por fuera de la experiencia musical en sí } \\
\text { misma }\end{array}$ \\
\hline \multirow{2}{*}{ Producción } & Productor & $\begin{array}{l}\text { Se trata de la(s) personas relacionadas con la interacción de los } \\
\text { diversos escenarios que requieren de programación de acciones y } \\
\text { procesos para garantizar la finalización del producto }\end{array}$ \\
\hline & $\begin{array}{l}\text { Productor } \\
\text { técnico }\end{array}$ & $\begin{array}{l}\text { Se trata de sujetos con saberes especializados en momentos } \\
\text { específicos de la producción, desde el mezclado hasta el manejo de } \\
\text { pro-tools. }\end{array}$ \\
\hline \multirow{3}{*}{$\begin{array}{l}\text { Compositor - } \\
\text { interpretación }\end{array}$} & Compositor & $\begin{array}{l}\text { Sujetos que componen los elementos que interactúan al interior del } \\
\text { discurso musical }\end{array}$ \\
\hline & Músico & $\begin{array}{l}\text { Sujetos que interpretan instrumentos (incluida la voz) y que son } \\
\text { parte de la banda o artista, puede ser un músico pago. }\end{array}$ \\
\hline & $\begin{array}{l}\text { Músico } \\
\text { invitado }\end{array}$ & $\begin{array}{l}\text { Sujetos que son independientes al artista del álbum, que puede } \\
\text { contar con un reconocimiento específico diferente al artista central } \\
\text { del álbum }\end{array}$ \\
\hline $\begin{array}{l}\text { Sin participación } \\
\text { directa }\end{array}$ & - & $\begin{array}{l}\text { Como se mencionó se trata de elementos o fragmentos sonoros que } \\
\text { incluyen a sujetos que no son relacionados directamente con el } \\
\text { álbum pero son parte integral del discurso musical, por ejemplo la } \\
\text { incorporación de un discurso de un presidente en el marco de una de } \\
\text { las piezas musicales, pero además se les reconocen créditos al } \\
\text { interior del álbum. }\end{array}$ \\
\hline
\end{tabular}

Fuente: Construcción de categorías por el autor.

Como se puede observar, se ha buscado dejar en mayor evidencia segregando los dos elementos claves de la producción de un álbum musical, y al establecer porcentualmente la relevancia de cada uno de los roles encontrados se construye la siguiente imagen: 
4. Sujetos involucrados en la producción de los álbumes.

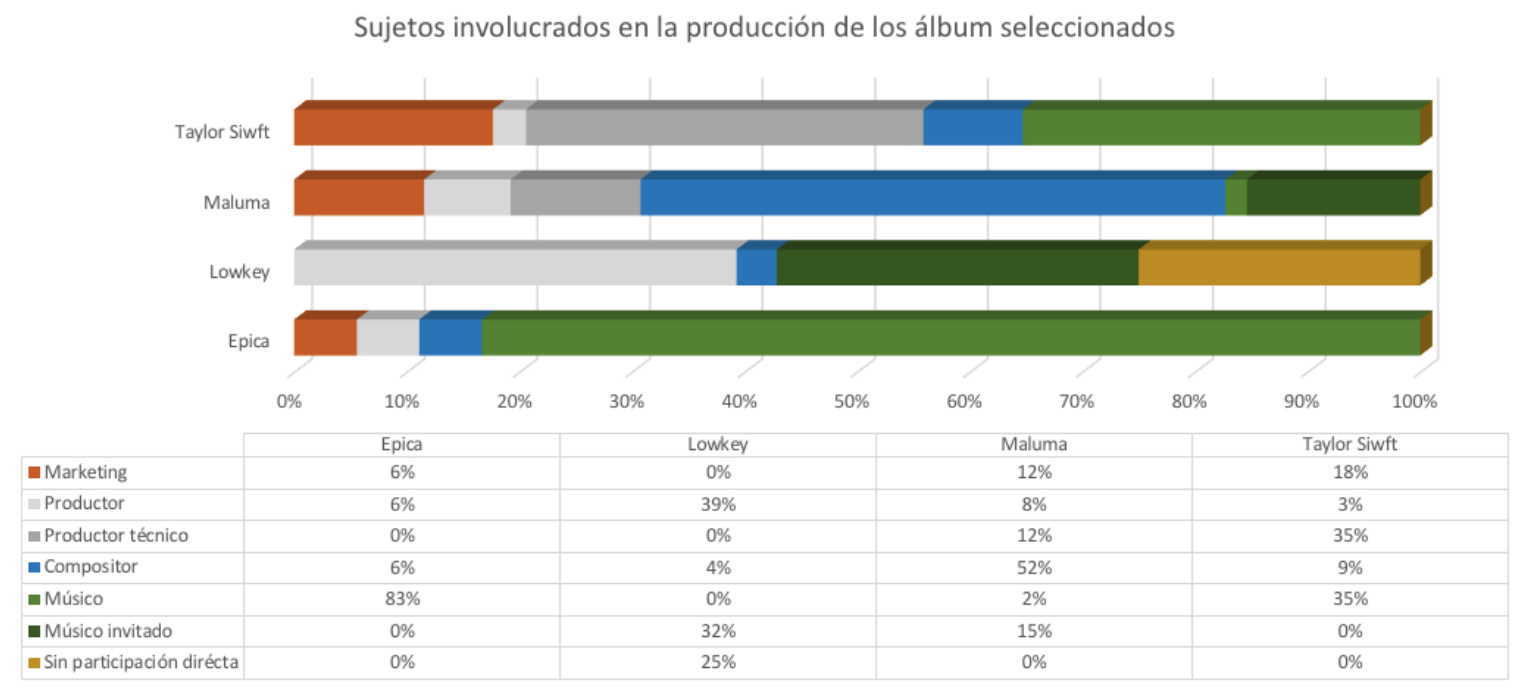

Fuente: Producción del autor de la investigación

Iniciemos este breve recorrido por los actores vinculados con el proceso de producción de las mercancías en análisis, uno a uno, pues las gráficas al presentarse en términos de porcentajes requieren de ciertos niveles de detalles, como por ejemplo tener claro que de los cuatro el que menos personas se relacionan con la producción completa de la mercancía es Epica, con 18 personas de las cuales sólo una se dedica al marketing, mientras que en el caso de Maluma se relacionan 52 personas de las cuales 6 se dedican ese mismo escenario. Aún así porcentualmente las diferencias son evidentes entre los artistas.

En el caso de Epica, que cuenta con el menor número de personas relacionadas con la creación de la mercancía musical, es clave mencionar que 15 de las 18 personas son músicos $(83 \%)$, es decir sujetos que interpretan instrumentos que para el caso del rock sinfónico varían desde la guitarra eléctrica hasta los violines, pasando por voces altas y bajas de coros de apoyo. En este caso se cuenta con un productor de todo el proceso y un compositor, que además es parte de la banda. El álbum “The phantom Agony” lanzado el 5 de julio de 2003. 
Lowkey con su álbum "Soundtrack to the Struggle" lanzado el día 16 de octubre de 2011, fue un álbum que inicio su producción en el año 2009 y finalizó en el 2011, tomando casi tres años para su producción, es el segundo en términos de menos personas vinculadas (28 en total) de las cuales 9 son sujetos vinculados de forma indirecta, como se explicó en líneas anteriores. Sin embargo, cada uno de estos nueve sujetos son parte integral del álbum mediante cortes o fragmentos al interior del mismo denominados como "Skits", por medio de los cuales se conectan las piezas musicales centrales del álbum. Este es el único caso en el que no se cuenta con nadie de marketing en los créditos de su desarrollo, ahora bien porcentualmente es el que mayor cantidad de productores tiene (11), efecto del tiempo de grabación y que prácticamente cada pieza musical fue producida por un sujeto diferente, contó con un solo compositor (Lowkey) y en 9 ocasiones las piezas musicales cuentan con el apoyo de otra voz, especialmente de la cantante Siria Mai Khalil que acompaña varias de las piezas musicales de este álbum.

Hasta este punto observamos los dos artistas que se relacionan con el campo de lo real, es decir que no se encuentran en el campo de lo mainstream, elemento que podremos comprender al observar las particularidades de los dos siguientes artistas, y en ellos las relaciones y tipos de sujetos que son parte de la producción de las mercancías.

Para la producción del álbum titulado “1989” lanzado el día 27 de octubre de 2014, participaron 34 personas, de las cuales seis de ellas se encuentran relacionadas con el marketing del material (18\%), se contó con un productor y tres compositores (12\%), se contrataron 12 músicos para su realización (35\%) y se contó con un apoyo de 12 productores técnicos (35\%). Así las cosas, cuando se contempla los sujetos que interpretan y componen el disco en los términos artísticos se cuenta con la participación del 44\% de las personas, el restante 56\% son 
sujetos relacionados con la técnica para garantizar el sonido adecuado y el marketing, comienza en este caso a dejarse en evidencia la relevancia que se produce en términos de la producción de las mercancías musicales en el marco del mainstream, resalta entonces, el de la garantía técnica del sonido que pueda garantizar las ventas, así la incorporación por lo tanto de un valor relativo de mayor peso en la producción técnica dejando de lado la composición e interpretación.

Cerrando el ejercicio encontramos a Maluma con su álbum "pretty boy, dirty boy” lanzado el 30 de octubre de 2015, donde se involucraron 52 personas para su producción, de las cuales seis de ellas se dedican al escenario del marketing (12\%), se contó con 4 productores y 6 productores técnicos (19\%), llamando la atención de contar con la mayor cantidad de compositores de los cuatro álbumes estudiados, 27 (52\%) multiplicando por nueve la cantidad de compositores utilizados en el álbum de Taylor Swift, la siguiente en uso de compositores con 3 de ellos, finalmente, en clave de lo que se relaciona con la interpretación y puesta en escena de las piezas musicales se cuenta con un músico y ocho artistitas invitados (17\%). En líneas generales es llamativo que la mayor parte de los sujetos que se relacionan con la producción de este álbum se relacionan con la composición.

Ahora bien es llamativo que estos dos últimos álbumes relacionados con la categoría de la realidad dejan en evidencia un uso y vinculación de sujetos que no necesariamente se vinculan con la producción artística, pero que sin lugar a dudas generan un impacto relevante en la consolidación de la experiencia musical, dejando en evidencia las diferencias en términos de producción de un álbum del mainstream, frente a los dos álbumes iniciales que se encontrarían por fuera de este escenario desde la vinculación misma de los sujetos relacionados con la 
producción de la mercancía, pero para poder dar razón completa de este proceso es necesario poder comprender otra mirada del mercado, se trata de la distribución.

\section{3 verso: la industria cultural musical - Distribución.}

En el momento que nos disponemos a trabajar la distribución de las mercancías de la ICM, el primer punto a reconocer es que el proceso se vincula en muchos casos, en especial en el mainstream desde la producción de las mercancías mismas, bajo la categoría que denominamos marketing. Ahora bien, ese mismo espacio nos abre la posibilidad de reconocer dos momentos claves en la distribución.

El primero de ellos inicia en el momento de la producción misma del álbum, con la incorporación de sujetos especialistas en marketing que buscan e incorporan los elementos requeridos para la posterior distribución de la mercancía, llegando en muchos casos a producir otras mercancías en el marco de garantizar la buena distribución del álbum producido, un ejemplo de esto es el documental "some kind of monster" donde se documenta la grabación con todos sus detalles posibles de un álbum de la banda norteamericana Metallica, quien reaparece en el mercado después de más de 5 años sin publicar un álbum, así parte de la estrategia de distribución del disco es la producción paralela y publicación de un documental audiovisual.

El segundo de los escenarios es el más complejo pues en él se vinculan estrategias que ocupan diversos canales y lugares propios de todas las industrias relacionadas con la cultura. Por ejemplo (Straw, 2001) evidencia como el participar en una banda sonora de una película de cine, se transforma en un poderoso gancho para impulsar las ventas del álbum que contiene aquella pieza musical que cautivó a un publico por medio de su presencia en un historia del celuloide, 
por otro lado, se pueden generar nuevas mercancías, no sólo un documental (caso especial) sino que por lo general el single del álbum se promociona no sólo en la radio, sino que además cuenta con la producción de un video musical que hoy por hoy no rotará por la TV sino por sitios de videos como VIMEO, Vevo o YouTube (Illescas, 2015), permitiendo de esta forma promocionar no sólo la canción sino con ella el acceso al álbum, pese a que negocios como el de ITunes, de Apple, al enfocarse en la pieza musical (single) a provocado y llevado incluso a que muchos artistas no produzcan como tal ya álbumes sino que se especializan en singles potentes que garanticen la descarga de millones de copias de las diversas plataformas digitales.

El componente anterior, nos deja en evidencia como la mercancía de la ICM cuenta hoy por hoy con una nueva forma, lo anterior en la medida que los medios digitales amplían su influencia en las formas de acceder a las experiencias musicales, dejando de lado muchos de los procesos que garantizan la posibilidad de producción de plusvalía, llevando a la ICM a un retorno sobre la experiencia musical primaria o en vivo, en la medida que los dispositivos o soportes que permiten esta experiencia dejan de ser rentables en términos de la producción de grandes ganancias.

La experiencia musical en vivo como clave de la distribución de los álbumes y las diversas piezas musicales es hoy en día una de las mayores claves de la distribución del discurso musical (Straw, 2001), se trata del uso, apropiación y generación de festivales de música de más de dos días, en los que se juntan bandas clásicas que garantizan los públicos, a las que se les incluyen otros artistas nuevos, permitiendo así su difusión, pero además en estos eventos se promueve el consumo de mercancías de la ICM que no se relacionan exclusivamente con la experiencia en sí 
misma, se trata de todos los objetos relacionados al artista como: camisetas, pocillos, afiches y un sin numero de posibilidades.

Acorde con lo anterior la ICM, diversifica hoy en día en sus posibilidades de distribución y generación de plusvalía por medio de diversas mercancías, entre las que cada vez pareciera contar con menor relevancia el dispositivo de reproducción. Es justamente en el punto que comprendemos los procesos que se vinculan con la distribución de la ICM, que es posible relacionar en su manera más amplia cómo esta industria representa la idea de la cultura capitalística, donde se borran fronteras de producción antes muy claras, la ICM producía discos, hoy en día, financia eventos musicales, imprime camisetas, traduce páginas web, etc.

Reconocemos por lo tanto que al interior de la ICM, al menos tres escenarios son claves, el primero de ellos el que permite la mercancía central sobre la cual se produce todo ejercicio de producción de plusvalía, se trata de la existencia y mantenimiento del fetiche en clave de la experiencia musical, el segundo de ellos, la simulación del sonido mediante la grabación y lo que denominamos como la producción de la mercancía, lo que nos lleva a este tercer lugar, la distribución de la mercancía en el espacio social. Ahora bien, esa distribución y para garantizar que sean deseadas las mercancías relacionadas con la banda o artista, es clave la consolidación de este en cuanto mercancía o marca.

Observemos que sucede con nuestros artistas frente a los procesos de distribución, es decir, ¿qué tipo de relaciones se establecen por parte de los artistas con los principales canales de distribución de los álbumes que son parte del ejercicio de investigación? 
Los artistas del mainstream, una mirada hegemónica de la ICM

Al observar el proceso de producción se comienza a dejar en evidencia la incorporación de un gran numero de sujetos en la conformación de las mercancías, sujetos que no necesariamente son parte relevante de la experiencia musical, es decir, se podría señalar que, por ejemplo, entre mayor es la presencia de la ICM se reconocen más roles necesarios en la producción de los soportes que permiten la experiencia musical, donde saberes técnicos de sonido son incorporados de la mano con saberes de marketing y promoción. En este caso el trabajo realizado por Maluma y Taylor Swift, permiten reconocer ese tipo de ejercicio en relación con las formas en que se produce el mainstream.

Ahora bien, ese proceso no sólo se enmarca en la producción, sino que será principalmente en el ejercicio de distribución donde se podrá dejar con mayor fortaleza las formas en que la ICM opera en el mercado mundial. Es clave por lo tanto observar algunas particularidades del proceso de distribución en estos dos artistas.

Iniciemos el recorrido por el tipo de soportes tecnológicos que son ofrecidos para alcanzar la experiencia musical de los álbumes de estos dos artistas, tanto Maluma como Taylor Swift, cuentan con la posibilidad de acceder a sus álbumes mediante los dos formatos predominantes del mercado: formatos digitales (mp3, mp4, etc.) y copias en CD (Compact Disc), ahora bien, Taylor Swift permite además el acceso a la experiencia musical mediante un formato especializado para grupos de consumidores en el mercado actual, se trata de los LP (Long Play) también conocido como vinilo.

Al interior de la ICM, los formatos a partir de los cuales se distribuye el discurso musical, reconocen el éxito de los mismos a partir de sistemas de medición que "cuentan” el número de 
ventas de los formatos sobre los cuales se fija el discurso musical que permitirá la reproducción de la experiencia, entre los diversos ejercicios de conteos sobre salen dos en la historia de la música, la primera de ellas, United Word Chart, rastrea las ventas de los álbumes a nivel mundial, reconociendo a Taylor Swift el segundo puesto en ventas para finales del año 2014, con más de cuatro millones de discos vendidos, mientras que Maluma no es parte de este conteo de los 100 álbumes más vendidos.

Principalmente se trata del número de ventas, además, por medio de la industria misma, se otorgan premios por este aspecto, éstos al aparecer en los diversos medios, ayudan a impulsar aún más las ventas, así por ejemplo se encuentra la Recording Industry Association of America (RIAA), quien se encarga de otorgar los conocidos discos de platino al alcanzar un determinado número de ventas, esta organización otorgó a Taylor Swift seis discos de platino, mientras que a Maluma le otorgó uno. A su vez la British Phonographic Industri (BPI), encarga del mercado británico, otorgó un disco de plata, seis platinos y un oro a Taylor Swift, mientras que Maluma no recibió ningún tipo de reconocimiento por parte de esta organización.

Los elementos anteriores, reconocen dos de los marcados más importantes de la música, en ellos se puede reconocer no sólo como la industria genera sus propios premios con el fin de impulsar aun más las ventas, sino que además en ellas se reconocen los avances de las grandes de la producción mundial.

No toda la ICM en clave de distribución cuenta con este tipo de procesos de reseña o de promoción musical, en especial cuando dejamos de lado los mercados que se basan en la compra de la mercancía física musical, e ingresamos al campo digital de la distribución, así entonces por ejemplo el más grande escenario de distribución musical digital paga, es Itunes de la gigante 
tecnológica Apple, donde no es posible encontrar una suerte de escalafón temporal de las ventas y/o descargas de la música que ofrecen en su tienda virtual, en especial al contemplar que el código que utilizan para medir la popularidad de la música, se modifica casi en tiempo real, dejando en evidencia la popularidad de la pieza musical en el momento de la búsqueda, así entonces una pieza que pudo ser muy popular en años anteriores, al pasar el tiempo y dejar de ser buscada o perder la "novedad" de igual forma pierde su popularidad. El punto anterior nos lleva a omitir la popularidad de las piezas musicales tanto en este esquema mainstream como posteriormente se realizará en los discursos contra hegemónicos de la ICM, no obstante es preciso señalar que los cuatro álbumes de esta investigación pueden ser escuchados y/o comprados en la tienda virtual de Apple.

Por otro lado, la competencia de Apple en la distribución musical, puede encontrarse principalmente en los usuarios de otras plataformas tecnológicas, en especial las que se denominan bajo el nombre de Andorid, desde las cuales se accede a la tienda en línea de otro gigante informático Google, al interior de la conocida google play, Taylor Swift cuenta con un poco menos de 18.000 opiniones sobre su álbum, mientras que Maluma contará con un poco más de 11.000 opiniones. El dato anterior parece poco relevante a la luz de las 572 millones de veces que ha sido escuchado el álbum de Taylor Swift en Spotyfi, o los más de seis millones de seguidores con los que cuenta en Drezzer, datos que parecen ser opacados por Maulma, con sus 
más de 867 millones de reproducciones en Spotyfi, y sus poco más de 222 mil seguidores en Drezzer $^{22}$.

A continuación se presenta un breve cuadro resumen donde puede observarse con mayor detalle las particularidades o presencia de estos dos artistas en la ICM y algunos de los canales de distribución que permiten rastrear las formas en que operan estos artistas al interior del mercado internacional.

2. Presencia de los álbumes mainstream (hegemónicos) en los procesos de distribución.

\begin{tabular}{|c|c|c|}
\hline Artista & \multirow{2}{*}{ Taylor Swift } & \multirow{2}{*}{ Maluma } \\
\hline Elemento & & \\
\hline Nombre del álbum & 1989 & Pretty Boy Dirty Boy \\
\hline Año & 2014 & 2015 \\
\hline Tipo de soporte & CD - LP - Digital & $\mathrm{CD}$ - Digital \\
\hline United Word Chart & $\begin{array}{l}\text { Segundo puesto }\left(4^{\prime} 619.000\right) \text { finales } \\
\text { de } 2014\end{array}$ & No registra \\
\hline RIAA & Múltiples discos de platino & Un disco de platino \\
\hline BPI & 1 disco de plata, 6 platinos, 1 oro & No registra \\
\hline Presencia Itunes & $\begin{array}{l}143 \text { puntos de popularidad sobre } 416 \\
\text { posibles }\end{array}$ & $\begin{array}{l}128 \text { puntos de popularidad sobre } 416 \\
\text { posibles }\end{array}$ \\
\hline $\begin{array}{l}\text { Presencia en Google } \\
\text { Play }\end{array}$ & $\begin{array}{l}\text { No. Opiniones: } 17.921 \\
\text { Votos } 5 \text { estrellas: } 15.337 \\
\text { Votos } 4 \text { estrellas: } 1.032 \\
\text { Votos } 3 \text { estrellas: } 450 \\
\text { Votos } 2 \text { estrellas: } 164 \\
\text { Votos } 1 \text { estrella: } 938 \\
\text { Promedio: } 4,7 \\
\text { Popularidad: } 1,4 \text { sobre } 5\end{array}$ & $\begin{array}{l}\text { No. Opiniones: } 11.024 \\
\text { Votos } 5 \text { estrellas: } 9.0002 \\
\text { Votos } 4 \text { estrellas: } 565 \\
\text { Votos } 3 \text { estrellas: } 370 \\
\text { Votos } 2 \text { estrellas: } 150 \\
\text { Votos } 1 \text { estrella: } 937 \\
\text { Promedio: } 4,5 \\
\text { Popularidad: } 1,5 \text { sobre } 5\end{array}$ \\
\hline Presencia en Spotyfi & $\begin{array}{l}\text { Total reproducciones: } 572^{\prime} 675.059 \\
\text { Mín reproducciones: } 8^{\prime} 733.754 \\
\text { Máx reproducciones: } 159^{\prime} 003.485 \\
\text { Promedio: } 35^{\prime} 792.191 \\
\text { Popularidad: } 6,7 \\
\end{array}$ & $\begin{array}{l}\text { Total reproducciones: } 867^{\prime} 939.298 \\
\text { Mín reproducciones: } 8^{\prime} 538.068 \\
\text { Máx reproducciones: } 326^{\prime} 035.492 \\
\text { Promedio: } 54^{\prime} 246.206 \\
\text { Popularidad: } 7,1 \\
\end{array}$ \\
\hline Presencia en Drezzer & $\begin{array}{l}\text { Seguidores: 6'293.676 } \\
\text { Popularidad Max: } 9,08 \\
\text { Popularidad Min: } 5,53 \\
\text { Promedio: } 6,9 \\
\end{array}$ & $\begin{array}{l}\text { Seguidores: } 222.993 \\
\text { Popularidad Max: } 9,2 \\
\text { Popularidad Min: } 5,29 \\
\text { Promedio: } 6,6\end{array}$ \\
\hline
\end{tabular}

Fuente: Cuadro realizado por el autor con información recolectada en las páginas de los servicios de streeming musical y premios en los días 11, 12 y 14 de marzo de 2018.

${ }^{22}$ Los datos señalados en este párrafo fueron recolectados por el autor en los días 11, 12 y 14 de marzo del año 2018. 
El anterior cuadro termina de configurar la posición que ocupan los artistas, en este caso del mainstream, en relación con las ventas de sus discos y las descargas o su popularidad en los servicios más importantes de distribución musical en los escenarios digitales contemporáneos. Sin embargo este elemento tan sólo nos deja en evidencia de forma parcial los procesos de distribución, pues como se señaló en líneas anteriores, las giras de promoción y los festivales son también un ejercicio clave en la configuración de los procesos de distribución de las mercancías que permiten la experiencia musical. Así entonces es preciso en este caso, reconocer las dos giras mundiales que se realizaron por parte de estos artistas.

5. Gira mundial de Taylor Swift

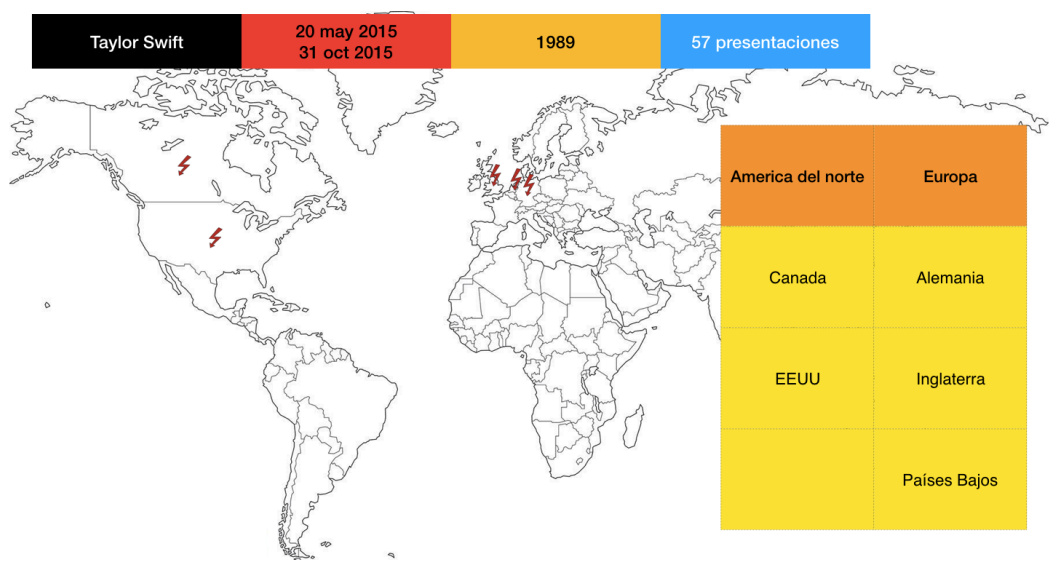

Fuente: Imagen construida por el autor a partir de la información de la gira mundial de Taylor Swift 1989

El primer caso se trata de Taylor Swift, quien realizara en menos de un año 57 presentaciones en cinco países, destacando uno de todos ellos donde se realizarán más de 45 de todas las presentaciones, Estados Unidos. Ahora bien, se trata de una artista que para el momento de esta gira y el lanzamiento del álbum 1989, ya es una persona conocida y ampliamente consumida en el marco de la música en el mercado global, a diferencia de Maluma, quien con el álbum "Preety boy Dirty boy”, inicia su carrera, es decir, este será su primer gran gira en el mercado, motivo 
por el cual su gira de lanzamiento será la más amplia y compleja de todos los artistas que son parte de esta investigación como se puede ver a continuación.

6. Gira mundial de Maulma

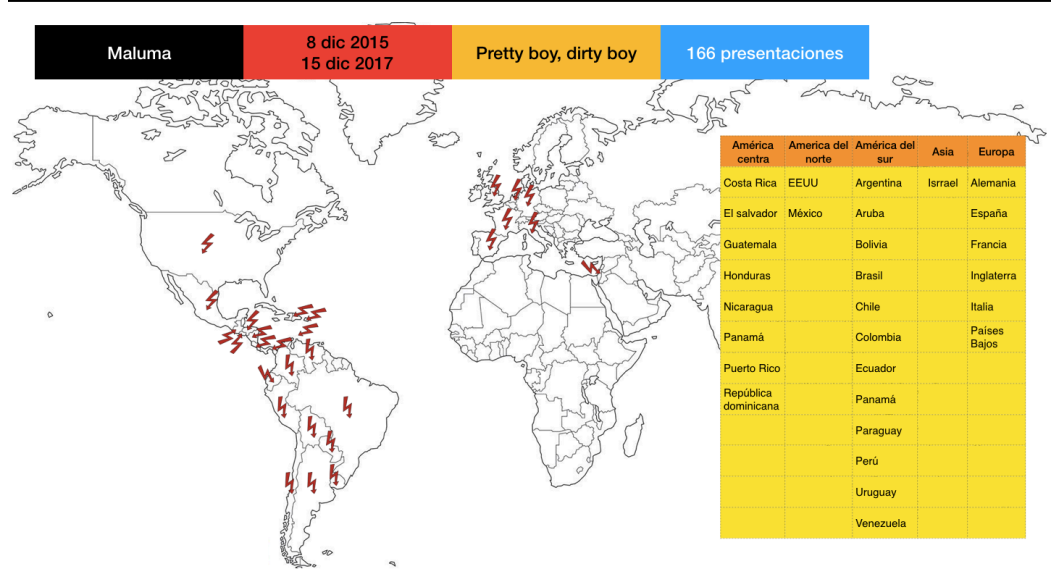

Fuente: Imagen construida por el autor a partir de la información de la gira mundial de Maluma "Pretty Boy Dirty boy"

Como se puede observar, se trata de 166 presentaciones en dos años de gira, visitando 29 países. Es tal vez el caso más complejo, pues no se trata exclusivamente de una gira de promoción del álbum, sino que además en esta gran gira también se incorporan presentaciones alrededor de festivales musicales, 22 en total. Un elemento en común tiene las dos giras de los artistas, y es que en el caso Taylor Swift las presentaciones se producen en grandes escenarios deportivos, igual que Maluma, aunque este último también contará con presentaciones en escenarios de menor relevancia en términos de sus capacidades de públicos, no obstante, la presencia en grandes escenarios para las dos giras son la constante de estos dos procesos de distribución de los álbumes.

Nos resta un componente que se considera clave de las formas de distribución de los discursos musicales de estos dos artistas, se trata de la promoción de los álbumes por medio de la producción de videos musicales, además de la presencia de los artistas en las redes sociales, como estrategias de generar conocimiento no sólo del álbum, de las giras y de los singles que se 
lanzan, sino además de otra cantidad de mercancías relacionadas con los artistas como lo pueden ser camisetas, perfumes, entre otra gran cantidad de posibilidades que se abren en el mercado musical.

3. Presencia en redes sociales de los artistas mainstream (hegemónicos)

\begin{tabular}{|l|l|l|}
\hline \multicolumn{1}{|c|}{ Elemento } & \multicolumn{1}{c|}{ Taylor Swift } & \multicolumn{1}{c|}{ Maluma } \\
\hline Nombre del álbum & 1989 & Pretty Boy Dirty Boy \\
\hline Año & 2014 & 2015 \\
\hline Videos musicales & 9 videos de 16 piezas musicales & 13 videos de 16 piezas musicales \\
\hline YouTube & $\begin{array}{l}\text { Cuenta oficial relacionada con Vevo, } \\
27 \text { '965.175 suscriptores }\end{array}$ & $\begin{array}{l}\text { Cuenta oficial relacionada con Vevo, } \\
\text { 14'331.676 suscriptores }\end{array}$ \\
\hline Facebook & $\begin{array}{l}\text { Página oficial, 73'576.654 peronsas } \\
\text { gustan de la página y 69'905.239 } \\
\text { siguen la página }\end{array}$ & $\begin{array}{l}\text { Página oficial, 23'314.622 peronsas } \\
\text { gustan de la página y 22'735.384 } \\
\text { siguen la página }\end{array}$ \\
\hline Twitter & $\begin{array}{l}\text { Usuario oficial activo desde } \\
\text { diciembre de 2008 con 85,6 millones } \\
\text { de seguidores }\end{array}$ & $\begin{array}{l}\text { Usuario oficial activo desde Junio de } \\
\text { 2010 con 5,4 millones de seguidores }\end{array}$ \\
\hline Wikipedia & $\begin{array}{l}\text { Traducción de su página en 94 } \\
\text { idiomas diferentes }\end{array}$ & $\begin{array}{l}\text { Traducción de su página en 25 } \\
\text { idiomas diferentes }\end{array}$ \\
\hline
\end{tabular}

Fuente: Información recolectada por el autor en las redes relacionadas el día 14 marzo de 2018

Acorde con la información presentada hasta este punto, es relevante observar como estos dos artistas cuentan con interesantes y amplios canales de difusión (distribución) de sus mercancías musicales, teniendo en cuenta además que los dos artistas son parte de lo que se denomina como las tras grandes de la ICM. En el año $2017^{23}$ en las listas de las 100 canciones más escuchadas en Drezzer (Colombia), Youtube y Sopityfi (Nivel mundial), al contemplar las 300 canciones resultantes, el $86 \%$ de la música pertenecía a uno de los tres grandes conglomerados de la ICM: Warner, Universal y Sony music. A su vez Taylor Swift trabaja con la disquera "Big machine" disquera que es parte de Universal Music Group, mientras que Maluma es un artista de Sony

${ }^{23}$ Como parte de la aproximación a este ejercicio investigativo, se rastrearon los listados de estos lugares de distribución de música en línea, permitiendo establecer este tipo de relaciones de la industria cultural musical, la base de datos y sus principales elementos pueden ser referenciados en los anexos de esta investigación. 
Music, los dos por lo tanto cuentan con el apoyo de los grandes de la ICM, permitiendo el ingreso de importantes recursos que permiten la producción y distribución con las características anteriores, ¿cómo funciona entonces la ICM no hegemónica o mainstream? Observemos lo que sucede con Lowkey y Epica.

Los artistas del underground, una mirada contra hegemónica de la ICM

En el apartado anterior cerramos con la idea de cómo Taylor Swift y Maluma son parte de los grandes conglomerados de la ICM a nivel mundial, en una lógica muy diferente se encuentran Epica y Lowkey, quienes por un lado trabajan en disqueras independientes o realizan sus propias grabaciones (caso de Lowkey), estas al parecer, diferencias al interior de la industria, no sólo evidencian las capacidades o recursos con los que se cuenta en la producción de las mercancías, como observamos en el apartado dedicado a este elemento, sino que además cuentan con profundos efectos a la hora de la distribución como podremos observar en este apartado.

Mientras los trabajos musicales que observamos en el apartado predecesor cuentan con premios por sus ventas, los trabajos de Epica y Lowkey no aparecen en el listado de United World Chart, tampoco cuentan con premios por ventas de la RIAA o de BPI, es decir, si se contemplara la existencia de la música exclusivamente por las relaciones que se establecen con este tipo de organizaciones, simplemente estos dos artistas no existirían.

En gran medida al interior de la ICM, el poder contemplar este tipo de premios y reconocimientos implica el contar con amplios recursos que se relacionan desde la producción de los álbumes con sujetos dedicados al marketing, hasta la incorporación de las disqueras de sujetos dedicados a la promoción de los artistas, así las cosas, es notable la diferencia entre, por ejemplo, la realización de conciertos y giras por parte de las y los artistas, en este caso, por 
ejemplo, Lowkey, no realizó giras exclusivas sobre su álbum, más allá de participar en actos políticos en territorios como palestina (según informa WikiLeaks), dejando en evidencia más una postura del orden político que de promoción de su álbum en cuanto mercancía para la venta.

En la línea de la producción del álbum para la venta si se encuentra Epica, quien realizó una gira de 118 presentaciones, prácticamente el doble de Taylor Swift, por un grupo de 12 países en tres continentes, datos que podrían dar a pensar una gran gira mundial, no obstante al rastrear y comparar los lugares de estos conciertos las diferencias son relevantes, mientras Maluma y Taylor Swift, se presentan en estadios de eventos deportivos, arenas dedicadas a conciertos o grandes parques, Epica se presenta principalmente en pequeños bares de ciudades principalmente de países bajos, lugar del cual es originaria la banda.

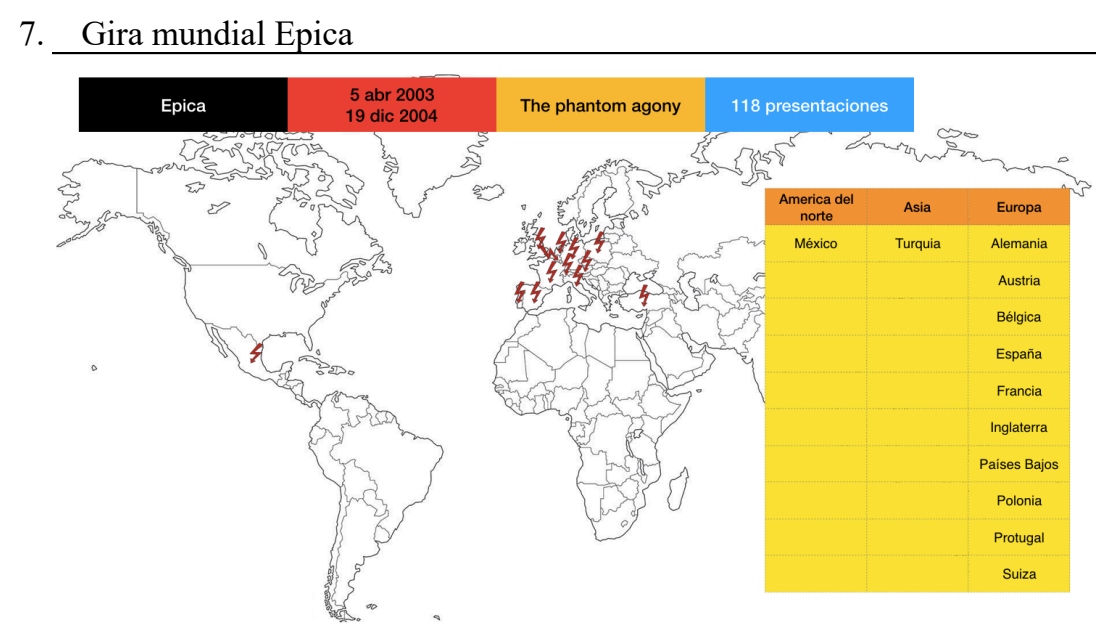

Fuente: Imagen construida por el autor a partir de la información de la gira de Epica "The Phantom Agony"

Acorde con lo presentado hasta este punto comienzan a resaltar las profundas diferencias que existen en el proceso de distribución en el marco de la industria hegemónica frente a los procesos que pueden ser contra hegemónicos o independientes. 
Ampliando el ejercicio realizado con los otros artistas, las diferencias siguen siendo cada vez más notorias, como puede ser observado al contemplar los datos generales que también fueron rescatados en el apartado anterior.

4. Presencia de los álbumes underground (contra-hegemónicos) en los procesos de distribución

\begin{tabular}{|c|c|c|}
\hline Artista & Epica & Lowkey \\
\hline Nombre del álbum & The Phantom Agony & Soundtrack to the struggle \\
\hline Año & 2003 & $2009-2011$ \\
\hline Tipo de soporte & CD - LP - Digital & Digital \\
\hline United Word Chart & No registra & No registra \\
\hline RIAA & No registra & No registra \\
\hline BPI & No registra & No registra \\
\hline Presencia Itunes & $\begin{array}{l}94 \text { puntos de popularidad sobre } 234 \\
\text { posibles }\end{array}$ & $\begin{array}{l}156 \text { puntos de popularidad sobre } 650 \\
\text { posibles }\end{array}$ \\
\hline $\begin{array}{l}\text { Presencia en Google } \\
\text { Play }\end{array}$ & $\begin{array}{l}\text { No. Opiniones: } 611 \\
\text { Votos } 5 \text { estrellas: } 573 \\
\text { Votos } 4 \text { estrellas: } 32 \\
\text { Votos } 3 \text { estrellas: } 5 \\
\text { Votos } 2 \text { estrellas: } 0 \\
\text { Votos } 1 \text { estrella: } 1 \\
\text { Promedio: } 4,9 \\
\text { Popularidad: } 1,4 \text { sobre } 5\end{array}$ & $\begin{array}{l}\text { No. Opiniones: } 169 \\
\text { Votos } 5 \text { estrellas: } 160 \\
\text { Votos } 4 \text { estrellas: } 7 \\
\text { Votos } 3 \text { estrellas: } 0 \\
\text { Votos } 2 \text { estrellas: } 0 \\
\text { Votos } 1 \text { estrella: } 1 \\
\text { Promedio: } 4,9 \\
\text { Popularidad: } 1,6 \text { sobre } 5 \\
\end{array}$ \\
\hline Presencia en Spotyfi & $\begin{array}{l}\text { Total reproducciones: } 13^{\prime} 028.887 \\
\text { Mín reproducciones: } 326.593 \\
\text { Máx reproducciones: } 4^{\prime} 607.444 \\
\text { Promedio: } 1^{\prime} 477.654 \\
\text { Popularidad: } 3,4\end{array}$ & $\begin{array}{l}\text { Total reproducciones: 7'979.495 } \\
\text { Mín reproducciones: } 85.219 \\
\text { Máx reproducciones: 1'035.644 } \\
\text { Promedio: } 319.180 \\
\text { Popularidad: } 2,3\end{array}$ \\
\hline Presencia en Drezzer & $\begin{array}{l}\text { Seguidores: } 276.946 \\
\text { Popularidad Max: } 5,34 \\
\text { Popularidad Min: } 3 \\
\text { Promedio: } 3,7 \\
\end{array}$ & $\begin{array}{l}\text { Seguidores: } 2.736 \\
\text { Popularidad Max: } 3,17 \\
\text { Popularidad Min: } 2,05 \\
\text { Promedio: } 2,9 \\
\end{array}$ \\
\hline
\end{tabular}

Fuente: Cuadro realizado por el autor con información recolectada en las páginas de los servicios de streeming musical y premios en los días 11, 12 y 14 de marzo de 2018.

Como se puede observar en los datos anteriores, las diferencias con los artistas del mainstream son cuantitativamente significativas, diferencias que de igual forma pueden ser observadas al contemplar las formas en que los artistas se relacionan con los otros escenarios de la distribución: 
5. Presencia en redes sociales de los artistas undergorund (contra-hegemónicos)

\begin{tabular}{|l|l|l|}
\hline \multicolumn{1}{|c|}{ Elemento } & \multicolumn{1}{c|}{ Epica } & \multicolumn{1}{c|}{ Lowkey } \\
\hline Nombre del álbum & The Phantom Agony & Soundtrack to the struggle \\
\hline Año & 2003 & 2009-2011 \\
\hline Videos musicales & $\begin{array}{l}\text { 2 videos de 9 piezas musicales; se } \\
\text { lanzó como mecanismo de promoción } \\
\text { un video acústico donde se } \\
\text { interpretan todas las canciones del } \\
\text { álbum }\end{array}$ & 12 videos de 25 piezas musicales \\
\hline YouTube & $\begin{array}{l}\text { Cuenta oficial de la banda, sin } \\
\text { relaciones comerciales con terceros } \\
\text { de la industria, cuenta con 148.199 } \\
\text { suscriptores }\end{array}$ & $\begin{array}{l}\text { No cuenta con cuenta oficial, los } \\
\text { videos son realizados y distribuidos } \\
\text { por la cuenta de Global Faction que } \\
\text { cuenta con 79.139 suscriptores }\end{array}$ \\
\hline Facebook & $\begin{array}{l}\text { Página oficial, 2'237.649 personas } \\
\text { gustan de la página y 2'125.642 } \\
\text { siguen la página }\end{array}$ & $\begin{array}{l}\text { Página oficial, 151.589 personas } \\
\text { gustan de la página y 149.434 siguen } \\
\text { la página }\end{array}$ \\
\hline Twitter & $\begin{array}{l}\text { Usuario oficial activo desde febrero } \\
\text { de 2009 con 238 mil seguidores. }\end{array}$ & $\begin{array}{l}\text { Usuario con el nombre original del } \\
\text { artista (no oficial) activa desde } \\
\text { febrero de 2015 con 25 seguidores }\end{array}$ \\
\hline Wikipedia & $\begin{array}{l}\text { Traducción de su página en 43 } \\
\text { idiomas diferentes }\end{array}$ & $\begin{array}{l}\text { Traducción de su página en 6 idiomas } \\
\text { diferentes }\end{array}$ \\
\hline
\end{tabular}

Fuente: Información recolectada por el autor en las redes relacionadas el día 14 marzo de 2018

Al integrar estos nuevos datos, es de hecho aún más evidente las diferencias en los canales y sus fortalezas como estrategias de distribución de los discursos musicales, en clave de los álbumes estudiados en esta investigación, ahora bien, es clave poder establecer y reconocer las principales diferencias entre los discursos musicales que se encuentran en esta investigación.

\section{4 verso: Miradas hegemónicas y contra hegemónicas de la ICM}

En lo recorrido de este capítulo, se ha logrado reconocer la mercancía musical en la cual se hace presente su fetiche (la experiencia musical), además de la forma en que la mercancía se encuentra no sólo en cuanto materialidad y fetiche, sino que además se buscó reconocer elementos claves de su producción y distribución de las mercancías, éstas comprendidas en su materialidad o soporte a través del cual circulan las posibles experiencias musicales.

En este proceso sobresale la mirada del mainstream, en clave de la lógica de lo hegemónico, comprendiendo como la construcción mayoritaria que se produce en la sociedad, en este caso a 
través del discurso musical mayoritario, como se ha señalado en otros apartados de esta investigación, la posibilidad de la hegemonía requiere de la contra hegemonía, pues al ser una absoluta pierde su capacidad en sí misma, como lo plantea Laclau (2014).

En esta dinámica se puede observar como en los procesos de distribución desde los conciertos que son parte de las giras, los artistas del mainstream garantizan la puesta en escena de sus discursos en grandes eventos con lugares como arenas especializadas en conciertos, mientras que en el caso de lo denominado como contra hegemónico o underground, se trata de bares en pequeñas ciudades o en encuentros políticos (caso de Lowkey).

Pero más allá de los lugares de los conciertos llama profundamente la atención que las redes utilizadas por los artistas del mainstream, garantizan la posibilidad de llegar con sus discursos musicales a bastos grupos poblacionales, por ejemplo, Taylor Swift a través de sus reproducciones en spotify llegó a un grupo poblacional similar a la población de Estados Unidos e Indonesia juntas, es decir el tercer y cuarto país con mayor población del mundo, o si se quiere podría ser la mitad de la población de China. Por su lado Maluma bajo el mismo criterio, sería escuchado por Estados Unidos, Indonesia y Brasil juntos, los países tercero, cuarto y quinto con mayor población del mundo, mientras que Epica alcanzaría a ser escuchada por la población como la del país número 74 según el tamaño de sus poblaciones: Zimbabue, a su vez Lowkey llegaría a la población de una ciudad como Bogotá o la del país número 104: Serbia.

La capacidad de distribución pasa de forma radical a representar por el lado del mainstream los países más habitados del mundo mientras que en el caso de los undergroud se trataría de pequeños países del orden mundial, sin embargo la relevancia no se encuentra en el tamaño de los países, sino, en las probabilidades de escuchar estos discursos musicales en una serie de 
escenarios que no necesariamente se encuentran bajo el control de los sujetos que escuchan o consumen los discursos, en especial cuando retomamos las formas en que estos discursos ocupan los canales de distribución musical digital, en términos prácticos, la posibilidad de escuchar y reconocer las piezas musicales de Taylor Swift y Maluma en un café, en la radio, en el streaming musical son radicalmente más amplias que las de vivir la experiencia de escuchar a Epica o Lowkey en un café de Starbucks.

De la mano con este ejercicio de distribución, es posible entonces reconocer las diferencias que también se reconocen en la producción de las piezas musicales, como se observó en otros apartados de este documento, desde este, se relacionan una serie de actores y sujetos en la producción de los discursos que garantizan los sonidos adecuados para los mercados, bajo la noción de producción técnica, existente exclusivamente en los álbumes de Maluma y Taylor Swift, además de la incorporación de un grupo relevante de personas dedicadas al marketing de los mismos.

Así las cosas en la medida que se abordan los procesos y mecanismos de la ICM, se puede observar y reconocer las materialidades de la cultura capitalística, donde se garantizan una suerte de mercancías que permiten la reproducción del sistema en sí mismo, retomando de esta forma aquella idea que se formuló en el primer capitulo, los aparatos ideológicos del mercado, de la mano con la construcción del hechizo discursivo.

Muevan las industrias, titulo no sólo de una canción de prisioneros sino del capítulo que habla de la Industria Cultural Musical, donde, como pudimos observar bajo los cuatro álbumes que se encuentran en el ojo de esta investigación, se cuenta con recursos apropiados, es decir el capital 
que mueve la industria, los discursos que componemos en clave musical pueden contar con mayores escenarios, públicos y por lo tanto posibilidades de singularización.

Reconocer estos elementos no se trata sólo de observar y ser una suerte de testigos de como funciona la producción y distribución de la mercancía musical, sino además de lograr dejar materialmente algunos alcances del discurso musical, donde además es clave comprender las posibilidades de conocer, reconocer y apropiar diversos discursos, de donde surgen varias preguntas, ¿sí el lector no fuera latinoamericano, reconocería a los prisioneros? De hecho, ¿basta con ser latino para reconocer una banda chilena?

Al moverse las industrias se amplían las posibilidades con las que cuentan los discursos musicales de frente a los hechizos discursivos y por lo tanto también con sus efectos en los procesos de singularización. Por lo tanto nos resta preguntarnos por las principales características en términos de los hechizos discursivos que se contienen y se producen en los discursos de las piezas que comprenden el corpus de esta investigación, es el momento por lo tanto de reconocer cuales son las particularidades de los álbumes de Taylor Swift, Maluma, Epica y Lowkey, teniendo siempre en cuenta sus roles en términos de la reproducción del sistema en el marco de los aparatos ideológicos del mercado y en ellos, la fundamentación de lo que denominamos como cultura capitalística y los hombres-maquina productores, en este caso, de deseos en relación con los discursos musicales y sus hechizos discrsivos. 


\section{Capítulo 5}

\section{Brain Damage: Particularidades de los discursos musicales analizados.}

\section{Introducción:}

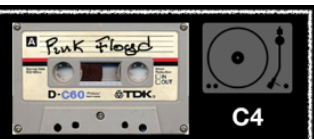

Brain Damage, una de las canciones más místicas de la banda británica Pink Floyd da título a este capítulo, es preciso mencionar como su nombre original fue The Dark side of the moon, nombre que terminaría por darle vida al álbum más vendido de la banda, el cual cierra con Brain Damage y Eclipse. Entre los fanáticos de la banda, existen diversas historias sobre esta canción, se ha optado por una que permite comprender la apuesta de este capítulo, se trata de la experiencia de la locura de uno de los fundadores de la banda, Syd Barret, de allí que la lirica de la canción se encuentre en primera persona, tratando de dar cuenta de la experiencia del sujeto en la locura y las formas de desbordar en sí misma esa experiencia.

Así, en este capítulo se busca establecer la experiencia de los álbumes que componen el corpus de esta investigación, evidenciar a partir del análisis de los planos del discurso musical, aquello que se encuentra en el lado oscuro de la luna, o por que no decirlo, en el lado oscuro del discurso musical.

El capítulo se compone de cuatro secciones, cada una de ellas dedicada a uno de los álbumes, a su vez, cada una de estas secciones se ha organizado mediante la estructura general del documento, por medio de versos y estribillos, en los primeros se busca responder una serie de preguntas, relacionadas con el discurso musical y con los principales elementos de debate establecidos hasta este punto, los segundos -estribillos- establecen los ejemplos, canciones y 
espacios específicos sobre los cuales se configura o se legitiman los elementos de cada uno de los versos, que son establecidos a partir de las relaciones que se encuentran en el plano musical del discurso, es decir desde las dimensiones del tiempo, la intensidad, la armonía y el ritmo como elemento central del análisis permitiendo aproximarnos a una lirica que se encuentra supeditada a los aspectos sonoros, rompiendo por lo tanto con las miradas hegemónicas del análisis de los discursos musicales, donde por lo general, se ha entregado la relevancia casi única a la letra, dejando de lado uno de los elementos más importantes de un discurso musical, su experiencia sonora.

Acorde con lo anterior iniciemos el recorrido por el corpus, teniendo en cuenta, que al igual que en el capítulo Muevan las Industrias, se ha organizado a partir de los discursos que se considerar hegemónicos o mainstream, frente a los contra-hegemónicos o underground que se encargan de cerrar el capítulo.

\section{"Los chicos solo quieren amor si es una tortura"24 Taylor Swift, el discurso musical del}

(des)amor.

El álbum 1989, esta compuesto por 13 piezas o cortes, en las cuales los sonidos son generados principalmente a partir de dispositivos digitales, son pocas las piezas en las que se puede reconocer el uso de algún tipo de instrumento musical diferente a los sintetizadores y los beatbox, recordemos que es una de los álbumes del corpus de trabajo que mayor cantidad de productores técnicos tiene, de allí que el sonido es limpio, es decir, no es posible rastrear ruidos

\footnotetext{
${ }^{24}$ Tomado de la canción "Blanck Space”, segundo corte del álbum 1989 de Taylor Swift.
} 
de interpretación de instrumentos o de ambiente, se trata de un álbum con plena garantía de reproducción de los sonidos que se planearon y construyeron, como si nada quedara al azar, de allí, que, no es posible establecer contextos de los hechos o de las narraciones que tienen lugar en las líricas de las canciones.

Al segmentar las piezas musicales a partir de los cambios en las melodías, en cada una de ellas, se establecen sus singularidades en las armonías y el ritmo, permitiendo así construir una suerte de textura o plano del comportamiento del álbum en su integridad, este se encuentra a continuación:

8. Imagen de las relaciones entre la armonía en relación con el ritmo en los segmentos de melodía del álbum 1989 de Taylor Swift.

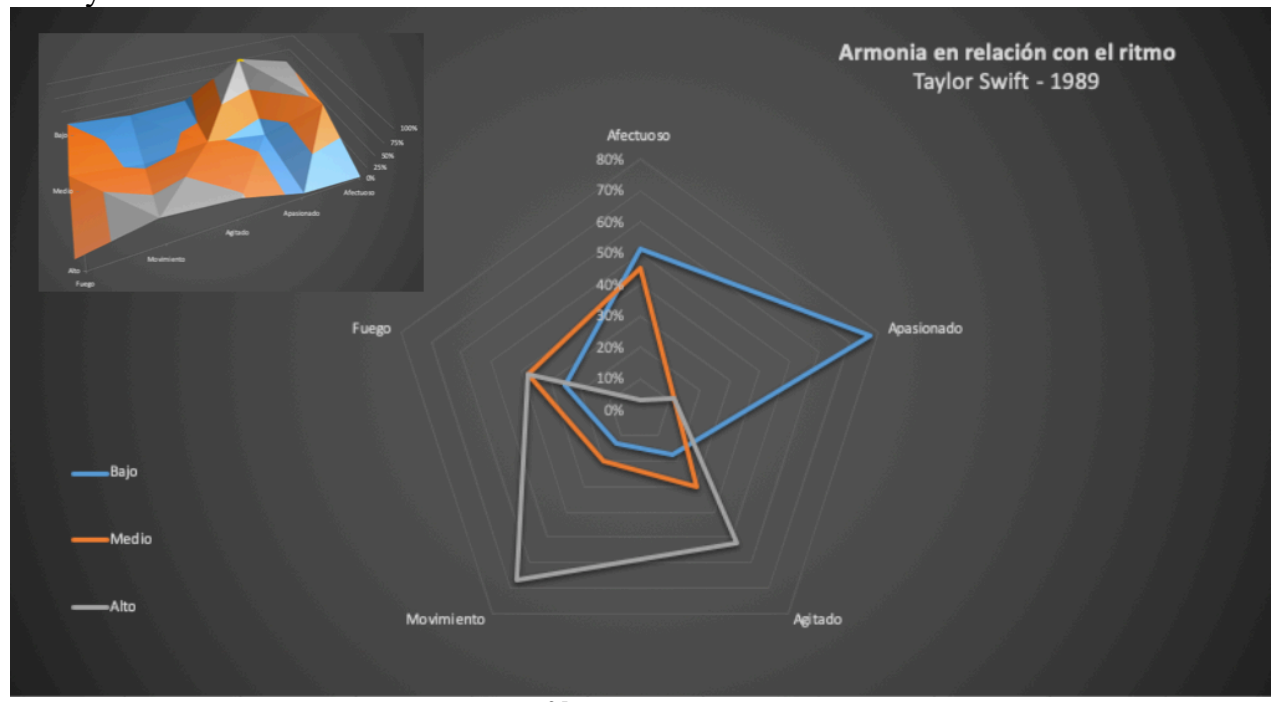

Fuente: Elaborado por el autor de la investigación ${ }^{25}$.

En términos del comportamiento sonoro del álbum la armonía que más se utiliza es la baja, es decir, se cuenta con poca frecuencia o intensidad musical, (en azul en la gráfica anterior),

${ }^{25}$ Para cada uno de los álbumes que componen el corpus de trabajo, se realizó un conteo por medio de frecuencias simples y estadística descriptiva, a partir de la cual se pueden construir las imágenes que representan las texturas de los álbumes de acuerdo al comportamiento de sus dimensiones en los diversos fragmentos que se reconocieron en las canciones. 
relacionándose este tipo de armonía con un ritmo principalmente apasionado y afectuoso, siendo en muy pocas ocasiones la relación con el fuego, el agitado y el movimiento, elementos que como veremos más adelante permiten la consolidación de un discurso específico. Con igual relevancia se puede contar a la armonía media y alta, aunque sus relaciones con los ritmos varían de forma relevante, como puede observarse en la gráfica. En total se reconocieron 120 melodías, o segmentos musicales, que fueron analizados cada uno en su composición musical, además de vincularlo con las líricas en los casos que esto es posible, pues algunos de los elementos melódicos se relacionan con puentes o pasos de un momento de la pieza a otro donde el grano o voz no tiene vínculo o juego.

Ahora bien, para poder comprender de forma mucho más completa y dinámica que implica el análisis desde las armonías, es preciso entrar a los versos que se encuentran a continuación, cada uno de ellos aborda las particularidades del discurso musical de Taylor Swift.

1 verso armonía baja. Los planos de la intimidad: el amor duele.

La experiencia sonora en este campo es de sonidos íntimos, seleccionados, es decir, no se contempla un entramado de sonidos denso, por el contrario son pocos instrumentos, con sonidos distanciados, además de la presencia constante del grano de la vocalista, evocando cercanía, en ocasiones dolor, o melancolía, en general el sonido es muy próximo, como se mencionó, establece una suerte de cercanía entre el discurso y el oyente, incluso en las ocasiones donde el ritmo es fuego o movimiento, pues en estos casos, pese a que cuenta con más fuerza, sigue manteniendo la experiencia relacionada con la intimidad.

A su vez, la lírica, cuando se contempla la armonía baja, el mensaje que se construye se relaciona con la experiencia del amor, en especial, dando razón de momentos de reflexión que se 
construyen en torno a las acciones y hechos que tienen lugar en la relación de pareja, se trata además de una relación heterosexual, aunque, se habla no de una relación sino de muchas, dando razón, por ejemplo, de la memoria y la necesidad de ser recordada. En este punto, es posible observar que a lo largo de este plano existe una heroína o personaje principal de desarrollo de todo el discurso, que habla o mejor, en este momento canta con una textura reflexiva sobre su experiencia en primera persona, dando así la sensación de una mujer que ha pasado por el dolor del amor, y nos cuenta lo que ha pensado y construido en torno a esa experiencia amorosa.

A lo largo de este plano, no se pueden reconocer referencias espaciales o de sujetos específicos, es decir, al buscar en la lírica enlaces o nexos con el mundo, como ciudades, o personajes públicos, no es posible, hecho que podría ser relacionado de la misma forma con los sonidos que se utilizan a lo largo del plano, sonidos que de igual forma son producidos por medio de tecnologías digitales, como lo pueden ser sintetizadores y beat-box, dejando poco espacio para el reconocimiento de instrumentos como percusiones, guitarras eléctricas o acústicas, configurando de esta forma una experiencia tanto sonora en el plano musical como en la lírica, de elementos de ficción, que se enlazan con la vida intima pero que no cuentan con enlaces o referentes directos.

Al contemplar todos los elementos relacionados hasta este punto, frente al plano de lo íntimo con una armonía baja, es posible, establecer algunas particularidades, que, desde ese sonido íntimo con texturas reflexivas del grano, nos habla de una experiencia del amor. Donde el amor es construido como un recipiente, el cual como espacio cuenta con un adelante y un atrás, que se constituye desde el tiempo, así el contenedor cuenta con una espacialidad amplia, donde en el atrás se encuentra lo sucedido y con ello la memoria, que en este caso se relaciona 
exclusivamente con la experiencia de la heroína en el amor; además el recipiente cuenta con una espacialidad del arriba y abajo, en la medida que la experiencia amorosa se establece como el viaje de un avión que sube, cuando todo está bien, pero también puede caer en picada, de esta forma las posibilidades espaciales de movimiento se transforman casi en infinitas, pues el avión como metonimia del amor, puede moverse en prácticamente cualquier dirección.

Pese a lo anterior, el avión (amor), no es plenamente libre en sus posibles recorridos, pues éste se encuentra determinado y conectado con el pasado (atrás), la memoria, así pasa constantemente a ser un recurso que puede orientar los posibles caminos que el avión tomará. Ahora bien, en el avión como metonimia del amor, se reconoce que este no es individual, sino que se construye entre dos sujetos, pero a su vez, ese amor construido por dos cuenta o se le otorga agencia, es decir, se constituye como un sujeto con posibilidades de acción, muchas de ellas se relacionan con la memoria de los dos sujetos en relación al amor, podría decirse, aquellos que ocupan el avión, pero que no lo manejan, pues sus memorias e historias, en especial la de la heroína, pueden frenar, o mover el camino que el avión toma, frente a lo cual se relaciona también como la memoria puede ser lavada, por medio de la lluvia, permitiendo así que el avión no sufra mayores desvíos por causa de la heroína.

Finalmente, al interior de este plano, el amor cuenta con el futuro de producir frutos, que se comprenden como los retoños de una mata, es decir, como flores, pues el amor florece, y para garantizar que esto pueda suceder, de nuevo, la memoria, nos ha permitido reconocer todos los actos, acciones o experiencias que pueden desviar al avión de la ruta deseada, pues existen otros sujetos que desean que ese avión (amor) no llegue a destino, por lo cual, el amor (avión) debe 
variar sus caminos con el fin de poder esquivar a aquellos sujetos que no quieren que todo se desarrolle a favor de quienes ocupan el amor (avión).

\section{Estribillo.}

A lo largo y ancho del álbum 1989 de Taylor Swift, se encuentran fragmentos con armonía baja (en sus trece piezas), sobresaltando algunos casos por una gran presencia de este tipo de armonía, como es el caso de la pieza número nueve (Wildest dreams) y la número once (This love). En algunos casos la armonía baja es utilizada para las introducciones de las canciones y para los espacios sonoros intermedios al interior de las piezas musicales, como es el caso de la pieza número diez (How you get a girl).

Al contemplar el amor como un sujeto, en lo que se plantea como avión, dos piezas son claves en esta construcción, se trata de This Love en sus coros, además de Clean, donde en el coro y en alguna de sus estrofas reafirma esta idea, además en esos mismos espacios se consolida la idea de la lluvia como limpiadora de la memoria. A su vez, la idea del amor con una memoria que puede dificultar el camino o viaje del avión se puede rastrear en el puente de Clean, finalmente las ideas del amor con un fruto, se encuentran en This Love, en sus coros.

La construcción de un amor que se encuentra en riesgo por otros actores, que determinan el movimiento del avión además de la necesidad de ese movimiento es posible rastrearlos en la pieza Shake it off y I Know Places. A su vez, el amor como un sujeto que se mueve y requiere de ese movimiento, es posible encontrar este rastreo en las piezas: New York, Out of the Woods y This love. Mientras que la perspectiva relacionada con el adelante y atrás del tiempo puede ser encontrado en Wildest Dreams y This Love; existen acciones y procesos metonímicos que se relacionan con la experiencia del amor, donde el sujeto con el que se relaciona la heroína es 
desposeído de agencia mediante el reemplazo de él por sus acciones o por sus formas de vestir, hechos que pueden encontrarse en I Wish You Wold y Bad Blood. En estas dos últimas piezas musicales, es posible también rastrear la construcción del amor como un avión en picada cuando las cosas no se desarrollan de la forma deseada.

Es preciso en este punto, contemplar que al tratarse de un discurso musical, la reducción del mismo a lo escrito (lírica) o a su exposición por medio de palabras, puede constituir una forma de reducción del discurso, que así mismo, reduce la experiencia musical (sonora) de allí que en términos de armonía baja se ha construido un ejemplo, de fragmentos de las piezas musicales, a partir de las cuales se ha desarrollado este plano del discurso musical de Taylor Swift, acorde con esto, la invitación en este punto es a escuchar algunos de los fragmentos que permiten este espacio, experimentando de esta forma los sonidos y posibles sentidos que surgen.

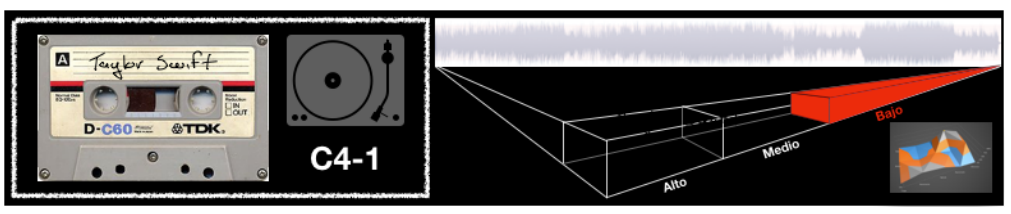

2 verso armonía media. Los planos del territorio: donde amamos.

Al asumir la armonía media, los sonidos son mucho más intensos, un poco más densos, pero mantienen la posibilidad de intimidad, pues la densidad no es agresiva en la escucha, sino que de hecho se relacionan de forma rítmica con el grano, de nuevo la presencia de la heroína en este espacio es de gran relevancia, donde el sonido principalmente de la percusión por medio de beatbox es un componente que resalta, en la medida que tanto el grano como los sonidos producidos por el beat-box parecieran jugar con las mismas frecuencias o tonalidades. 
Bajo la experiencia de la armonía media a lo largo del discurso musical, se evidencian ejercicios musicales que si bien mantienen la intimidad, lo hacen desde una suerte de tensión o presión, es decir, es más fuerte en términos de la densidad, de allí que se construya, una suerte de presión o de relevancia a lo que se expresa mediante el discurso.

En cuanto al ro de la heroína, esta se encuentra incorporando en este caso un referente importante, se trata del espacio urbano en negación del rural, además de establecer el urbano con un referente conocido a nivel mundial, la ciudad de New York. Así se comienza a orientar el viaje del avión (amor) hacia un espacio urbano, como lugar en el cual se puede desarrollar, pues en medio de la congestión y el desorden es posible ocultarse (de aquellos que se encuentran en contra posición de la relación), esa estrategia de ocultamiento en lo urbano, no es posible en el marco de lo rural, garantizando que se establezca una idea de destino, el cual se encuentra adelante, siempre hacia el futuro, dejando sin posibilidad el presente, pues hasta este punto se cuenta con el pasado (atrás) que se liga a la memoria y las experiencias fallidas del amor, y un futuro, como destino de la relación (donde se podrá florecer), y en la ciudad el lugar del ocultamiento para proyectarse al futuro.

Además de lo anterior, al interior del avión (amor) donde se encuentran los dos pasajeros, el destino del camino, se relaciona con un juego, donde se cuenta con reglas como lo son la dominación y el poder, y como elemento de puja del juego o premio, se encuentra la heroína, de allí que en el avión puedan pasar varios pasajeros a acompañar nuestra heroína, que como premio, reconoce y se otorga al ganador, a partir de leer o construir sus compañeros desde sus acciones y las formas de vestir, como ejercicio de lucha o de saber si merecen o no el premio (ella misma). Aquí la memoria es la que sirve como elemento de evaluación de las acciones y 
formas de vestir de aquello que quieren ser pasajeros de la relación, por lo cual en ocasiones la heroína quiere lavarse con lluvia la memoria, pues ésta le impide que algunos buenos candidatos a pasajeros puedan continuar con el viaje. Finalmente el destino es descrito o construido con la idea del hogar, la casa, así el viaje del avión de llegar a buen destino, será el hogar urbano donde los dos pasajeros podrán estar.

\section{Estribillo.}

Al interior de este plano se cuenta con la presencia de prácticamente todos los cortes del álbum, a excepción de: Wildest Drems, How to Get a Girl y This Love, donde principalmente se encuentran relaciones con segmentos musicales donde se desarrollan ideas (estrofas) al interior del discurso musical.

La construcción en torno al juego del amor donde ella es reconocida como el premio, es posible rastrearla en la pieza Blank Space, mientras que la construcción en torno a poder borrar la memoria se encuentra en Clean, a su vez la referencia y construcción de lo urbano (New York) esta en la pieza Welcome to New York, reconocer o reemplazar los sujetos posibles del amor por sus acciones y formas de vestir se pueden rastrear en la última pieza citada en este párrafo además de en Style.

Uno de los elementos que surgió se relaciona con la memoria y como esta puede ser modificada para que el destino pueda cumplirse, este elemento se encuentra en piezas como Out of the Woods, All you need to do was saty, I Wish you Wold y Bad Blood. Recordando la idea del destino como el hogar, el cual se encuentra relacionado con dos piezas, Style y I Wish you Wold, en ésta última se relaciona con los coros, elementos que se repiten y por lo tanto cuentan con una relevancia especial. 
Los elementos relatados en este estribillo, pueden ser ampliados, igual que todos los estribillos de esta capítulo en los BonusTrack de la investigación, donde se ha construido una serie de matrices y gráficas que amplían y evidencian el detalle para que el lector que lo desee pueda entrar a los detalles más específicos, de igual forma se ha construido un breve ejemplo relacionado con este tipo de armonía en el discurso musical de Taylor Swift.

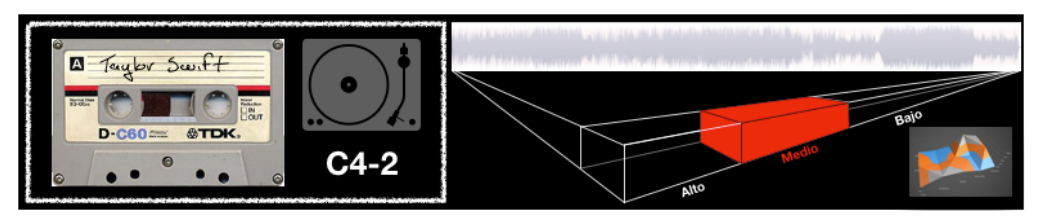

3 Verso armonía alta. Los planos de la seguridad: el lugar confiable para el amor.

La experiencia sonora en este caso, se enmarca en la mayor densidad de sonidos, principalmente por apoyos en el grano, es decir la lírica cuenta con varios planos de sonido, apoyando con notas de voz, por ejemplo, así como frases o palabras que de fondo del plano sonoro se incorporan y producen una suerte de sonido más drástico, en este caso, más concentrado sobre el grano de la vocal (Taylor Swift) que en los sonidos de instrumentos, así entonces, aunque se vuelve más denso el sonido, este efecto es principalmente efecto de varios granos al tiempo, recordando la idea de múltiples sonidos fundidos en un mismo momento.

Aunque la armonía es alta, en este caso, la intimidad que se produce se mantiene de forma coherente con el resto del discurso, dejando en evidencia en el uso de líricas y sonidos, momentos de mayor dolor o de reflexiones más contundentes, así en este plano se podría decir, se aseguran elementos del discurso, se reafirman por medio de la intensidad presente en la armonía. 
Lo anterior, es posible escucharlo en la medida, que en este plano del discurso se consolida la ciudad como la forma del espacio del contenedor donde el amor (avión) debe volar y orientar sus trayectos, pues es en este territorio donde podrá desarrollarse, esto implica que se mantiene la idea del destino en el futuro (adelante), es preciso comprender que la idea de como la ciudad es el espacio adecuado, se relaciona constantemente con la posibilidad de ser sincero en la ciudad, como si lo rural implicara una suerte de enmascaramiento o imposibilidad de desarrollarse plenamente.

En la misma distinción que se plantea entre lo urbano y lo rural, la ciudad es establecida como el lugar de luz, mientras que lo rural es oscuro, como el bosque, en el cual se reafirma, viven los que quieren que los ocupantes del avión no puedan llegar a su destino, por lo tanto la luz de la ciudad es un aspecto clave que se relaciona con la sinceridad, pues esa luz se encuentra compuesta por las relaciones que llegan al destino.

Así, en este plano, de nuevo se cuenta con un referente claro de relación, es de nuevo la ciudad, New York, el bosque no cuenta con un referente específico, quedando en la imagen de cualquier tipo de espacio lleno de árboles, a su vez, no se incorporan otro tipo de referentes que permitan establecer co-textos o contextos en los cuales se desarrollan las historias, que como se menciono en la armonía baja, se mantienen en primera persona, sobre la voz de la heroína, que es materializada en el grano de Taylor Swift, aunque ella no se reconozca directamente a lo largo del discurso musical.

Estribillo.

Al interior de la armonía alta, se pueden reconocer al menos 70 fragmentos musicales, de los cuales resalta por ejemplo la relación con el ritmo afectuoso, el cual cuenta con un segmento en 
la pieza Style, como la introducción de la pieza, donde además se continúa con mayor densidad estableciendo dos elementos que ya fueron descritos, la posibilidad de sacudirse los problemas (Shake it off) y la posibilidad de contar con espacios de ocultamiento que garanticen la posibilidad de la relación (I know places).

Welcome to new york, se transforma de nuevo en el unico referente espacial con vínculo en el mundo cotidiano, donde la idea de la ciudad como espacio de desarrollo de las relaciones amorosas es su foco, en contradicción con la idea de lo rural y el bosque presente en Out of the Woods, incoporando el deseo de la producción de la relación por medio de I wish you Would, pese a que el sujeto siempre podrá ser leido como una revista, en especial por su estilo y forma de vestir, donde Style vuelve a surgir como referente.

Fuera de los elementos anteriores, surge un componente en torno a los pasajeros del avión, se trata de, como la memoria permite comprenderlo, establecer la exclusión de un sujeto, un dentro o fuera del viaje en el amor (All you had to do was stay), donde además en la misma pieza, se construyen elementos deseables para la relación, donde el silencio del amante debe ser una pieza clave, pues el silencio es una gran demostración de amor, el dialogo constante pareciera en este caso, es uno de los mayores enemigos que en conjunto con los árboles del bosque (sujetos que dañan la relación), de cualquier relación, así el silencio es un elemento especial para poder ganar el juego que se propone en en la armonía media.

De la misma forma que en los dos planos anteriores, es posible experimentar un grupo de fragmentos de la armonía alta, y es posible observar mayores detalles de este elemento en los Bonus-track. 


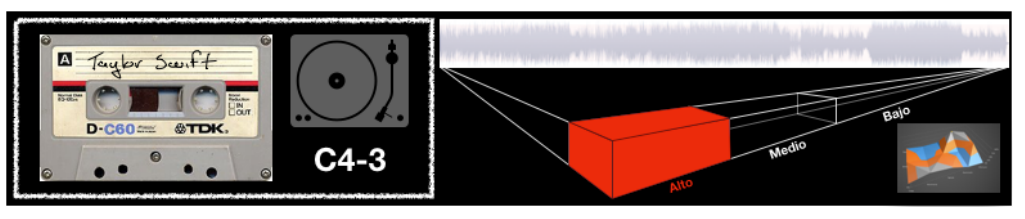

4. Verso. Generalidades del discurso musical de 1989.

Acorde con lo presentado hasta este punto, es posible, establecer que el álbum 1989 de la artista Taylor Swift, como unidad de análisis, se relaciona con la experiencia del amor, con unas particularidades como discurso musical, las cuales se han fragmentado en tres planos (cada uno de los versos anteriores), permitiendo así construir como a partir de las armonías en relación con los ritmos se consolidan elementos que permiten una experiencia específica del tema del (des)amor.

Así entonces, en una armonía baja, la artista a lo largo del álbum constituye lo que fue denominado como "los planos de la intimidad: el amor duele", donde se construyen los principales elementos del recipiente del amor, apareciendo así la idea de la memoria como elemento que puede no permitir el amor, además del tiempo, en el cual es importante reconocer como siempre se encuentra, en este caso, anclado al pasado y orientado al futuro, donde el aquí y el ahora se desaparecen, solo queda el destino. Se denomino como: el amor duele, pues, a lo largo del discurso musical de Taylor Swift, son constantes las imágenes de lo mal que han sido sus experiencias amorosas, de allí la constante necesidad de emprender la huida a sujetos que la buscan a ella y su pareja en relación, para hacerles daño bajo la imagen del cazador y de los árboles.

Este último elemento, el bosque, se relaciona con "los planos del territorio: donde amamos", que cuenta con una armonía media, por lo tanto un poco más tensa en la densidad musical, 
relacionando así el escape, la salida, la huida de aquellos que quieren hacer daño, encontrando en la ciudad el espacio en el cual las personas son sinceras y por lo tanto será más fácil garantizar una relación amorosa, todo en medio de una velocidad, marcada por la armonía y el ritmo, que implican en este caso el movimiento y la salida de la vida rutinaria y lenta relacionada con el bosque, la ciudad, con su desorden, en especial New York, como espacio en el cual es posible amar.

Pese a lo anterior, la ciudad no es del todo segura, así en "los planos de la seguridad: el lugar confiable para el amor", con una armonía alta, sonidos que constantemente se apoyan en varias capas del grano, mantienen el mismo tema, pero en este caso se expone como al interior de la ciudad y del anonimato que ésta ofrece es posible encontrar espacios de ocultamiento de los demás para que el destino pueda florecer.

A lo largo de los tres planos la memoria y el pasado (atrás) juegan como una suerte de lastre, algo que frena al destino, pues gracias a esto, la protagonista (heroína) del discurso, que como observamos se instala en primera persona, utiliza estos elementos (memoria e historia) para poder determinar los intereses y formas de actuar de los sujetos con los que busca entablar una relación y llegar al destino, siendo siempre, las heridas que tiene del pasado las que la llevan a cambiar de ruta, a destruir ella, la posibilidad del amor, por eso su interés en sacudirse los problemas y a lavarse la memoria, todo como un mecanismo de llegar a destino finalmente.

Así las cosas, el discurso musical de Taylor Swift, nos plantea una producción completa de como se experimenta, principalmente, el dolor en el amor, y como nuestra experiencia es un factor determinante en esta experiencia amorosa, invitando además constantemente a olvidarla (la memoria), para poder emprender un nuevo camino que si nos lleve al destino deseado. 
Al observar en líneas generales es posible la lectura completa de la textura del álbum, que se presenta a continuación:

9. Imagen textura y relaciones de los planos de 1989 de Taylor Swift

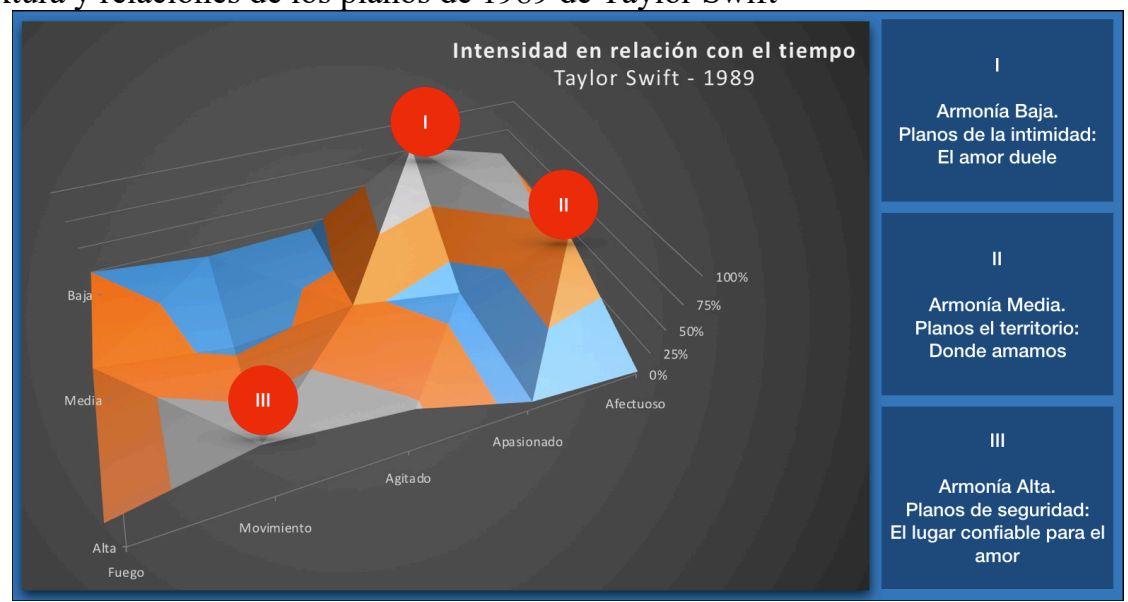

Fuente: Realizado por el autor de la investigación.

"Haciéndome el amor hasta la madrugada"26 Maluma, el discurso musical de la sexualidad.

El álbum Pretty Boy - Dirty Boy (PB/DB), está compuesto por 16 piezas o cortes, al interior de los cuales, los principales sonidos provienen igual que en el caso de Taylor Swift, de sonidos digitales, además de Beat-box y sintetizadores, en muy pocos casos es posible reconocer instrumentos acústicos, aunque es preciso señalar el caso de la pieza Vuelo hasta el olvido, la cual se encuentra desarrollada con una guitarra acústica. Recordemos que este álbum es acompañado de 1989, el que cuenta con la mayor participación de productores, en este caso, es relevante recordar que se contó con 27 compositores para la construcción del álbum.

${ }^{26}$ Tomado de la canción "Me Gustas”, cuarto corte del álbum Pretty Boy - Dirty Boy de Maluma 
Por otro lado, en este álbum se incorporan pocos ruidos o sonidos que permitan establecer contextos, por ejemplo, en el caso de El Perdedor, se incorpora el sonido de un celular en vibrador, abriendo la pieza musical con una suerte de conversación que por el ruido incorporado se asume es una charla telefónica entre un hombre y una mujer, este es el único caso de incorporación de ruidos en las piezas musicales que permitan la construcción de contextos desde este tipo de experiencias sonoras.

El mapa de relaciones que surgen al contemplar las particularidades del álbum, se puede observar a continuación, donde de nuevo la armonía baja es la de mayor relevancia:

10. Imagen de las relaciones entre la armonía en relación con el ritmo en los segmentos de melodía del álbum $\mathrm{PB} / \mathrm{DB}$ de Maluma.

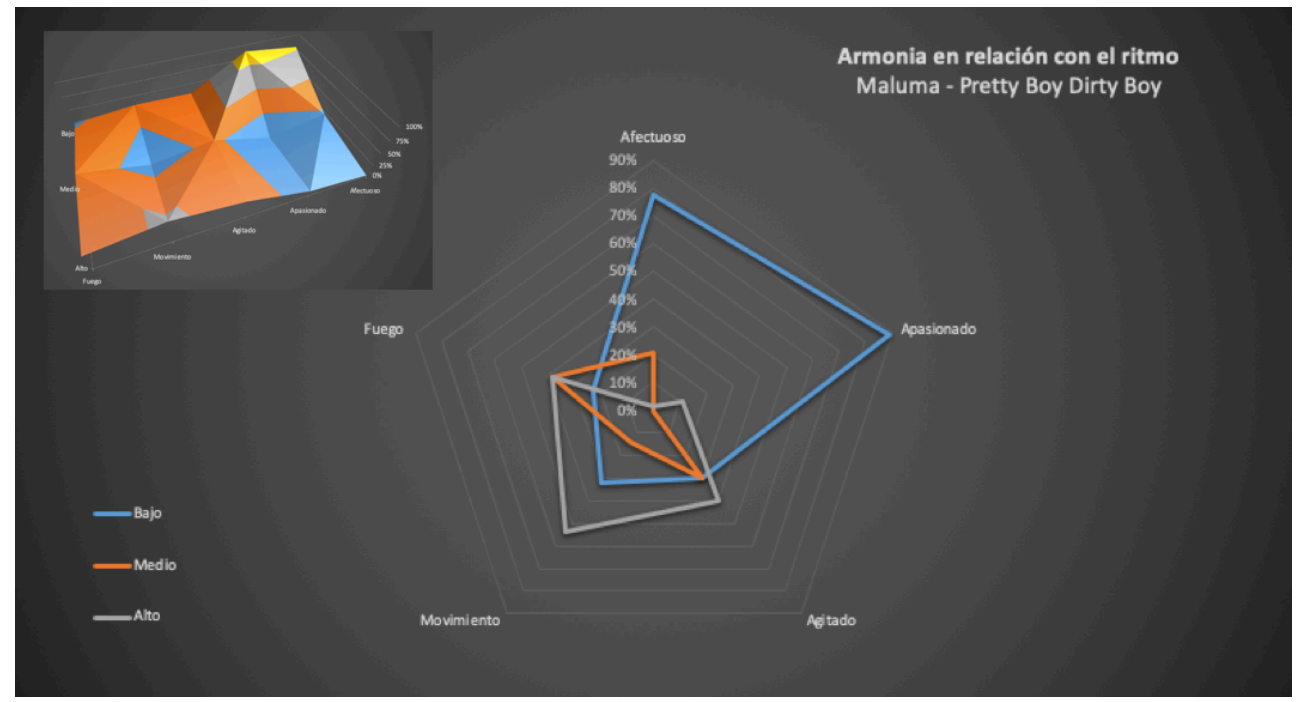

Fuente: Elaborado por el autor de la investigación.

Al contemplar la imagen anterior, sobresale la gran relevancia de la armonía baja, en especial con el ritmo apasionado y el afectuoso, la segunda armonía en presencia se trata de la alta, que se relaciona principalmente con el ritmo movimiento, dejando a la armonía media con relaciones con agitado y fuego. Estos elementos, surgen de lo que se vive en la escucha del reguetón, un género musical que cuenta con una cadencia musical específica, con armonías bajas, pero con 
cadencias en términos de ritmo que invocan el movimiento del cuerpo, con presencias de percusiones (digitales) como principal elemento sonoro.

Como se mencionó, la presencia de la percusión es uno de los elementos más importantes al interior de esta experiencia sonora, pero además, es preciso contemplar como los granos de este discurso musical, se trabajan con frases cortas, dejando así que la textura sea un elemento que requiere un trabajo que no debe demandar el uso de la misma emulando el sonido de otros instrumentos o de otras formas de canto. Se puede relacionar este tipo de grano, con la experiencia del RAP (Rhythm American Poetry), donde el valor del grano se encuentra más allá de sus tonos o capacidades sonoras, se encuentra concentrado en el ritmo de las frases que se utilizan, como si fuese poesía, tal vez por este elemento, el álbum contó con un numero superior de compositores al número de piezas musicales. Este elemento, plantea así, toda una experiencia musical específica, pues los sonidos de percusión acompañados de letras que riman y se acompañan mutuamente es un rasgo importante de este discurso musical.

Acorde con estos breves elementos, es posible profundizar en lo que nos plantea este discurso musical, a partir de las tres formas de melodía que se rastrearon en relación con los ritmos, para lo cual contamos con los cuatro siguientes versos, de nuevo, al finalizar cada uno de los versos, se encuentra el ícono que permite la reproducción de un fragmento de la experiencia musical con espacios sonoros del álbum, y no resta invitar la visita a los Bonus-Track, donde se pueden observar más particularidades de estos componentes.

1. Verso armonía baja. Planos de la sexualidad: ¿qué es el sexo?

Al contemplar la armonía baja, los sonidos de los sintetizadores y del beat-box son la mayor marca, sonidos que se juegan principalmente como una suerte de banda sonora, están de fondo, 
son el acompañamiento, tal vez, esto se relacione con el origen mismo de los sonidos, pues pareciera que lo más importante en este espacio armónico sea las letras, sin embargo, no es menor la presencia armónica y rítmica de este plano, en especial en términos de las percusiones y sonidos que mueven el cuerpo.

Esa experiencia en torno al movimiento del cuerpo, se puede encontrar en las formas en que la lírica construye el sentido de la danza, pues en esta, se consolida el mensaje por medio del cual las mujeres hacen saber a los hombres su interés, el acceso a sus territorios (cuerpos), así, la mujer se transforma en un territorio donde se expresa o materializa el placer, ellas cuentan con las llaves para su acceso y por medio de la danza, por ejemplo, invitan a los hombres, que en el discurso musical, siempre se reconoce un nombre específico, Maluma, quien se encuentra en primera persona narrando historias y sucesos.

La mujer como territorio del placer, puede invitar al hombre a desencadenar el placer, es decir, en el discurso, es el hombre el que lleva y entrega el placer, como quien entrega flores por la semilla que éstas representan, las mujeres por lo tanto, se consolidan como territorios donde su agencia se encuentra en abrir las puertas para el placer que llega encarnado en el hombre. Además, como territorio del placer, las mujeres deben garantizar el cambio y la innovación, pues por lo contrario, en la monotonía, el hombre puede buscar nuevos territorios del placer, saltando incluso las normas o leyes, pues frente al placer no existen limites posibles.

El placer así se constituye como el cielo, que se alcanza en un viaje de orden psicodélico, que es la forma en que metonímicamente se reemplaza el acto sexual, de donde, la mujer como territorio del placer, requiere de la visita del hombre para poder alcanzar el cielo, la gloria, el anhelo definitivo. El amor, surge cuando el territorio del placer garantiza la diversidad y la 
ausencia de monotonía en los encuentros sexuales, transformándose de esta forma en un ángel puro, en el cielo, en el éxtasis del acto sexual.

Los territorios del placer, cuando no logran transformarse en el ángel del cielo, son cambiados fácilmente como en la fiesta, donde de nuevo se retoma la idea de la danza, pues en una fiesta se puede bailar con muchas parejas, de igual forma, la vida es un juego en el carnaval, el cual se baila constantemente, buscando el placer, así se puede bailar con los territorios del placer que sean necesarios.

El sexo, como acceso al placer, termina por constituir un sujeto pasivo, el territorio del placer, que puede en cuanto sujeto abrir las puertas o invitar al sujeto activo (Maluma) quien brinda o entrega el placer que permite llegar al cielo en ese viaje psicodélico, pero si el placer que ofrece ese territorio no es suficiente o es monótono, puede y debe, ir en busca de nuevos territorios del placer, pues siempre se está buscando el cielo.

\section{Estribillo}

Ahora bien, la construcción del cuerpo de la mujer como territorio del placer, además de la mirada sobre la sexualidad como un ejercicio del placer, es posible rastrearlo en piezas como Sin Contrato, Una Aventura, Pretextos y Ya no es una Niña, a su vez, el cielo como lugar de éxtasis en un viaje psicodélico en el cual la mujer puede ser reconocida como el ángel puro se encuentra en Tengo un amor.

Las relaciones como un proceso del placer que implican el juego, la variación y la danza pueden establecerse en relación con Me Gustas, Sin Contrato y Solos, espacios en los que la 
seducción desde el baile son un punto importante de desarrollo del discurso musical, donde el placer que lleva el hombre (Maluma) al territorio de placer, se rastrea en Recuérdame y Solos.

Finalmente, en términos de las relaciones que se reconocen en el verso anterior, se encuentra la idea del amor y el sexo como centros del placer, donde el que entrega el placer es Maluma, en una vida que se relaciona con la danza, que es la forma en que la mujer presenta su disposición o apertura como territorio del placer, elementos que se pueden rastrear en Sin Contrato, El Tiki y El Carnaval.

Los elementos que se han presentado, en este ejercicio de reconocimiento de la armonía baja en Malulma, donde la experiencia sonora invita constantemente al baile, se construyeron a partir de poco más de 180 elementos presentes en el discurso musical de $\mathrm{PB} / \mathrm{DB}$, el cual como se señaló en líneas anteriores es el más potente de este discurso.

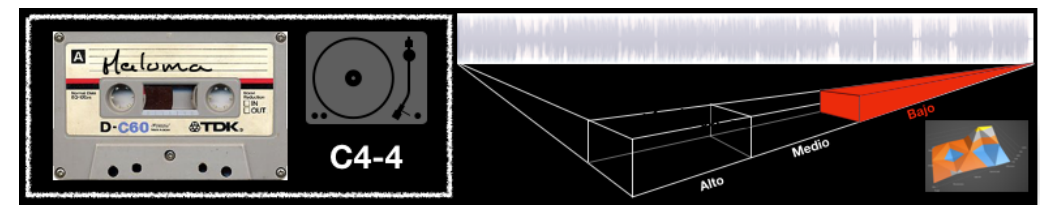

2 Verso. Armonía alta. Planos sobre la posesión del cuerpo: la mujer

Al relacionar la armonía alta, los sonidos que evocan la experiencia sonora se incrementan aunque no establecen un proceso de densidad potente, así entonces, la característica esta en la incorporación de más sonidos pero respetando la percusión y el orden que este propone a lo largo de todo el discurso musical, principalmente con un ritmo de movimiento que aumenta la danza, o la necesidad del cuerpo de moverse, de danzar si se quiere. En total se cuenta con 69 vínculos o fragmentos musicales del discurso, que profundizan en la experiencia recién expuesta. 
Ahora bien, en la medida que la necesidad de danzar con la armonía y el ritmo se incrementa, la relación con la lírica se relaciona con el cuerpo de la mujer, que como observamos ya se había constituido como territorio del placer, sin embargo, ahora, se proponen algunas características específicas de ese territorio del placer, dejando así en evidencia que no cualquier mujer se establece o comporta como territorio del placer para Maluma.

Es en la danza, que se transforma metonímicamente en el acto sexual, donde además el que mejor baila es Maluma, el territorio del placer (la mujer), deja en evidencia sus capacidades sexuales en la forma de bailar, para poder seducir al hombre, así la danza de la mujer, se transforma en la invitación de entrada al territorio del placer frente al hombre. Al ingresar en el territorio, este se encuentra debidamente cuidado, por medio de gimnasio, y dietas, pues se trata de un territorio que se cuida para garantizar entregar el placer al hombre que ingresa, pero no solo se trata del cuidado del físico.

Además de lo anterior, el territorio del placer, se entrega al hombre, de allí que sea sumiso, dejando que el hombre haga lo que le genera placer en ese territorio, allí el placer, para el territorio del mismo, se genera en el éxtasis del hombre, no en el placer de la mujer, por esto la sumisión se manifiesta en la mirada a los ojos, que no contradice ni opone resistencia, se deja por lo tanto, que el ocupante del territorio plazca sus pulsiones, y allí se llega al cielo.

Una vez que el territorio del placer se entrega a un ocupante, no podrá recibir nuevos ocupantes o diferentes al que ya se realizó la entrega. Lo anterior pues parte de la sumisión es la garantía que sólo un sujeto es el que entrega el placer, otros no lo pueden hacer, mucho menos si no son Maluma, sin embargo, el hombre si puede habitar diversos territorios del placer, según sus necesidades y las danzas que se le ofrezcan para ser ocupadas en las fiestas. 
Es en las fiestas donde se danza, donde se ofrecen los territorios del placer, que si se encuentran en estado de embriagues seguramente podrán ofrecerse mejor como territorios a ser ocupadas, llegando de esta forma a experimentar el placer (residual) contenido en los placeres que el hombre se da al habitar esos territorios. Además, en medio de la borrachera, aunque sea deseada en el territorio del placer, sin importar su estado, no podrá perder la memoria, utilizando la metonimia del cassette en vez de la memoria, pues se puede borrar, pero este acto hace que se pierda la potencia del hombre que habita ese territorio y le hace sentir el placer en sus deseos.

Las referencias que se utilizan en este proceso, más allá del reconocimiento (una vez más) constante del autor del placer: Maluma, la fiesta como espacio de encuentro y de vender el territorio del placer como mercancía para los hombres, no se encuentran mayores relaciones o referencias, donde la fiesta es la más potente, aunque se trata de una fiesta de reguetón, no de otro tipo de escenario o fiesta.

Estribillo.

Como se pudo observar el baile/danza, es uno de los elementos más importantes de este espacio o plano armónico, el cual es posible rastrearlo en piezas como Me Gustas, Sin Contrato, Tengo un amor, El Tiki y El Carnaval, piezas en las que además se fortalece la forma en que la mujer como territorio del placer, se ofrece mediante la danza, siendo este el mayor elemento de seducción mediante la invitación a poseer ese territorio y entregar el placer a partir de los deleites del otro.

Ahora bien, la exclusividad de ocupación del territorio y la imposibilidad de borrar los recuerdos del placer que ese hombre exclusivo entrega al territorio del placer, se encuentran en piezas como Borro Cassette, Una Aventura y La Misma Moneda, que dejan en evidencia como 
la ocupación del hombre del territorio del placer, es un deber de la mujer, materializando así el rol sumiso de reconocimiento y de producción de placer mediante la entrega.

Las particularidades más fuertes del territorio del placer, como un territorio que se cuida y se organiza para dar la bienvenida al ocupante, se rastrean en Borro Cassette, Me gustas y Recuérdame, así la mujer, a lo largo de todos estos elementos señalados es construida, determinada como un sujeto pasivo que será ocupado y llenado de placer, pero de no ser así, la culpa no recae en el hombre que ocupa, sino en la falta de sumisión, innovación o descuido del territorio del placer.

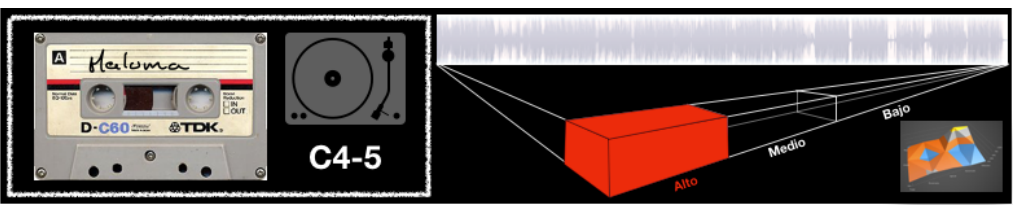

3. Verso armonía media. Los planos de la reafirmación: mujer para tirar.

En este campo, la experiencia sonora toma una cadencia que sigue implicando el movimiento, la danza, pero en este caso con un grano que es más íntimo, como si se tratara de un ejercicio de seducción, donde lo principal es el grano por encima de las experiencias sonoras que puede proponer la armonía media, en la cual se pueden reconocer al menos 61 fragmentos musicales.

En este espacio sonoro, a partir de las líricas se construye de forma más específica las características del territorio del placer, pero ya no como en la armonía fuerte, sino que se otorgan nuevos elementos, que caracterizan el comportamiento de la mujer en cuanto territorio del placer, pues ésta no debe ser esquiva o insegura, así como territorio que es ocupado se entrega plenamente, sin resguardos, sin reparos. 
Lo anterior, en la medida que no solo el estado del territorio del placer (cuidado con gimnasio y dieta), sino también su forma de entrega, hace que sea, realmente un territorio deseado por el hombre (Maluma y amigos), pues un territorio del placer inseguro, es señal de garantía que no se logrará el éxtasis pleno, pero además, por eso mismo, es una perdida de tiempo, así, el territorio del placer, se entrega plenamente, constituyéndose de esta forma en una mercancía, que es plena cuando es ocupada.

Lo anterior, implica que la mujer en cuanto territorio del placer, invita al hombre para que la posea, pero no puede, decidir sobre su salida del territorio, pues esto lleva a que sea desocupada como territorio, desposeída, y por lo tanto no pueda volver a ser plena de placer sin aquel que la lleno de placer. Estos elementos llevan a que se construya una idea de futuro, que es el encuentro sexual, pues la mujer, como territorio del placer solo tiene una posibilidad futura, ser llenada de placer por parte del hombre que la posee y ocupa.

La mujer, así queda construida de una forma pasiva, en la medida en que ésta genera una gestión de sus pasiones más allá de la entrega, se encontrará desposeída, vacía, sin placer, por lo tanto la capacidad de gestión de la mujer por fuera de un territorio del placer el cual debe ser dispuesto por un hombre, queda relegada a un futuro vacío, el mismo futuro que ocupan las mujeres inseguras o que no permiten la plena ocupación y uso de sus territorios.

\section{Estribillo.}

La construcción de esta mujer como territorio pasivo a ser ocupado se pueden encontrar en piezas como Dónde Estás, Me Gustas, Una Aventura, Recuérdame y La Misma Moneda, a su vez, la posibilidad de encontrar el futuro como el encuentro sexual también se rastrean en las piezas anteriores a excepción de la que abre y cierra ese grupo de piezas, donde a su vez, el 
cuerpo de la mujer como territorio del placer, se construye como una mercancía que cuenta con valor toda vez que esta siendo ocupada mediante la experiencia del placer, elemento que se encuentra en la pieza Sin contrato y Tengo un Amor.

En este campo de armonía, finalmente, la forma en que el hombre posee a la mujer para entregarle sentido de vida en términos de ser territorio del placer de otro, y donde además no puede contar con agencia o decisión, mucho menos para optar por quien deja de ocuparla, se encuentra en Recuérdame.

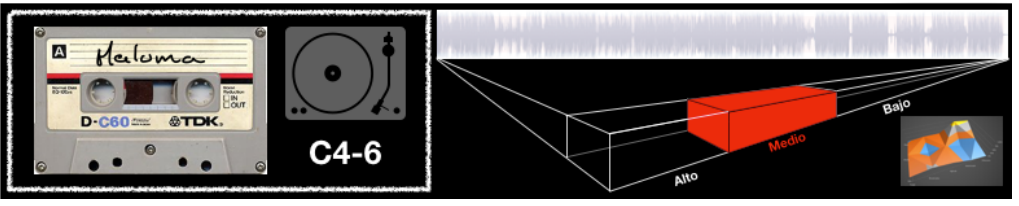

4. Verso. Generalidades del discurso musical de PB/DB.

En el discurso musical de PB/DB sobresalen armonías en sus variaciones y relaciones con el rimo, que invitan a la danza, que es tal vez, en si misma, el mayor contenedor que se construye a lo largo del álbum, pues ésta es la invitación, la experiencia, la imagen del sexo, donde se concentra todo el proceso de experiencia sonora, así entonces, se construyen dos cuerpos que se encuentran en el futuro de ese contenedor danza, mediante el acto sexual.

Al interior de ese acto el sexo se construye como el placer del hombre al ocupar el territorio del placer (la mujer), como pudimos ampliarlo en “los planos de la sexualidad: ¿Qué es el sexo?", donde la armonía baja, que evoca la danza más lenta más comprometida es un rasgo relevante, ahora, esa forma de sexo (posesión del hombre sobre el cuerpo de la mujer) es la expresión más fuerte en términos rítmicos, pues al ser éste alto, se construye la forma en que el hombre ocupa, posee y disfruta del territorio del placer, llenando del mismo a la mujer, que es 
pasiva, se constituye como el recipiente del placer del otro, en el futuro de la danza, que es el encuentro sexual.

Así, en "los planos sobre la posesión del cuerpo: la mujer”, el encuentro sexual se establece de la forma más amplia, como posesión de un cuerpo, pero ese cuerpo a su vez cuenta con una serie de características espaciales que permiten su dominación mediante la sumisión y la plena entrega como se pudo profundizar en "los planos de la reafirmación: la mujer para tirar", donde se reconoce que no toda mujer sirve o es digna como territorio del placer de ser poseída y ocupada.

Las relaciones entre estos tres planos armónicos, nos permiten comprender como en el discurso musical de Maluma, se construye un proceso específico del valor de la vida, el futuro como el sexo y la fiesta como su lugar de encuentro, así la mujer, se transforma en el espacio del placer, que puede en ocasiones aburrir por su falta de innovación, pero además que no puede tomar decisiones sobre su ocupador, se construye una textura del álbum, siempre desde la danza y una cadencia armónica que invita a danzar.

11. Imagen textura y relaciones de los planos de $\mathrm{PB} / \mathrm{DB}$ de Maluma

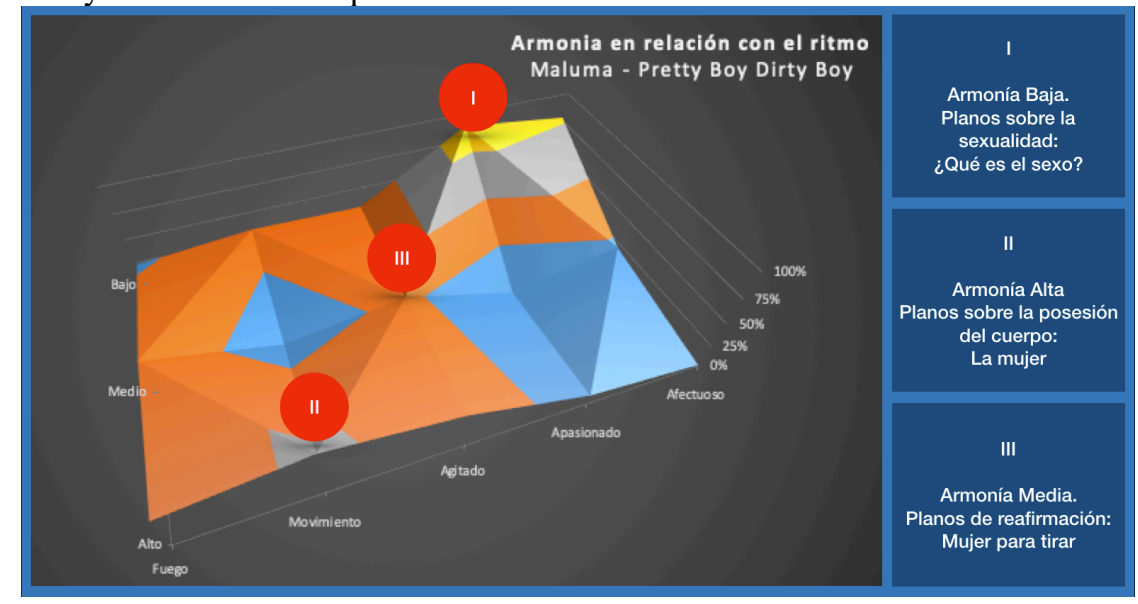

Fuente: Realizado por el autor de la investigación. 


\section{"Soy el producto del sistema que nací para destruir" ${ }^{27}$ Lowkey, el discurso musical en la guerra preventiva de Irak.}

Desde el título de este apartado del capítulo, ya es posible reconocer una referencia importante, la guerra de Irak después de los eventos que tomaron lugar en New York en el Word Trade Center el 11 de septiembre de 2001. Se ha querido iniciar este apartado por este elemento en la medida que la experiencia musical de este artista se centra en estos eventos y en lo que se desarrollaría posteriormente en Oriente Medio, elementos que no solo se encuentran en las líricas del álbum, sino que además se puede rastrear en los ruidos incorporados a lo largo de todo el desarrollo del mismo, pues éste, cuenta con seis piezas, que como partes constitutivas del álbum no son canciones, sino apartados de discursos e intervenciones públicas entre otras experiencias sonoras, que permiten encontrar un contexto a lo que se propone y desarrolla en su integridad, resalta por ejemplo, el sonido de la milicia norteamericana disparando desde un helicóptero a civiles en Afganistán, audio que sería público tras las filtraciones que realizara Snowden por medio de diversos medios Ingleses y Norteamericanos.

En total el álbum se encuentra compuesto por 25 piezas, 19 de ellas canciones, donde como se observó en el capítulo "muevan las industrias", cada una de ellas ha sido editada y producida por personas diferentes, en espacios o estudios también diferentes, sin embargo, pese a lo anterior el álbum cuenta con un sonido característico, con la presencia constante de instrumentos como pianos, baterías y por su característica de Hip-Hop, con sonidos también electrónicos y digitales,

27 Tomado de la canción "soundtrack to the struggle", primer corte del álbum Soundtrack to the struggle de Lowkey 
lo anterior, es importante en la medida que pese a ser de ese genero (Hip-Hop), supera ampliamente en el uso de instrumentos tradicionales a los álbumes de Taylor Swift (Pop) y Maluma (Reguetón).

La experiencia sonora es de mucha densidad, a lo largo de todas sus armonías se evidencia la mezcla de sonidos diversos, entre instrumentos, ruidos y coros, además de la participación de muchos artistas invitados, al igual que en el caso de Maluma, el foco se encuentra en la rima de las líricas a la hora de contemplar el rol del grano, sumando en este caso, que el cruce de granos, entre el artista central (Lowkey) y los invitados, en especial granos femeninos que en muchas ocasiones suenan como lamentos, granos de dolor. En líneas generales al contemplar las armonías que se identifican a lo largo del álbum, surge unas series de relaciones, que pueden encontrarse a continuación, permitiendo así establecer algunas particularidades del discurso musical de Lowkey en su álbum Soundtrack to the struggle.

12. Imagen de las relaciones entre la armonía en relación con el ritmo en los segmentos de melodía del Soundtrack to the struggle de Lowkey.

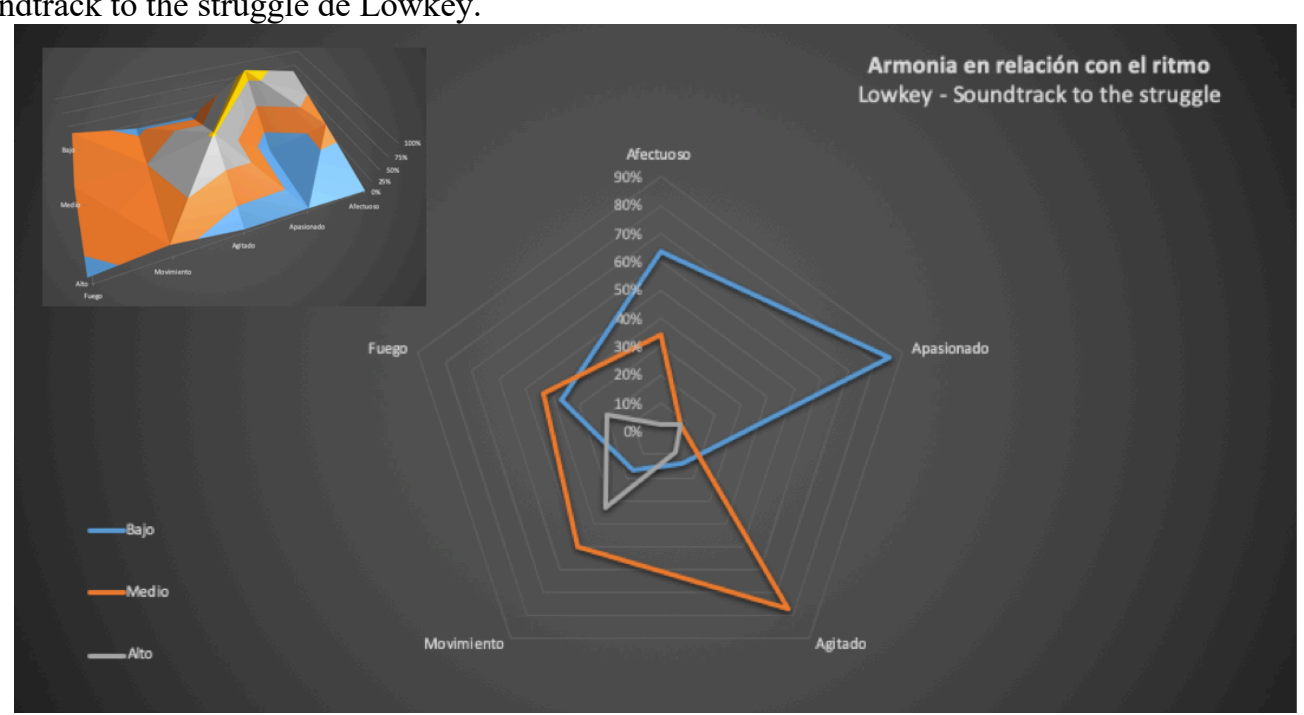

Fuente: Elaborado por el autor de la investigación.

Dos armonías cuentan con una relevancia destacable, se trata como se puede observar de la media y la baja, donde la primera se encamina a ritmos apasionados, mientras la segunda a 
agitados, así como se podrá observar en los versos que desarrollan las armonías, al ser bajas, se compromete el discurso con muchos de los hechos y vivencias (específicas) de lo que ha sido la guerra contra el terrorismo, que iniciara en el año 2001 y hoy después de dieciocho años, continúa marcando el desarrollo de la historia. A su vez al contar con una armonía media, se exponen muchos ejemplos de lo que ha sido la forma en que se ha materializado la violencia de esa guerra en sujetos, que en palabras de Lowkey, no tienen voz, por el hecho de estar muertos.

1. Verso armonías bajas. Planos del dolor: Una mirada a la guerra preventiva.

La experiencia sonora de esta armonía, se contempla con sonidos densos, pero no son rápidos, sino que, pese a sus texturas densas, llena el plano sensorial de posibilidades, de lamentos en muchos casos, a partir de granos invitados, que pareciera, se lamentan, en compañía de los múltiples ejemplos, así, en este discurso la armonía, que es acompañada por la lírica, cuenta con una práctica muy específica, se trata la de las metonimias, con las cuales, mediante ejemplos de la vida práctica y casos documentados, se cambian constantemente los actos por los hechos, así al hablar de terror, en vez de explicarlo o mostrarlo de una forma determinada, se utilizan múltiples ejemplos de como se vive el terror en los cuerpos de los sujetos del mundo árabe.

Por medio de los ejemplos, y de su forma de exponerse a lo largo del discurso musical, se construye la idea de la guerra preventiva, y como esta, se construyó con un sentido específico, donde desde la negación binaria, se construyen seres de bien y de mal, de luz y de sombra, los que operan las armas y desarrollan la guerra son la luz (Estados Unidos, Gran Bretaña e Israel), que accionan en contra de los seres de sombra (el pueblo árabe), así se tiene un pasado que se vivió gracias a las sombras (septiembre de 2001), justificando de esta forma el sometimiento de éstos por parte de los seres de luz, en este proceso se han generado millones de muertos, que 
persiguen y acompañan a los seres de sombra, recordándoles que la libertad no se regala y se debe luchar, en este espacio las mujeres que sobreviven a la guerra son un baluarte, pues son las encargadas de mostrar los horizontes posibles, para salir de la dicotomía de la luz y la sombra, en donde la libertad es el principal objetivo a conseguir.

La guerra preventiva de esta forma, construyó unos sujetos de sombra, de mal, los árabes, quienes buscan en el horizonte por medio de sus luchas por la libertad y el fin del sometimiento alcanzar sus sueños, que son lo más importante, pues la ocupación de los seres de luz, no puede comprarlos o quietarles sus sueños y anhelos de libertad, que se consigue por medio de la lucha.

En medio de la guerra preventiva, el mundo, que no es luz o sombra, se encuentra dormido mirando las pantallas que les cuentan como se produce esta contradicción, pese a contar con expresiones de este ejercicio milenario de sometimiento, bastando ir a un museo de los imperios para ver en ellos, como su grandeza se establece en el saqueo de las culturas árabes.

En este campo de producción de lo que denominamos como la construcción de la guerra preventiva, las relaciones o referentes que se construyen son muchos, personas, casos, presidentes derrocados, en fin, las líricas de este espacio armónico se encuentran como todo el discurso de Lowkey, llenos de ejemplos, que por medio de la metonimia establecen los sentidos sobre la guerra preventiva, como la mentira que busca consolidar la dominación del mundo árabe para garantizar por medio de ella, la expansión del estilo de vida de EEUU y sus aliados.

\section{Estribillo.}

Los elementos que se han presentado en el verso anterior sobre la guerra preventiva, se relacionan a lo largo de todo el álbum, donde canciones como Voices of the Voiceless y Haunted, 
es la encargada de evidenciar como los muertos son ahora una compañía y en ella el anhelo por la libertad, mientras que Terroris, nos muestra como se puede manipular la expresión terrorista de acuerdo a los intereses que se tienen como imperio en un momento específico de la historia. En Something Wonderful, la mujer es el foco o centro, pues es ella la que permite el desarrollo de los horizontes, de lo que puede ser lindo en medio de la lucha y las victimas que produce la guerra preventiva de EEUU.

Los horizontes, como se señaló se llenan de sueños que se encuentran en los sujetos que nos presenta Dreamers, sueños que son atacados por la idea del estilo de vida de EEUU y sus aliados, que se puede rastrear en Obamanation y Creadle of Civilization. El dolor frente a las acciones de muerte que genera esa guerra preventiva se escucha en Dear England, buscando en los sueños salir de ese efecto devastador en The Buterfly Efect, donde la lucha por la libertad se puede llevar todo (Everithing $i$ am) pues como se mencionó, en la lucha de la libertad no se puede perder el alma (My Soul).

Es en el cierre del álbum, donde la lucha del pueblo árabe se materializa con las prácticas presentes en Millon man March, en todos estos elementos, la idea de la luz y la sombra se construyen, con las víctimas que persiguen, las mujeres que sobreviven y permiten establecer un horizonte más allá de la negación binaria para poder soñar.

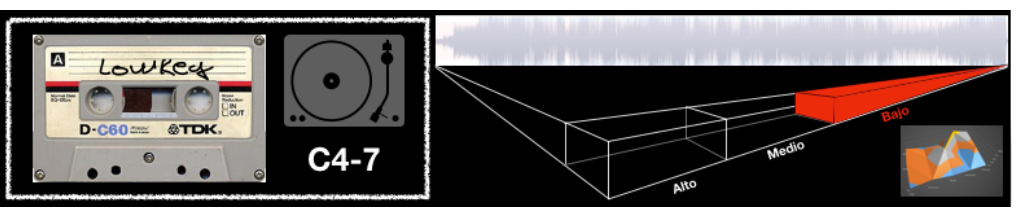


2. Verso armonías medias. Planos del despertar: Entender la violencia terrorista.

Al escuchar las armonías medias que cuentan con una relevancia similar en sus volúmenes a las bajas, sobresalen sonidos reflexivos, procesos que convocan a pensar, a sentir, en medio de todo a generar una suerte de reconocimiento con los elementos que se narran a lo largo de este espacio armónico, de nuevo, al ser un género que se basa en la lírica y su rima, aquí el grano es central, donde diversas veces se utilizan los granos múltiples como procesos de fortalecimiento y construcción de densidad, la cual por lo general, puede encontrarse en las velocidades que utiliza el grano principal Lowkey en sus rimas.

A partir de esos sonidos, se busca construir elementos que permitan comprender como se vive la guerra preventiva, para lo cual, de nuevo desde la estrategia metonímica, se utilizan muchos ejemplos para dar razón del proceso que se busca establecer, así, el comprar un café de Starbucks es financiar una empresa israelí y de allí es poner un bala en el fusil de un soldado israelí que puede matar a un niño palestino; así entender la guerra preventiva, implica establecer una relación con el deseo del consumo, por lo tanto todo aquel que no quiera o no pueda consumir, se transforma en la sombra, pues es el enemigo del estilo de vida.

Antes de continuar con el problema del deseo, es necesario establecer como la llegada de la ocupación militar en muchos territorios del mundo árabe, marcaron un antes y un después, en ese después, se reduce la posibilidad del consumo, así, los deseos desde ese campo también se obstruyen, se produce la oscuridad, la sombra, el mal, que lleva a desear elementos más profundos, como la libertad y la posibilidad de soñar, mucho más, cuando las ciudades, las casas, los hogares fueron destruidos. 
Aquel que no desea consumir es el enemigo, del estilo de vida, la guerra preventiva como guerra contra el terrorismo, se basa en someter por medio del terror a los pueblos para que todos deseen y consuman de la misma forma, no se establece exclusivamente en oriente medio, sino que todo el mundo esta inmerso en este proceso, en muchos casos, se establece como nos convertimos en los aliados de la guerra preventiva, como en el caso de un café que se mencionó en líneas anteriores.

Los ejemplos, casos, historias a lo largo de este espacio armónico son contundentes en la construcción de una estrategia metonímica que permite rastrear los elementos que se señalaron hasta este punto.

\section{Estribillo.}

Las relaciones que se producen en torno al dinero, el consumo y el deseo se rastrean en Too Much, Something Wonderfoul y Cradle of civilization, mientras que las formas en que construimos el consumo como forma de vida pese a que esto tenga o produzca victimas a lo largo del mundo se relaciona con espacios como Voices of the Voiceless, Long Live Palestine y Terrorist.

A partir de los cortes que se mencionaron en el párrafo anterior, en especial Long Live Palestine, se construye las formas en que se vive y se oculta en el consumo y el deseo la guerra preventiva, dejando a las personas cada vez más dormidas, es decir, menos enteradas de lo que realmente pasa en esta guerra que inició en 2001.

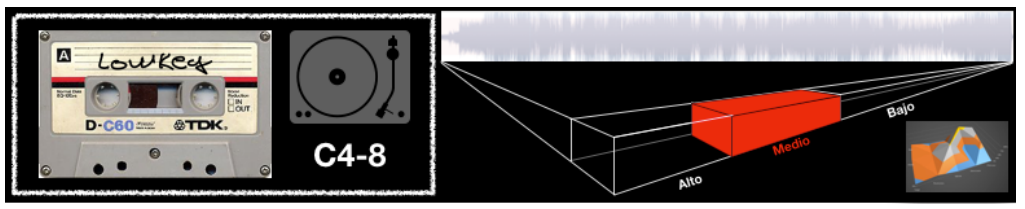


3 Verso. Planos ocultos: Lo que no quieren que veas del terror.

La experiencia sonora en este campo armónico es el más potente en densidad, pero especialmente en la fuerza del grano, produciendo tensión y casi que desesperación en el dolor, las líricas, la textura del grano y la velocidad de este, dejan en evidencia una suerte de urgencia en lo que se plantea en las relaciones de todos los componentes del discurso.

Lo anterior cobra mayor fuerza, cuando se relaciona el plano de la lírica que nos muestra como el sistema como dominador es el que valora e incita al consumo desde el deseo, valiéndose de cantantes, por ejemplo, donde se construyen ídolos del consumo, que nos alejan de los hechos que toman lugar en otros territorios, así, la guerra como forma de garantía del consumo es el futuro, y este hecho se nos oculta por medio de los mensajes que nos dejan llegar por los medios que el sistema mismo controla. Así el sistema del deseo en el consumo solo podrá ser viable en la guerra continua, ese hecho se nos oculta, pues es la experiencia de la guerra televisada.

\section{Estribillo}

Son tres piezas claves las que nos permiten rastrear los elementos del discurso presentados en el apartado anterior, se trata de Soundtrack to the Struggle, Hand on your gun y Blood, Sweat and tears. Donde el sistema del consumo desde el deseo y el ocultamiento de la violencia que contrae la guerra preventiva es en sí misma la garantía del sistema para seguir activo y operando mediante los deseos que se producen en sujetos alrededor del mundo.

Las piezas Too much y Everithing I am, son las encargadas de posicionar el tema de la resistencia y como desde el anhelo de la libertad es posible ser conciente del sistema que se fundamenta en el deseo que oculta mediante el consumo la verdad de la violencia terrorista. 


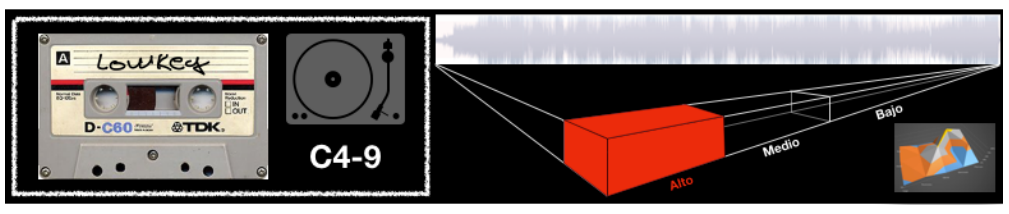

4. Verso. Generalidades del discurso musical soudntrack to the struggle.

Las relaciones que se establecen al comprender los tres planos del discurso desde las armonías en Lowkey, inicialmente reconociendo su gran potencia metonímica, en términos de establecer constantemente ruidos mediante ejemplos, que instalan todo el discurso musical en una serie de eventos en el mundo, como es el 11 de septiembre de 2001, además de los que puede pasar en Palestina e Irak, hecho que plantea de inmediato una particularidad a diferencia de los otros dos discursos musicales analizados hasta este punto, la presencia de eventos que marcan reflexiones en un territorio específico con fechas, sujetos y eventos, saliendo de la ficción y entrando en un proceso de documentación casi de orden histórica.

Así en la armonía baja, se consolida lo que se vive en la guerra preventiva permitiendo de esta forma el contacto más profundo con las emocionalidades del sujeto oyente, pues se trata, como observamos, de armonías bajas con ritmos apasionados, invitando así al reconocimiento del dolor del pueblo y el mundo árabe por la guerra preventiva, pasando así, al segundo plano que inicia el ejercicio desde la armonía media de invitar a comprender que no es una guerra de luz contra la sombra, sino que la sombra se construye de acuerdo a los intereses.

Desde los intereses, se enlaza el proceso con las armonías altas, que es lo que oculta la violencia, en términos de la guerra como la garantía del futuro en el deseo y el consumo, lejos de la libertad y la posibilidad de soñar por fuera de estos marcos o referentes de vida. La guerra es en sí misma el objetivo, no la libertad o la luz, pues los seres de luz que tapan a las de sombra 
terminan por invertirse en este ejercicio, los imperios y sus guerras son la sombra, mientras que los que luchan por sus sueños y la libertad son la luz.

A continuación, es posible observar la textura general del álbum de Lowkey, teniendo en cuenta que como se mencionó en líneas anteriores, este discurso ha sido compuesto por un grupo de piezas que podrían ser consideradas como extra-musicales, son en realidad espacios de contexto y ruido que llenan de sentido todo el discurso musical.

13. Imagen textura y relaciones de los planos de Soudntrack to the struggle de Lowkey

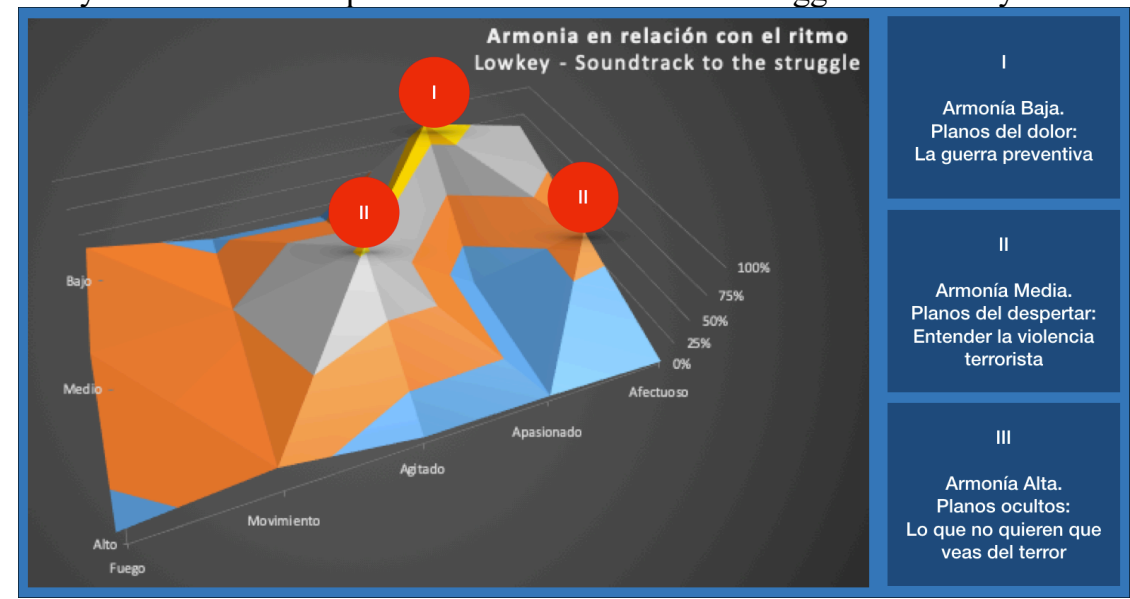

Fuente: Realizado por el autor de la investigación.

Son las voces que se incorporan en las piezas del álbum, las que además de los múltiples ejemplos, como metonimias, que se utilizan a lo largo del discurso musical, las que permiten con mayor contundencia, enlazar lo que se escucha y se siente musicalmente con eventos que pueden ser o no reconocidos por el sujeto oyente, de igual forma que en los planos armónicos, se ha querido incorporar un breve fragmento de estos elementos constitutivos del discurso musical de Lowkey.

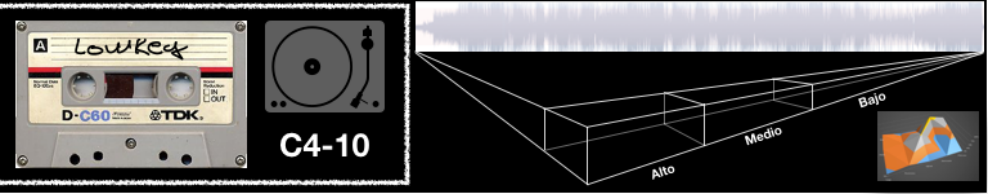




\section{"La agonía fantasmal"28 Epica, El discurso musical de la realidad.}

De todos los álbumes que se contemplaron en este corpus, este es el más complejo en términos musicales, cuenta con la mayor participación de artistas, donde como se mencionó antes, tiene la conformación clásica de una banda de metal, guitarristas, bajista, baterista, pianista y cantante líder, pero además por ser metal sinfónico se integran sonidos de instrumentos clásicos como son violines, chelos, vientos (flautas, saxos, clarinetes) y coros, aumentando así las exposiciones de los granos.

El elemento anterior es muy importante en términos de la experiencia musical, pues los granos cada uno pareciera cumplir con un rol, así, los granos compuestos por coros de mujeres y hombres además de mixtos, por lo general cantan en latín, lo que evoca una suerte de plano místico y sagrado, son como las voces del más allá que anuncian elementos importantes, además se cuenta con la voz líder, Simone Simons quien es mezzosoprano, dando una textura elegante, distinguida, clásica, que se contrapone con el grano de la guitarra líder, Marck Jensen, quien basa su textura en sonidos guturales, como si fueran del inframundo, así el nombre de la banda en sí mismo cobra más sentido Epica, como la literatura de este nombre (con tilde).

Así entre los granos en compañía de sonidos de violín casi permanentes en el fondo del discurso, apoyados en momentos específicos por guitarras, más fuertes o baterías con una velocidad muy alta, los granos hablan entre ellos, contando una historia, en este caso relacionada

${ }^{28}$ Tomado de la canción "The Phanthom Agony”, noveno corte del álbum The Phantom Agony de Epica. 
con la verdad, el sentido de la misma y las formas en que las construimos desde esos discursos místicos que nos dicen lo bueno y lo malo, el valor de la verdad en el marco de una creencia.

Además de abordar temas místicos, este discurso musical cuenta con un solo referente temporal, el cual se incorpora mediante un discurso de Tony Blair, el entonces primer ministro de Gran Bretaña (Inglaterra), donde anuncia la guerra preventiva, permitiendo así, establecer el vínculo entre la guerra que inició al comenzar el siglo, y tras casi dos décadas sigue presente, con el discurso místico.

En líneas generales al observar los planos armónicos, el discurso de Epica cuenta con unas particularidades como se puede observar a continuación:

14. Imagen de las relaciones entre la armonía en relación con el ritmo en los segmentos de melodía del The Phantom Agony de Epica.

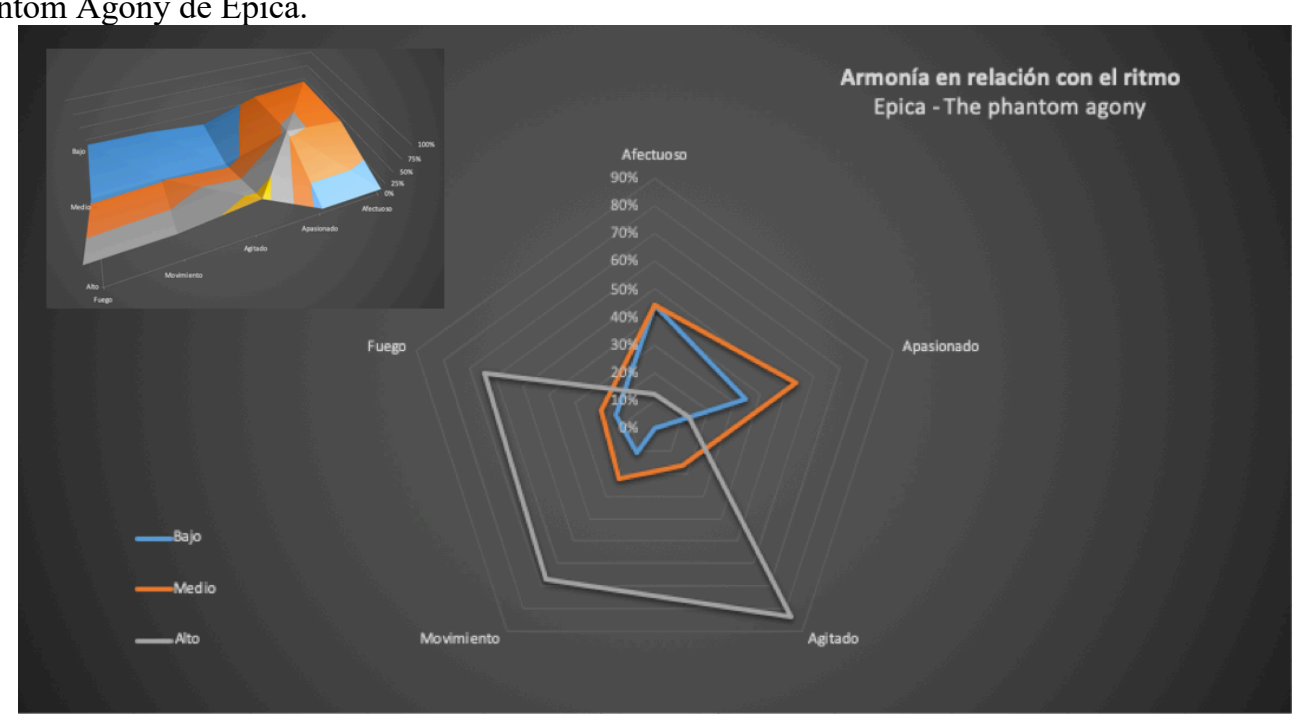

Fuente: Elaborado por el autor de la investigación.

La principal distinción entre este discurso y todos los demás es la relevancia de la armonía alta que se relaciona con el ritmo fuego, agitado y movimiento, esto tal vez por el género, pues se trata de metal sinfónico, y el metal como género se caracteriza por la velocidad y densidad de sus 
armonías, así, el segundo plano armónico es el medio, dejando de último al más relevante en los otros tres discursos musicales analizados, el bajo.

Ahora bien, estas particularidades como discurso musical, plantean algunos elementos relevantes, pues la mayoría de los segmentos que se relacionan con la armonía alta se encuentran en términos de puentes o fragmentos en los cuales no se incorporan líricas, pero si marcan la intensidad con las que los granos se relacionan con el discurso, así, por ejemplo, entre más alta es la intensidad, por lo general el grano gutural se incorpora, mientras que el grano de la líder se relaciona con armonías medias y bajas. Así, es necesario poder observar las particularidades de este discurso a partir de las intensidad armónicas, que se han organizado desde las bajas hasta las altas, en la medida que las líricas, en este sentido cuentan con un elemento que se relaciona con el discurso mismo, por lo general las nueve piezas que componen el álbum inicias con armonías bajas, para ir subiendo su intensidad, hasta cerrar por lo general de nuevo con armonías bajas, por este motivo se ha mantenido la misma estructura de análisis.

1. verso armonías bajas. Planos de sensación de verdad: El engaño de la verdad La experiencia musical de este plano armónico (bajo) se caracteriza por los sonidos de los instrumentos clásicos, con pocas notas de guitarras, aunque la batería suele ser un acompañante, en este caso marcando los tiempos, más no siendo central como sucede en otros planos armónicos. Además, los granos que suelen escucharse en este tipo de segmentos son los coros o la de la vocalista, voces muy educadas (musicalmente).

Otro elemento importante de incorporarse en este segmento son las relaciones de contexto o ruidos que se han incorporado, donde aparece la voz de Tony Blair, que ya se mencionó en otros 
apartados de este documento. Así en este plano armónico bajo, se cuenta con la mayor y única relación contextual de todo el álbum.

A lo largo de este plano, en relación con las líricas, se establece como la experiencia del sujeto, en cuanto sus sentidos, determinan la forma en que cree o construye la realidad, así la racionalidad se encuentra supeditada a la información que los sentidos le entregan, así, el contexto en el cual se desarrolla el sujeto le entrega la información por los sentidos que determinan su realidad, que por lo tanto puede ser una mentira construida en el contexto donde otros sujetos se encuentran, y entregan la información a los sentidos. La lucidez en este escenario aparece como la posibilidad de la libertad, es decir, el poner en tensión todo aquello que se le entrega al sujeto como realidad.

Dicha lucidez, en este caso, es reconocida por los que están en el contexto como inocentes, pero la inocencia es perseguida por demonios de diversas épocas de acuerdo al momento en el que se encuentre el sujeto, así se busca que no se trate de buscar la lucidez y la libertad, pues estas rompen las nociones de realidad, de allí que se necesita el sometimiento mediante el abandono de la lucidez y la libertad.

Las persecuciones que se generan por los demonios a aquellos que buscan la lucidez en la libertad, se materializan en el discurso mediante la imagen de la nieve teñida de sangre desde el más allá, espacio donde están los seres divinos o del más allá.

\section{Estribillo}

Los elementos que se señalaron en el verso anterior, surgen de cerca de 61 fragmentos de los 207 que se encontraron a lo largo del discurso musical de Epica, donde la idea de la realidad 
como mentira construida en el contexto, se puede rastrear principalmente en Feint, Fcade of Reality y The Phantom Agony, mientras que la propuesta de los demonios que persiguen a los sujetos que buscan la lucidez y la libertad se rastrean en Run for all, dejando además en evidencia como se construye la idea de quien se encuentra viviendo o gozando de esa realidad y opera por medio de los discursos místicos como mecanismo de dominación en Selfal Din.

Es preciso recordar que, en la mayoría de estos pasajes, con una armonía que es profundamente elegante en sus sonidos, el grano que mayor presencia realiza es la de la vocalista, que cuenta con una textura de mezzosoprano, el único caso de todos los discursos trabajados donde se puede reconocer el tipo de textura bajo cánones musicales.

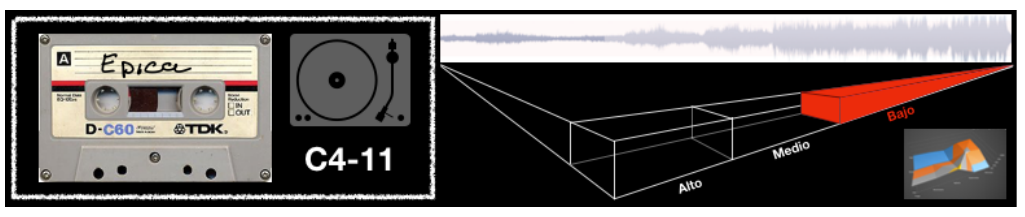

2 Verso. Planos de seguridad en la mentira: Sumergidos en la ausencia de verdad.

La armonía media, se caracteriza por sonidos más densos, que generan más estrés en el oyente, pero a su vez, pueden llevar a prestar más atención a los sonidos y granos que lo incorporan, tal vez este elemento pueda relacionarse con la construcción de la mentira en la realidad, es decir, ésta construida como verdad falsa, que brinda una sensación de seguridad, pero la verdad es imposible de alcanzar, pues esta depende de los contextos, dioses y demonios que nos persiguen.

Así en este fragmento del discurso la conciencia como posibilidad de encontrar la lucidez, es un problema mayor, pues establece la ruptura de la realidad, de las seguridades que construimos frente a una existencia que no tiene nada seguro, donde el miedo a esas ausencia de destino, hace 
que nos acobijemos en las creencias místicas que nos ofrecen sentidos y destinos a lo largo de la vida, la conciencia por lo tanto en la lucidez hace que el destino se pierda pues la realidad no tendría destino, así la conciencia en el conocimiento solo garantiza que entre más sabemos menos podemos hacer frente a la realidad.

Por lo anterior, la autonomía no puede existir. Es así reemplazada por la creencia, principalmente mística, donde el miedo desaparece, la realidad mística reaparece y llena de seguridad al sujeto, que, en su conciencia, con lucidez y conocimiento pierde todo destino.

A lo largo de este espacio de armonía media, las relaciones con ruidos específicos no existen, sin embargo, la idea de lo místico, los dioses son relevantes, nombrando varios en una misma línea, como constructores de realidades místicas que permiten que el sujeto no sienta ansiedad ante el desierto de la realidad, brindando así un sentido místico de destino.

\section{Estribillo}

Las principales piezas de este espacio son Cry for the Moon, Donde el sentido místico es expuesto como constructor de una realidad falsa con un destino que permite ocultar el miedo que presenta el mundo, a su vez en illusive concensus, la imposibilidad de la conciencia como plena aparece, pues siempre se encuentra determinada por las ideas y creencias de época, construyendo realidades místicas donde las fachadas de la realidad son impuestas para garantizar la obediencia en Fcade of reality.

El uso de estos discursos y construcciones de realidades llenas de seguridades y destinos místicos son usados para la dominación y el poder de algunos que quieren ser seguidos, así Self 
al din, nos presenta como el discurso místico puede ser malinterpretado, construyendo la realidad que agoniza en su destino prometido e inalcanzable (The phantom Agony).

La construcción sobre una realidad mentirosa y su experiencia en los sentidos, que nublan la razón y la conciencia, llevando a querer creer en un espacio de seguridad de la existencia mística como experiencia puede rastrearse en Sensorium.

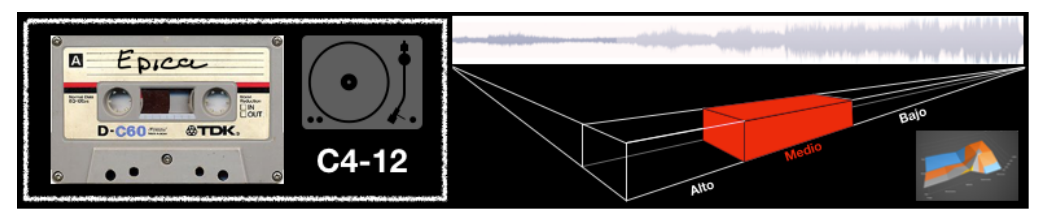

3 Verso. Planos de la sádica verdad: Abrazando la muerte.

En el último, pero más importante de los planos armónicos de Epica, el sonido constante de la batería como traqueteos, es un elemento que lo distingue, se trata del sonido de un doble bombo, con presencias de granos guturales, pero también de los coros, aquí la tensión musical se encuentra al máximo expresada, dando así una suerte de urgencia a lo que propone el discurso musical.

Aquí la fe en los principios místicos es puesta bajo toda tensión, pues la fe, garantiza la seguridad en la mentira de la realidad propuesta por el pensamiento místico, la lucha es entonces por romperla, por destruirla, por no dejar en pie la posibilidad de ocultarse en la fe para escapar de la incertidumbre de una realidad sin misticismos que permitan ocultar el miedo.

Así se produce el enfrentamiento a la verdad, la única verdad: la muerte. Los pensamientos místicos quieren sopesar el miedo a la muerte por medio de destinos, en los que se garantiza que los demonios de las épocas no podrán hacerse de los sujetos, así, la existencia es una batalla 
contra la muerte, tratando de escapar de ella, la propuesta de la lucidez, la conciencia y en últimas de la verdad, es abrazar la muerte como destino, comprender que ninguna lucha tiene sentido desde el orden místico cuando se comprende que la muerte es en sí misma la única verdad de la existencia.

En este escenario armónico, el grano gutural es tal vez, el más relevante, no en su número de apariciones en los fragmentos, sino por la construcción o mensajes incluidos en sus líricas, además del plano musical armónico fuerte con ritmo agitado y fuego, dejando así en evidencia una suerte de caída en el destino.

\section{Estribillo}

Los anteriores elementos se construyen a lo largo de todo el álbum, a excepción de la primera pieza, que abre con sonidos de coros en latín, a lo largo de todo el discurso musical de Epica, en la mayoría de las ocasiones que se presenta el grano gutural, éste se encarga de poner en tensión los elementos que se han construido con las otras texturas de los granos presentes, llevando poco a poco, pero de forma contundente a la consolidación de la muerte como destino y verdad.

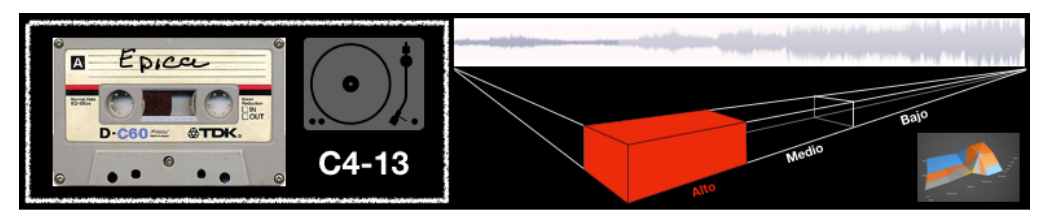

4 Verso. Generalidades del discurso musical The phantom agony.

A o largo del discurso musical propuesto por Epica, se construye un contenedor, la realidad, el cual cuenta con un espacio geográfico, que se separa por una marea, bajo ella se encuentra la verdad, arriba en el cielo se encuentran las promesas del destino místico, donde habitan los seres 
de ese orden, que se esconden tras la nubes y guardan silencio, así el acto de sumergirse bajo la marea en búsqueda de la verdad, por medio de la conciencia y la lucidez se trasforma en abrazar la muerte, que es en últimas la verdad.

Así, entonces, los poderosos sabiendo de este ejercicio, donde el miedo nos hace perder las ganas de sumergirnos, pues perdemos el destino, se apoderan del discurso místico para orquestar guerras, de allí los párrafos que se incluyen de Tony Blair, permitiendo de esta forma que el discurso de la muerte sea el que reemplaza el orden místico garantizando sus intereses en el mundo material.

La guerra de Irak después del 2001, termina por convertirse en un discurso místico desde el cual se sustenta la aniquilación de otros sujetos, todos en la búsqueda de superar sus miedos al destino y la persecución de los demonios de cada uno de los credos, invitando así a comprender que todas estas luchas no tienen sentido, pues la única verdad es la muerte, con la cual no se puede pelear.

15. Imagen textura y relaciones de los planos de The phantom agony de Epica

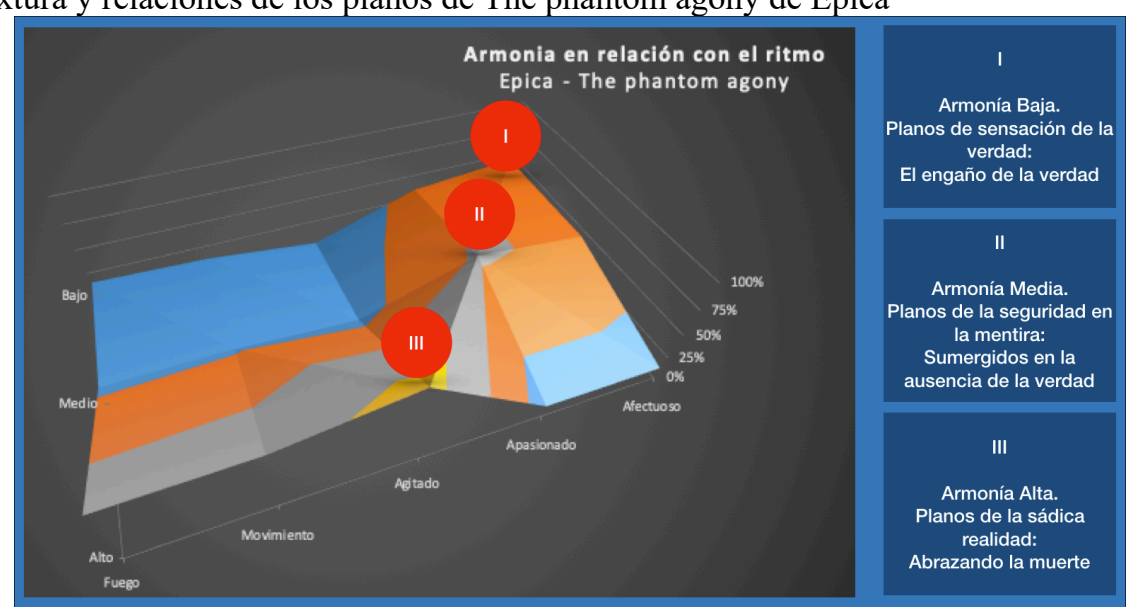

Fuente: Realizado por el autor de la investigación. 
Acorde con la gráfica anterior, desde la armonía baja se construye la idea de la realidad mística que permite salir o evitar el miedo de la verdad, construyendo planos de seguridad (armonías medias) en el orden místico como escape de lo que puede ser la verdad absoluta, que es entonces abrazada en la armonía alta, los planos de la sádica realidad: abrazando la muerte.

Ya reconocidos los elementos característicos de los cuatro discursos musicales (álbumes), es posible ahora pasar al último capítulo, el idioma de los dioses, donde se pondrán los elementos que se han construido en todos los capítulos anteriores en dialogo, permitiéndonos cerrar el proceso de investigación. 


\section{Capítulo 6}

\section{El idioma de los dioses: El discurso musical y los procesos de singularización.}

\section{Introducción.}

Llegamos así al Idioma de los dioses, una canción que da nombre a esta investigación, del rapero español Nash, la cual por su hechizo discursivo sobre la música en la vida, terminó por ser la más representativa de lo que se investigó a lo largo de este documento, de este proceso, donde la música es más de lo que se puede evidenciar en el proceso de objetivación realizado, en el cual, se logra contener el discurso musical como objeto de apropiación, en el cual a su vez, se rastrear particularidades, sobre el discurso y sus funciones en la producción de sentido en posibles sujetos oyentes del discurso.

Así las cosas, este capítulo de cierre, busca reconocer los objetivos que se rastrearon a lo largo del proceso, permitiendo de esta forma ir dando unas conclusiones, llevar la aguja del tocadiscos al centro del LP, llegar al momento donde el silencio que produce la ausencia de música anuncia el final de un momento de vida, de un momento de reflexión y construcción, en este caso, del idioma de los dioses.

Contemplando que el objetivo central de este proceso se enfoco en: describir el tipo de singularizaciones que se pueden producir a partir de los discursos musicales que componen el corpus de investigación, se ha querido que este capítulo reflexione en torno a esa idea, donde sea posible retomar otros elementos generados o construidos a lo largo de los cinco capítulos centrales de este texto. 
Así mismo, se ha contemplado los objetivos específicos, donde se consideró en un primer objetivo específico: Reconocer los procesos de producción y distribución que son empleados por los artistas que componen el corpus de investigación, elementos que se desarrollaron en el capítulo titulado "Muevan las industrias", donde se construyen elementos relacionados con la cultura capitalística, es decir, en cómo se traduce o compone la idea de la experiencia musical como el fetiche principal en la mercancía musical.

En un segundo espacio se buscó establecer las particularidades de los discursos musicales de las y los artistas que componen el corpus de la investigación en los diversos planos que componen el discurso musical, donde el capítulo "Brain Damage" se enfocó en el desarrollo de esas características contemplando la experiencia de escucha de los planos sonoros en relación con las líricas y los procesos metafóricos que en ellos pudieron ser evidenciados.

En un tercer espacio, se buscó consolidar las particularidades del discurso musical como objeto de investigación con sus singularidades específicas como proceso de objetivación, donde el capítulo "El pueblo unido jamás será vencido" y "Hurt", contemplan y construyen la objetivación del discurso musical, en relación con la ideología, el discurso y la cognición en diversos sentidos, así, se permite desde ese lugar de observación consolidar el objeto propio de un análisis de discurso musical que guiará el resto del proceso de producción que aquí se contiene.

Finalmente, en un cuarto espacio, el proceso se oriento a: reconocer las grietas o líneas de fuga presentes en los discursos musicales que puedan producir procesos de singularización, el cual se relaciona profundamente con el objetivo general de la investigación y que, como se mencionó en líneas anteriores, contará con su desarrollo a lo largo de este último capítulo. 
Para consolidar y lograr dar razón del objetivo general y de los procesos de singularización, este capítulo de cierre, se ha organizado en tres versos, en el primero de ellos, se retomará el hechizo discursivo que se encuentra contenido en cada uno de los álbumes del corpus, permitiendo pasar, a un segundo verso, en el cual se reconocen las particularidades del hechizo discursivo, llegando así al último de los versos, el discurso musical. Así entonces, iniciemos el

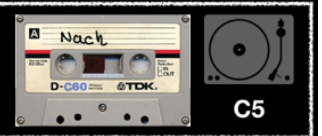
recorrido por estas discusiones de cierre en torno al discurso musical y los procesos de singularización.

\section{Verso. Hechizos discursivos en el idioma de los dioses.}

En este verso, se quiere reconocer que tipo de hechizos discursivos se producen en el marco del corpus, permitiendo de esta forma observar cuatro universos simbólicos diferentes, contenidos en los álbumes, donde es posible establecer los elementos de mayor relevancia o importancia además de vincular estos universos con formas diferentes de violencias que se desarrollaron a lo largo de los dos primeros capítulos (violencia, subjetiva, simbólica y objetiva), esto con el fin de reconocer cuales son los hechizos discursivos del corpus observado.

Iniciemos entonces, reconociendo que por la forma de construcción del corpus, por medio de relaciones entre lo real-local, real-global (contra hegemónico o underground) en relación con la realidad-local, realidad-global (Mainstream o hegemónico), se producen una serie de distinciones que se hacen evidentes a lo largo del análisis realizado en Brain Damage, donde se construyen cuatro universos simbólicos diferentes, retomando aquella categoría que Berger y Luckman (2005) construyen en la Construcción Social de la Realidad, sin embargo, para comprender este punto es necesario adentrarnos un poco más en la experiencia musical, donde, en este caso tomaremos como referencia otra forma de arte, la literatura, en la cual se encuentran las 
imágenes apropiadas para poder construir un álbum como un momento significativo, así las cosas:

"Nunca podrás abarcar la música en un solo instante, que tienes que esperar mientras transcurre, ir escuchando una nota detrás de otra y hacerte la ilusión de que estás aferrándola. Pero resulta que suena la última nota, regresa el silencio y todo se desvanece. Uno nunca puede tener la música aunque almacene todos los discos del universo; terminas de escuchar el disco, lo guardas en una funda y vuelve a ser una cosa entre las cosas. Lo único que uno hace es ser testigo de su paso, lo mismo que sucede con la vida" (Garay, 2019, pág. 115)

La anterior imagen de la literatura se hace necesaria en la medida que por el proceso de objetivación realizado al discurso musical, es preciso contemplar cada álbum como unidad, es decir, como la experiencia misma de la vida en el acto de escucha, en el cual se desarrollan experiencias, ideas y formas de comprender el mundo, de allí, que se iniciara con la idea del universo simbólico (Berger \& Luckmann, 2005) que transcurre en el acto de escuchar, de prestar atención a cada detalle sonoro que se emite, en ultimas, en la acto que implica la experiencia musical en su campo más significativo.

Así, cuatro universos simbólicos se nos presentan, la experiencia del (des)amor con Taylor Swift, la sexualidad con Maluma, la guerra preventiva con Lowkey y la muerte como verdad con Epica. En cada uno de ellos, a partir de los sonidos y las metáforas que se construyen en las formas que se toman del sonido, es posible reconocer algunos elementos de esos universos simbólicos que se relacionan con el hechizo discursivo y nos permiten comprender, al menos esos cuatro sentidos, en el mundo cotidiano. 
Inicialmente, podría pensarse que los dos álbumes provenientes del sector mainstream o hegemónico, son los que menor contenido o reflexión pueden permitir, ¿tienen acaso Taylor Swift y Maluma algo que decir de lo real?, la respuesta es: sí, tienen mucho que plantearnos, de allí que sea necesario entender que cada universo simbólico construye sus propias formas de lo real y de la realidad, evidenciando de esta forma las violencias (simbólica, subjetiva y objetiva), así las cosas, cada hechizo discursivo contiene en sí mismo forma objetivas de su reproducción.

En el primer universo simbólico sobre el (des)amor, en Taylor Swift, se puede reconocer a partir del contenedor metafórico (Lakoff \& Johnson, 2004) que emerge del proceso, al menos una forma de violencia subjetiva, donde el dolor de la heroína en el discurso expresa su experiencia frente al amor, esta experiencia opera sobre el sujeto como violencia, en términos del dolor que se expresa desde el pasado en las vivencias sobre el amor, dejando huellas, en la memoria, que en este caso determinan la experiencia del presente y el pasado, así el amor y su práctica, está determinada por la violencia subjetiva construida desde la experiencia del pasado. A su vez, la violencia simbólica se reconoce por fuera de la experiencia, en la construcción de los enemigos del amor, en este caso, se construye aquella idea de los cazadores que buscan destruir la experiencia amorosa, así se consolida la idea de un enemigo del amor que es simbólico y busca destruir constantemente la posibilidad del amor; así se juntan dos formas de violencia, la memoria y la experiencia como violencia subjetiva, sumada a la simbólica materializada en los enemigos de la relación.

Así, la violencia objetiva, se materializa en que las dos formas anteriores de violencia no permiten evidenciar o pensar en términos del amor como la experiencia en sí misma, en el aquí y ahora, lo que a su vez no permite reconocer el amor en un marco más amplio, como por ejemplo, 
resultado de una forma de garantizar las relaciones entre parejas para garantizar la reproducción del sistema, mediante el reconocimiento de la herencia de los hijos de la relación, como lo plantea "El origen de la familia, la propiedad privada y el Estado" (Engels, 2017), de esta forma, en el re-sentir la violencia subjetiva de las experiencias del pasado, y en la violencia simbólica de aquellos enemigos del amor, se hace casi imposible comprender la idea de como en el marco de la cultura capitalística, se construyen las pasiones (Guattari, 2017) que determinan, por ejemplo, la experiencia deseada del amor.

Acorde con lo anterior, la realidad en la que se instala el universo simbólico en el discurso musical de Taylor Swift, da razón del dolor y la profunda necesidad del amor en la vida, de allí que se hablara constantemente del (des)amor, donde se instala la violencia subjetiva y objetiva, permitiéndonos de esta forma reconocer lo real, en este caso relacionado con la forma en que el amor como expresión de una forma de organización de las relaciones en la cultura capitalística, permite, por ejemplo, la garantía de la herencia necesaria en el capitalismo, el amor entonces, se transforma en una forma del deseo por medio de la cual el sistema en sí mismo se reproduce en un nivel orgánico, la necesidad del amor.

A su vez, cuando realizamos un proceso similar en el caso de Maluma, se puede encontrar a lo largo del discurso como el hombre es construido a partir de las posibilidades de acceso al placer sexual, el cual, se encuentra en el territorio-mujer, espacio en el cual se construye al mismo tiempo la violencia subjetiva, en la medida que el hombre no cuenta con otras posibilidades de agencia, se encierra por lo tanto la experiencia y la posibilidad del hombre en su propia sexualidad, el lugar de mayor pulsión y deseo. Frente a esta violencia subjetiva, se presenta la imposibilidad de acceso al placer sexual, las mujeres (en general) que no son dignas del placer, o 
aquellas que son indecisas e infieles, es decir, las mujeres que no son fáciles en el acceso al sexo por parte del hombre, se constituyen como las formas de la violencia simbólica, donde además se encuentra la imposibilidad del desarrollo del hombre que, como vimos, se encierra en la experiencia sexual.

En este caso, la violencia objetiva, es decir, aquella que se oculta por medio de las otras dos violencias, se puede observar en la imposibilidad de asumir, por ejemplo, la cultura patriarcal, es decir, se construye una sola forma de relacionamiento entre hombres y mujeres, dejando de lado otras formas posibles, como por ejemplo, el poliamor, de hecho, también se oculta la forma de construcción de la sexualidad por fuera de la idea de la mujer como territorio del placer que es ocupado por el hombre, donde, sea la ocupación del hombre por parte de la mujer el origen o la forma del placer.

Lo anterior, nos lleva a construir una realidad en la que el hombre es el origen del placer, es quien lleva y entrega el placer a la mujer, una realidad contenida en la sexualidad y las pulsiones sexuales, a su vez, lo real, la mujer es reconocida como una suerte de mercancía por medio de la cual el hombre accede al placer, una mercancía construida al interior, de nuevo, de la cultura capitalística, el foco de la pasión en la pulsión sexual con una construcción específica, que ya observamos en líneas anteriores.

Hasta este punto, contamos con los dos discursos hegemónicos, en los cuales podemos observar la presencia de discursos que se encuentran en un orden individualizado, es decir, en los dos casos se relaciona toda la producción con la sexualidad y las relaciones de pareja, desde una mirada del sujeto en su contexto, pocos referentes territoriales o históricos (como observamos en Brain Damage), construyendo de esta forma desde el mainstream, formas de la cultura 
capitalística en la que sobresale la intensidad de la vida íntima, de allí que se afirme la individualización de los sujetos, elemento propio del capitalismo, en especial en escenarios como el capitalismo internacional mundializado (CIM) (Guattari \& Rolnik, 2005).

Al observar los discursos musicales contra-hegemónicos o underground, la experiencia como se evidenció en el capitulo anterior cambia, las relaciones a elementos específicos de la vida más amplia (social) e histórica se encuentran presentes, así las cosas, observemos que tipo de violencias y construcciones de lo real y la realidad se constituyen en Lowkey y Epica.

En el caso de Lowkey, un discurso musical construido en torno a la guerra preventiva después de lo hechos que tomaron lugar en New York en el año 2001, la violencia subjetiva se instala en los cuerpos que experimentan los bombardeos, ocupaciones y en general la guerra en espacios como Irak y Palestina, es decir, se instala en la muerte, en los pueblos que viven en carne propia la guerra preventiva, esta forma de violencia subjetiva que opera sobre los sujetos, cuenta con un origen o causante, se trata de la violencia simbólica, donde se construye un enemigo, que por su nombre mismo no puede reconocer un sujeto específico, se trata de Estados Unidos, Inglaterra e Israel, que como violencia simbólica son en si mismas un ejercicio metonímico, pues se cambian los sujetos que activan la violencia subjetiva (militares y políticos) por un Estado Nación.

Ahora bien, en este caso la violencia objetiva, aquella que ocultan las dos formas anteriores, se relaciona con el CIM (Guattari \& Rolnik, 2005), es decir, se ocultan formas de organización social, política y económica a lo ancho y largo del planeta, que constituyen formas del deseo mediante la cultura capitalística, en donde, por ejemplo no es posible observar los problemas relacionados con la distribución del poder en las sociedades contemporáneas (Bakunin, 1990), o 
el rol del Estado Nación en la garantía de los procesos propios del capitalismo y no de la defensa de los derechos humanos por fuera del proyecto capitalista en sí mismo (Marx, 2013).

Acorde con lo anterior, se construye una realidad en la que la violencia opera principalmente sobre sujetos, que son de territorios construidos como rebeldes o terroristas (de sombra), de esta forma esas condiciones son las que garantizan la violencia subjetiva desde los que representan la violencia simbólica, una realidad, en la que se construye el enemigo y se comprende al mismo, de acuerdo, a los intereses de aquellos que constituyen lo simbólico de la violencia. Frente a esta realidad, lo real, se encuentra en el ocultamiento, por ejemplo, del rol del Estado-Nación, en últimas, se podría decir, que en el ocultamiento de la cultura capitalística, en la cual se enmarca para este caso, el deseo por la libertad, propia del surgimiento del sistema capitalista (Marx, 2013), siendo a su vez, el mayor deseo de lucha, rebelión y resistencia.

El último de los discursos musicales: Epica, es tal vez el más complejo de todos, pues se relaciona íntimamente con lo que implica la noción del hechizo discursivo, pareciera así que esta banda se presentara pensando o presentando en su discurso musical elementos que se han desarrollado a lo largo de este documento. Lo anterior se comprende cuando la principal noción como se evidenció en los planos musicales de su discurso, se enmarca en la noción de verdad. Así, la violencia subjetiva se encuentra en la mentira que vive cada uno de los sujetos desde sus creencias, es decir, el sujeto en su contexto construye nociones de verdad, esas verdades son las que entregan los miedos a los sujetos, esos miedos son las manifestaciones de las violencias subjetivas, ahora bien, éstas cuentan (similar al caso de Lowkey) con un origen o responsable, se trata de la violencia simbólica, donde son los dioses y los seres del más allá los que entregan para el uso de otros sujetos, estas formas de conocimiento o explicación del mundo, así la violencia 
subjetiva da una forma particular de la verdad se encuentra originada en seres del más allá (ocultos) que son los que permiten esas producciones de sentido con un orden específico del mundo y la experiencia en el mismo.

La violencia objetiva, se puede vincular directamente con la violencia simbólica, pues no se trata de dioses o seres del más allá, que construyen formas de producción de la verdad y el sentido del sujeto en el mundo, se trata de otros sujetos que, disponen de estos discursos para garantizar procesos de dominación. Acorde con lo anterior, la violencia objetiva se encuentra en la forma como el pensamiento místico es utilizado como un mecanismo de poder, dominación y sometimiento, desde lo más profundo del ser, su producción de sentido, pulsión, deseo en torno a todos los ejes de la vida.

La realidad entonces, en esta caso se encuentra construida a partir de las nociones de verdad y sus relaciones con el orden místico, es decir con las creencias que como sujetos aceptamos e integramos en nuestros hechizos discursivos, permitiéndonos construir la forma de comprensión del mundo, a su vez, lo real, se encuentra en cómo lo místico no existe, sino se trata de la construcción de hechizos funcionales en la cultura capitalística, donde se opone la única verdad, es decir, la muerte como verdad única y absoluta, lo real es por lo tanto es la muerte como única certeza.

$\mathrm{Al}$ interior entonces, de los discursos musicales contra-hegemónicos o underground, se puede observar elementos un poco más amplios de la construcción del sentido, es decir, en este caso los discursos musicales del corpus, no se relacionan con lo íntimo, por un lado nos plantea todo un universo simbólico en torno a la guerra en el planeta contra el terrorismo, y por el otro lado, nos evidencia como las creencias colectivas de orden místico no tienen sentido frente a la verdad de 
la muerte. Se puede reconocer por lo tanto cuatro universos, en dos grupos distintivos con funciones diferente en el entorno mismo de la cultura capitalística, donde a su vez, permiten el construir o reconocer hechizos discursivos específicos.

Ahora bien, si ya observamos cuatro universos simbólicos que emergen desde los discursos musicales, permitiendo así establecer cuatro formas o hechizos discursivos, es necesario comprender que el discurso no se encierra en la materialidad del discurso contenido en lo musical, es decir, en el capítulo Hurt, se relacionó el hechizo discursivo en el caso de la música, con la experiencia del sujeto en el mundo vivido, es decir, reconocidos los elementos propios del discurso en sus estructuras, es preciso ahora pasar a reconocer en términos cognitivos que puede suceder con estos discursos musicales.

\section{Estribillo}

"Das sentido a mi existencia, tú desobediencia, / tú, sola presencia merece reverencia, / Tú me diste un don, fuiste espada, / siempre encerrada en tu prisión si la inspiración faltaba" (Sánchez, 2011), así abre la canción el cantante español Ignacio Fornés (Nach), para presentar lo que es para él la música, es como se pudo observar, la que entrega sentido a la existencia, así las cosas, se podría pensar como la existencia cobra sentido en este caso en cuatro direcciones, el (des)amor, la sexualidad, la guerra preventiva y la verdad, cuatro sentidos que se relacionan con planos y formas de la existencia.

Desde los discursos musicales como elementos contenidos en la objetivación que se realizó en este proceso, donde aún no se integra el sujeto oyente, es posible reconocer cuatro experiencias en las que se puede establecer que tipo de don o espada, permiten Taylor Swift, Maluma, Lowkey y Epica, dones que podrían considerarse desde lugares políticos diversos, pero, 
principalmente desde construcciones de deseos, miradas, anhelos, a partir de los cuales los hechizos discursivos consolidan coordenadas de sentido, diversos, en especial, esta imagen puede comprenderse a continuación.

\section{Verso. Particularidades del hechizo discursivo.}

Frente a los cuatro discursos musicales, pueden existir infinitas posibilidades interpretativas, la que se presenta en este documento, emerge de una análisis de sus estructuras, de sus ejercicios metafóricos y de sus sonidos, ahora bien, es la experiencia en el mundo del sujeto oyente el que puede producir el sentido y en éste el ejercicio de prácticas, recordamos entonces la discusión entre Umberto Eco y Jacques Derrida en torno al intérprete (Eco, 2000), donde el sentido del proceso semiótico se produce en últimas para Derrida en el intérprete, esta investigación también apuesta por el intérprete, en este caso materializado en el sujeto oyente, el cual desde su experiencia en el mundo vivido, como se observó a lo largo del capítulo Hurt, construye sus marcos mentales en procesos que se relacionan con la experiencia del mundo, permitiendo así la singularidad, y en ella, posibles ejercicios de singularización, es decir, estos procesos, se producen en un orden molecular (Guattari, 2017) en el sujeto al interior de sus prácticas, de allí que desde las mismas preguntas de investigación se planteara sobre las posibilidades de la singularización, comprendiendo la imposibilidad de abordarlas todas o de producir una suerte de leyes o elementos básicos que encierren la totalidad del proceso de producción de sentido.

Así las cosas, con el fin de retomar algunos elementos que se presentan en Hurt, y con el interés de generar unas pautas que permitan al lector comprender los sectores desde los cuales se rastrean los posibles procesos de singularización, se ha querido trabajar desde las pasiones que se pueden movilizar en los discursos musicales del corpus, a partir de la propuesta realizada en el 
texto El gobierno de las emociones (Camps, 2012) el cual fue abordado en Hurt, a partir de cinco experiencias o formas de las mismas, a saber: I) la vergüenza, II) la compasión, III) la indignación, IV) el miedo y, V) la confianza. Recordando que son las pasiones y las emociones, las que permiten la práctica de los sujetos, como lo plantea Nussbaum (2007), así ingresamos en el campo del proceso cognitivo del discurso musical.

De lo anterior que, por ejemplo, en Taylor Swift se construye la vergüenza en torno al pasado y la memoria que interrumpe las posibilidades del amor en el presente que se orienta al futuro, en Maluma se presenta como no llegar a ser el hombre que le brinda placer al territorio mujer que se desea o escoge, por otro lado la vergüenza en Lowkey, se expresa en la guerra preventiva como un acto que debería ser repudiado, mientras que para Epica, es el seguir los pensamientos místicos como ordenes sin ningún tipo de duda o capacidad crítica.

En términos de compasión, el daño que los otros producen sobre una relación amorosa se expresa en Taylor Swift, evocando la necesidad de reconocerla a ella como victima que busca compasión de los otros, similar a Maluma, que relaciona esta emoción con los hombres que no pueden entregar el placer a los territorios mujer que permiten su acceso, o de aquellas que engañan a los hombres. A su vez, los sin voz, los que la perdieron en conjunto con sus propias vidas y por eso no tienen voz, son el foco de la compasión el Lowkey, mientras que para Epica se relación con aquellos que no pueden vivir por fuera de los enmarcados que los saberes místicos les han planteado.

En una tercera pasión, la indignación se encuentra en el destino, es decir, no importa cuantos (des)amores se vivan, siempre de cuenta con ese destino del amor posible, y cada (des)amor, impulsa con más valentía la búsqueda del destino sin importar cuantas experiencias negativas se 
deba vivir, se puede rastrear en Taylor Swift, mientras que Maluma, presenta la indignación frente a las mujeres que no permiten el ingreso a sus territorios para llenarlas de placer, a las indecisas. Por otro lado Lowkey construye la indignación frente a los actores de la violencia simbólica, los países que bombardean y producen a los sin voz, se tratará entonces de esta pasión frente a Estados Unidos, Inglaterra e Israel, finalmente, el uso de los saberes místicos para la dominación y el ejercicio del poder sobre sujetos sin capacidad crítica, es la propuesta de Epica.

Al contemplar el miedo, siempre será posible que el destino del amor no se cumpla en Taylor Siwft, o que no se puede llenar de placer al territorio mujer en Maluma, mientras que, podemos seguir viviendo en un mundo que se construye sobre las ruinas de una guerra preventiva que produce millones de muertos en Lowkey y finalmente en Epica se materializa en seguir viviendo en una realidad enmarcada por otros, en la lógica de impedirnos pensar otras formas posibles de vivir o pensar el mundo.

Finalmente, la confianza, que se produce casi de frente al miedo, donde el destino en Taylor Swift, como su nombre lo indica siempre llegará, la posibilidad del amor es algo que tiene certeza en el futuro mismo, los hombres a su vez siempre tendrán la potencia y capacidad sexual de llenar de placer al territorio mujer en Maluma. Para Lowkey es preciso confiar en que las personas podrán comprender el orden de la guerra preventiva y así cambiar sus posiciones políticas frente a esa expresión de miseria y muerte, similar a Epica, quien plantea la confianza en que muchos podrán romper el velo de la realidad, rompiendo con los saberes místicos permitiendo la muerte.

Estas posibilidades de las pasiones frente a los discursos musicales, siempre se relacionarán con la experiencia del sujeto en el mundo vivido, así las cosas, lo que se acaba de presentar, es la 
lectura de un sujeto en especial, el que escribe esta investigación y cuenta con una experiencia en el mundo, una experiencia que no sólo atraviesa sus contenidos musicales, sino también todas sus formas de subjetividad y de singularidad, permitiendo así la construcción de una lectura, entre muchas otras posibilidades, es decir, se trata de un interprete (sujeto oyente) que busca dejar en evidencia las lecturas que encontró en un proceso de lectura juiciosa y ante todo de oyente de los discursos musicales.

Esa experiencia en el mundo vivido, no es absolutamente singular, aunque se trate de un sujeto en especifico, éste se encuentra inmerso en un proceso cultura, en un contexto (co-texto), el cual se ha buscado dejar en evidencia constantemente por medio de la noción de la cultura capitalística, la cual, permite la consolidación de lo que Guattari denomina como hombresmaquina, los cuales producen, entre las cosas que producen, se encuentran los deseos, las pasiones y las emociones, pero éstas producciones se encuentran en el marco del capitalismo, pues éste ha permitido adentrarse en las producciones de los elementos más íntimos del sujeto, a partir de sus pulsiones, por ejemplo (Guattari, 2017).

Esto implica que la subjetividad se encuentra en un co-texto que determina las formas del sentido, pero a su vez las experiencias permiten diferenciarnos entre todos, donde nos consolidamos en la singularidades, que son en gran medida resultado de las experiencias en el mundo vivido, recordemos los ejemplos que se plantearon en el capitulo Hurt, ahora bien, una forma de comprender o de aproximarnos a esa perspectiva de la cultura capitalística se encuentra en el capítulo Muevan las industrias, donde por ejemplo, se logro evidenciar como cada uno de los álbumes en términos de su producción y distribución cuentan con la relación de diversos agentes, por medio de los cuales se garantiza la construcción de sentidos, pasiones y 
posibilidades que permitan el consumo final de sujetos, así entonces, por ejemplo, de no ser por esta investigación, quien construye la misma, jamás hubiera accedido a los discursos de Maluma y Taylor Swift, pues la experiencia del mundo vivido no se relaciona con estos tipos de discursos musicales, siendo estos a su vez, los que produjeron rupturas en el hechizo discursivo, es decir, llevaron a la construcción de pensamientos no pensados, vale decir a la singularización.

Ahora bien, si pudiésemos pensar en los hombres-máquina que pueden surgir de cada uno de los álbumes que materializan el corpus de la investigación, se podría pensar inicialmente que Taylor Swift construye un hombre-máquina que desea constantemente la experiencia del (des)amor como experiencia vital de la vida, a su vez en Maluma la posibilidad del éxtasis, en clave de experiencia sensorial desde el placer sexual en la ocupación de la mujer, dos hombresmaquina al servicio de la cultura capitalística más profunda, donde el hechizo discursivo hegemónico no es puesto en mayor tensión, sin embargo como se observará más adelante, estos elementos no pueden ser abordados de forma direccional absoluta.

A su vez, en Lowkey se podría reconocer un hombre-maquina que se encuentra constantemente en el deseo de la caída de los imperios y en la lucha por evidenciar las perversidades del sistema económico y político, entrando casi en la idea de la militancia política, mientras que Epica nos propondría un deseo por el rechazar cualquier tipo de pensamiento que nos proponga un futuro infinito, abrazando entonces la idea de la muerte en un futuro finito.

Diversas formas de lo real y de la realidad surgen, presentadas hasta este momento, acompañadas de las violencias, algunas de ellas funcionales a lo que denominamos como hegemonía, en otros casos de orden contra-hegemónico, esto podría hacer pensar que cada una de ellas llevaría a formas específicas de singularizaciones, sin embargo, como plantea Lakoff 
(2007), o Lauclau (2014), estas no pueden existir de forma absoluta, requieren de la presencia del otro para su propia existencia, así, la negación reafirma en sí mismo, es decir, cuando por ejemplo, se plantea el destino y la esperanza del mismo en Taylor Swift se niega esa posibilidad también, y es justamente, en esos ejercicios y posibilidades donde se abren las singularizaciones.

Para este caso y desde la experiencia de quien escribe estas líneas, se quiere presentar algunos elementos que salen del texto científico, es decir, se enmarcan en la experiencia misma de las violencias que se movilizan en un investigador, en los pensamientos y reflexiones que surgieron a lo largo del proceso. Así entonces, en cada uno de los álbumes se produjeron efectos, reflexiones y pensamientos que modificaron algunos hechizos discursivos del autor de esta investigación.

En el caso de Taylor Swift, el amor como dolor, el amor como espera y complemento, llevó a revisar y a generar una aproximación a lo que se denomina como amor romántico, pero principalmente, permitió entrar en crisis frente a las formas en que se vivieron y viven las relaciones de pareja, dejando de lado, aquella idea que es el entorno, el que malogra o daña las experiencias del amor, llevando a repensar que se sueña o se desea de la experiencia con otra persona en lo que se reconoce una relación de pareja.

El territorio mujer como depósito de la sexualidad y el placer en Maluma, llevo a una reflexión sobre la sexualidad, sobre las formas en que una relación de pareja puede ser construida y deseada desde ese orden, sin comprender o abrir la posibilidad de otras formas posibles de relacionarse, es decir, en este caso se sintió lo que se denomina matriz patriarcal en el cuerpo del investigador, una ruptura muy violenta, pues se trata de reconocer estos hechizos discursivos de la cultura capitalística en clave patriarcal, en el cuerpo de un sujeto que lee, y que busca 
reconocer la teoría de género y los aportes feministas en sus prácticas cotidianas, ese mismo sujeto se encontró en una perspectiva sexual de la mujer como deposito del placer, tal vez la mayor ruptura de quien escribe este texto provino del discurso que parecía inicialmente el más incipiente, el PB/DB de Maluma.

Para el caso de Lowkey, un artista conocido antes de esta investigación, el proceso fue de dolor, reconocer como un discurso que se consideró como contra hegemónico, de resistencia y oposición política, termina reafirmando la existencia y necesidad del Estado Nación, sin poder poner en tensión la distribución del poder al interior de las sociedades, llevó a comprender como ese discurso en sí mismo termina por ratificar y solidificar la cultura capitalística, un hechizo discursivo que desde las márgenes de la lectura del sistema reafirma los límites del mismo y por lo tanto encierra aún más la posibilidad de pensar otras formas posibles de organización social, la responsabilidad del cambio se le entrega a las instituciones, de lado el sujeto y su agencia política, en clave molecular como plantea Guattari (2017), quien sería al cierre de esta investigación un autor que llevaría incluso a poner en tensión los discursos propios de la experiencia del mundo vivido por el autor, como se evidencia en las líneas de este párrafo.

Finalmente, en el caso de Epica, otro álbum conocido y disfrutado, el cual en parte da origen a este proceso de investigación, terminaría por convertirse en sí mismo en un hechizo discursivo místico, es decir, en su pelea por desestabilizar el orden místico, el mismo se constituye en ese otro orden místico, donde la muerte es el destino y se debe abrazar, de forma similar al nirvana o el cielo, es el destino final, un nuevo orden místico, y en él, la incapacidad de poder pensar el mundo de formas absolutas o relativas, es decir, la condena eterna a los hechizos discursivos 
sobre los cuales tratamos día a día de consolidar y construir el sentido de nuestras vidas en el aquí y ahora, pero también en el pasado y los posibles futuros.

Antes de seguir con el siguiente verso, es preciso reconocer que aquí se presentan desde el sujeto con sus singularidades los procesos de singularización que vivió en un proceso de investigación titulado el idioma de los dioses, ahora bien, se trata de una experiencia, de un solo intérprete, con una experiencia del mundo vivido, se abren por lo tanto todas las posibles experiencias en torno a estos sentidos, donde por ejemplo, las experiencias del mundo vivido por el lector de este texto, en este momento, pueden conducirlo(a) a otras posibilidades diferentes, de acuerdo a esas experiencias previas en el mundo vivido. La singularización por lo tanto es una experiencia molecular (Guattari, 2017), donde se genera la re-vuelta, el viaje hacia adentro del sujeto en sus singularidades para movilizar y poner en tensión sus propias prácticas y hechizos discursivos, y en esos cambios que conlleva la singularización se produce la revolución, de nuevo en clave molecular, la revolución en términos de escapar por una grieta, una línea de fuga, momentáneamente de la cultura capitalística.

\section{Estribillo}

"Me das retos, aventuras y responsabilidad, / me das éxito y dinero me quitas la intimidad, / me exiges crear, me haces temblar, soñar, me curas / me eliges para hablar si las calles están mudas” (Sánchez, 2011), estas líneas en clave de rap, con sonidos densos, cada vez más densos a medida que avanza la pieza musical, significan más de lo que la letra encierra, experiencias del pasado, pasiones y cariños, amistad, como se referencia en la dedicatoria de esta investigación, el título de esta investigación se encontró en una red social, posteada por un amigo de años pasados. Al escucharla, por ser recomendada de alguien a quien se le otorgó un conocimiento 
musical valioso, se sintió alegría, pasión y ante todo, se generó una forma de compromiso, la experiencia musical en una canción recomendada por alguien del pasado.

Esa pequeña historia sobre lo que es la música para Nach, produjo reflexiones, conducentes a toda una tesis doctoral, en la cual, se ha querido explorar la música y sus posibles relaciones con las singularizaciones, toda una experiencia del mundo vivido materializado en un proceso de varios años. En la que en este punto, se reduce a un párrafo de la letra de la canción, en la que la música se permite otorgar a los oyentes, rutas, caminos, senderos, faros, entre muchas otras posibilidades.

\section{Verso. El discurso musical.}

El discurso musical, en este campo, es preciso iniciar por la idea de lo contextual de la música, elemento que se abordó en la idea de lo bueno o lo malo de la música (Dahlhaus \& Eggebrecht, 2012), donde es posible comprender entonces, como el discurso musical se debe comprender en el orden de su contexto, el cual no solo se relaciona con el espacio físico o el momento en el que se escuchan los discursos, sino que como observamos en los últimos párrafos del verso anterior, también se trata del oyente, de su historia de vida, así se nos vinculan dos elementos, por un lado el contexto físico y por el otro, lo que podemos denominar el contexto singular del oyente.

Estos dos contextos en su interacción abren aún más las posibilidades del intérprete (sujetooyente) en la producción de sentido, desde, en, y modificando posiblemente los hechizos discursivos, recordemos, por ejemplo, que los scripts nos permiten comprender el guion de acción frente a situaciones específicas, de la misma forma, estos pueden condicionar los tipos de 
escucha, sin llegar a ser plenos o absolutos esos esquemas o formas de abordar el discurso en sí mismo, pues los contextos y sus variaciones pueden producir casi que infinitas posibilidades de escucha, superando así la idea de los tipos de escucha planteados por Adorno (2006).

Al comprender este ejercicio, es posible retomar la propuesta de la música y lo inefable, donde se establece, por ejemplo, que la música no significa nada (Jankélécitch, 2005), refiriéndonos a la garantía de un proceso semiótico compartido por grupos de poblaciones amplios, o si se quiere por culturas y sociedades. Frente a la música nos enfrentamos a lo inefable, su ausencia de significado colectivo, en la medida que la experiencia del sujeto en el mundo marca, o establece las posibilidades de la significación, en un marco singular que como observamos a lo largo de toda esta investigación pueden manifestarse en la singularización, donde los hechizos discursivos se modifican, mutan y cambian, siempre en movimiento, pero nunca en su ausencia plena, así un mismo discurso puede generar, evocar y producir sentimientos, pasiones o reacciones totalmente diferentes, llevándonos de esa forma a prácticas sociales también diferenciadas. Lo inefable en este caso, se relaciona con lo contextual de la música, de allí, que por ejemplo, en el caso de quien escribe estas líneas, en el contexto de una investigación con unos intereses de escucha de un discurso musical, realizando una escucha atenta y sistemática por el contexto investigativo, se termine realizando todo un ejercicio reflexivo, en el orden de la singularización, en torno a Maluma, mientras que en otros casos, se pudo pasar al baile o a la crítica por la ausencia de instrumentos o armonías más elaboradas.

El ejemplo anterior, sumado al hecho que el mismo lector de este documento puede estar contrariado, con lecturas opuestas, contrarias o similares de los mismos discursos musicales, es la materialidad de la experiencia en el mundo vivido, sumado además al contexto tanto del 
proceso de escucha, como la tecnología utilizada, sumado a la presencia o no de una finalidad o apropiación del discurso musical, en últimas, nos aproximamos a la idea de lo inefable (Jankélévitch, 2005), la incapacidad de garantizar un sentido único sobre un discurso.

Lo inefable en relación con la historia de vida, o el mundo vivido por el oyente, es el punto tal vez de mayor relevancia en el proceso de reflexión que evoca el idioma de los dioses, donde todos esos elementos se relacionan íntimamente con la experiencia sonora, no a cualquier oyente resulta atractiva las combinaciones de granos que se encuentran en el discurso de Epica, pero en algunos casos puede ser una obra magistral que de hecho hace cobrar sentido al nombre de la banda épica. De igual forma, de acuerdo, a las experiencias sonoras, tal vez los discursos que se integran a lo largo The Soundtrack to the struggle, son solo ruido, sin sentido, elementos incorporados para rellenar un álbum, o pueden ser elementos categóricos de sentido, o pistas para continuar pesquisas sobre los recorridos que se configuran al interior del discurso musical.

Cuando se establece la concepción de la experiencia musical previa y actual, como elemento central de la música contextual en lo inefable, se hace necesario comprender que la música se lee con los oídos, como se señaló al inicio de este capítulo, con las palabras de Garay, es por lo tanto casi imposible separarnos de la idea del lector, el cual no es leído desde la concepción de lo ideal, sino desde un contexto con una historia lectora, resaltando tres elementos muy interesantes: el acceso, la disponibilidad y la materialidad (Guzmán \& Acero, 2019), desde los cuales es posible asumirlos en la experiencia musical del sujeto oyente.

Cuando nos planteamos el acceso, la experiencia en el mundo vivido por un sujeto oyente en especial, nos llevaría a preguntarnos por su historia oyente, ¿qué géneros pudo escuchar de niño? A que tipos de discursos musicales se aproximó, en que momentos de la vida, es decir, se trata 
prácticamente de comprender la relación entre la historia y los sonidos en discursos musicales que acompañaron todo ese proceso de vida, recordemos así que esos sonidos serán parte constitutiva de los entramados neuronales en la experiencia vivida del mundo, así entonces, sonidos, expresiones y demás pueden movilizar marcos mentales específicos, llevándonos así de nuevo a aquellas ideas que se relacionan con la sinestesia (Sacks, 2007), los sonidos musicales de los discursos musicales, de esta forma mediante la idea del acceso, marcan momentos, experiencias, sentidos de vida, así, se transforman en una suerte de banda sonora de la vida, y en ese sentido entran desde la experiencia del sujeto oyente a determinar las expresiones o sentidos que pueden evocar al enfrentarse a un discurso musical específico. La música contextual se relaciona por lo tanto con las experiencias frente los discursos musicales a lo largo de la vida, así articulan posibles sentidos, singularidades y singularizaciones.

Frente a la disponibilidad, de nuevo los contextos materiales son muy importantes, el territorio geográfico, los consumos e industrias que disponen de procesos de distribución de discursos musicales, no todo sujeto oyente podrá contar materialmente con el acceso a los mismos tipos de acceso o disponibilidad de discursos musicales, tengamos en cuenta por ejemplo la disposición de discursos que se consideran de alta clase, Bach, no se escuchara en cualquier contexto, por lo tanto, el sujeto oyente puede incorporar o no este tipo de experiencias musicales en su historia de vida, de acuerdo también a los lugares que se ocupan, podría aquí plantearse desde la idea de clase o desde sus propios capitales (cultural, social y económico) (Bourdieu, 2000), donde en términos de herencia en su lugar podrá acceder o no a determinados discursos musicales que moldearan la experiencia sonora, de forma similar a la experiencia lectora (Guzmán \& Acero, 2019). 
El acceso y la disponibilidad, nos permiten comprender como lo inefable de la música, se construye justamente en la experiencia del sujeto en el mundo y sus posibles relaciones con los discursos musicales, en este caso desde dos lugares, desde las relaciones en la historia de vida con los sonidos (a forma de banda sonora) y éstos en relación al contexto material, las posibilidades de distribución y los consumos culturales en los que se desarrolla la experiencia en el mundo del sujeto oyente. El tercer elemento que nos permite reconocer este ejercicio es la materialidad, donde es preciso recordar la discusión que se produce en torno a la industria cultural musical en Muevan las Industrias, donde se evidencian los cambios en los formatos o en los dispositivos por medio de los cuales es posible acceder a la mercancía musical, en la cual, recordemos, se plantea el fetiche en la experiencia musical, que ahora nos aborda como el foco central de lo inefable de la música y de la música contextual.

En esas líneas, de Muevan las Industrias, y en el análisis que se realiza de los álbumes al interior de los procesos de producción y distribución, se realiza en un momento el rastreo del tipo de soportes en los cuales es posible encontrar los discursos del corpus, en este punto, la experiencia del sujeto-oyente resulta relevante de nuevo, pues es desde esa historia que podrá contar con acceso a diversos soportes y encontrar en ellos formas diferentes de apreciación del discurso musical, por ejemplo, para la realización de este proceso se utilizaron archivos de audio de alta calidad, archivos que fueron transformados a señal análoga mediante un DAC externo al computador para poder evitar la incorporación de ruidos provenientes de las placas de la computadora, además se escucharon las piezas por medio de unos audífonos de monitoreo propios de los procesos de edición musical. Esta experiencia puede ser radicalmente diferente si se realiza con unos audífonos genéricos con el convertidor de digital a análogo que tiene un celular inteligente, con formatos de audio de baja calidad. 
Así en la materialidad, se reconocen muchos elementos, conocimientos y experiencias que desarrolla el sujeto oyente, en relación con el acceso y la disponibilidad, donde se termina entonces de comprender como el discurso musical, se transforma no sólo en la banda sonora, sino además brinda diversas formas contextuales que pueden variar en relación con las singularidades la apropiación y el acto de escucha del discurso musical, de nuevo, podemos comprender el orden de lo inefable de la música, que ahora nos conduce en torno a un elemento que ha sido mencionado en líneas anteriores, lo molecular.

Lo molecular implica o se relaciona con el sujeto, la subjetividad, lo singular en ese proceso de producción de subjetividades y allí la posibilidad de la singularización (Guattari \& Rolnik, 2005), se trata por lo tanto de un proceso íntimo, relacionado con la experiencia del sujeto en el mundo vivido, es decir, lo molecular tiene que ver con lo inefable, no puede ser asumido o construido en colectivo, es el sujeto en su experiencia y por eso la dificultad de garantizar la misma significación en grupos de sujetos que escuchan los mismos discursos musicales, pues como sujetos singulares pueden generar singularizaciones igualmente singulares.

Así entonces lo molecular se relaciona con la re-vuelta, comprendiendo por ella la posibilidad del sujeto de adentrarse en sí mismo, de encontrarse de frente con sus hechizos discursivos y modificarlos (singularización) generando así cambios en sus estructuras y coordenadas de significación del mundo cotidiano, de su experiencia misma en el mundo. Esa experiencia de revuelta se transforma por medio de las prácticas en ejercicios re-volucionarios, pues se transforman no solo las coordenadas sino que también con ellas las prácticas, se trata de la revolución molecular (Guattari, 2017). 
Así entonces, el arte, la música y en especial el discurso musical, abre las posibilidades de la experiencia del sujeto en el mundo, no solo estableciendo una banda sonora de la vida, como se evidenció en líneas anteriores, sino que también modifica y abre las posibilidades de singularizaciones en sujetos oyentes, tal vez, como se mencionó en El pueblo unido jamás será vencido, el discurso musical ha sido utilizado con propósitos de propaganda, de adoctrinamiento político o de entrenamiento militar, y es por este tipo de ejercicios que la música es no solo sujeto de la industria cultural musical que reproduce la cultura capitalística, también es perseguida, en especial bajo modelos de poder autoritarios, pues la música, como el arte, desborda los procesos de significación, y allí la singularización y las revoluciones moleculares pueden poner en tensión los ordenes sociales establecidos, el status quo.

Nos queda una última idea por desarrollar, vinculada con lo inefable que trabajamos desde la propuesta de Jankélévitch, a su vez Quinard (2011) señala que la música no re-presenta nada, es decir, no puede ser asumida en su discurso como formas o practicas totalizantes o generales, se trata por lo tanto de una forma del discurso que nos lleva a re-vivir (Quinard, 2011), a re-sentir la experiencia de la vida, y es justamente en ese proceso que puede modificar las estructuras y coordenadas de los hechizos discursivos. Cuando asumimos los procesos ideológicos como una característica compartida en todo su sentido, perdemos la posibilidad de agencia y singularización, borramos la singularidad, así las cosas, los hechizos discursivos comparten fragmentos de las producciones de sentido, pero no pueden ser totales o universales, pues son sujetos singulares quienes las viven y sienten en sus coordenadas de sentido del mundo.

Lo anterior, implica comprender que por ejemplo, cuando comprendemos que la música no re-presenta, nos referimos a esa idea que generaliza la experiencia humana en el mundo, mientras 
que el re-sentir, re-vivir, se relaciona con lo más íntimo del sujeto que experimenta el mundo y en esas experiencias, construye, modifica y en últimas fluye a través del mundo desde sus hechizos discursivos, que, en este caso, puede modificar a través de los discursos musicales, que por esa posibilidad de re-sentir el mundo, y las experiencias, cuenta con una potencia que otras experiencias del y en el mundo, no pueden generarse de la misma forma. Es en el discurso musical donde se puede comprender de mejor forma los movimientos de los hechizos discursivos y sus variaciones a través de los procesos de singularización, modificando no sólo la experiencia del mundo vivido, sino que además nos permite fluir en nuevas coordenadas de la producción de sentido, retomando aquella idea de pensar el pensamiento no pensado.

\section{Estribillo.}

"La grandeza de John Coltrane improvisando con el saxo, / la mirada niñada de Michael Jackson. / Y es que tu son me sedujo, tu luz me dejo perplejo y caí, / reviví como el son en la forma de Soul y R\&B” (Sánchez, 2011), Es la música la que nos hace re-vivir muchas cosas, sin importar a donde lleguen estas palabras, este texto, sin duda, las 60 piezas musicales que componen este ejercicio investigativo, interpretado por cuatro artistas, se constituyeron ya como parte de la banda sonora de la vida del autor de este texto, siempre que suenen esas melodías, serán recordados los seis capítulos, por sus nombres y sonidos, pero principalmente, lo que será re-vivido serán los procesos de cambio, que evocó y produjo el idioma de los dioses.

Lo anterior, enmarcado siempre en el cambio, en recordar constantemente que los hechizos discursivos son cambiantes, que en los momentos apropiados se comportan como una pieza de jazz, que se improvisa, la vida en sí misma se compone en unos marcos (hechizos discursivos) que se mueven constantemente de acuerdo con las capacidades de improvisación 
(singularizaciones) que llevan a consolidar nuevos marcos para continuar con la interpretación de la vida misma. De allí, que el idioma de los dioses se relacione con la forma en que significamos la vida, con los hechizos discursivos y con muchas categorías metafóricas, desbordando en muchos casos los cánones científicos, de ser una pieza musical, este texto debería tratar de ser un jazz, que se improvisó en su composición, en la medida que se fue construyendo cada nota, palabra, sonido y reflexión. 


\section{Bibliografía}

\section{Libros}

Adorno, T. (2006). Escritos musicales I-III. Madrid: Akal

Bakunin, M. (1990). Escritos de filosofía política I: Crítica de la sociedad. Madrid: Alianza editorial.

Bellon, M. (2010). El ABC del Rock. Bogotá: Santillana.

Berguer, P., Luckmann, T.(2005). La construcción social de la realidad. Buenos Aires: Amorrortu.

Bolaño, C. (2013). Industria cultural, información y capitalismo. Barcelona: Gesdisa.

Bourdieu, P. (2000). La distinción. Bogotá: Taurus.

Browne, R. (2009). De la comunicación disciplinaria a los controles de la comunicación. Sevilla: Alfar.

Browne, R. (2014). El campo en disputa: discontinuidades, postautonomías e indisciplinas de la comunicación y la cultura. Santiago de Chile: RIL editores.

Camps, V. (2012). El gobierno de las emociones. Barcelona: Herder.

Copland, A. (2014). Cómo escuchar la música. México: Fondo de cultura económica.

Dahlhaus, C., Eggebrecht, H. (2012). ¿Qué es la música?. Barcelona: Acantilado. 
Deleuze, G., Guattari, F. (2004). Mil mesetas: Capitalismo y esquizofrenia. Valencia: Pretextos.

Deleuze, G., Guattari, F. (2001) ¿Qué es la filosofía?. Barcelona: Anagrama.

Durkheim, E. (1928). El suicidio. Madrid: Editorial Reus.

Eagleton, T. (1997). Ideología: una introducción. Buenos Aires: Paidós.

Eco, U. (2000). Los límites de la interpretación. Barcelona: Lumen.

Engels, F. (2017). El origen de la familia, la propiedad y el estado. Moscú: Editorial Progreso.

Giraldo, J. (2011). Música champeta y africana en el caribe colombiano. Córdoba: Babel.

Gramsci, A. (1975). Los cuadernos de la cárcel: tomo 1. México: Ediciones Era.

Guattari, F. (2017). La revolución molecular. Madrid: errata Naturae.

Guattari, F., Rolnik, S. (2005). Micropolítica: cartografías del deseo. Madrid: Vozes.

Guzmán, D., Acero L. (2019). La lectura en Colombia: formas de estudiarla y promoverla. Bogotá: Filomena edita.

Habermas, J. (2011). Teoría de la acción comunicativa: complementos y estudios previos. Madrid: Cátedra.

Han. B. (2017). Psicopolítica: neoliberalismo y nuevas técnicas del poder. España: Herder. 
Hardt, M., Negri, A. (2000). El imperio. Cambridge: Harbard University press.

Hosbawn, E. (1998). Historia del siglo XX. Buenos Aires: Grijalbo.

Illescas, J. (2015). La dictadura del video clip. Barcelona: el viejo topo.

Jankélévitch, V. (2005). La música y lo inefable. Barcelona: Alpha Decay.

Laclau, E. (2014). Los fundamentos retóricos de la sociedad. Buenos Aires: Fondo de cultura económica.

Lakoff, G. (2013). Puntos de reflexión: manual del progresista. Barcelona: Península.

Lakoff, G. (2007). No pienses en un elefante. Madrid: Editorial Complutense.

Lakoff, G., Johnson, M. (2004). Metáforas de la vida cotidiana. Madrid: Cátedra.

Lynskey, D. (2011). 33 revoluciones por minuto: historia de la canción protesta. Barcelona: Malpaso.

Maconie, R. (2007). La música como concepto. Barcelona: Acantilado.

Mallarino, C. (2010). Un modelo para armar: teorías y conceptos del desarrollo. Lima: Fondo editorial universidad católica de Perú.

Marx, K. (2014). El cpaital vol 1. México: Fondo de cultura economíca.

Marx, K. (2013). Páginas malditas: sobre la cuestión judia y otros textos. Buenos Aires: Ediciones Narres. 
Marx, K. (1986). Grundrisse. México: Siglo XXI

Nussbaum, M. (2017). Paisajes del pensamiento. Barcelona: Paidós.

Pardo, N. (2013). Como hacer análisis crítico del discuros: una perspectiva latinoamericana. Bogotá: OPR-Digital.

Pardo, C. (2001). La escucha oblicua: una invitación a jhon cage. Madrid: Sexto piso

Quinard, P. (2011). Butes. México: Sexto piso.

Sacks, O. (2007). Musicophilia: tales of music and the brain. New York: Vintage.

Vam Dijk, T. (2010). Estructuras y funciones del discurso. México: Siglo XXI.

Veron, E. (1996). El discurso político. Buenos Aires: Hachette.

Wallerstein, I. (2003). Abrir las ciencias sociales. Buenos Aires: Siglo XXI.

Wallerstein, I. (2005). Análisis del sistema mundo. México: Siglo XXI.

Weber, M. (1996). Economía y sociedad. México: Fondo de cultura economíca.

Weber, M. (2015). Los fundamentos racionales y sociológicos de la música. Madrid: Tecnos.

Zîzêk, S. (2009). Sobre la violencia: seis reflexiones marginales. Buenos Aires: Paidós. 


\section{Capítulo de libro.}

Adorno, T. Del L. (2008). Ideología: un mapa de la cuestión. En P. Zîzêk, S (Eds.), Mensaje en una botella (pp. 43-76). Buenos Aires: Fondo de cultura economíca.

Althusser, L. Del L. (2008). Ideología: un mapa de la cuestión. En P. Zîzêk, S (Eds.), Ideología y aparatos ideológicos del estado (pp. 115-156). Buenos Aires: Fondo de cultura economíca.

Benhabib, S. Del L. (2008). Ideología: un mapa de la cuestión. En P. Zîzêk, S (Eds.), la crítica de la razón instrumental (pp. 77-114). Buenos Aires: Fondo de cultura economíca.

Bourdieu, P., Eagleton, T. Del L. (2008). Ideología: un mapa de la cuestión. En P. Zîzêk, S (Eds.), Doxa y vida cotidiana: una entrevitsa (pp. 295-308). Buenos Aires: Fondo de cultura economíca.

Condor, S., Antaki, C. Del L. (2000). El discurso como estrutura y proceso. En P. Van Dijk, T (Eds.), Cognición social y discurso (pp. 453-490). España: Gedisa.

Dews, P. Del L. (2008). Ideología: un mapa de la cuestión. En P. Zîzêk, S (Eds.), Adrono, el postestructuralismo y la crítica de la identidad (pp. 55-76). Buenos Aires: Fondo de cultura economíca.

Firth, S. Del L. (2001). La otra historia del rock. En P. Firth S., Straw W., y Street J (Eds.), La industria de la cultura popular (pp. 53-85). Barcelona: Manon tropo. 
Lacan, J. Del L. (2008). Ideología: un mapa de la cuestión. En P. Zîzêk, S (Eds.), El estadio del especomo como formador del yo(je) tal como se nos revela en la experiencia analítica (pp. 107-114). Buenos Aires: Fondo de cultura economíca.

Pêcheux, M. Del L. (2008). Ideología: un mapa de la cuestión. En P. Zîzêk, S (Eds.), El mecanismo del reconocimiento ideológico (pp. 157-168). Buenos Aires: Fondo de cultura economíca.

Rorty, R. Del L. (2008). Ideología: un mapa de la cuestión. En P. Zîzêk, S (Eds.), Feminismo, ideología y deconstrucción: una perspectiva pragmatista (pp. 253-262). Buenos Aires: Fondo de cultura economíca.

Ruiz, J. Del L. (2015). Signatura. En P. Nitrihual, V., Fierro, J. (Eds.), Semiótica del miedo social (pp. 123-143). Temuco: Ediciones Universidad de La Frontera.

Sierra, B. Del L. (1991). Psicología de la memoria. En P. Ruiz, J. (Eds), Los esquemas: su representación y funciones de la memoria (pp. Sd-Sd). Madrid: Alianza.

Straw, W. Del L. (2001). La otra historia del rock. En P. Firth S., Straw W., y Street J (Eds.), El consumo (pp. 87-112). Barcelona: Manon tropo.

Theberge, P. Del L. (2001). La otra historia del rock. En P. Firth S., Straw W., y Street J (Eds.), Conectados: la tecnología y la música popular (pp. 25-52). Barcelona: Manon tropo.

Thwaites, M. Del L. (1994).Gramsci mirando al sur: sobre la hegemonía en los 90. En P. Ferreyra, L (Eds), La noción gramsciana de hegemonía en el convulsionado fin de siglo (pp. 1582). Buenos Aires: K\&Kal-Johen y Asociados internacional. 
Absalón, J. Del L. (2006). La práctica investigativa en ciencias sociales. En P. Absalón, J. y Torres, A (Eds), La construcción del objeto y los referentes teóricos en la investigación social (pp. 15-28). Bogotá: Universidad Pedagógica Nacional.

Zîzêk, S. Del L. (2008). Ideología: un mapa de la cuestión. En P. Zîzêk, S (Eds.), Introducción: el espectro de la ideología (pp. 7-42). Buenos Aires: Fondo de cultura economíca.

Vega, J. Del L. (2015). Reflexionando las disciplinas. En P. Riascos, O (Eds.), Prácticas comunicativas, habitus e identidades políticas en procesos de comunicación local (pp 221-232). San Juan de Pasto: UNIMAR.

\section{Publicaciones oficiales del gobierno de Chile.}

Chile. Ministerio de Gobierno. (1992). Ley - 19132. Santiago de Chile: Biblioteca del Congreso Nacional.

\section{Audiovisual}

Fiennes, S. (Director) y Zîzêk, S (Escritor). (2012). Guía perversa para la ideología. Reino Unido: Coproducción Reuno Unido-Irlanda; P Guide LTD / Blinder Films / Bord Scannán Na Entretainment / Neue Vitaskop Film.

Sztajnszrajber, D. (Escritor). (2011a). La identidad. En: Mentiras la verdad. Buenos Aires: Canal encuentro.

Sztajnszrajber, D. (Escritor). (2011b). El conocimiento. En: Mentiras la verdad. Buenos Aires: Canal encuentro. 
Tijoux, A. (Escritor). Concha, J (Dirección). (2014). Versos migrantes. En: La maquinita. Santiago de Chile: Productora delgada 13C.

Wheeler, D., Dunn, S., y McFadyen, S. (Directores), Bascunan, R. (Escritor). (2016). HipHop evolution. Canada: Netflix.

\section{Páginas web.}

Billboard. (2018). Music Charts. 4 de marzo de 2018. https://www.billboard.com/music

Alvárez, R. (2014). Jorge gonzalez desglosa "pateando las piedras" de principio a fin. 15 junio de 2018. http://larata.cl/jorge-gonzalez-desglosa-pateando-piedras-de-principio-a-fin/

\section{Canciones.}

Brain damage (1973). [LP]. Reino Unido: Harvest Records

El idioma de los dioses (2011). [CD]. Madrid: Universal.

El pueblo unido jamás será vencido (1973). [LP] Santiago de Chile: Warner.

Hurt (1995). [CD]. Santa Mónica: Interscope Records.

Hurt (2000). [CD]. New York: Legacy recording.

Muevan las industrias (1985). [CD]. Santiago de chile: EMI

The house of the rising sun (1964)- [LP]. Estados Unidos: Motown. 


\section{Entrevista.}

Castro Gómez. S. (18 de abril de 2017). Entrevista realizada por Medellín, F. y Gutierrez, F. Recuperado de https://www.youtube.com/watch?v=JrE1UdlWX4g. 


\title{
Bonus track.
}

\section{Sobre la producción del idioma de los dioses. Ampliación metodológica.}

\author{
Introducción
}

El ejercicio que se presenta a continuación como bonus track, describe de forma completa la metodología que se construyó para la producción del idioma de los dioses, para este fin se ha querido construir cuatro escenarios de dialogo, el primero de ellos, presenta una reflexión epistemológica, donde se evidencia el posicionamiento desde el cual se construyó el proceso y sus relaciones con los capítulos principales de la investigación, en un segundo momento, se presentan las fases que se emplearon a lo largo del proceso de investigación, donde se abre el tercer espacio, el técnico, donde se muestran algunos ejemplos del proceso realizado, apoyado principalmente en Atlas.Ti, finalmente se encuentran las unidades de análisis, donde se puede observar algunas particularidades de los elementos empleados para categorizar y reconocer las particularidades de los discursos musicales.

\section{Reflexión epistemológica}

La aproximación epistemológica se relaciona con el núcleo denominado por Samaja (Samaja, 2004), en la relación teorías hechos, así entonces es preciso reconocer que el recorrido de este texto (El pueblo unido jamás será vencido, Hurt y Muevan las industrias) buscó por medio de una serie de discusiones de orden teórico aproximar y consolidar un objeto de investigación: el discurso musical y los procesos de singularización. 
Ahora bien, es preciso adentrar un poco la noción de "objeto de investigación” el cual en esta apuesta investigativa poco tiene que ver con la categoría del objeto externo al sujeto investigador que garantiza la objetividad y la neutralidad valorativa, por el contrario se trata de un proceso de objetivación, vale decir en este sentido la construcción de un espacio, escenario o fenómeno de indagación, el cual al ser configurado a partir de un entramado de ideas y de elementos de corte teórico configura principalmente, la construcción de un algo que no se encuentra en el mundo social, sino que a partir de este ejercicio se evidencia y se configura como algo observable, así las cosas el objeto de esta investigación, es el producto del ejercicio de problematización, donde desde una serie de hechos empíricos y sus relaciones con apuestas interpretativas de orden teórico se configura y concentra la mirada del investigador.

Acorde con lo anterior, es preciso por lo tanto reconocer cuales son las cualidades del objeto construido a partir de la problematización constituyente de la objetivación del fenómeno en investigación. Se tratará por lo tanto del discurso musical, con unos rasgos y características específicas, las cuales se abordaron a lo largo de los capítulos que abren el documento.

El discurso musical, como foco principal de esta investigación se contempla con un espacio social y cultural de significación, por medio del cual se crean y modifican los hechizos discursivos, proceso en el cual se movilizan las fronteras del orden social reconocido por los sujetos, ese fenómeno lo denominamos como singularización, de allí que la pregunta de investigación de este proceso sea ¿Qué tipo de singularidades se pueden producir en los sujetos a partir de los discursos musicales?

Ahora bien, como se evidencia en el proceso de construcción de nuestro objeto de investigación no se trata de la producción o construcción de una serie de reglas sociales o si se 
quiere de axiomas del comportamiento humano, en ningún momento esta investigación busca relacionar un tipo de género con una forma ideológica específica, elemento que puede ser retomado en el marco de la comprensión de la noción de música buena y mala, donde el contexto es un factor que no permite la producción de determinaciones de ese orden bajo el proceso investigativo. Acorde con lo anterior, es posible señalar que el proceso no se enmarca bajo una lógica de orden positivista, alejándose por lo tanto de apuestas relacionadas con el estructuralfuncionalismo.

Bajo la propuesta de la experiencia de vida de sujeto en el mundo, se buscó abrir las posibilidades en el orden de no permitir determinaciones absolutas de los efectos del discurso musical en las y los sujetos, alejándonos de esta forma de la idea de la audiencia masa y, aproximándonos por lo tanto a las audiencias con singularidades y particularidades que varían las formas en que se aborda el discurso musical y por lo tanto de los posibles efectos del mismo en la producción de singularizaciones de orden singular.

Por otro lado, teniendo en cuenta que esta investigación no se orienta a la producción de axiomas en la producción de hechizos discursivos, es preciso señalar que tampoco busca reconocer las formas en que los sujetos productores de los discursos desarrollan una experiencia vital, es decir, el objeto construido ingresa en el campo del desconocimiento del autor(idad) como único dueño del sentido del discurso (Browne, 2014), abriendo por lo tanto las posibilidades de significación en los sujetos que interactúan con los discursos, en este sentido es preciso recordar la discusión mantenida entre Humberto Eco y Jacques Derrida frente al intérprete, donde los autores centran el sentido o verdadero significado de un discurso en lugares 
diferentes, este trabajo se enfoca en la mirada propuesta por Derrida, como se evidenció en el capítulo El idioma de los dioses.

El anterior componente implica el reconocimiento de otro interés investigativo que se aleja del origen del discurso, así las cosas, las aproximaciones de orden fenomenológico que buscan el reconocimiento del mundo de la vida en el fenómeno en observación como lo señala Husserl, se alejan del orden de objetivación de nuestro proceso investigativo.

A partir de lo expuesto hasta este punto, es posible señalar que esta investigación se aleja de propuestas epistemológicas basadas ya sea en el positivismo a partir de características estructural-funcionalistas y de las apuestas de aproximación fenomenológicas. A su vez su aproximación busca ser de orden hermenéutico, a partir de la interpretación del discurso musical y la búsqueda de sus efectos en los procesos de singularización.

Acorde con esta apuesta que en gran medida determina el proceso de objetivación, esta investigación busca la consolidación de un proceso descriptivo del discurso musical, por medio del cual sea posible la interpretación de los sentidos que se pueden generar a partir de este discurso de frente al orden social en el cual se encuentra inmerso el sujeto que puede producir el proceso de singularización.

En la medida que esta investigación cuenta con este enfoque se construyó el corpus de la investigación, el cual por sus características no permite la producción de resultados o 
conclusiones de corte universal, se trata por lo tanto de cuatro casos o escenarios seleccionados en forma de estudio de caso, de forma coherente ${ }^{29}$ con el abordaje epistemológico.

Por otro lado, como se podrá observar en el verso "sobre partituras" se desarrolló un diseño metodológico o estrategia de investigación mediante el cual se busca respetar y mantener esta apuesta de coherencia interna de la investigación, la cual parte y es efecto del rol del investigador; los autores, relaciones y apuestas de configuración del objeto de estudio no han sido el resultado del azar, por el contrario son un proceso de reconocimiento de estudios realizados en el campo, organizados y sistematizados a partir del interés investigativo del autor de este estudio, así las cosas, se trata de un entramado con una intención, buscar las formas en que es posible la revolución, comprendiendo por ella el cambio en las estructuras sociales, en el sujeto a partir del proceso de singularización.

Ahora bien, previo a ingresar en el verso "sobre partituras" es preciso reconocer el sujeto que ha seleccionado, organizado y en ultimas construido el objeto de esta investigación, proceso que busca establecer el lugar de mirada, la subjetividad latente en cada una de las líneas que componen este texto, es una forma de buscar la reflexividad en el marco investigativo que se propone.

${ }^{29}$ En este punto se trata de la relación con la coherencia interna de una investigación, donde se busca una vigilancia epistemológica y metodológica que garantice las relaciones internas de los procesos investigativos. 
Una breve biografía musical del investigador.

El lugar desde el cual miramos lo que miramos nunca tendrá nada de inocente, siempre estará cargado por las pasiones, anhelos y por nuestras historias, al menos así he asumido el recorrido de mi vida, tanto en lo que soy como sujeto, como en lo que trabajo, que indefectiblemente son parte de un mismo sujeto, es decir yo.

Teniendo en cuenta lo anterior, comprender o mejor, responder a la pregunta de por qué investigo aquello que investigo, pasa por mi historia de vida; nací en 1979 en la ciudad de Bogotá, siendo muy pequeño mis papás en conjunto con mi hermana (mayor) viajamos a la ciudad de Ibagué, lugar en el que vivimos por un espacio de tres años, pero del cual no guardo recuerdo alguno, más allá de las historias que escucho por parte de mi papá o mi mamá; pasados esos tres años en la capital del departamento del Tolima, volvimos a Bogotá.

De allí recuerdo mis primeros pasos en el sistema educativo, en el jardín infantil "el mundo de los niños", y posteriormente mi ingreso al colegio San Tarsicio, un colegio bogotano donde se educan niños pertenecientes a las elites de la ciudad, elites intermedias, pues la más altas están en el Gimnasio Moderno. De ese colegio guardo muy gratos recuerdos, toque el triangulo en la banda de guerra y temía profundamente a los cucarrones que vuelan por el colegio en épocas de lluvia.

Esos lindos recuerdos se interrumpen cuando la familia viaja a la ciudad de Cali, un nuevo trabajo y un futuro prometedor para mi papá se abría en esta ciudad, así que nos cambiamos una vez más, lastimosamente los recuerdos de esos seis años no son los más gratos. 
En mi primera semana de colegio, recuerdo que la profesora de tercero de primaria, me tomaría por el brazo para decirme al oído que era un "rolo" (apelativo despectivo para los bogotanos en las regiones del país) bruto y que sin lugar a duda perdería el año. Ese hecho implicaría un quiebre para mi muy fuerte, de un escenario de felicidad y bienestar a uno donde algo hacia que no pudiese vivir de forma plena - hoy en día lo explico por medio del miedo pero las cosas no finalizarían con un comentario de mi docente.

Al día siguiente yo no salía del baño para ir al colegio así que mis papás abrieron de forma brusca la puerta, pues yo estaba encerrado, al abrirla recuerdo las caras al verme sentado en la tasa del baño llorando de forma desconsolada pues por un lado yo era bruto y por el otro perdería el año. El apoyo de mis papás fue inmediato, me llevaron al colegio y hablaron con el rector, quien de paso era amigo de mi papá, pues los dos estudiaron juntos, en la época que mi papá quería ser padre franciscano. Como resultado, la docente fue despedida del colegio, y yo por el otro lado comencé a sufrir la sed de venganza de mis compañeros que la querían como su docente.

En resumen, durante seis años viví aquel fenómeno que ahora denominan buling, fueron años en que al menos una vez a la semana llegaba con algún tipo de moretón en el cuerpo por los golpes que mis compañeros más grandes del colegio me propinaban, recuerdo que los que más duro me daban eran los chicos que estaba por salir del bachillerato, mientras yo estaba comenzando. En este escenario es que un nuevo miembro entra a la familia, mi perro Mateo, quien sería el resultado de las tantas visitas a las psicólogas, quienes lo recomendaron para reponer un poco el tema de mi autoestima perdida, además del inicio en clases de budo-karate- 
guyuriu-ken-cho-kay, arte marcial que me enseñaron para que me defendiera en el colegio y no siempre me golpearan tan duro.

Ahora bien, mateo fue algo lindo en la vida, durante 18 años ese perro fue un compañero genial, aunque el nombre no se lo pusiera yo, sino mi hermana. Yo además encontré otros caminos para componerme tal vez, o simplemente para resistir ese momento, fue la música. En el colegio había un árbol muy grande, en el que perfectamente uno podía subirse y casi acostarse en sus ramas, así que para evitar que me persiguieran los demás compañeros, yo opté por subirme a ese árbol, siempre acompañado de mi walkman, baterías extras, y mucha música rock, en ese árbol pase la mayoría de mis descansos, escuchando música y preguntándome por las historias que narraban, además de por que llegaron a ser construidas, hecho que me llevó a aprender algo de ingles.

Al finalizar esos seis años, la vida en Cali finalizó con otro evento que creo marcaría mi forma de asumir la vida, mi padre fue secuestrado por un narcotraficante del cartel de Cali, como forma de presionar la finalización de una obra civil que mi papá dirigía en ese momento, lugar donde se realizaba lavado de dinero. Al salir del secuestro mi papá rastreo rápidamente de quien eran los demás contratos de la empresa con la que él trabajaba, encontrando que la mayoría estaban a nombre del mismo testaferro, la solución fue empacar todo y en una semana salir de la ciudad, retornando a Bogotá para recomponer la vida, pues implicó pasar de contar con muchos recursos económicos a vivir de los prestamos de los bancos.

Después de estar una semana en Bogotá tras nuestra salida de Cali, ya con 12 años, nos fuimos a vivir a Manizales, lugar donde logré reinventarme, el rock, sus historias, la disciplina del karate, además de mis ganas de no repetición, me llevaron y me permitieron en un nuevo 
territorio forjar un nuevo camino, en el cual debía mostrar que era fuerte, así entonces pase de ser el niño que le hacían buling a ser uno de los "malos" del colegio, yo no se la montaba a nadie, pero era el "peligroso" me llene de amigos que eran atracadores de la ciudad o vendían drogas, gente que me respaldara, pues aunque se karate no soy bueno peleando, las tres veces que me enfrente a alguien, siempre salí perdiendo.

Manizales fue un momento muy lindo de la vida, al menos fue muy tranquilo para mi, al cumplir los 16 años volvimos a Bogotá, lugar donde finalice mis estudios de secundaria, preste el servicio militar obligatorio, y comencé a estudiar ingeniería civil, tras cinco semestre renuncie a esa empresa e inicie mi carrera como sociólogo.

En estos ires y venires de mi historia, comencé con el tiempo, la lectura y en la reflexión a reconocer que el principal factor que guió muchas de mis acciones, fue el miedo, con diferentes catalizadores o expresiones, pero estaba allí presente, en el rock, en el karate, en la ingeniería, en la sociología, en mis relaciones de pareja.

Creo firmemente a partir de mi historia, que odie con todas mis fuerzas cada sujeto que pretendió influenciar o intervenir en mi vida, para las psicólogas en Cali y en Bogotá más tarde, cuando sufrí un ataque en la calle y me rompieron la cabeza en el año 2013, que era fácil recomendar la compra de un perro o la generación de una disciplina del combate como solución a mis problemas, pero tan sólo yo tendría que enfrentar el costo y los efectos de esas acciones, sólo yo sentía el dolor en mis piernas, brazos, en el cuerpo, pero más que eso, en mi ser, los miedos, los anhelos perdidos, los sueños rotos. Al estudiar sociología comprendí que el rol del humanista, en muchas ocasiones se traduce en la intervención de otros sujetos, hecho que por mi historia es supremamente complejo, pues no quiero hacer a otros, aquello que yo viví, entonces, 
mis procesos de intervención o los efectos que busco giran en torno a un sujeto, yo mismo, soy así entonces el territorio de mis investigaciones, soy el sujeto que vivencia las acciones que yo mismo encamino.

Estudiar la música, es entonces una forma de comprender el rol que ese discurso jugó en las formas que supere miedos, que configure otros sentidos de vida sentando en aquel árbol del colegio en Cali, pero además cómo produjo toda una estética en la cual me fue posible la producción de sentidos diferentes a los hegemónicos en la sociedad.

Sobre partituras: Estrategia metodológica

La estrategia de investigación ha sido una parte constituyente del documento en todas sus partes, en la medida que desde el título del documento se viene abordando el objeto desde un lugar específico, el discurso, el cual además contó en el capitulo Brian Damage con toda una serie de discusiones que permitieron la producción del discurso o su abordaje a partir de los elementos que se rastrearon en el discurso musical.

Así las cosas la estrategia de esta investigación se basa en el rastreo y reconocimiento de cada uno de los planos del discurso musical en un corpus, llevando así al reconocimiento de los elementos singulares de cada una de las canciones que componen los álbumes que materializan el corpus de la investigación.

En líneas generales la estrategia se basa en seis fases:

\section{Fase 0. Reconocimiento de lo que se estudia en la música desde la comunicación (estado}

del arte). Existe una fase 0, no se ha querido incorporar numeración inicial de uno, en la medida que si bien esta, es una fase que permite el desarrollo de la investigación y se vincula 
profundamente con el proceso metodológico, tiene también efectos profundos en el proceso de problematización y de objetivación. Así entonces, para esta fase, se realizó un proceso de revisión documental, de la cual desde una perspectiva hermenéutica crítica, se construyeron categorías emergentes, relacionando los documentos (artículos científicos) rastreados, éstos fueron seleccionados en la medida que sus objetos de trabajo investigativos se relacionaran con la música y la comunicación, de este proceso, se construyó un texto breve que da razón de las formas en que se aborda la música en comunicación, y que permitió en su momento construir rutas posibles para el posterior desarrollo de la investigación. El texto resultante de esta fase podrá observarse en el apartado Sobre los Instrumentos.

Fase I. Construcción del corpus de investigación. Como se evidencio en el capítulo Muevan las industrias, se inicia el proceso de desarrollo metodológico de la investigación, iniciando por la construcción del corpus, el cual giró en torno a las relaciones entre la realidad, lo real, lo global y lo local, estableciendo de esas relaciones géneros musicales apropiados, desde los cuales se buscaron autores y álbumes que permitieran un análisis posterior en términos de lo hegemónico y lo contra-hegemónico. Al final, se contó con el género Pop, representado por Taylor Swift con el álbum 1989 (relación realidad-global) acompañada por Maluma con su producción PB/DB (relación realidad-local), a su vez en la mirada undergrownd, Lowkey con su disco Soundtrack to the struggle (relación real-global), fue acompañado de la banda Epica con su álbum The phantom agony (relación real-local).

Como se puede recordar, este ejercicio de reconocimiento del corpus de investigación, no sólo se baso en el poner o señalar cuales son los artistas y sus discos, sino que además, se rastrearon elementos relacionados con los procesos de producción y distribución de los mismos, como 
evidencias de los procesos de producción de la cultura capitalística, otorgando de esta forma contenidos básicos a la mercancía musical, presente en los discursos musicales.

Fase II. Reconocimiento de las particularidades de las piezas musicales. Una vez se contó con la selección de los cuatro álbumes, cada una de las 60 piezas contó con el mismo proceso de reconocimiento de las particularidades, así se utilizó el software Atlas.ti, donde se incorporaron dos archivos o fuentes por cada pieza musical, el sonido en archivo de audio y la lírica en archivo textual. En el primer archivo (sonido) se utilizaron códigos relacionados con los planos exclusivamente sonoros, donde la armonía en relación con el tiempo y la intensidad fueron el centro de análisis, más adelante se ampliarán los códigos utilizados (en el apartado de unidades de análisis), además también se incluyeron códigos para la diferenciación de los granos en las voces presentes en el campo sonoro, éstos variaron en cada uno de los álbumes de forma coherente con la presencia que se reconocían en estos de granos diferenciados.

De forma paralela, en el archivo de texto (líricas) se utilizaron códigos para el reconocimiento de las tres formas claves de las metáforas (ontológicas, orientacionales y metonímicas), elementos que fueron descritos y trabajados en el capítulo Hurt, donde se estableció como las metáforas en sus procesos de anidación o relacionamiento entre ellas, consolidan evidencias de los marcos mentales, donde se materializan los hechizos discursivos.

Así, en esta fase se trata de dos procesos de lectura, una con los oídos (el audio) y la otra con los ojos (el texto), contando de esta forma con las particularidades de cada una de las piezas de los cuatro álbumes, organizadas estas particularidades a partir de momentos o fragmentos de las piezas musicales, éstas, provienen de la primera lectura (los oídos con el audio), de donde es 
posible la agrupación de particularidades, la cual es la fase III, pero para la cual fue necesario realizar siempre este proceso con todas las piezas de cada uno de los álbumes.

Antes de seguir con la siguiente fase, es preciso señalar, como se realizó este proceso con proyectos diferentes en el software Atlas.ti, con el fin de poder garantizar las particularidades de los álbumes, pues cada uno de ellos contó con algún elemento que requería de la diferenciación de algunos códigos, como son los granos, la presencia de ruidos y de discursos públicos, por ejemplo.

Fase III. Agrupación de particularidades. Una vez se contó con todos los elementos de sonido y metafóricos en las letras de las piezas musicales, se inició un proceso de vinculación por medio de la construcción de un mapa general de cada álbum, donde se organizaron las citas sonoras, expandidas con la lírica para cada una de las piezas musicales, consolidando de esta forma una red de relaciones donde además se reconocieron como elemento distintivo las armonías en su intensidad (Baja, Media y Alta), siendo éstas a su vez, el componente o eje central del posterior análisis. La agrupación de particularidades, por lo tanto deja como evidencia cuatro mapas generales de los álbumes, ya en el siguiente apartado (Sobre instrumentos interpretados) se podrá observar los resultados de este proceso.

Una vez finalizado el proceso de agrupación, se puede continuar con la siguiente fase de trabajo, la construcción de los mapas de sentidos sonoros y metafóricos.

Fase IV. Construcción de mapas de sentidos sonoros y metafóricos. Producto del mapa general del álbum, es posible la construcción de quince nuevos mapas, cinco por cada una de las armonías desde su intensidad, en la medida que se trata de cinco tiempos establecidos en los 
códigos, así, la construcción de cada uno de esos mapas, permite la lectura de grupos de fragmentos, que se relacionan por las formas de la armonía desde la intensidad y el tiempo. Una vez construidos estos grupos de fragmentos musicales relacionados con sus líricas, se hace posible la lectura de las metáforas agrupadas, para poder realizar el análisis.

Fase V. Elaboración del análisis. Podría denominarse este proceso como las cascada de los significados, lo anterior, en la medida que a partir de cada uno de los quince mapas que surgieron de los fragmentos musicales desde sus intensidades, se reconocen los procesos metafóricos, agrupando así sentidos en el orden ontológico, orientacional y metonímico, de donde por medio de las notas de Atlas.ti, se construye un nuevo mapa, en el cual se cruzan las intensidades, los tiempos y las formas metafóricas, de donde surge un primer texto de análisis mucho más descriptivo que el contenido en Brain Damage, donde además se construyeron sujetos que emergen de cada álbum y la historia que narran, como elementos de soporte para la construcción del capitulo de análisis ya mencionado en líneas previas. Estos textos como evidencias del proceso técnico de trabajo se podrán observar en el siguiente apartado.

Así las cosas, por medio de las seis fases, se logra evidenciar en líneas generales el procesos de construcción del proceso desarrollado a lo largo del idioma de los dioses para la puesta en marcha del estudio del discurso musical, cabe anotar en este punto, que la metodología fue construida a la medida que se avanzaba en la investigación, pues las apuestas de trabajo en torno a la música desde lo sonoro, por lo general se enfocan en las construcciones de la gramática de la misma, elemento que no se abordó en esta investigación por la búsqueda de coherencia con la forma de objetivación presente en El pueblo unido jamás será vencido y en Hurt, por otro lado, desde la comunicación, los ejercicios de análisis suelen concentrarse en las líricas de las 
canciones, dejando de lado los elementos sonoros, siendo una apuesta de esta investigación, lograr la relación de estas dos, con el fin de poder ofrecer una estrategia metodológica que aborde el discurso musical de una forma más completa.

Sobre instrumentos interpretados: Nivel técnico

En este apartado, se deja en evidencia los elementos técnicos utilizados o empleados como mecanismos para construir las evidencias que permitieron el desarrollo del idioma de los dioses, en este punto se generan otros documentos de soporte, los cuales no se incluyen en su desarrollo, son nombrados, a su vez pueden encontrarse en el CD que acompaña al texto, donde además se encuentran los fragmentos musicales que se relacionan a lo largo de todo el texto.

Acorde con lo anterior, a continuación de acuerdo a cada una de las fases, se presentan los elementos técnicos empleados, a su vez, de ser necesario se vinculan los documentos de soporte que se encuentran en el CD.

\section{Fase 0. Reconocimiento de lo que se estudia en la música desde la comunicación (estado}

del arte). Este ejercicio del estado del arte, se construyó mediante una matriz de sistematización de las lecturas realizadas a partir de la lógica de Resúmenes Analíticos de Investigación RAI, desde la cual se construyeron elementos que permitieran vincular sentidos o elementos en común, a partir de los cuales se categorizo y se permitió la construcción del texto final, así entonces, dos elementos claves en el nivel técnico deben ser tenidos en cuenta en este punto, la matriz y el texto, la estructura de la primera se presenta a continuación, el texto puede ser consultado en el CD bajo el nombre de The house of the rising sun. 


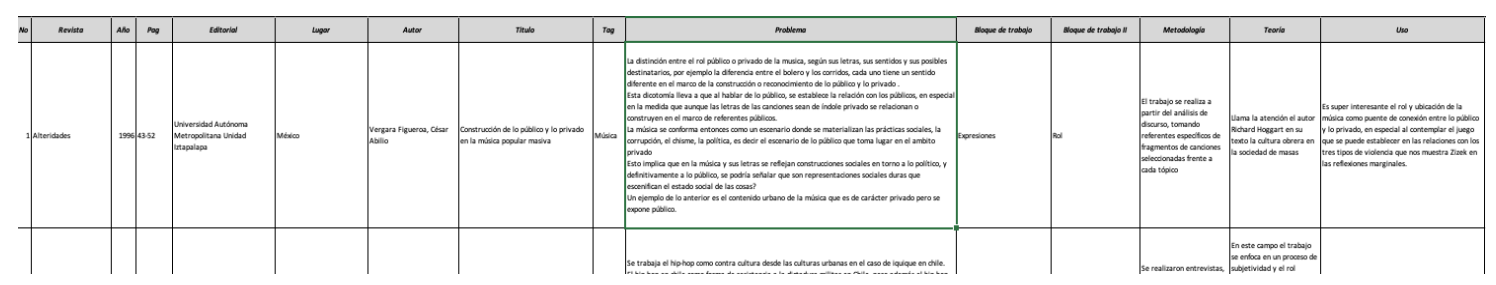

La imagen anterior, es del proceso de sistematización realizado, en el cual se utilizan los primeros siete campos para el reconocimiento bibliográfico (autor, revista, año, páginas, lugar y título) posteriormente se uso un campo denominado como tag, el cual sirvió apara el proceso de agrupación final, se trabajo un campo central, el problema, donde se describió el fenómeno en el que se concentra la investigación, permitiendo dos nuevos campos de agrupación, desde sentidos o fenómenos desde su abordaje en común. Posteriormente se trabajaron dos campos, uno sobre metodologías utilizadas en las investigaciones y las teorías o enfoques empleados, finalmente se construyo un espacio de uso, el cual enmarca aquellos elementos que se consideraron relevantes en ese momento podrían aportar al desarrollo del idioma de los dioses.

\begin{tabular}{|c|c|c|}
\hline \multicolumn{3}{|c|}{ Epica - The Phantom Agony } \\
\hline 1. Adyta & 4. Feint & 7. Run for fall \\
\hline 2. Sensorium & 5. Illusive consensus & 8. Seif al din \\
\hline 3. Cry for the moon & 6. Fcade of reality & 9. The Phantom Agony \\
\hline \multicolumn{3}{|c|}{ Lowkey - Soundtrack to struggule } \\
\hline 1. Sondtrack to struggule & 10. Obama nation & 19. My soul \\
\hline 2. Too much & 11. Skit 3 & 20. Skit 6 \\
\hline 3. Voices of the voices & 12. Cradle of civilisation & 21. The butterfly effect \\
\hline 4. Hand on your gun & 13. Skit 4 & 22. Dear england \\
\hline 5. Skit 1 & 14. Blood, sweat and tears & 23. Haunted \\
\hline 6. Terrorist? & 15. Everything i am & 24. Terrorist? \\
\hline 7. Something wonderful & 16. Skit 5 & 25. Million man march \\
\hline 8. Dreamers & 17. Long live Palestine & \\
\hline 9. Skit 2 & 18. We will rise & \\
\hline \multicolumn{3}{|c|}{ Maluma - PB.DB } \\
\hline 1. La temperatura & 5. Me gustas tanto & 9. Duele tanto \\
\hline 2. La curiosidad & 6. Climax & 10. Tus besos \\
\hline 3. Addicted & 7. La invitación & \\
\hline 4. Carnaval & 8. El punto & \\
\hline \multicolumn{3}{|c|}{ Taylor Swift - 1989} \\
\hline 1. Welcome to New York & 7. I wish you would & 13. Clean \\
\hline 2. Blank space & 8. Bad blood & 14. Wonderland \\
\hline 3. Style & 9. Wildest dreams & 15. You are in love \\
\hline 4. Out of the Woods & 10. How you get the girl & 16. New romantics \\
\hline 5. All you had to do was & 11. This love & \\
\hline 6. Shake it off & 12. I know places & \\
\hline
\end{tabular}


Fase I. Construcción del corpus de investigación. En el reconocimiento del corpus de la investigación, se desarrollo un capítulo completo Muevan las industrias, de donde en el nivel técnico queda en evidencia un pequeño cuadro donde las 60 piezas se encuentran reconocidas:

El resumen anterior de las piezas, es organizado de acuerdo a los álbumes que se trabajaron a lo largo del proceso investigativo, teniendo en cuenta que en varios de estos existen varias ediciones que incluyen canciones o versiones diferentes de las piezas que lo componen, así se establecen los contenidos.

Además de lo anterior, en el nivel técnico para garantizar una correcta escucha de los sonidos que se vinculan al interior de las piezas de los diversos álbumes, se utilizaron los siguientes equipos y elementos técnicos:

- Archivos de audio comprados en la plataforma de Apple music, en formato m4a, con una velocidad de 44,1 Khz.

- Para la conversión del sonido de digital a análogo se empleo un DAC audioengine D1, el cual cuenta con un rango desde los $32 \mathrm{Khz}$ hasta los $192 \mathrm{Khz}$.

- El proceso de escucha se realizó mediante el uso de unos audífonos de monitoreo de estudio, Audio-Technica ATH-M40X.

Los anteriores elementos de orden técnico buscaron garantizar la mejor aproximación posible a los sonidos de los álbumes, reduciendo así la incorporación de posibles ruidos por la placa del computador, de allí que se optara por un DAC externo, además de unos audífonos por permitir diferenciar elementos específicos de los planos sonoros, por ese motivo se opto por unos de 
monitoreo, que no cuenten con amplificación o modificación artificial de bajos como es el caso de los auriculares de marcas como Bose o Beats.

Fase II. Reconocimiento de las particularidades de las piezas musicales. Como se observó en este componente, el ejercicio se encaminó a la construcción del plano general de los álbumes desde los elementos que se trabajaron en los códigos a través de Atlas.ti, de donde se pueden evidenciar los siguientes cuatro planos, a forma de ejemplo de lo realizado se presentan dos fragmentos de los mapas, que por sus dimensiones no pueden ser presentados de forma completa.

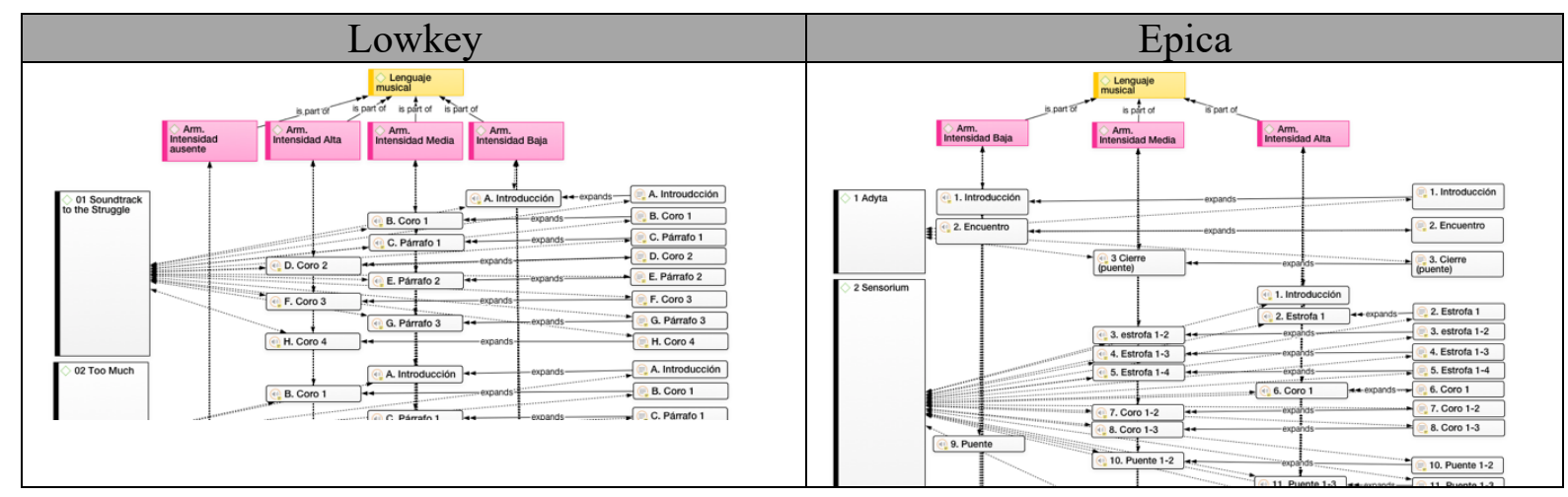

Una vez se logró contar con los cuatro mapas, que en el orden técnico se consolidaron desde las redes semánticas que ofrece Atals.Ti, de donde se pudo pasar a la siguiente fase de trabajo.

Fase III. Agrupación de particularidades. Como se enunció en la estrategia metodológica, este proceso generó al menos quince mapas por cada álbum, en algunos casos fue necesario subdividir un poco más el proceso, en la medida que se contaba con muchas piezas musicales y no se podría realizar la lectura en un solo mapa, se trata del caso de Lowkey, de forma similar al caso anterior, a continuación, se muestran los mapas construidos para uno solo de los casos, Taylor Swift, en la intensidad baja.

Mapa relaciones entre intensidad baja y tiempo movimiento 


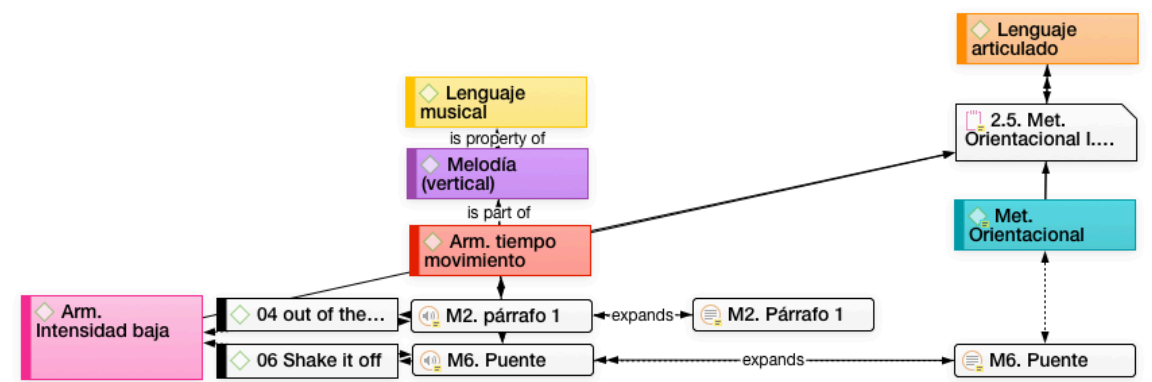

Mapa relaciones entre intensidad baja y tiempo fuego

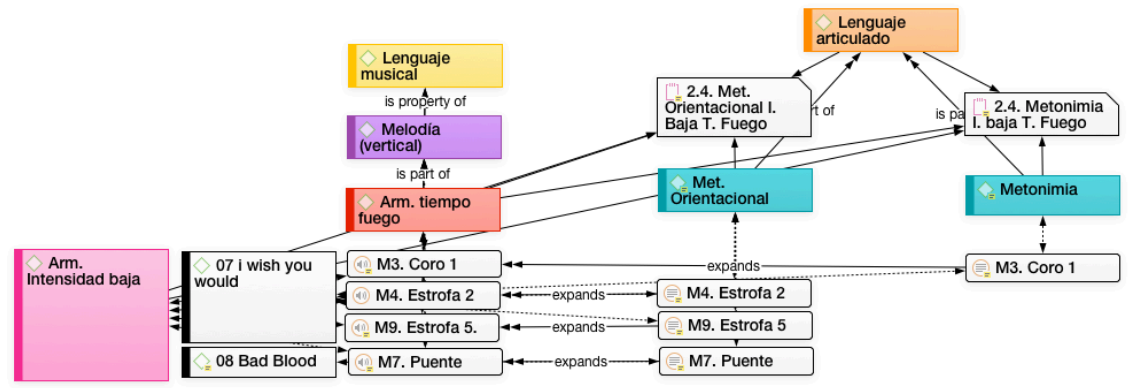

Mapa relaciones entre intensidad baja y tiempo apasionado (fragmento)

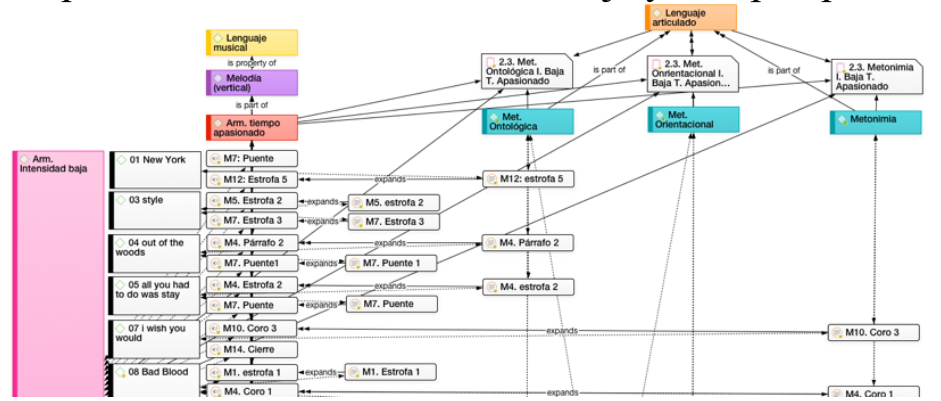

Mapa relaciones entre intensidad baja y tiempo agitado

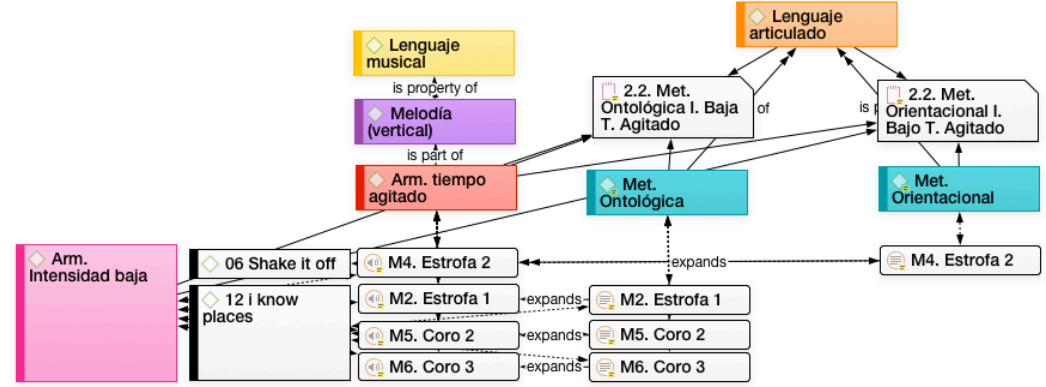

Mapa relación intensidad baja con tiempo afectuoso

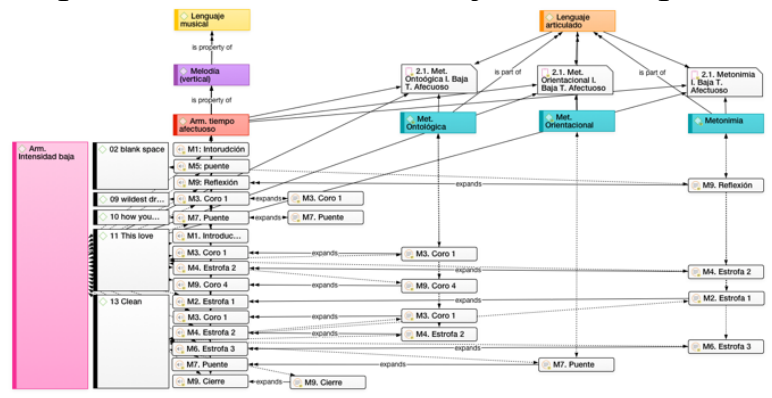


A partir de la lectura de estos procesos es posible la construcción de los mapas de sentidos sonoros y metáforicos.

Fase IV. Construcción de mapas de sentidos sonoros y metafóricos. Los mapas anteriores, permitieron, como se señaló en las fases, la producción de nuevos mapas cargados de las metáforas reconocidas en sus relaciones, de estas surgen tres mapas de lectura general del álbum, cada una de ellas relacionada con la armonía en su intensidad, a continuación a forma de ejemplo se evidencian algunas de ellas:

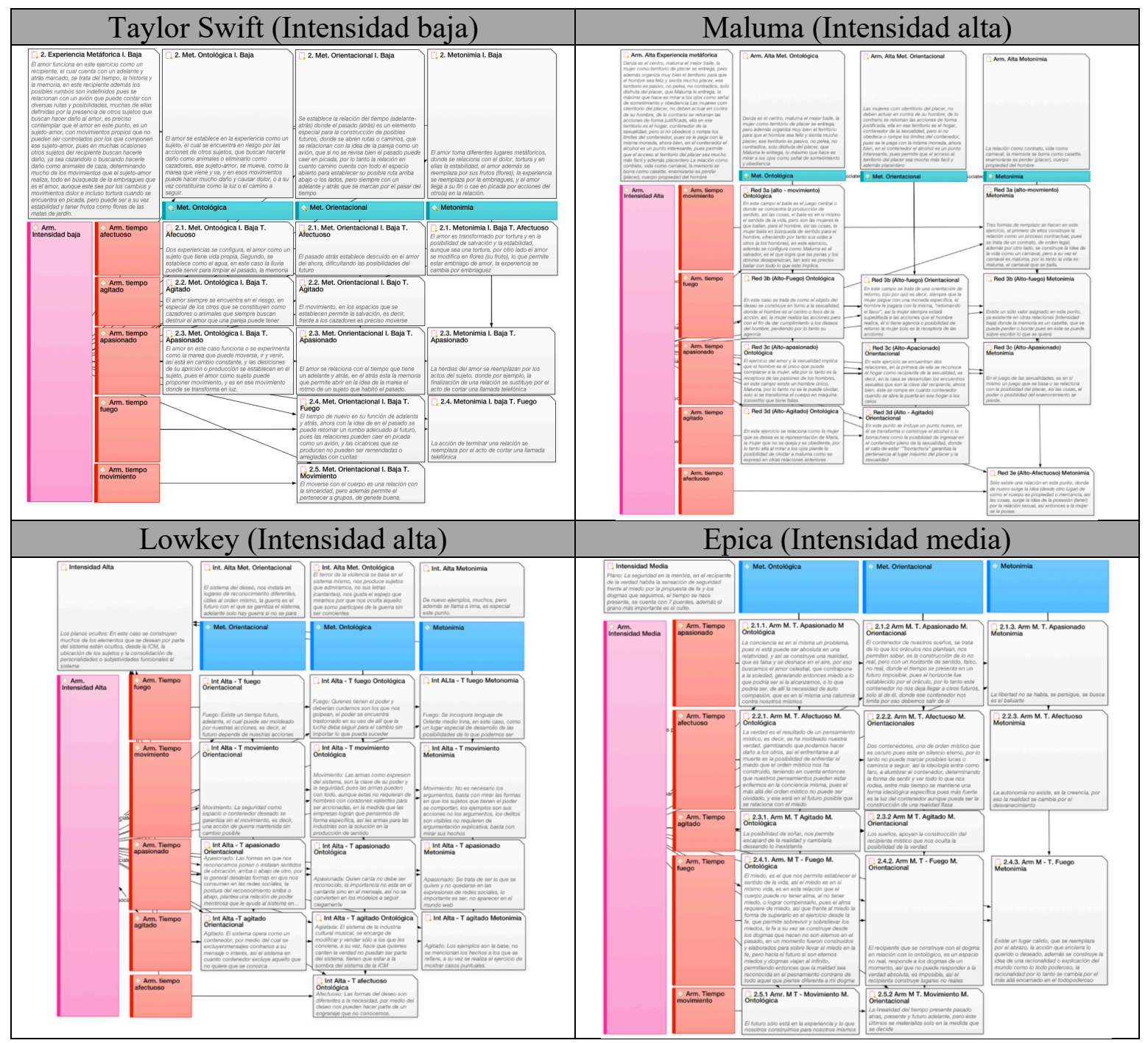


Es a partir de los planos anteriores que se logra la consolidación del proceso de análisis, vinculando los aspectos sonoros con los metafóricos vinculados al interior de las líricas.

Fase V. Elaboración del análisis. Finalmente, como se evidenció en el apartado anterior, en esta fase se construyó un texto de análisis descriptivo a partir del cual se construye el capítulo brain damage, así las cosas, el texto titulado la $9^{\mathrm{a}}$ sinfonía puede ser observado en el CD que acompaña este texto, en el cual además se encuentra el rastreo de un sujeto emergente del álbum y la historia que narra cada uno de los artistas en sus producciones musicales.

\section{Unidades de análisis}

En este último punto, es preciso reconocer que las unidades de análisis en su gran mayoría fueron abordadas a lo largo de los capítulos el pueblo unido jamás será vencido y hurt, no obstante, se encuentran aquí reseñados en los sentidos o aspectos que se buscaron y desarrollaron a lo largo del ejercicio metodológico en un nivel, tal vez, más instrumental.

A continuación entonces se ofrece una matriz en la que se explican los sentidos y elementos abordados en el reconocimiento de las particularidades del discurso musical, elemento central del desarrollo del proceso de investigación.

\begin{tabular}{|l|l|}
\hline \multicolumn{2}{|c|}{ Armonía, la intensidad } \\
\hline Tipo de intensidad & \multicolumn{1}{c|}{ Sentido } \\
\hline Alta & $\begin{array}{l}\text { Se reconoce densidad alta, presencia de múltiples sonidos en } \\
\text { un mismo espacio o fragmento musical, es el más denso de } \\
\text { todos, se establece en relación con la pieza en sí misma. }\end{array}$ \\
\hline Media & $\begin{array}{l}\text { Se reconoce una densidad que no es la más alta de la pieza, } \\
\text { pero tampoco es la menor posible, se encuentra entre el alta y } \\
\text { la baja, en relación con la pieza en sí misma }\end{array}$ \\
\hline Alta & $\begin{array}{l}\text { Se reconoce la menor densidad musical, pocas notas o sonidos } \\
\text { incorporados, con tiempos distanciados en la interpretación, de } \\
\text { nuevo se reconoce en relación con la pieza en sí misma. }\end{array}$ \\
\hline \multicolumn{1}{|c|}{ Armonía, El tiempo } \\
\hline
\end{tabular}




\begin{tabular}{|c|c|}
\hline Tipo de tiempo & Sentido \\
\hline Apasionado & $\begin{array}{l}\text { En este espacio se rastrean o encuentran los sonidos que se } \\
\text { sienten con pasión, que convocan a sentir en lo profundo, que } \\
\text { conmueven }\end{array}$ \\
\hline Afectuoso & $\begin{array}{l}\text { Se trata de lo sonidos que movilizan afectos, en especial, } \\
\text { compasión, es decir, el reconocimiento del otro, en el sonido, } \\
\text { este se vincula mucho con el grano y su performance. }\end{array}$ \\
\hline Agitado & $\begin{array}{l}\text { Son sonidos que son rápidos y dispares. Se trata de sonidos } \\
\text { que producen atención y fragmentan relaciones previas de las } \\
\text { piezas musicales }\end{array}$ \\
\hline Fuego & $\begin{array}{l}\text { Sonidos que como su nombre lo indica queman, son densos y } \\
\text { rápidos, acompañados por lo general de granos múltiples o con } \\
\text { texturas que llaman la atención sobre algo en especial. }\end{array}$ \\
\hline Movimiento & $\begin{array}{l}\text { Sonidos que evocan el movimiento del cuerpo, que incitan por } \\
\text { su densidad y velocidad a que el cuerpo deba generar una } \\
\text { reacción, como entrar a la danza o mover la cabeza }\end{array}$ \\
\hline \multicolumn{2}{|r|}{ Metáforas } \\
\hline Ontológicas & $\begin{array}{l}\text { Evidencian las formas como pensamos y reconocemos el } \\
\text { mundo que nos rodea, se pueden reconocer entonces procesos } \\
\text { relacionados con puntos o coordenadas específicas de la } \\
\text { experiencia humana del mundo (extensiones de la tierra, el } \\
\text { campo visual, acontecimientos, acciones, actividades y } \\
\text { estados). }\end{array}$ \\
\hline Orientacionales & $\begin{array}{l}\text { Se establecen relaciones del orden bipolar (arriba-abajo, } \\
\text { dentro-fuera, adelante-atrás, profundo-superficial, central } \\
\text { periférico), se trata la producción del espacio y la ubicación en } \\
\text { el mismo. }\end{array}$ \\
\hline Metonimias & $\begin{array}{l}\text { Se cambia una entidad por otra (la parte por el todo, el } \\
\text { producto por el producto, el objeto usado por el usuario, el } \\
\text { controlador por lo controlado, una institución por la gente } \\
\text { responsable, el lugar por la institución, el lugar por el } \\
\text { acontecimiento) }\end{array}$ \\
\hline
\end{tabular}

En el cuadro anterior, se pueden así encontrar los elementos a partir de los cuales se rastrearon las singularidades de cada una de las piezas musicales que permitieron la construcción de los mapas en Atlas.ti para finalizar con la producción del texto escrito del idioma de los dioses. 